Portland State University

PDXScholar

Summer 8-8-2014

\title{
Social Networks of Intimate Partner Violence Perpetrators
}

Wendy Elaine Viola

Portland State University

Follow this and additional works at: https://pdxscholar.library.pdx.edu/open_access_etds

Part of the Domestic and Intimate Partner Violence Commons Let us know how access to this document benefits you.

\section{Recommended Citation}

Viola, Wendy Elaine, "Social Networks of Intimate Partner Violence Perpetrators" (2014). Dissertations and Theses. Paper 1933.

10.15760/etd.1932

This Dissertation is brought to you for free and open access. It has been accepted for inclusion in Dissertations and Theses by an authorized administrator of PDXScholar. For more information, please contact pdxscholar@pdx.edu. 
Social Networks of Intimate Partner Violence Perpetrators

by

Wendy Elaine Viola

A dissertation submitted in partial fulfillment of the requirements for the degree of

Doctor of Philosophy

in

Applied Psychology

Dissertation Committee:

Eric Mankowski, Chair

Todd Bodner

Chris Huffine

Thomas Kindermann

Cynthia Mohr

Laurie Powers

Portland State University

2014 
(C) 2014 Wendy Elaine Viola 


\title{
SOCIAL NETWORKS OF INTIMATE PARTNER VIOLENCE PERPETRATORS
}

\author{
Abstract \\ Empirical research in the areas of substance abuse (Beattie \& Longabaugh, 1997; \\ Beattie \& Longabaugh, 1999; Falkin \& Strauss, 2002; Gordon \& Zrull, 1991; Humphreys \\ \& Noke, 1997; Mohr et al., 2001; Zywiak, Longabaugh \& Wirtz, 2002) and general \\ antisocial behavior (Browning, 2002; Capaldi, Dishion, Stoolmiller \& Yoerger, 2001; \\ Dishion, Patterson \& Griesler, 1994) and a theoretical model of sexual assault \\ perpetration (DeKeseredy \& Schwartz, 1993; DeKeseredy, 1990a; DeKeseredy, 1988; \\ Schwartz \& DeKeseredy, 1997) highlight the role of peer groups' attitudes and behaviors \\ in shaping those of their members. Intimate partner violence (IPV) among men's parents \\ (Arriaga \& Foshee, 2004; Doumas, Margolin \& John, 1994; Silverman \& Wiliamson, \\ 1997) and peer groups (Abbey, McAuslan, Zawacki, Brown \& Messman-Moore, 2010; \\ Clinton, \& Buck, 2001; Capaldi et al., 2001; Raghavan, Rajah, Gentile, Collado, \& \\ Kavanagh, 2009; Reed, Silverman, Raj, Rothman, Decker, Gottlieb, Molnar, \& Miller, \\ 2008; Silverman \& Williamson, 1997) is also related to their own perpetration of IPV, \\ specifically. However, existing research is yet to examine the extent to which men \\ participating in batterer intervention programs (BIPs), a common form of treatment for \\ perpetrators of IPV, receive messages about the perpetration of IPV from within their \\ social networks, or whether or how BIP participants contribute to dialogues about abuse \\ within their social networks.
}

The purposes of the current study were to (1) describe the members of BIP participants' social networks and the ways in which they communicate about IPV with 


\section{SOCIAL NETWORKS OF INTIMATE PARTNER VIOLENCE PERPETRATORS}

BIP participants, and (2) to describe how BIP participants address IPV with the members of their social networks, and the social network members with whom they do so. Focus groups with BIP facilitators and participants were conducted to develop inventories of abuse-relevant behaviors. One hundred and two BIP participants were surveyed to describe the members of their social networks, how the members of their social networks address the perpetration of IPV, and how BIP participants communicate about IPV to the members of their social networks. A series of multilevel models were tested to examine the characteristics of BIP participants' social networks and patterns of communication about abuse therein. An additional focus group provided interpretations of the quantitative findings.

Findings reveal that the current sample of BIP participants has social networks that are smaller than those of the general population, and which consist of their current and former partners, friends and roommates, bosses and coworkers, family of origin, children, in-laws, and others. Participants' network members engage in behaviors that convey both pro-abuse and anti-abuse attitudes to BIP participants, participants engage in indirect anti-abuse behaviors with their social network members, and participants are less satisfied with network members who engage in more pro-abuse behaviors. Primary implications of the current study include (1) the understanding of BIP participants as bystanders who actively intervene in abuse-relevant social norms in their social networks; (2) a detailed picture of how and from whom BIP participants receive support for the 


\section{SOCIAL NETWORKS OF INTIMATE PARTNER VIOLENCE PERPETRATORS}

perpetration of IPV; and (3) the creation of two new behavioral inventories that may be used to explore patterns and effects of abuse relevant communication in greater depth. 


\section{SOCIAL NETWORKS OF INTIMATE PARTNER VIOLENCE PERPETRATORS}

\section{Acknowledgements}

I would like to express my gratitude to Dr. Eric Mankowski, my dissertation chair and graduate advisor, for his intellectual, professional, and logistical support and mentorship, and for the innumerable hours spent reviewing and discussing drafts of my work over the last five years. I would also like to thank my committee members, Dr. Thomas Kindermann, Dr. Cynthia Mohr, and Dr. Laurie Powers for their multitude of suggestions and insights into the design of the current project and the nuances of its findings. Special thanks to Dr. Todd Bodner for his statistical consultation, and Dr. Chris Huffine for graciously granting me access to the staff and clients at Allies in Change, in addition to their committee membership. I am also grateful for the members of the Tri County Batterer Intervention Provider Network who volunteered their time and wisdom to participate in a focus group, and all of the staff and clientele at Allies in Change for their flexibility, curiosity, and participation; this project simply would not have been possible without their support and engagement. I owe many thanks to Shilpa Trivedi and Susan Miller for their company and assistance with data collection on trips to Allies in Change, and Aunna Morkert and Rachel Smith for their data entry and focus group comoderation efforts.

Additionally, I would like to thank Dr.'s Mary Gray and Lindsey Patterson for their guidance and mentorship, and my colleagues and friends, Sarah Arpin, Tori Crain, Caitlin Demsky, Erin Stack, Kate Laudermilk, and Maura Pisciotta for their unwavering enthusiasm, patience, and understanding through this process. Further heartfelt thanks to 


\section{SOCIAL NETWORKS OF INTIMATE PARTNER VIOLENCE PERPETRATORS}

the Yoga Union Community Wellness Center for their unconditional support and

constant reminders to maintain perspective. Finally, I owe all the gratitude in the world to

my parents, Nancy and Lou Viola, for their perpetual encouragement, the opportunity to pursue higher education, and instilling me with the skills, hardiness, and sense of humor to persevere. 


\section{SOCIAL NETWORKS OF INTIMATE PARTNER VIOLENCE PERPETRATORS}

\section{Table of Contents}

\begin{tabular}{|l|l|}
\hline Abstract & i \\
\hline Acknowledgements & iv \\
\hline List of Tables & ix \\
\hline List of Figures & x \\
\hline & \\
\hline Chapter 1. Introduction & 1 \\
\hline Overview & 1 \\
\hline The Problem of IPV & 5 \\
\hline Who Perpetrates IPV? & 8 \\
\hline A Response to the Problem: Batterer Intervention Programs & 11 \\
\hline The Efficacy of BIPs & 15 \\
\hline Social Networks & 23 \\
\hline Influence Within Social Networks & 26 \\
\hline Relationship Quality and Influence Within Social Networks & 27 \\
\hline Social Networks' Influence on Individuals & 33 \\
\hline Social Networks and Substance Use & 33 \\
\hline Social Networks and Antisocial Behavior & 40 \\
\hline Social Networks and IPV & 43 \\
\hline Processes of Social Networks' Influence on the Perpetration of IPV & 47 \\
\hline Influence Through Direct Communication & 47 \\
\hline $\begin{array}{c}\text { Direct communication with families and peers during childhood } \\
\text { and adolescence }\end{array}$ & 47 \\
\hline Direct communication with peer groups in adulthood & 50 \\
\hline Influence Through Social Norms & 51 \\
\hline Social norms in childhood and adolescence & 51 \\
\hline Social norms in adulthood & 52 \\
\hline The Potential for Pro-Social Influence & 60 \\
\hline Individuals' Reciprocal Influence on their Social Networks & 62 \\
\hline Rationale and Significance & 68 \\
\hline Summary of Known and Unknown Information & 68 \\
\hline Measurement of Social Networks' Relationship to Violence Against & 77 \\
\hline Women & \\
\hline Chapter 2. Present Study & 79 \\
\hline Purpose & 79 \\
\hline Research Questions and Hypotheses & 80 \\
\hline Research Question One & 80 \\
\hline Research Question Two & 80 \\
\hline & \\
\hline
\end{tabular}




\section{SOCIAL NETWORKS OF INTIMATE PARTNER VIOLENCE PERPETRATORS}

\begin{tabular}{|c|c|}
\hline Research Question Three & 81 \\
\hline Research Question Four & 81 \\
\hline Hypotheses & 82 \\
\hline Moderating Variables & 82 \\
\hline Method & 84 \\
\hline Participants & 84 \\
\hline Protection of human subjects & 87 \\
\hline Design & 89 \\
\hline Procedure & 90 \\
\hline Measure development & 90 \\
\hline Survey pilot testing & 99 \\
\hline Survey data collection & 104 \\
\hline Member checking and reporting & 109 \\
\hline Measures & 112 \\
\hline Network members & 112 \\
\hline Network members' IPV-relevant behaviors & 113 \\
\hline Relationship quality & 114 \\
\hline Participants'IPV-relevant behaviors & 115 \\
\hline Potential moderating variables & 115 \\
\hline Additional descriptive information & 117 \\
\hline Survey Participants & 118 \\
\hline Survey Findings & 125 \\
\hline Data Preparation and Screening & 125 \\
\hline Research Question One & 126 \\
\hline Further description of participants' social networks & 129 \\
\hline Research Question Two & 131 \\
\hline Research Question Three & 134 \\
\hline Research Question Four & 156 \\
\hline Hypotheses & 178 \\
\hline Summary of Findings & 184 \\
\hline Chapter 3. Discussion, Implications and Limitations & 192 \\
\hline Addressing Gaps in Prior Literature & 194 \\
\hline Criminally Oriented Participants' Social Networks & 205 \\
\hline Implications for Practice & 206 \\
\hline BIP Participants as Bystanders & 207 \\
\hline Supporting BIP participants as bystanders & 210 \\
\hline General Efficacy of BIPs & 213 \\
\hline Abuse-relevant communication and satisfaction & 213 \\
\hline Participants' use of anti-abuse communication & 216 \\
\hline
\end{tabular}


SOCIAL NETWORKS OF INTIMATE PARTNER VIOLENCE PERPETRATORS

\begin{tabular}{|c|c|}
\hline Reciprocity of anti-abuse communication & 216 \\
\hline Participants' interactions with specific network members & 218 \\
\hline Implications for Theory & 222 \\
\hline Deviancy Training & 223 \\
\hline DeKeseredy's Model of Male Peer Support for Violence Against Women & 224 \\
\hline Implications for Research & 230 \\
\hline Measure Development & 230 \\
\hline Next Steps: Exploring Processes of Change over Time & 237 \\
\hline Limitations & 243 \\
\hline Study Design & 243 \\
\hline Data Collection, Processing and Analysis & 246 \\
\hline $\begin{array}{l}\text { Limitations of Research on Male Peer Support for Violence Against } \\
\text { Women }\end{array}$ & 251 \\
\hline Conclusion & 255 \\
\hline References & 259 \\
\hline Appendix A: BIP Facilitator Focus Group Recruitment Flier & 284 \\
\hline Appendix B: BIP Facilitator Focus Group Recruitment Email & 285 \\
\hline Appendix C: Consent Form for BIP Providers' Focus Group & 286 \\
\hline Appendix D: Script for BIP Providers' Focus Group & 288 \\
\hline Appendix E: Initial Item Pool used in Survey Development & 290 \\
\hline Appendix F: Points from BIP Providers' Focus Group & 294 \\
\hline Appendix G: Item Pool Resulting from BIP Providers' Focus Group & 295 \\
\hline Appendix H: Consent Form for BIP Participant Focus Group & 301 \\
\hline Appendix I: Script for BIP Participants' Focus Group & 303 \\
\hline Appendix J: Points from BIP Participants' Focus Group & 305 \\
\hline $\begin{array}{l}\text { Appendix K: Behavioral Inventories Resulting from BIP Participants' Focus } \\
\text { Group }\end{array}$ & 308 \\
\hline Appendix L: Survey Instrument used for Pilot Testing & 312 \\
\hline Appendix M: Consent Form for Pilot Testing Focus Group & 332 \\
\hline Appendix N: Script for Pilot Testing Focus Group & 335 \\
\hline Appendix O: Final Version of Survey Instrument & 337 \\
\hline Appendix P: Consent Form for Survey Administration & 365 \\
\hline Appendix Q: Consent Form for Release of Administrative Records & 367 \\
\hline Appendix R: Consent Form for Member Checking Focus Group & 369 \\
\hline $\begin{array}{l}\text { Appendix S: Handout of Quantitative Findings for Member Checking Focus } \\
\text { Group }\end{array}$ & 371 \\
\hline Appendix T: Script for Member Checking Focus Group & 373 \\
\hline Appendix U: Themes from Member Checking Focus Group & 376 \\
\hline
\end{tabular}




\section{SOCIAL NETWORKS OF INTIMATE PARTNER VIOLENCE PERPETRATORS}

\section{List of Tables}

\begin{tabular}{|l|c|}
\hline Table 1: Participants' Racial/Ethnic Identity & 120 \\
\hline Table 2: Participants' Referral Source to Allies in Change & 121 \\
\hline Table 3: Participants' Self-Reported Income & 121 \\
\hline Table 4: Participants' Highest Level of Education Completed & 122 \\
\hline Table 5: Participants' Self-Reported Religious Affiliation & 123 \\
\hline Table 6: Participants' relational ties to the people that they live with & 124 \\
\hline Table 7: Participants' relational ties to their social network members & 128 \\
\hline $\begin{array}{l}\text { Table 8: Percent of relational ties nominated by participants nominating 1 thru } \\
\text { 8 network members }\end{array}$ & 131 \\
\hline $\begin{array}{l}\text { Table 9: Average MFQ-RA scores of network members with various relational } \\
\text { ties to participants }\end{array}$ & 134 \\
\hline Table 10: Network Members' Average Use of Each IPV-Relevant Behavior & 137 \\
\hline $\begin{array}{l}\text { Table 11: Significant Comparisons of Pairwise Differences in Network } \\
\text { Members' Use of Behaviors }\end{array}$ & 142 \\
\hline $\begin{array}{l}\text { Table 12: Use of Each Behavior by Network Members of Participants in } \\
\text { Criminally Oriented and Non Criminally Oriented Groups }\end{array}$ & 149 \\
\hline Table 13: Network Members' Total Use of Behaviors by Relational Tie & 151 \\
\hline $\begin{array}{l}\text { Table 14: Network Members' Use of Pro-Abuse and Anti-Abuse Behaviors by } \\
\text { Relational Tie }\end{array}$ & 156 \\
\hline $\begin{array}{l}\text { Table 15: Participants' Average Use of Each IPV-Relevant Behavior with } \\
\text { Network Members }\end{array}$ & 159 \\
\hline $\begin{array}{l}\text { Table 16: Significant Comparisons of Pairwise Differences in Participants' Use } \\
\text { of Behaviors }\end{array}$ & 163 \\
\hline $\begin{array}{l}\text { Table 17: Use of Each Behavior by Participants in Criminally Oriented and } \\
\text { Non Criminally Oriented Groups }\end{array}$ & 170 \\
\hline $\begin{array}{l}\text { Table 18: Participants' Total Use of Behaviors with Network Members by } \\
\text { Relational Tie }\end{array}$ & 173 \\
\hline Table 19: Participants' Average Use of Behavior Composites by Relational Tie & 178 \\
\hline $\begin{array}{l}\text { Table 20: Summary of Research Questions, Hypotheses and Associated } \\
\text { Findings. }\end{array}$ & 185 \\
\hline Table 21: Summary of Substantive Findings & 193 \\
\hline
\end{tabular}




\section{SOCIAL NETWORKS OF INTIMATE PARTNER VIOLENCE PERPETRATORS}

\section{List of Figures}

Figure 1: Mechanisms of social networks' influence on the perpetration of IPV 45

Figure 2: Phases, goals, and corresponding approaches, to data collection

Figure 3: Distribution of number of network members nominated

90

127




\section{SOCIAL NETWORKS OF INTIMATE PARTNER VIOLENCE PERPETRATORS}

\section{Chapter 1. Introduction}

\section{Overview}

The purpose of the current study is to describe the members of batterer intervention program (BIP) participants' social networks, the ways that these networks may address intimate partner violence (IPV) with BIP participants, and the ways that BIP participants may address IPV with the members of their social networks. IPV is thought to consist of behaviors, within the context of intimate relationships, which cause physical, psychological, or sexual harm to one's partner (Krug, Dahlberg, Mercy, Zwi \& Lsano, 2002, p. 89). BIPs are group-based intervention programs intended to mitigate the violence perpetrated by men against their intimate partners (Saunders, 2008).

The paper begins with a description of IPV and its impacts, and variables that have been associated with the perpetration of IPV. BIPs, as a response to the problem of IPV, are then described. Research regarding BIPs' efficacy is reviewed, highlighting the inconsistency of the findings, and BIPs' lack of emphasis on their participants' social networks as a potential cause of their inconsistently identified efficacy. Social networks, or sets of individuals who are connected to each other through known, or potentially known, relational ties (Wasserman \& Faust, 1994) are then defined in greater detail. Relational ties, the types of affiliations between two people are also described, as is the process of influence, the process by which individuals' attitudes or behavior impact those of others (Lippitt, Polansky \& Rosen, 1952). The impact of one person's influence on another is tempered by their relationship quality, or the extent to which the individual on 


\section{SOCIAL NETWORKS OF INTIMATE PARTNER VIOLENCE PERPETRATORS}

the receiving end of the influence behavior is satisfied with their relationship with the person exerting the influence (Priester \& Petty, 2001; Terry \& Hogg, 1996).

Research regarding social networks' impact on substance abuse recovery is then reviewed for two purposes: (1) to illustrate that findings about social networks' role in treatment may be translated into changes in treatment program functioning, and (2) to describe some of the factors and processes within individuals' social networks that may impact the extent of their behavior change as they participate in treatment programs. Then, findings that establish links between social networks' attitudes and behaviors and individuals' antisocial behavior in general, and their perpetration of IPV, more specifically, are reviewed. Collectively, this body of theory and research indicates that examining the links between BIP participants' IPV-specific attitudes and behaviors, and those of their social network members is worthwhile. A first step in determining whether and how this occurs is describing BIP participants' social networks and the behaviors that may generate IPV-specific influence therein.

In the section that follows, a model of the process by which adult men and their social networks exert sexual-assault specific influence upon each other during adulthood is described (DeKeseredy, 1988; DeKeseredy, 1990a, Schwartz \& DeKeseredy, 1997). The current study does not intend to test this model, but the model provides an illustration of processes through which BIP participants may be subject to the influence of their social networks, and provides a framework for discussing influence processes that may occur within social networks. The particular model was selected because it highlights 


\section{SOCIAL NETWORKS OF INTIMATE PARTNER VIOLENCE PERPETRATORS}

three important processes: social networks' exertion of influence on individuals through direct communication, social networks' exertion of influence on individuals through social norms, and individuals' exertion of influence on their social networks.

Adopting a transactional worldview (Altman \& Rogoff, 1987) may be informative in understanding the nature of the reciprocal impact that individuals and their social networks may exert upon each other. While this construct is not detailed in the paper that follows, it may be useful to bear in mind while conceptualizing how individuals are embedded within and contribute to their social networks. Viewing phenomena through a transactional worldview involves adopting a holistic perspective and examining a person and their environment, jointly, as an inseparable unit of analysis (Altman \& Rogoff, 1987): the individual cannot be understood outside of the context of their social network, and the social network cannot be disentangled from its members. Within a transactional worldview, change is ongoing and intrinsic, and results from the complex interactions between elements within a system, such that any aspect of the system may be considered a causal variable or an outcome variable on different occasions (Altman \& Rogoff, 1987). Hence, the individual's attitudes and behaviors may be considered either a cause of the attitudes and behaviors of their social network members, or a result of their social network members' attitudes and behaviors. As such, social networks' exertion of influence on individuals may also be interpreted in the reverse: any attitude or behavior manifested by an individual contributes to the collective attitudes and behaviors of their 


\section{SOCIAL NETWORKS OF INTIMATE PARTNER VIOLENCE PERPETRATORS}

social networks, and individuals' exertion of influence upon each other is inherently the exertion of influence upon their shared social network.

The purpose of the current study, to describe the social networks of BIP participants and the ways that they and their social network members may communicate with each other about IPV, is elaborated, as are specific research questions and hypotheses to this end. The methods section includes a description of the steps that will be taken to ensure the protection of participants. Pre-existing measures that will be included in the survey instrument, and their psychometric properties are described. The study's procedure includes conducting focus groups, to develop measures of the ways in which BIP participants and their social network members communicate about IPV. Following the development of these measures and piloting of the survey instrument, BIP participants will be surveyed about the members of their social networks, the quality of their relationships with these social network members, and their IPV-relevant communication with their social network members. An additional focus group will then be conducted to elicit BIP participants' interpretations of the quantitative findings. The specific analyses that will be used to address the research questions and hypotheses are described. The study's implications for BIP participants, the members of their social networks, and their broader communities are described, as are the limitations of the current study. 


\section{SOCIAL NETWORKS OF INTIMATE PARTNER VIOLENCE PERPETRATORS}

\section{The Problem of IPV}

Intimate partner violence (IPV), defined as "any behavior within an intimate relationships that causes physical, psychological or sexual harm to those in the relationship" (Krug, Dahlberg, Mercy, Zwi \& Lozano, 2002, p. 89) occurs universally (Krug et al., 2002) and is a significant social problem in the United States (Krug et al., 2002; CDC, 2006; CDC, 2008; Catalano, 2007; Tjaden \& Thoennes, 2000; Coker, Smith, McKeown \& King, 2000; Tjaden \& Thoennes, 1998; Thompson, Bonomi, Anderson, Reid, Dimer, Carrell \& Rivara, 2006). The terms abuse, IPV and domestic violence are often used interchangeably, as individuals' domestic partners are generally considered their intimate partners. However, not all intimate relationships involve cohabitation, and these relationships are also captured by the phrase IPV. The term "abuse" refers to acts of physical and sexual violence, as well as verbal aggression and the withdrawal of affection within romantic relationships, in order to maintain control over one's intimate partner (Hegarty, Sheehan \& Schonfeld, 1999). There is also overlap between the phrase "dating violence" and IPV, as the distinction between a dating partner, or romantic partner, and intimate partner may be blurry. Sexual assault may occur within dating relationships, intimate relationships, or outside of the context of an ongoing relationship; sexual assault and IPV are not mutually exclusive. All of behaviors implied by these phrases, when they pertain to violence perpetrated by men against women, may fall into the broad category of violence against women. 


\section{SOCIAL NETWORKS OF INTIMATE PARTNER VIOLENCE PERPETRATORS}

IPV includes acts of physical aggression; psychological abuse including intimidation, constant belittling and humiliating; sexual assault and coercion; or controlling behaviors, including isolation from family and friends and restricting and monitoring movement and access to information and assistance (Krug et al., 2002) that occurs within the context of sexual relationships, or thwarted sexual relationships (Jewkes, 2002), or perpetrated by a current or former spouse, cohabiting partner, boyfriend or girlfriend, or date (Tjaden \& Thoennes, 2000). Victims' emotional involvement and frequent economic dependence upon those who perpetrate violence against them shape the dynamics of the abuse, and necessitate specific approaches to intervention (Krug et al., 2002). While both men and women are victimized by their intimate partners and IPV occurs in the context of both homosexual and heterosexual relationships (Dutton, 2011), IPV is most often perpetrated by men against their female partners (Catalano, 2007).

As of 2000, one in every four women within the United States were expected to be the victims of domestic violence within their lifetimes (Tjaden \& Thoennes, 2000); roughly 1.3 million women are the victims of 5.3 million instances of IPV every year (CDC, 2006; Tjaden \& Thoennes, 2000). The results of a 2003 telephone survey of American women found that forty-four percent of participants had ever been the victim of IPV (Thompson et al., 2006). Among women who report having experienced rape, physical assault, and/or stalking since age eighteen, sixty-four percent report that the abuse was perpetrated by current or former intimate partners or dates (Tjaden \& 


\section{SOCIAL NETWORKS OF INTIMATE PARTNER VIOLENCE PERPETRATORS}

Thoennes, 2000). The majority of women who experience one type of IPV are also subject to additional forms of violence perpetrated by an intimate partner (Thompson et al., 2006). Between eleven and twenty-one percent of victims of IPV are victimized by more than one intimate partner over the course of their lives, and between fourteen and eighteen percent of victims experience twenty or more instances of physical or sexual abuse in their lifetimes (Thompson et al., 2006).

Furthermore, violence perpetrated by current or former intimate others is more likely to result in injury to the victim than violence perpetrated by men who are unknown to them (Tjaden \& Thoennes, 2000), with IPV resulting in two million injuries and the loss of eight million days of work each year (CDC, 2006). The CDC (2006) reports that costs of IPV surpass $\$ 5.8$ billion annually, including $\$ 4.1$ billion towards the provision of medical and mental health services. Only approximately one third of women who are the victim of sexual or violent assaults seek treatment (Tjaden \& Thoennes, 2000).

Female victims of IPV are more likely to report disabilities, arthritis, asthma, limitations in activity, strokes, high cholesterol, heart attacks, heart disease, risk factors for HIV or other STDs, tobacco use, and heavy or binge drinking (CDC, 2008), as well as any form of chronic disease and more days recuperating in bed (Ruiz-Perez, PlazaolaCastano \& del Rio-Lozano, 2007) than women who have not experienced IPV. Those who have been victims of IPV are also more susceptible to depression, suicide attempts, chronic pain disorders, gastrointestinal disorders, irritable bowel syndrome, and a number of reproductive health consequences (Krug et al., 2002, p. 101). 


\section{SOCIAL NETWORKS OF INTIMATE PARTNER VIOLENCE PERPETRATORS}

Across nations, lower homicide rates are related to higher prevalence of IPVrelated homicides (Pilger \& Watts, 2013), indicating that, even within countries where homicide in general is minimal, deaths resulting from IPV persist (Graduate Institute of International and Development Studies, 2012), leading some to describe IPV as "the last frontier of violence" (Alvazzi del Frate, 2012).

Who perpetrates IPV?

Many perpetrators of IPV have a tendency towards antisociality. In both community samples and samples of men with arrest histories, perpetration of IPV has been linked to the following individual-level factors: general antisocial behavior (Capaldi \& Crosby, 1997; Harris, Hilton \& Rice, 2011; Magdol et al., 1997), childhood exposure to IPV among one's parents (Hilton \& Harris, 2005), severity of substance abuse (Harris, Hilton \& Rice, 2011; Hilton \& Harris, 2005; Magdol et al., 1997), a lack of social support (Magdol et al., 1997), poor mental health (Magdol et al., 1997), lack of education (Magdol et al., 1997), poverty (Jewkes, 2002), and chronic unemployment (Magdol et al., 1997). Assortive partnering on the basis of antisocial behavior may also contribute to IPV, such that men with antisocial tendencies become involved with partners with similar patterns of antisociality (Capaldi \& Crosby, 1997), potentially increasing the volatility of their relationships. The association between general antisocial behavior and IPV, and perpetrators' denial that engaging in abusive behavior warrants being identified as a batterer (Goodrum, Umberson, \& Anderson, 2001) are discussed below. 


\section{SOCIAL NETWORKS OF INTIMATE PARTNER VIOLENCE PERPETRATORS}

While it is a distinct pattern of behavior, the perpetration of IPV often co-occurs with more general antisocial behavior. Capaldi and Crosby (1997) followed a sample of young men, identified as being at an especially high risk for delinquent behavior, for a year to two years after their senior year of high school. Among these young men, general antisocial behavior was particularly predictive of their perpetration of IPV. Harris, Hilton and Rice (2011), defining antisociality in terms of psychopathy, antisocial personality disorder, and patterns of non-domestic violence, found that antisociality was overwhelmingly more predictive of IPV than perpetrators' attitudes or the features of their intimate relationships or neighborhoods of residence. Using a sample of 547 men with arrest records for IPV, the authors concluded that antisociality accounts for a large portion of the variation in individuals' perpetration of general interpersonal violence, and especially the frequency of their perpetration of IPV. It should be noted, however, that criteria for inclusion in the sample necessitated a criminal record, and may be prone to any biases within the criminal justice system. A study of 43621 -year-old men in New Zealand similarly found that perpetration of severe physical violence was correlated with manic disorder, psychosis, antisocial personality disorder, the perpetration of violence towards strangers, and general criminality (Magdol et al., 1997). In 2005, Hilton and Harris published a review of pre-existing research. Parallel to Harris, Hilton and Rice's (2011) findings, the review concludes that, among other individual characteristics, the following should be considered in attempts to identify men at risk of perpetrating IPV: conduct disorder, psychological aggression, personality disorder, mood disorder, anger, 


\section{SOCIAL NETWORKS OF INTIMATE PARTNER VIOLENCE PERPETRATORS}

hostility, jealousy, lack of appropriately assertive behavior, pro-violence attitudes, and non-violent conflict within the relationship.

However, there is also a population of IPV perpetrators who do not display antisocial behavior outside the contexts of their relationships. Holtzworth-Munroe and Stuart (1994) identified three subtypes of men who perpetrate IPV: those who are generally violent and antisocial across relationships and context, and those who restrict their use of violence to their families, a subset of whom are described as dysphoric or borderline. While general violence and antisocial behavior may be risk factors for perpetrating IPV (Magdol et al., 1997), not all men who are at risk of perpetrating IPV may be identified by their aggression, hostility, anger, or conduct disorder.

Batterers tend to avoid viewing themselves as such, and may avoid contact with people who do view them in that way. Goodrum, Umberson, and Anderson (2001) examined perpetrators' constructions of themselves and their partners. They found that perpetrators were frustrated with being defined by their abuse, as they did not feel that this behavior was a reflection of their true selves. Similarly, participants felt that the label of "batterer" was not merited when their perpetration of abuse had been limited to single instances or single individuals, or when the abuse that they had perpetrated was not particularly severe. Many participants denied the extent and impact of their abuse, resisted viewing themselves as responsible for their violent behavior, avoided information about the harm that their abuse had caused, and often dismissed or 


\section{SOCIAL NETWORKS OF INTIMATE PARTNER VIOLENCE PERPETRATORS}

discredited others' accusations and criticisms. Therefore, perpetrators likely prefer to surround themselves with others who justify or normalize their IPV.

Thus, many, though not all, of the men who perpetrate IPV also have histories of antisocial behavior, which, as described in a later section, has been empirically linked to having friends and family members who also engage in antisocial behavior (Dishion, Andrews \& Crosby, 1995; Dishion, Capaldi, Spracklen \& Li, 1995; Dishion, Patterson \& Griesler, 1994; Patterson, Dishion \& Yoerger, 2000; Warr, 2006). Perpetrators, both with and without antisocial tendencies, may choose to avoid others who are critical of their use of abuse. Programs that address the perpetration of IPV put perpetrators in direct contact with program facilitators, information, and new perspectives that are critical of the perpetration of IPV. Batterer intervention programs (BIPs), as described below, are such community-based interventions that address perpetrators' use of violence towards their intimate partners.

A Response to the Problem: Batterer Intervention Programs

While both men and women who perpetrate IPV may be made to participate group-based programs to address their use of violence (Rosenbaum \& Leisring, 2001), the current review will focus on groups specifically for men, as most commonly, IPV is perpetrated by men, against women, and most programs addressing the use of violence within relationships offer services exclusively for men (Catalano, 2007). The BIPs 


\section{SOCIAL NETWORKS OF INTIMATE PARTNER VIOLENCE PERPETRATORS}

discussed and surveyed in the current project serve male clients, the majority of whom have perpetrated violence against female partners.

BIPs serving male offenders are group-based intervention programs, in which one or two facilitators guide groups of men through cognitive-behavioral therapy and gender resocialization (Saunders, 2008). Groups are ideally co-facilitated by one male and one female group leader (Rosenbaum \& Leisring, 2001). Most programs consist of a didactic, educational component that provides information about IPV and strategies to reduce it, as well as a process-oriented component, in which participants explore their personal histories that may contribute to their individual perpetration of IPV (Rosenbaum \& Leisring, 2001). Most programs utilize films and printed material as teaching tools, and maintain contact and exchange information and resources with participants' partners (Rosenbaum \& Leisring, 2001). Motivated by concerns that involving other community members may compromise victim safety (Rosenbaum \& Leisring, 2001), most BIPs engage only the perpetrators of abuse in their programming (Saunders, 2008; Rosenbaum \& Leisring, 2001), though facilitators may correspond with perpetrators' victims outside of the group to keep them abreast of the perpetrators' progress. Therefore, BIPs rarely intervene in other contexts that program participants occupy or with the men's social networks, ignoring the transactional nature of the relationship between individuals and their social environment.

The first BIPs were founded in the late 1970's, beginning with the Emerge program in Massachusetts in 1977 (Edleson, 2012; Emerge, 2012). The women's 


\section{SOCIAL NETWORKS OF INTIMATE PARTNER VIOLENCE PERPETRATORS}

movement of the 1970's brought greater public attention to the recognition of abuse, facilitated the creation of shelters and safe houses for victims of IPV, and ultimately led to the widespread establishment and use of BIPs (Gondolf, 2002). Throughout the early 1980s, pressure from women's organizations and victims' rights groups encouraged police departments to enforce more consistent responses to violent crimes regardless of the contexts in which they were perpetrated, and to punish perpetrators of IPV more harshly, leading to increased numbers of men being prosecuted for IPV (Edleson, 2012). The overcrowding of American prisons in the 1980s, for reasons unrelated to IPV, in combination with increases in the prosecution of IPV perpetrators, led to a growing reliance on BIPs to treat and manage perpetrators in the community (Gondolf, 2002).

There is great variability among BIPs in terms of both their structure and, to a lesser extent, their content. BIPs vary in the number of weekly sessions that participants are required to attend, group facilitators' training, and the exact program content (Edleson, 2012), including the amount of emphasis on power and control issues in the curriculum (Rosenbaum \& Leisring, 2008). Programs that utilize more pro-feminist approaches prioritize victims' safety, with implications for confidentiality or a lack thereof, and for programs' emphasis on managing batterers' behavior through communication with law enforcement and participants' partners as necessary (Rosenbaum \& Leisring, 2001). Programs that place greater emphasis on providing treatment to perpetrators are more inclined towards situating themselves as their clients' 


\section{SOCIAL NETWORKS OF INTIMATE PARTNER VIOLENCE PERPETRATORS}

advocates and confidents, to enable participants to speak openly about the problematic behavior in which they continue to engage (Rosenbaum \& Leisring, 2001).

Despite variability in the structure and content of BIPs, the majority of programs, both domestically and abroad, are guided by the Duluth curriculum (Paymar \& Barnes, 2006), which is an educational approach to working with perpetrators of IPV. At the core of the Duluth curriculum is the belief that men use abusive tactics to exert power over and control their female partners (Pence \& Paymar, 1993). This is the general lens that programs following the Duluth curriculum apply throughout their groups (Paymar \& Barnes, 2006)

Most contemporary BIPs, both those heavily influenced by the Duluth curriculum and those that are not, include an emphasis on power and control issues. Despite their differences, nearly all programs include components that teach participants to identify when they are becoming angry; strategies for removing themselves from situations when they feel that they are becoming angry; to examine and convey other emotions that they would otherwise ultimately express as anger; tangible consequences of acting aggressively; the ways that substance use contributes to their abusive behavior; nonviolent communication skills; how to replace cognitions that fuel their anger and judgment of their partners with less upsetting conjectures about their partners' behaviors and motivations; processes for mitigating stressors and relaxing; parenting skills; assertiveness; and techniques for developing empathy with their victims (Rosenbaum \& Leisring, 2001). Thus, programs teach participants strategies for modifying their own 


\section{SOCIAL NETWORKS OF INTIMATE PARTNER VIOLENCE PERPETRATORS}

behavior in situations when abuse is likely to occur. Despite variability in program structure and content, most BIPs address almost solely, processes and behaviors that the individual participants may utilize, either in isolation or during interactions with their partners. With the exceptions of strategies to mitigate stressors and parenting skills, most BIPs do not formally include modules that address aspects of participants' social networks. Despite evidence of the associations between individuals' antisocial and abusive behavior and that of their peers (Dishion, Andrews \& Crosby, 1995; Dishion, Patterson \& Griesler, 1994), detailed in a later section, most BIPs do not formally address the role of participants' social networks in shaping their behavior.

\section{The Efficacy of BIPs}

There is a lack of consensus in the literature regarding the efficacy of BIPs (Saunders, 2008). BIP participation is generally more effective at reducing violence perpetration than alternatives that do not address IPV directly (Coulter \& Vande Weerd, 2009; Lewis, 2004; Taylor, Davis \& Maxwell, 2001), though issues of measurement (Taylor, Davis \& Maxwell, 2001), pre-existing differences among program participants (Hanson \& Wallace-Capretta, 2000), program drop-out (Feder \& Wilson, 2005; Hanson \& Wallace-Capretta, 2000) and men's engagement in BIPs beyond mere attendance (Contrino, Dermen, Nochajski, Wieczorek \& Navratil, 2007) nuance this overall finding. Findings from a study of "successful" BIP participants indicate that the lack of emphasis 


\section{SOCIAL NETWORKS OF INTIMATE PARTNER VIOLENCE PERPETRATORS}

on BIP participants' friends and families in BIP curricula may have implications for their efficacy (Sheehan, Thakor and Stewart, 2012).

Across studies, findings regarding BIPs' ability to reduce recidivism among those who are mandated to attend programs are inconsistent. A 1999 meta-analysis of quasiexperiments and true experiments evaluating BIPs' efficacy concluded that BIPs are generally effective, and have substantial effects on recidivism, though they found no difference in outcomes among programs with different theoretical approaches and lengths (Davis \& Taylor, 1999). A 2004 meta-analysis of twenty-two existing studies corroborated these findings, identifying no differences between the effects of BIPs that used the Duluth curriculum and those that rely more heavily on cognitive-behavioral approaches, and generally small effects for all of the programs assessed across the studies reviewed (Babcock, Green \& Robie, 2004). Gondolf $(1997,2002)$ attempted to conduct interviews with 840 BIP participants from four programs across the US, and their partners, every three months for 15 months, beginning at participants' intake to a BIP, and then for four years thereafter. Despite decreased rates of physical assault among those who continued to participate compared to those who dropped out of the programs, many participants continue utilizing controlling behaviors, verbal abuse, and threats throughout and following their BIP participation (Gondolf, 1997). However, of those men who re-assault their partners after beginning a BIP, $40 \%$ reoffend within the first fifteen months thereafter, an additional $5 \%$ reoffend between the $15^{\text {th }}$ and $30^{\text {th }}$ months after beginning BIP participation, and $3 \%$ reoffend between the $30^{\text {th }}$ and $48^{\text {th }}$ months of 


\section{SOCIAL NETWORKS OF INTIMATE PARTNER VIOLENCE PERPETRATORS}

their BIP participation, indicating that the more time that has passed since participants begin attending a BIP, the less likely they are to recidivate for the first time (Gondolf, 1997; Gondolf, 2002).

Whether or not a study finds that BIP participation leads to reductions in recidivism often depends on how control groups are defined. In a study of 95 couples, Lewis (2004) found that, according to victim reports, only $33 \%$ of convicted batterers who participated in treatment programs continued to perpetrate abuse a year after their sentencing, compared to $70 \%$ of those men who were subject to fines or incarceration. Those who participated in the treatment condition reported an increased awareness of their own behavior and the ways in which it had been abusive (Lewis, 2004). A 2005 meta-analysis that also considered the results of published experiments and quasi experiments highlights this pattern: experimental studies of BIPs' efficacy generally concluded that the programs had modest benefits, while quasi-experiments had different conclusions depending on whether they used a no-treatment control group or a control group of men who had dropped out of BIPs (Feder \& Wilson, 2005). Quasi-experiments that compared outcomes for men who dropped out of BIPs to those of men who completed the programs found that BIPs produced large, positive effects, while quasiexperiments that compared BIP participants' outcomes to those who received no treatment had inconsistent results and occasionally found BIPs to produce small, harmful results (Feder \& Wilson, 2005). 


\section{SOCIAL NETWORKS OF INTIMATE PARTNER VIOLENCE PERPETRATORS}

Men who participate in BIPs through completion are less likely to recidivate than those who drop out prior to completing the program (Coulter \& Vande Weerd, 2009; Feder \& Wilson, 2005; Gondolf, 1997). Within 15 months of beginning a BIP, approximately one third of those who complete the program may be expected to perpetrate at least one instance of physical abuse, as reported by themselves and/or their partners, compared to $40 \%$ of those who drop out of the programs they began (Gondolf, 1997). Surveying 17,999 BIP participants in an entire Florida county between 1995 and 2004, Coulter and Vande Weerd (2009) found that 21.2\% of men who began, but did not complete, BIP participation were re-arrested for domestic violence during the study period, compared to only $8.4 \%$ of those who completed programs that they began.

However, many batterers do drop out of BIP programs before their completion, preventing them from receiving the full potential benefits of program participation: just over $30 \%$ of participants enrolled in the programs studied by Coulter and Vande Weerd (2009) ultimately dropped out. In addition to limiting programs' potential efficacy (Coulter \& Vande Weerd, 2009), participant drop out makes it difficult to assess the impact of programs implemented as intended (Hanson \& Wallace-Capretta, 2000).

A further complication in determining program efficacy is that the variables associated with individuals' dropping out of BIPs are similar to the variables associated with perpetration of IPV. A recent meta-analysis of 39 studies examining factors associated with drop-out from BIPs found that perpetrators who were employed, older, court mandated to BIP participation, attending the program after their first arrest for IPV, 


\section{SOCIAL NETWORKS OF INTIMATE PARTNER VIOLENCE PERPETRATORS}

and had higher incomes were more likely complete treatment than their unemployed, younger, non-court mandated counterparts with multiple prior charges for IPV and lower incomes, paralleling findings about characteristics associated with the perpetration of IPV (Jewell \& Wormith, 2010). Similar to factors associated with lower likelihoods of perpetrating abuse, being married, Caucasian, lacking alcohol or other substance abuse problems, and having attained higher education were also associated with a greater likelihood of BIP completion. In contrast to the perpetration of IPV, having been the victim of abuse, being exposed to IPV among one's parents, the severity of the abuse that one perpetrates, depression, and anger were not associated with perpetrators' likelihood of dropping out of treatment (Jewell \& Wormith, 2010). Being younger, single, and having more unstable lifestyles, lower verbal skills, more negative attitudes, and shorter relationships with their victims are also related to recidivism following program completion (Hanson \& Wallace-Capretta, 2000).

BIP participants who recidivate after completing a BIP also have more extensive histories of criminal behavior (Hanson \& Wallace-Capretta, 2000), and are less connected to the BIP that they attended (Hanson \& Wallace-Capretta, 2000), have been court-ordered to treatment (Hanson \& Wallace-Capretta, 2000), have negative attitudes towards program providers (Hanson \& Wallace-Capretta, 2000) and more likely to have dropped out of a BIP in the past (Coulter \& Vande Weerd, 2009; Gondolf, 1997). Histories of criminal behavior may indicate prior, and potentially concurrent, associations with antisocial friends (Warr, 2006), while lesser connections to BIPs may reflect less 


\section{SOCIAL NETWORKS OF INTIMATE PARTNER VIOLENCE PERPETRATORS}

investment in the interpersonal relationships with those involved with the program. Thus, recidivism may be related to participants' relationships with others both inside and outside of their programs.

Recidivism, defined in terms of re-arrest, is not the only metric that has been used to determine program success. Conclusions about the effect of BIP participation on recidivism also appear to vary depending on the source of information about continued abusive behavior. Taylor, Davis \& Maxwell (2001) conducted an experiment to compare continued perpetration of IPV between convicted batterers who did and did not attend BIPs. Men who had been arrested on charges of IPV were assigned to either 40 hours of community service or 40 hours of batterer intervention. Participants' perpetration of IPV was assessed on the basis of arrest reports, crime complaints, and victim reports. The authors found a significant reduction in perpetration among those who participated in the batterer intervention option, at both 6 months and a year following treatment completion, when arrest reports and crime reports were considered. However, using victim reports as the measure of recidivism, no statistically significant differences in recidivism were found between men who had and had not participated in the BIP.

BIPs increase their participants' knowledge of IPV and strategies to reduce their perpetration. As opposed to using re-arrest or victim reports as an outcome measure, Contrino and colleagues (2007) examined differences in BIP participants' ability to recall concrete information taught in their groups. Program facilitators rated participants' levels of attendance, nonviolence, sobriety, acceptance of the violence that they had perpetrated, 


\section{SOCIAL NETWORKS OF INTIMATE PARTNER VIOLENCE PERPETRATORS}

use of techniques taught in the group, help-seeking behaviors, consciousness of the processes involved in their change, active engagement in the program, self-disclosure, and use of sensitive language during group meetings (Contrino et al., 2007). Men who had engaged and appropriately participated in their BIP group meetings, as per their facilitators' ratings, were better able to recall forms of power and control and alternative noncontrolling behaviors, indicating that BIPs' effectiveness depends on more than participants' mere attendance (Contrino et al., 2007). These findings also indicate that participants absorb concrete knowledge from their BIP programs, which they may be capable of articulating to others.

BIP participants' relationships with their friends and family members, as well as other BIP participants and facilitators, are related to the success of their program participation. A number of studies have addressed BIP effectiveness by examining the processes that allow successful BIP participants to undergo changes in their behavior. Reviewing the results of six qualitative studies that examined processes of change among BIP participants who were successful in completing programs and changing their behavior, Sheehan, Thakor and Stewart (2012) found that many men who successfully complete BIPs are influenced by their relationships with others throughout their program participation. Many highly successful BIP participants enter the programs as a result of pressure either from community institutions or smaller groups, such as their families, and are motivated to complete the program by fears of losing familial relationships (Sheehan, Thakor \& Stewart, 2012). However, the majority of men participating in BIPs in the 


\section{SOCIAL NETWORKS OF INTIMATE PARTNER VIOLENCE PERPETRATORS}

United States are court mandated to do so (Gondolf, 2002), as opposed to motivated by pressure from friends and family. While perpetrators of IPV are often subject to police intervention and others in their lives may confront men about behaviors peripheral to their abuse (i.e., drinking), relatively few abusive men have been directly confronted by about their abusive behavior (Lewis, 2004). The results of interviews with 122 Scottish men who had been convicted of perpetrating IPV revealed that only $9 \%$ had been confronted by social contacts about their use of violence with their partner (Lewis, 2004).

Once participating in a program, changes in successful BIP participants' behavior has been theorized to result from taking responsibility for the abuse that they have perpetrated and learning new skills (Sheehan, Thakor \& Stewart, 2012). Two of the studies included in Sheehan and colleagues' review (2012) also noted that developing positive relationships with program facilitators and fellow participants appeared to enable change in participants' behavior; BIP participants, deemed successful in changing their abusive behavior by their group facilitators, partners, or through self-reports, increased their social contact other individuals with an awareness of the issues addressed in the BIP curriculum. While the extent and endurance of the change that BIP participants experience remains contested, Sheehan and colleagues' (2012) findings indicate that BIP participants' relationships with their pre-existing friends and family members are instrumental in bringing them in contact with programs, and that the relationships that participants develop through their involvement with BIPs have implications for their behavioral changes. 


\section{SOCIAL NETWORKS OF INTIMATE PARTNER VIOLENCE PERPETRATORS}

Despite conflicting evidence about the efficacy of BIPs and the challenges of disentangling program effectiveness from pre-existing differences among participants, participant drop-out, and varied approaches to defining and measuring program success, it appears that BIP participants' non-romantic relationships likely contribute to the effectiveness of their BIP participation. Members of BIP participants' social networks may influence their establishing of contact with BIPs, and engage with them about the topics covered in their programs. However, program participants' networks may also contribute to their perpetration of IPV. The following section includes a formal definition of social networks, the influence process and the role of relationship quality within social networks, and the impact of social networks on the perpetration of IPV.

\section{Social Networks}

Social networks are finite collections of actors, whose relationships to each other are, or can be, known (Wasserman \& Faust, 1994). Social network analysis refers to the study patterns of relationships among individuals and their implications for individuals' attitudes, behaviors, knowledge, and preferences. Individuals, or actors, are linked by social ties or relational ties, relationships that reflect a degree of contact or type of affiliation between them. Examples of ties include relationships that are defined by activities therein (such as the expression of friendship, liking, or respect or transfers of material resources) or by the physical proximity or formal relationships between individuals (such as neighborly, authority, or biological relationships). Ties can 


\section{SOCIAL NETWORKS OF INTIMATE PARTNER VIOLENCE PERPETRATORS}

encompass two individuals (dyads), three individuals (triads), groups, subgroups, relations (dyads, triads, or subgroups defined by the fact that they are linked by the same type of relationship within a larger group), or entire social networks (Wasserman \& Faust, 1994). For the purpose of the current study, a relational tie is defined as the type of affiliation between an individual and a specific network member, examples of which include friend, parent, coworker and employer. The set of an individual's relational ties comprise their social network; each network member also has their own set of relational ties with others who are therefore peripherally connected to the initial individual's social network.

Social networks have characteristic norms and values that are transmitted and manifested in social structures (Wasserman \& Faust, 1994; Wellman, 1982). Ties between individual actors vary as a function of larger structural unit in which they're embedded (Erickson, 1988), and the patterning of ties shape opportunities and constraints on social behavior (Wellman, 1982). Social networks encompass the simultaneous influence of an actor's ties to multiple others, as opposed to the influence of individual relationships in isolation, or the influence of factors at a much higher and more detached level of analysis; an individual's social network represents the entirety of their most immediate social environment (Borgatti, Mehra, Brass \& Labianca, 2009; Juras et al., 1997; Luke, 2005; Shinn \& Rapkin, 2000).

Individuals' attitudes are largely shaped through interactions with members of their social networks (Erickson, 1988; Borgatti, Mehra, Brass \& Labianca, 2009). 


\section{SOCIAL NETWORKS OF INTIMATE PARTNER VIOLENCE PERPETRATORS}

Erickson (1988) explains that individuals' attitudes are shaped through interpersonal processes, and that these interpersonal processes have a greater effect when they occur between members of the same social network, as opposed to strangers. Both the relational tie between individuals and the relationship's position among other relationships within the web of ties that comprise an individual's network, determine the relationship's effect on its participants (Erickson, 1988). Social networks are individuals' most immediate social context, as they are, by definition, the collection of people with whom an individual has relationships (Borgatti, Mehra, Brass \& Labianca, 2009). Most adults have immediate, or close, social networks that contain seven to eight others, including spouses, siblings, friends, and neighbors of both genders. Of adults' 7.5 network members, on average, only 0.7 of those relational ties are friends (Christakis \& Fowler, 2007).

Presumably, many individuals interact with more than eight people on a regular basis, and likely have more than one friend, indicating that social networks may be defined and assessed in a variety of ways. Additionally, this finding indicates the importance of considering family members, colleagues, and other relational ties in addition to friends when assessing and describing social networks.

Social networks, broadly defined, have been identified as a critical point of intervention (Christens, 2011; Erickson, 1988; Juras et al., 1997; Luke, 2005; Valente, 1996). Networks may contribute to patterns of problematic behavior, particularly those involving drug and alcohol abuse, as discussed in a following section. Additionally, research reviewed in a later section has established links between aspects of individuals' 


\section{SOCIAL NETWORKS OF INTIMATE PARTNER VIOLENCE PERPETRATORS}

social networks and their engagement in both antisocial behavior and perpetration of IPV. Additionally, social networks may contribute to IPV perpetrators' contact with, and success in, BIPs (Sheehan, Thakor \& Stewart, 2012). While individuals may strategically select members of their social networks (Kandel, 1978), once relationships with social network members are established, influence is the specific mechanism that is responsible for social networks' effects on individuals. The construct of influence is described next.

Influence Within Social Networks

Influence refers to the impact of individuals' expressions of their attitudes, beliefs or behaviors or on the attitudes, beliefs, or behaviors of others. Influence may occur through direct communication with another person about a particular attitude, belief, or behavior, or through contributions to social networks' norms by embodying relevant attitudes, beliefs, or behaviors. Direct influence is a process in which an individual engages in a behavior with the objective of affecting another person's behavior (Lippitt, Polansky \& Rosen, 1952). Direct influence includes having explicit conversations about attitudes or behaviors which one network member desires to modify in the other. In the case of direct communication, influence may be a function of relational ties characterized by authority, identification, expertise, and competition (Marsden \& Friedkin, 1993). Thus, influence may be intentional, though it need not be.

The process of interpersonal influence does not require direct communication about an attitude or behavior; only receipt of information about others' attitudes and 


\section{SOCIAL NETWORKS OF INTIMATE PARTNER VIOLENCE PERPETRATORS}

behaviors is necessary for influence to occur (Marsden \& Friedkin, 1993). Influence may occur through behavioral contagion, by which individuals spontaneously pick-up and mimic the behaviors of other actors who have no intention of creating any change in anyone else (Lippitt, Polansky \& Rosen, 1952). In ambiguous situations, individuals rely on social norms, comparing their attitudes and behaviors to those of others' around them to determine whether their own attitudes and beliefs are appropriate and normative (Erickson, 1988; Marsden \& Friedkin, 1993). Social norms have been defined as "rules and standards that are understood by members of a group and that guide and/or constrain social behavior without the force of laws. These norms emerge out of interaction with others; they may or may not be stated explicitly, and any sanctions for deviating from them come from social networks" (Cialdini \& Trost, 1998, as cited in Hogg, 2010, p. 1174). Individuals' receptivity to the influence of their social network members may reflect, and be motivated by, their feelings towards their network members.

\section{Relationship quality and influence within social networks. The extent of} individuals' influence on their network members, and vice-versa, is dependent upon the quality of the relationships between them. Features of relationships that are often used to judge their quality include closeness, intimacy, supportiveness, interdependence, emotional tone, loyalty, and prosocial behavior (Berndt, 2002; Hartup \& Stevens, 1997). The quality of adult friendship relationships are most often described in terms of solidarity (Hartup \& Stevens, 1997). Friendships that are high on one of these qualities tend to be high on the others as well, such that all of these positive features of 


\section{SOCIAL NETWORKS OF INTIMATE PARTNER VIOLENCE PERPETRATORS}

relationships may reflect a single dimension of relationship quality (Berndt, 2002).

Similarly, the presence of conflict, dominance attempts, and rivalry tend to co-occur within relationships, reflecting a separate dimension of relationship quality that correlates only weakly with the positive features of relationships (Berndt, 2002). Both the positive and negative dimensions of relationships must be considered in determining the overall quality of a relationship (Berndt, 2002). However, women tend to report higher rates of participation in the positive features of relationships, specifically those involving selfdisclosure, social understanding, and care, than do men (Hartup \& Stevens, 1997); inferring the subjective quality of a friendship based on the objective presence or absence of these features may not be equally valid for men and women. Alternative conceptualizations, such as the one used in the current study, define relationship quality in terms of satisfaction with a relationship with another person (Hawkley, Hughes, Waite, Masi, Thisted \& Cacioppo, 2008; Mendelson \& Aboud, 1999). For the purposes of the current study, relationship quality is considered specifically in terms of one person's satisfaction with their relationship with another person.

Individuals may have the option of disengaging from relationships that they do not find satisfying or high quality. However, Wellman (1982) found that many ties that individuals maintain are involuntary. About a quarter of each individual's network is composed of people that the individual does not like, and with whom they would not voluntarily associate, but whose familial relationship, geographic location, or employment situation necessitates its maintenance (Wellman, 1982). Specifically, 


\section{SOCIAL NETWORKS OF INTIMATE PARTNER VIOLENCE PERPETRATORS}

individuals tend to retain familial relationships, even if they are perceived as problematic: interviews and diagramming tasks with a community sample of men and women, ranging in age from 13 to 99 , revealed that individuals perceive their relationships with close familial ties (spouses, children, parents, and siblings) as a mixture of close and problematic (Fingerman, Hay \& Birditt, 2004). Therefore, individuals may have social network members whose attitudes and behaviors contribute less to the social norms to which they are motivated to conform. Additionally, individuals may be more inclined to use direct communication to attempt to influence the belief systems and behaviors of their family members, other long-term relations, or individuals with whom they have generally positive relationships (Frye, 2007) to bring their attitudes and behaviors into alignment. While individuals may be more inclined to try to exert influence upon network members with whom they have more problematic, yet more permanent relationships, social norms may be more influential within the context of close, highquality relationships (Festinger, 1954; Priester \& Petty, 2001; Terry \& Hogg, 1996).

Where an individual's attitudes and behaviors diverge from those of their comparison network members, they will be motivated to bring their attitudes and behaviors into alignment with those of their peers (Erickson, 1988). Individuals most often compare themselves to those others to whom they feel closest (Festinger, 1954), and both more frequent contact and stronger ties between network members are related to the importance attached to the presence of similarities or differences between them. Therefore, the higher the quality of the relationship between network members, the more 


\section{SOCIAL NETWORKS OF INTIMATE PARTNER VIOLENCE PERPETRATORS}

seriously their similarities or differences will be considered (Priester \& Petty, 2001; Terry \& Hogg, 1996) and the more they will attend to the norms that the other embodies. When an individual's attitudes and behaviors are already similar to those of their network members, the fact of their similarity, or perceived similarity, reinforces those shared attitudes and behaviors (Erickson, 1988).

According to the Theory of Planned Behavior, individuals' attitudes towards a behavior and their normative beliefs about what others expect of the individual in a given situation, shape individuals' behavioral intentions; behavioral intentions directly influence behavior (Ajzen \& Fishbein, 1970; Ajzen, 1971; Ajzen \& Fishbein, 1972). Attitudes towards a behavior and normative beliefs regarding that behavior are highly correlated (Ajzen, 1971). Individuals' attitudes towards a behavior are highly influenced by their beliefs about the social consequences of engaging in that behavior (Ajzen \& Fishbein, 1972). The importance of normative beliefs in shaping individuals' behavioral intentions is further compounded by individuals' motivations to comply with the social norms that they perceive (Ajzen \& Fishbein, 1974). The people in an individual's social network create the norms with which other network members are motivated to comply, thereby influencing their behavioral intentions. However, individuals may be more or less motivated to comply with norms that specific social network members have established (Ajzen \& Fishbein, 1970). Thus, specific members of BIP participants' social networks may influence their behavior to different extents. 


\section{SOCIAL NETWORKS OF INTIMATE PARTNER VIOLENCE PERPETRATORS}

Network members who are perceived as experts have a greater impact on behavioral intentions (Ryan, 1982), as do network members with whom individuals closely identify (Terry \& Hogg 1996). The closer individuals feel to members of their social networks, the greater those network members' influence on individuals' behavioral intentions (Terry \& Hogg, 1996). The same is true of network members about whom an individual feels very strongly (Priester \& Petty, 2001). Individuals experience a desire to agree with those network members whom they like, and to disagree with people whom they dislike, adjusting their own attitudes and behaviors to match those of network members that they like, and to contradict those of network members whom they dislike (Priester \& Petty, 2001). For example, men arrested on IPV charges are often less resistant to the views of themselves expressed by their children and police, whom they consider more objective third parties, than the views of their partners, and their partners' friends and family, with whom they have more combative relationships (Goodrum, Umberson, \& Anderson, 2001). Thus, the quality of individuals' relationships with the members of their social networks determine the direction and extent of those network members' influence.

To summarize, an individual's social network is the collection of people with whom they have some kind of relationship, or are bound by a relational tie. The members of an individual's social network may influence their attitudes and behaviors through direct communication about those attitudes and behaviors, or by simply manifesting attitudes and behaviors against which the individual compares their own. The 


\section{SOCIAL NETWORKS OF INTIMATE PARTNER VIOLENCE PERPETRATORS}

extent to which individuals exert influence over a network member's attitudes and behaviors, and vice-versa, is contingent upon the quality of their relationship. Individuals may be inclined to engage in direct influence with those with whom they have highquality relationships but whose attitudes and behaviors they find objectionable, to create more similarity in their attitudes and behavior. Individuals also maintain relationships that span a range of quality, and therefore differentially contribute to each others' normative beliefs and behavioral intentions; the better the quality of the relationship between two people, the more motivation they have for their attitudes and behaviors to align with each other's.

Thus, social networks generally influence individuals' attitudes and behaviors, and those social network members with whom individuals have high-quality relationships are assumed to be particularly influential. Research regarding substance use, more specifically, has produced a similar pattern of findings. The role or social networks in recovering alcoholics' sobriety has been well documented, as reviewed in the following section. In the section thereafter, research on the relationships between social networks and antisocial behavior more generally, and IPV in particular, is reviewed. Research regarding social networks and substance abuse recovery is more extensive than the research addressing social networks and antisocial behavior or social networks and the perpetration of IPV. Reviewing this literature serves two purposes: (1) to highlight that findings about social networks' role in substance abuse treatment may be directly translated into changes that improve the efficacy of treatment programs, and (2) to 


\section{SOCIAL NETWORKS OF INTIMATE PARTNER VIOLENCE PERPETRATORS}

illustrate some of the factors and processes within BIP participants' social networks that may be impacting their perpetration of IPV. As the following section demonstrates, research regarding social networks' impact on substance abuse recovery has identified the individuals who belong to treatment program participants' social networks, the quality of their relationships with treatment program participants, and their alcoholrelated behavior, in conjunction with individuals' own substance use. Given the relationships between these aspects of treatment program participants' social networks and their program outcomes, describing BIP participants' social networks and their interactions about IPV may also be informative.

\section{Social Networks' Influence on Individuals}

Social Networks and Substance Use

There is a relative abundance of research regarding the role of social networks in facilitating individuals' recovery from drug and alcohol abuse (Beattie \& Longabaugh, 1997; Beattie \& Longabaugh, 1999; Falkin \& Strauss, 2003; Gordon \& Zrull, 1991; Humphreys \& Noke, 1997; Mohr et al., 2001; Zywiak, Longabaugh \& Wirtz, 2002). The size of recovering alcoholics' social networks, and their network members' involvement in their treatment, are related to their sustained sobriety. Alcohol treatment program participants with larger networks report fewer days of heavy drinking following their completion of outpatient alcohol treatment (Zywiak, Longabaugh \& Wirtz, 2002). Treatment program participants who have more network members and who consider their 


\section{SOCIAL NETWORKS OF INTIMATE PARTNER VIOLENCE PERPETRATORS}

network members more important in their lives experience greater benefit from having relationships that are supportive of their abstinence; relationships with individuals who support abstinence have less of an impact for recovering alcoholics who do not have as many relationships or do not consider those relationships as important (Beattie \& Longabaugh, 1997).

When individuals with histories of alcohol consumption stop drinking, the size of their social networks tends to decrease as a result of de-selecting drinking friends as their behavior is no longer compatible with that of their former network members (Humphreys, Mavis \& Stoffelmayr, 1994). One benefit of participation in 12-step programs, or similar group-based self help programs, is the access that they provide to potential new network members whose behaviors are more compatible (Humphreys, Mavis \& Stoffelmayr, 1994; Humphreys et al., 1999).

The relational ties between recovering alcoholics and their network members also shape the extent of their influence on participants' outcomes. The attitudes and behaviors of friends and co-workers in recovering alcoholics' networks are more predictive of the number of days that they drink than those of patients' familial network members (Beattie \& Longabaugh, 1997; Gordon \& Zrull, 1991). However, the number of non-drinking family members who participate in recovering alcoholics' treatment is predictive of the number of co-workers in recovering alcoholics' social networks who support their recovery (Gordon \& Zrull, 1991). Therefore, interventions that engage patients' non- 


\section{SOCIAL NETWORKS OF INTIMATE PARTNER VIOLENCE PERPETRATORS}

familial social network members are at least as important as interventions within their family systems.

The content of recovering alcoholics' relationships with their network members is as important, if not more so, than the structure of their networks. While patients' subjective wellbeing is related to general aspects of their relationships with network members, their drinking behavior is most strongly related to their network members' alcohol-specific attitudes and behaviors (Beattie \& Longabaugh, 1997). General social support from network members is related to the proportion of days that people in recovery abstain from drinking, but this relationship is mediated by network members' alcohol-specific attitudes and behaviors (Beattie \& Longabaugh, 1999). Additionally, in the long term, alcohol-specific support has a greater impact on continued abstinence than more general social support (Beattie \& Longabaugh, 1999). Thus, there is a strong relationship between having network members who convey support for abstinence and recovering alcoholics' drinking behavior.

Alcohol treatment program participants' abstinence in the four to nine months following treatment completion is related to important social network members' drinking behaviors and support for abstinence (Beattie \& Longabaugh, 1997). Network members' encouragement and practice of abstinence are significantly and negatively related to the proportion of days on which participants engage in heavy drinking (Beattie \& Longabaugh, 1997). Those patients whose networks consist of higher percentages of abstainers and recovering alcoholics have better post-treatment prognosis (Zywiak, 


\section{SOCIAL NETWORKS OF INTIMATE PARTNER VIOLENCE PERPETRATORS}

Longabaugh \& Wirtz, 2002). Humphreys, Mankowski, Moos and Finney (1999)

surveyed male veterans entering treatment for their substance use, and conducted followup interviews one year after discharge, addressing participants' substance abuse, active coping responses, general friendship quality, friends' support for abstinence, and posttreatment involvement in substance-use related self-help groups. Self-help group participation was associated with increases in active coping responses, general friendship quality, and friends' support for abstinence, which mediated the relationship between self-help group participation and substance use (Humphreys et al., 1999). Specifically, friends' support for abstinence significantly mediated the relationship between participation in mutual help groups and abstinence from alcohol, to a greater extent than general friendship quality (Humphreys et al., 1999); social network members' support for abstinence was a more influential effect of self-help group participation than the more general quality of friendships that were potentially developed through participating in a self-help group (Humphreys \& Noke, 1997). Hence, social network members' behaviorspecific support has a unique effect on participants' outcomes, over and above more general aspects of their relationships.

It also appears that individuals in substance abuse treatment programs change their social networks throughout their treatment. Humphreys and Noke (1997) examined how participation in mutual help groups shaped participants' friendship networks, finding that continued participation in 12-step programs predicts better general friendship characteristics, such as the number of close friends, as well as substance-abuse specific 


\section{SOCIAL NETWORKS OF INTIMATE PARTNER VIOLENCE PERPETRATORS}

friendship characteristics, including the proportion of friends who abstain from drugs and alcohol. Throughout the first year that a sample of adults sought community-based treatment for alcoholism, approximately half of their social network members were abstainers and/or in recovery themselves (Rynes \& Tonigan, 2012). Following men receiving outpatient and aftercare treatment for alcoholism for 15 months, Kelly, Stout, Magill and Tonigan (2011) found that 12-step program attendance significantly predicted declines in the number of participants' social network members who were supportive of drinking, and slight increases in the number of participants' social network members who were actively supportive of abstinence. These changes in participants' social networks made significant contributions to declining drinking intensity (Kelly et al., 2011). In a separate sample of men participating in mutual help groups to address their substance use, participation was related to changes in the substance-abuse specific aspects of participants' relationships with their network members after a year (Humphreys, Mankowski, Moos \& Finney, 1999). While the size of participants' networks did increase after a year of mutual help group participation, whether the overall changes in substance-abuse specific aspects of their relationships were due to changes in their relationships with pre-existing network members, or whether the addition of new relationships was responsible for changes in the aggregated substance-abuse specific aspects of their relationships across their whole networks was unclear in the study described. 


\section{SOCIAL NETWORKS OF INTIMATE PARTNER VIOLENCE PERPETRATORS}

The work of Mohr and colleagues (Mohr, Averna, Kenny \& Del Boca, 2001) addresses some of the questions that Humphreys and colleagues' (1999) research raises. Most outpatient aftercare program participants identify friends who drink among their social network members, both at program intake and six months after program completion (Mohr et al., 2001). However, the number of drinking friends listed, and identified as especially important to participants, appears to decline during this time, while the number of non-drinking friends nominated and identified as particularly important appears to increase. Both the higher proportion of nondrinking friends nominated, and the relative increase in their importance, are both significantly predictive of decreases in the number of days that participants drink. Mohr et al.'s (2001) findings indicate that many treatment program participants experience some change in the individuals that comprise their social networks, but may retain some members of their original networks.

Influencing existing network members to be supportive of sobriety may be more beneficial and have a greater impact on behavior change than selection into new friendships, in the case of alcohol treatment (Beattie \& Longbuagh, 1999). Differentiating between general support and alcohol-specific support, network members' support for abstinence is most influential in the context of more generally supportive relationships. Receiving support from pre-existing friends who provide support across domains enables sobriety better than the receipt of alcohol-specific support from newer network members (Beattie \& Longabaugh, 1999). Recent corroborative findings show 


\section{SOCIAL NETWORKS OF INTIMATE PARTNER VIOLENCE PERPETRATORS}

that declines in drinking that are associated with developing a relationship with a sponsor during early involvement with Alcoholics Anonymous are not due to increases in the portion of social network members that abstain from drinking (Rynes \& Scott, 2012). It is more likely that sponsorship enables sobriety by providing close and supportive relationships with mentors (Rynes \& Scott, 2012), within the context of which abstinence-specific support may have an especially large impact. Thus, influencing particularly close or long-time network members to provide social support in general, specific forms of support, and encouragement of specific behaviors may better facilitate abstinence than selecting new network members.

In summary, peer associations are influential in enabling alcohol treatment program participants' sobriety (Beattie \& Longabaugh, 1999; Humphreys, et al., 1999; Humphreys, Mavis \& Stoffelmayr, 1994). Having social networks that are larger, contain more familial relational ties, and exhibit attitudes and behaviors that support sobriety is related to less drinking behavior. It also appears that the presence of prior social network members who support abstinence is related to improved outcomes for treatment program participants. These findings enable assertions about aspects of program participants' social networks that would best facilitate their recovery, and may be directly applied to the contents of treatment programs. Information about the individuals who comprise BIP participants' social networks and their IPV-supportive behavior may eventually be useful in making similar assertions, which may ultimately improve the efficacy of BIPs. However, almost nothing is known about the social networks of BIP participants. Social 


\section{SOCIAL NETWORKS OF INTIMATE PARTNER VIOLENCE PERPETRATORS}

networks have been examined in relation to youth and adults' engagement in antisocial behavior in general, as described in the next section, and in the perpetration of sexual assault and IPV more specifically. Though, with the exception of individuals' families of origin, little is known about the specific relational ties between IPV perpetrators and the members of their social networks or the ways in which they communicate their support for IPV. Even less is known about the social networks of BIP participants in particular.

Social Networks and Antisocial Behavior

Young adults' peer associations are related to their general antisocial behavior (Dishion, Capaldi, Spracklen \& Li, 1995; Patterson, Dishion \& Yoerger, 2000; Warr, 2006). Declines in the amount of time that young men spend with their friends is directly related to declines in their exposure to delinquent influences (Warr, 2006). Among participants aged 15 to 24 , exposure to delinquent peers is significantly related to delinquent activity (Warr, 2006). Among school-aged youth, the proportion of youths' social network members who participate in, or are sympathetic towards, deviant behavior predict their subsequent antisocial behavior during the following calendar year (Haynie, 2002).

Specific interactions during conversations about antisocial behavior have been implicated in the relationship between delinquent peer affiliates and adolescents' participation in antisocial behavior. Adolescent boys in particular reinforce each others' talk of breaking rules and engagement in antisocial behavior, a phenomenon known as 


\section{SOCIAL NETWORKS OF INTIMATE PARTNER VIOLENCE PERPETRATORS}

"deviancy training" (Dishion, Andrews, \& Crosby, 1995; Dishion, Patterson, \& Griesler, 1994). The more young men's peers reinforce their talk of participation in antisocial behaviors, the more likely they are to participate in those behaviors: young men whose peers engage them in conversation about rule breaking and antisocial behavior, and who laugh more during these conversations than during conversations of neutral topics, are more prone to later drug use (Dishion, Capaldi, Spracklen \& Li, 1995; Patterson, Dishion \& Yoerger, 2000), risky sexual activity (Patterson, Dishion \& Yoerger, 2000), arrests (Patterson, Dishion \& Yoerger, 2000), and perpetration of violence (Dishion, Capaldi, Spracklen \& Li, 1995), even after controlling for antisocial behavior earlier in childhood (Dishion, Eddy, Haas, Li, \& Spracklen, 1997; Patterson, Dishion \& Yoerger, 2000). Adolescents' own antisocial behavior seems to change in lockstep with that of their network members, due in theory to the reinforcement that their peers provide for such behavior (Dishion, Patterson, \& Griesler, 1994). Thus, social network members also exert influence on one another through positive reactions to conversations about antisocial behavior, including hostile talk about women (Capaldi et al., 2001).

The criminal justice field has acknowledged the role of peer affiliates in encouraging and enabling antisocial behavior. The notion that addressing the social networks of individuals who are convicted of violent crimes is central to curbing criminal behavior more generally runs throughout the Risk-Needs-Responsivity model. The RiskNeeds-Responsivity model (Bonta \& Andrews, 2007; Andrews \& Bonta, 2010) is a model that guides the assessment and rehabilitation of individuals convicted of crimes, 


\section{SOCIAL NETWORKS OF INTIMATE PARTNER VIOLENCE PERPETRATORS}

based on three principles: that criminal behavior may be reliably predicted and that individuals with the highest risk of recidivating should be prioritized for receiving treatment resources; that the design and delivery of treatment should be guided by individuals' criminogenic needs; and that treatment should take the form of cognitivebehavioral treatment tailored to individuals' learning styles, motivation, abilities, and strengths (Bonta \& Andrews, 2007). The Risk-Needs-Responsivity model identifies eight central criminogenic needs that put individuals at a heightened risk of re-offending (Bonta \& Andrews, 2007; Andrews \& Bonta, 2010). Among these central needs are social supports for crime, indicated by friends who have also been convicted of crimes and isolation from individuals with more pro-social orientations (Bonta \& Andrews, 2007). The intervention goal regarding social supports for crime is to replace individuals' criminally oriented friends with peers who are more pro-socially inclined (Bonta \& Andrews, 2007). The Risk-Needs-Responsivity model also states that the expected costs and rewards of criminal behavior, in the form of responses from important others, directly impact individuals' likelihood of engaging in criminal behavior (Bonta \& Andrews, 2007). Hence, maintaining relationships with individuals who also engage in criminal behavior may encourage individuals to continue their own perpetration of crime. Large proportions of individuals on probation display the criminogenic need of social support for crime. Forty-seven percent of adult probationers and $89.4 \%$ of juvenile probationers manifested needs with regard to their peer affiliates during their primary risk assessment at their first supervision session, based on a sample of 62 Canadian probation 


\section{SOCIAL NETWORKS OF INTIMATE PARTNER VIOLENCE PERPETRATORS}

officers who reported on a total of 154 individuals on their caseloads (Bonta et al., 2008). The high percentage of offenders with antisocial network members speaks to the relationship between criminal behavior and social networks. However, analyzing audiotapes of meetings between probation officers, whose work was intended to be guided by the Risk-Needs-Responsivity model, and their clients, revealed that meetings very rarely addressed clients' identified criminogenic needs (Bonta et al., 2008). Additionally, two separate meta-analyses of the effectiveness of correctional treatment found that none of the studies reviewed reported targeting individuals' peer associations as an aspect of their treatment (Dowden \& Andrews, 1999; Dowden \& Andrews, 2000). Even in situations where a model that acknowledges peer affiliates as a component of treatment is intended to guide treatment, practitioners neglected to address it as such.

Research regarding interactions as specific as laughter during particular conversations among youth has been used to inform general criminal justice practices. The criminal justice field now recognizes that offenders' social networks are an important point of intervention to prevent their continued engagement in criminal activity in general. As reviewed in the following section, research has also identified the role of individuals' social networks in shaping their perpetration of IPV specifically.

\section{Social Networks and IPV}

A small but growing body of literature demonstrates that other people in men's lives appear to influence their perpetration of IPV. Research has demonstrated the role 


\section{SOCIAL NETWORKS OF INTIMATE PARTNER VIOLENCE PERPETRATORS}

perpetrators' families of origin (Capaldi \& Clark, 1998; Cazenave \& Straus, 1995;

Collins, Maccoby, Steinberg, Hetherington, \& Bornstein, 2000; Doumas, Margolin \&

John, 1994; Dishion, Capaldi, Spracklen \& Li, 1995; Silverman \& Williamson, 1997) and adolescent peer groups (Arriaga \& Foshee, 2004; Capaldi et al., 2001; Schwartz \& DeKeseredy, 1997; Silverman \& Williamson, 1997) in their lifetime perpetration of IPV, while among adult men, friendships have been linked to the perpetration of sexual assault (Abbey et al., 2001; Brown \& Messman-Moore, 2010). Network members' violent behavior (Hearn \& Whitehead, 2006; Raghavan, Rajah, Gentile, Collado \& Kavanagh, 2009; Schwartz \& DeKeseredy, 1997; Silverman \& Williamson, 1997) has also been associated with concurrent perpetration of IPV. However, current research is yet to determine who belongs to IPV perpetrators' social networks, or how ideas about IPV are communicated therein. Despite the lack of a comprehensive theory of network influences on IPV specifically and relatively limited research in this area, some have speculated that the networks of adult male perpetrators of IPV may be potentially influential points to intervene in abusive behavior (Almeida \& Bograd, 1991; Bonta, Rugge, Scott, Bourgon \& Annie 2008; Coker, 2002; Neighbors, Walker, Roffman, Mbilinyi \& Edleson, 2008).

Some of the findings reviewed in the following section pertain IPV specifically, while others are specific to sexual assault. For the purposes of distinguishing between IPV and sexual assault, sexual assault may be perpetrated against intimate partners, strangers or acquaintances (Davies \& Dale, 1996), while IPV occurs within the context of intimate relationships. Sexual assault in the context of an intimate relationship is often 


\section{SOCIAL NETWORKS OF INTIMATE PARTNER VIOLENCE PERPETRATORS}

considered a form or component of IPV (Krug et al., 2002). Thus, the two behaviors may be highly inter-related, and are not mutually exclusive. When these behaviors are perpetrated by men within the context of heterosexual relationships, both of these behaviors fall within the category of violence against women. A model of the processes by which social networks may influence individuals' perpetration of IPV is depicted in Figure 1 below, wherein violence against women is abbreviated as VAW.

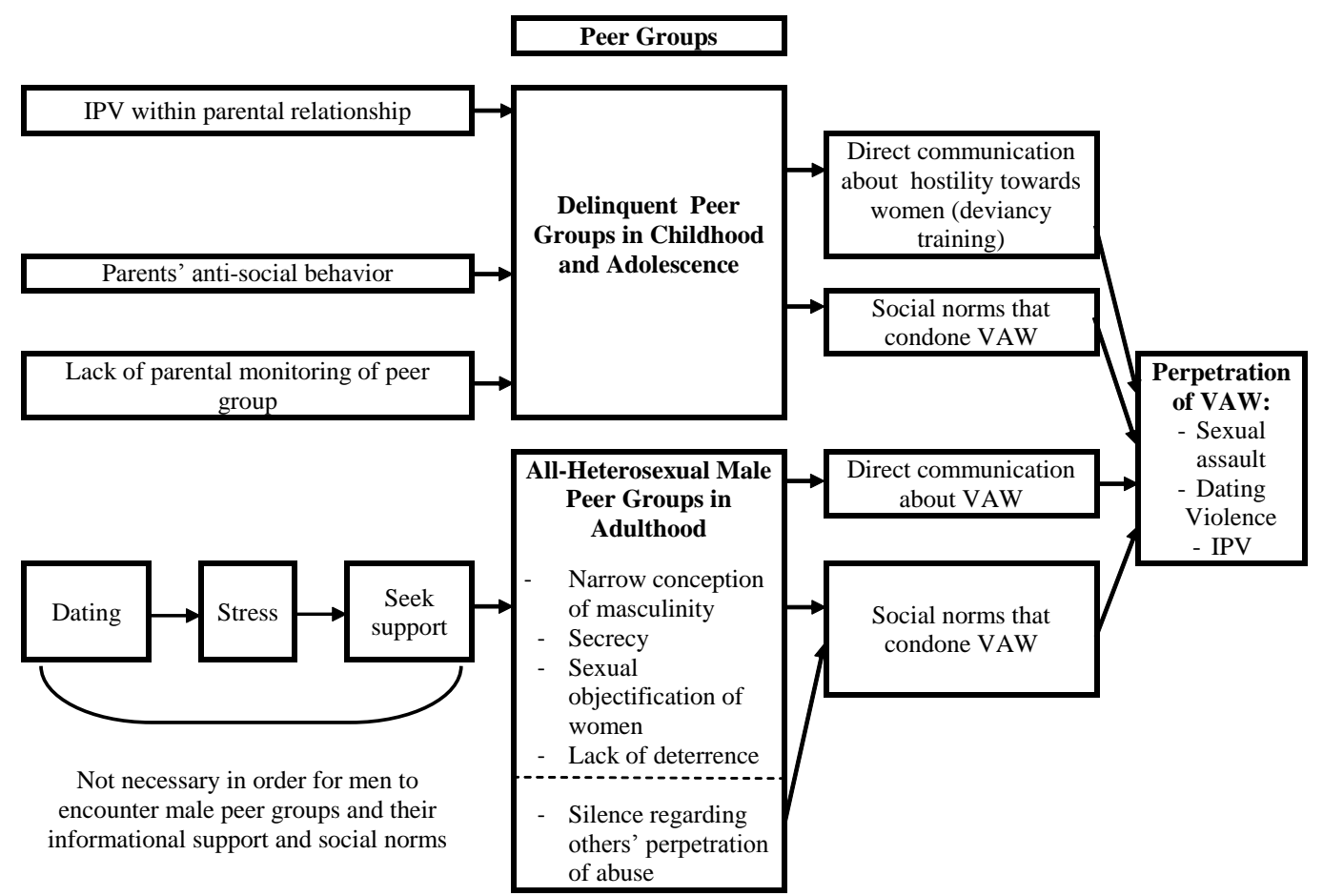

Figure 1. Mechanisms of social networks' influence on the perpetration of IPV.

The top half of the model depicted in Figure 1 was developed on the basis of empirical research, reviewed below, regarding social network influences on violence against women in childhood and adolescence. The bottom half of the model depicted in 


\section{SOCIAL NETWORKS OF INTIMATE PARTNER VIOLENCE PERPETRATORS}

Figure 1 was drawn from a model proposed by DeKeseredy and Schwartz (1993;

DeKseredy, 1990b; DeKeseredy, 1988; Schwartz \& DeKeseredy, 1997). DeKeseredy and Schwartz's (1993; DeKseredy, 1990b; DeKeseredy, 1988; Schwartz \& DeKeseredy, 1997) model describes social networks' contributions to sexual assault, specific to college campuses. The model provides a potential explanation of the mechanisms by which social networks influence the perpetration of IPV among adult men. The model was originally proposed by DeKeseredy in 1988, and was empirically supported using a sample of 33 male undergraduate students enrolled in several Ontario universities in 1987 (DeKeseredy, 1990b). Though the model is specific to sexual assault, and developed to apply to men on college campuses, it may also be relevant to the perpetration of IPV among adult men in the community.

The current study is not intended to test either the broad model depicted in Figure 1, or the model proposed by DeKeseredy and Schwartz. However, DeKeseredy and Schwartz's model does indicate that, in the case of male peers' influence on each other's use of violence in romantic relationships, (1) social networks may influence their members through direct communication, though (2) norms within social networks may also be a source of influence on network members, and (3) individuals may also influence their social networks to embody more pro-social attitudes and behaviors. The model depicted in Figure 1, including the portion proposed by DeKeseredy and Schwartz, is described in more detail below, and used as a framework for discussing relevant findings 


\section{SOCIAL NETWORKS OF INTIMATE PARTNER VIOLENCE PERPETRATORS}

from other programs of research, specifically those regarding social networks' influence on their members.

\section{Processes of Social Networks' Influence on the Perpetration of IPV}

Influence through Direct Communication

Direct communication with families and peers during childhood and adolescence.

As a subset of men's social networks, their families are highly influential in the likelihood of their perpetration of abuse. Research reviewed below demonstrates that much of the familial influence on IPV is due to familial influence on the peers with whom young men interact. Young men's direct communication with these peers contributes to their perpetration of violence against women. The ways that young men's families of origin contribute to their perpetration of IPV is depicted in the top half of Figure 1.

Witnessing IPV within one's family of origin increases the likelihood that men will perpetrate IPV. Among a community sample of intact families, the perpetration of IPV was transmitted between generations (Doumas, Margolin \& John, 1994). Exposure to IPV within men's families of origin predicted increased perpetration of violence against their intimate partners, as well as their young sons' aggressive behavior (Doumas, Margolin \& John, 1994).

However, the relationship between parental IPV and children's perpetration of IPV may be the result of more than simply modeling behavior: parents' general antisocial 


\section{SOCIAL NETWORKS OF INTIMATE PARTNER VIOLENCE PERPETRATORS}

behavior, aggression, and especially parenting skills, have been identified as stronger predictors of their sons' violence towards their dating partners than IPV within parental relationships (Capaldi \& Clark, 1998). In a study of adolescent men who were identified as being particularly high risk for delinquency, Capaldi and Clark (1998) found that parents' general antisociality predicted the amount of violence between them, as well as their son's perpetration of IPV in young adulthood. Parenting behaviors also impact the non-familial aspects of their children's social networks, shaping their exposure to other influences on later abusive behavior (Capaldi \& Clark, 1998; Cazenave \& Straus, 1995; Collins et al., 2000).

Parental guidance about the peers that their sons should incorporate into their social networks also determines the extent of boys' exposure to peer influences regarding IPV (Collins et al., 2000). Associations with deviant peers mediate between familial behavior and adolescent males' own behavior. Parental monitoring of adolescent sons partially determines whether young men join networks that enable or encourage antisocial behavior (Dishion et al., 1995). Similarly, Silverman and Williamson (1997) found that college-age men who report having witnessed abusive behavior among their parents are more likely to select network members who are themselves abusive and provide more explicit advice to inflict violence upon intimate partners (Silverman \& Williamson, 1997). Using a predominantly White sample of 193 male undergraduate students in an American university, the authors found that the relationship between witnessing IPV among parents and later perpetration of IPV was fully mediated by 


\section{SOCIAL NETWORKS OF INTIMATE PARTNER VIOLENCE PERPETRATORS}

associating with peers who support the perpetration of violence against women (Silverman \& Williamson, 1997). Surveying young men in the eighth and ninth grade at two points, six months apart, Arriaga and Foshee (2004) found that dating violence both among participants' friends and IPV within their parents' relationships were correlated with participants' own perpetration of violence against romantic partners at that time. However, only participants' friends' perpetration of dating violence significantly predicted participants' perpetration of IPV at the later measurement point. Therefore, much of the influence of parental IPV on their sons' perpetration of abuse is due to the mediating impact of their sons' friends. Thus, including both family members and friends in measures of IPV perpetrators' networks appears informative.

More specifically, the content of adolescent males' interactions with their peers is predictive of their concurrent and later participation in IPV. Similar to the process of deviancy training, the occurrence of specific conversations with friends is predictive of adolescent men's perpetration of IPV in addition to more general antisocial behavior. Specifically, Capaldi and colleagues (2001) videotaped interactions between a set of boys attending schools in neighborhoods with above-average rates of delinquency, and the three male friends with whom they spent the most time, at several points throughout their late childhood and adolescence. The extent of the participants' conversations with their friends about hostility towards women significantly predicted their perpetration of IPV in late adolescence (Capaldi et al., 2001). General antisocial behavior, participation in deviant peer groups, and the perpetration of violence in dating relationships later in 


\section{SOCIAL NETWORKS OF INTIMATE PARTNER VIOLENCE PERPETRATORS}

adolescence were found to be closely interconnected. Associations with antisocial male network members in mid-adolescence, participation in antisocial behavior and early and mid adolescence, and discussion of hostile attitudes towards women with friends in late adolescence predict the likelihood of perpetrating IPV in young adulthood (Capaldi et al., 2001). Thus, when defining social networks as three friends with whom participants spend most of their time, conversations explicitly about hostility towards women within one's social network are related to perpetration of IPV.

Direct communication with peer groups in adulthood. At the crux of DeKeseredy's model is the assertion that having relational ties to male peers who support violence against women is predictive of perpetrating violence against women (DeKeseredy \& Schwartz, 1993; DeKseredy, 1990b; DeKeseredy, 1988; Schwartz \& DeKeseredy, 1997; Silverman \& Williamson, 1997). According to DeKeseredy’s model, as men become involved in progressively more serious dating relationships, they experience more stress (DeKeseredy, 1990b; Schwartz \& DeKeseredy, 1997). The more stress, particularly dating-related stress, that men experience, the more likely they are to seek the support of their close male peers (DeKeseredy, 1988; DeKeseredy, 1990b; Schwartz \& DeKeseredy, 1997). The more social support that men seek, from peer groups that endorse violence against women, the more likely they are to receive support that often encourages their use of violence against women (DeKeseredy, 1988; DeKeseredy, 1990b; DeKeseredy, 1997). 


\section{SOCIAL NETWORKS OF INTIMATE PARTNER VIOLENCE PERPETRATORS}

Support from male peers may include explicit advice that encourages men to perpetrate physical, sexual, or psychological abuse against their dating partners, and may also include instructions about how to do so (DeKeseredy, 1988; DeKeseredy, 1990b). Specifically while they are drinking in all-male groups, men may have explicit conversations about how to perpetrate sexual assault using alcohol (DeKeseredy \& Schwartz, 1993). Reinforcing statements or jokes about perpetrating violence against women, or engaging in deviancy training (Dishion, Andrews, \& Crosby, 1995; Dishion, Patterson, \& Griesler, 1994), as described previously, may have the same effect of encouraging the use of violence. Thus, social network members may have explicit, “node-to-node," (Borgatti, Mehra, Brass \& Labianca, 2009) or person-to-person conversations that encourage the perpetration of violence in romantic relationships. The relationship between these conversations and perpetration of violence is likely moderated by the quality of the relationship between those conversation partners (Terry \& Hogg, 1996).

Influence through Social Norms

Social norms in childhood and adolescence. Among male children and adolescents, the social norms within their social networks and broader communities are also related to their perpetration of IPV. Soliciting adolescent IPV perpetrators' own perspectives on their social environments, Reed and colleagues (2008) conducted semistructured interviews with 19 young men with established histories of dating violence. 


\section{SOCIAL NETWORKS OF INTIMATE PARTNER VIOLENCE PERPETRATORS}

Analysis of interview transcripts produced five overarching themes in the young men's contexts, including an absence of positive male role models and peer groups characterized by substance use, gang involvement, negative attitudes towards women, and the sexual maltreatment of women. Participants' descriptions of their friendships with other young men often included norms of derogatory treatment and sexual coercion of their dating partners; these adolescent perpetrators of IPV indicated that their own abusive behavior was normative among the friends within their social networks.

Social norms in adulthood. According to DeKeserdy's model, being integrated into a network of men who perpetrate violence against their dating partners may increase the likelihood of a young man's perpetration of abuse, whether or not they actively seek support from this social network (DeKeseredy, 1990a). Membership in an all-male social group, or intense immersion in portion of one's network that consists entirely of heterosexual male peers, particularly those with patriarchal belief systems, may lead to a narrow, yet unspoken, conception of masculinity specific to that group, secrecy within that cluster of network members, and sexual objectification of women (Schwartz \& DeKeseredy, 1997). These factors, in addition to the absence of deterrence, lead to woman abuse (Schwartz \& DeKeseredy, 1997). Having relationships with peers who perpetrate IPV may foster belief systems that enable violence against women and discretely encourage abusive behaviors for which network members may also provide explicit informational support (Silverman \& Williamson, 1997). Silence regarding other peers' perpetration of violence is another form of informational support, as it conveys the 


\section{SOCIAL NETWORKS OF INTIMATE PARTNER VIOLENCE PERPETRATORS}

information that violence towards a dating partner is not objectionable (DeKeseredy, 1990a): men need not talk to each other about dating violence in order to communicate their expectations about its use.

Network members do not necessarily have to talk about violence, or have high quality relationships in order for their behavior to influence each other's use of violence. Among adult men, those who indicate that at least one of their friends perpetrates IPV report greater beliefs that battering is justified and that perpetrators are less responsible for their behavior than men who do not report that any of their friends perpetrate abuse (Silverman \& Williamson, 1997). Abbey, McAuslan, Zawacki, Clinton \& Buck (2001) also found that, among male undergraduate students, individuals' perpetration of sexual assault was predicted by their peers' attitudes towards that behavior. Peers' attitudes towards sexual assault were measured by asking participants whether their friends, collectively, would approve of specific sexually assaultive behaviors, and whether the participant had felt any pressure to engage in sexual assault (Abbey et al., 2001). One of the factors that distinguished college men who had and had not committed sexual assault was the identification of social network members who expressed approval of forcing sex on dating partners. Subsequent studies corroborate these findings.

Among a more diverse sample, drawn from a large, urban commuter university with a largely low-income, immigrant, and ethnic minority undergraduate student body, affiliating with violent male social networks was related to the perpetration of IPV (Raghavan et al., 2009). Approximately $35 \%$ of the 479 male participants reported that a 


\section{SOCIAL NETWORKS OF INTIMATE PARTNER VIOLENCE PERPETRATORS}

member of their social network had perpetrated IPV in the six months prior (Raghavan et al., 2009). However, network members' perpetration of IPV was assessed by asking participants whether any men who provide them with social support had perpetrated physical, verbal, sexual, or emotional abuse in the six months prior to the study. Thus, participants reported only about those network members who provide social support, and may have relied on speculation, or their perceptions of their network members' perpetration of violence.

Men's attitudes towards sexual assault and their willingness to intervene in sexual assault are also highly correlated with their network members' attitudes. Among a sample of 95\% White college men in the Midwestern United States, men's personal attitudes towards sexual aggression and their perception of their peers' attitudes towards sexual aggression were highly positively correlated (Brown \& Messman-Moore, 2010). However, network members' attitudes towards sexual assault were more predictive of individuals' willingness to intervene in instances of sexual assault than their own attitudes (Brown \& Messman-Moore, 2010). Network members' attitudes towards sexual assault were measured using the prompt "most of my friends think...," relying on participants' perceptions of their friends' attitudes. This metric also considers the friends who belong to participants' social networks as a single unit, as opposed to individuals with whom participants have distinct relationships, and ignores social network members with whom participants have other relational ties. 


\section{SOCIAL NETWORKS OF INTIMATE PARTNER VIOLENCE PERPETRATORS}

Regarding the population of interest in the current study, the potential impact of altering individuals' social networks has also been acknowledged within some corners of the field of batterer intervention. The reduction in violence among IPV perpetrators who participate in BIPs, as opposed to community service programs without any form of batterer intervention, may be due to the IPV-specific supervision that BIPs provide (Maxwell, Davis \& Taylor, 2010). Reduction in the perpetration of IPV during men's participation in BIPs is more likely due to pressure to suppress their antisocial behavior during the treatment period, as opposed to undergoing any cognitive changes that would result in a more permanent reduction in abusive behavior (Maxwell, Davis \& Taylor, 2010). Presumably, sufficient pressure from social network members may serve the same function, if sufficiently strong and consistent: social network members' vehement and consistent disapproval of IPV may exert a sufficiently strong negative influence on batterers' behavior to reduce their perpetration of violence. Hence, changing both the individuals who belong to perpetrators' networks (Almeida \& Bograd, 1991) and the nature of their interactions with network members (Neighbors et al., 2008) have been proposed as approaches to mitigating IPV.

Spanning the levels of the community and the individual, Almeida and Bograd (1991) created a sponsorship model for curbing the perpetration of IPV among men with histories of such behavior. The intervention intends to alter perpetrators' social networks by assigning perpetrators a male sponsor without any history of violence, to dilute their networks' sanctioning of IPV and to provide a consistent source of support for 


\section{SOCIAL NETWORKS OF INTIMATE PARTNER VIOLENCE PERPETRATORS}

maintaining changes begun in the program. Ideally, non-violent sponsors help to create bridges between domestically abusive men and pockets of their communities that do not condone IPV, incorporating more non-violent peers into men's social networks. It has been speculated that assessing the networks that abusive men belong to can enable the identification of existing relationships that support men in changing this behavior (Neighbors et al., 2008). The identification and fortification of these relationships may enable facilitating and strengthening non-violent network members' positive influence on perpetrators of IPV (Neighbors et al., 2008). Currently, however, these processes and their efficacy in curbing abusive behavior are speculative. A first step towards addressing their validity may be identifying the social networks of BIP participants, and their interactions regarding IPV.

While the studies reviewed here have demonstrated relationships between the attitudes and behaviors of social network members and the perpetration of IPV, the descriptions of perpetrators' networks that they provide are incomplete. With the exception of the study by Raghavan and colleagues (2009), all of the studies reviewed in this section define networks as participants' male friends, excluding family members, coworkers, and other relations; Raghavan and colleagues (2009) defines social networks as the men and women in participants' lives who provide the participant with social support. All of the studies reviewed have asked participants about their network members in the aggregate, as opposed to as individuals, with whom participants have unique relationships of varying quality. Additionally, the studies reviewed relied on 


\section{SOCIAL NETWORKS OF INTIMATE PARTNER VIOLENCE PERPETRATORS}

participants' perceptions of their network members' attitudes and behaviors about violence against women, which are prone to inaccuracies (Gidycz, Orchowski \& Berkowitz, 2011; Neighbors et al., 2010; Flood et al., 2008). The current study will provide a fuller description of BIP participants' social networks, including multiple types of relational ties and participants' assessments of relationship quality. A more objective measure of network members' support for IPV will be constructed and used to assess each network members' sanctioning of IPV. The ways that participants address IPV with each member of their social networks will also be described, to provide a richer description of BIP participants' social networks and the IPV-relevant interactions therein.

The occurrence of social influence via comparison to others in one's network has been examined in the context of alcohol consumption (Berkowitz, 2004; Borsari \& Carey, 2001) violence (Flood, 2008), sexual assault (Berkowitz, 2004; Gidycz, Orchowski \& Berkowitz, 2011; Kilmartin et al., 2008), in addition to IPV (Fabiano et al., 2004; Gidycz, Orchowski \& Berkowitz, 2011; Neighbors et al., 2010; Lewis, 2004). These "social norms campaigns" are based on the notion that individuals will change their attitudes and behaviors as a function of their perceptions of those of comparable peers (Berkowitz, 2004; Flood, 2008). Social norms campaigns on American university campuses publicize the extent of campus men's adherence to sexist norms and support for the use of violence. These phenomena are often much less common than widely believed (Berkowitz et al., 2004; Flood, 2008). These campaigns draw individuals' attention to their over-estimation of their peers' condoning of sexist and violent behavior 


\section{SOCIAL NETWORKS OF INTIMATE PARTNER VIOLENCE PERPETRATORS}

(Flood, 2008). The potential outcomes of social norms campaigns are two-fold: men may be deterred from perpetrating sexual violence if they perceive it as non-normative among comparable peers, and men may also be more likely to intervene in others' perpetration of violence if they believe that peers similar to themselves would support them in doing so (Gidycz, Orchowski \& Berkowitz, 2011).

Men that perpetrate IPV, specifically, also tend to overestimate their comparable peers' perpetration of partner violence. A community sample of IPV perpetrators were asked to estimate the percent of men who had ever engaged in each of the following seven behaviors with their partners: throwing something that could hurt; pushing, grabbing, or shoving; slapping or hitting; choking; beating up their partner; threatening with a gun; and forcing sex upon a partner. The sample of perpetrators substantially over-estimated the occurrences of all seven behaviors in the general population, and greater over-estimates of the frequency of these behaviors were related to their perpetration of IPV. However, the study was based on a relatively small sample, and, as a result of the study's cross-sectional nature, it was unclear to the authors whether participants perpetrate abuse in response to their perceptions of abusive behavior as normative, or whether abusive men consider IPV more common as a means of justifying their abusive behavior (Neighbors et al., 2010). A 2004 study of 95 Scottish couples also provides support for the influence of perpetrators' beliefs about the incidence of IPV on their own perpetration. However, it also found that abusive men's tendency to justify their perpetration of violence by comparing their own behavior to that of similar others 


\section{SOCIAL NETWORKS OF INTIMATE PARTNER VIOLENCE PERPETRATORS}

may potentially make BIP participation counter-productive. Participation in groups of many other men who also have histories of IPV may reinforce perpetrators' belief that their behavior is normative and commonplace among comparable peers, enabling further justification of their abuse (Lewis, 2004).

According to DeKeseredy's model, mere integration into a network that is supportive of violence against women encourages men's perpetration of violence within romantic relationships, regardless of whether they actively seek support from that network (DeKeseredy, 1990a). Social networks may subtly convey pro-abuse messages (Silverman \& Williamson, 1997), and provide the social norms against which individual men compare their own behavior (Flood, 2008; Gidycz, Orchowski, \& Berkowitz, 2011). Perceiving violence against women as more normative is related to the perpetration of IPV (Neighbors et al., 2010), and justifying one's own use of abuse (Lewis, 2004). These mechanisms enable the relationships between social networks' attitudes and behaviors and those of their members, even when individuals do not explicitly seek the support and guidance of their social networks. Those network members with whom individuals have especially high-quality relationships are particularly influential in motivating individuals to adhere to the norms that they have established (Festinger, 1954; Terry \& Hogg, 1996).

To summarize, the impact of individuals' families of origin (Capaldi \& Clark, 1998; Cazenave \& Straus, 1995; Doumas, Margolin \& John, 1994; Silverman \& Williamson, 1997) and peer groups, both in adolescence (Arriaga \& Foshee, 2004; Capaldi et al., 2001; Schwartz \& DeKeseredy, 1997; Silverman \& Williamson, 1997) and 


\section{SOCIAL NETWORKS OF INTIMATE PARTNER VIOLENCE PERPETRATORS}

adulthood (Abbey et al., 2001; Brown \& Messman-Moore, 2010; Hearn \& Whitehead, 2006; Raghavan, et al, 2009; Schwartz \& DeKeseredy, 1997; Silverman \& Williamson, 1997) indicate that social networks influence individuals' perpetration of IPV. Therefore, a first step towards improving the efficacy of BIPs through attention to participants' social networks may necessitate an understanding of: (1) who are the people in BIP participants social networks, and (2) what IPV-specific interactions occur within their social networks. However, BIP participants are not passive receptacles of their social networks' influence; they may also reciprocally communicate with the members of their social networks about IPV.

The Potential for Pro-Social Influence

DeKeseredy and colleagues were careful to qualify their model, noting that, certainly, not all clusters of heterosexual male friends contribute to their members' perpetration of violence against women. Peer groups in which informal sanctions against violence against women are present, if only subtly, may be less likely to encourage sexual assault and dating violence (Schwartz \& DeKeseredy, 1997). Social network members who promote respectful attitudes and behaviors towards women may influence other members of their peer group to do the same (Silverman \& Williamson, 1997) by expressing disdain for other's perpetration of violence. Common examples of behaviors that men may use to address violence towards women among their network members include making short, informal remarks in response to violent or offensive language or 


\section{SOCIAL NETWORKS OF INTIMATE PARTNER VIOLENCE PERPETRATORS}

comments; initiating conversations with network members who they feel are mistreating their partners; and intervening in abusive or potentially abusive interactions between other men and vulnerable women (Casey \& Ohler, 2012).

Individuals are inclined to continue to expressing attitudes and behaviors that their network members reinforce, and to reduce their expression of attitudes and behaviors that their peers punish or ignore (Dishion, Patterson \& Griesler, 1994), particularly in the cases of network members with whom they have high quality relationships (Terry \& Hogg, 1996). If network members convey a disapproval of IPV, individual men may be less likely to continue perpetrating partner violence, or may at least reduce their talk of it. In this way, social networks may also prevent the perpetration of violence against dating partners through informal sanctions (Schwartz \& DeKeseredy, 1997). By communicating norms and values that are critical of violence against women, individuals within a social network may help mitigate that network's culture of violence against women (Schwartz \& DeKeseredy, 1997). This final caveat in DeKeseredy's model has an important implication: individuals are not merely at the mercy of their social networks, but individuals who object to violence against women are also positioned to have an impact on their network members. The current study will therefore describe the ways in which BIP participants' network members may convey their support for continued perpetration of IPV, as well as the ways in which BIP participants may communicate the opposite to the members of their networks. The 


\section{SOCIAL NETWORKS OF INTIMATE PARTNER VIOLENCE PERPETRATORS}

following section describes the ways in which individuals may generate changes within their social networks.

\section{Individuals' Reciprocal Influence on their Social Networks}

The distinction between processes of networks' influence on individuals and individuals' influence on their networks is blurry and crude: individuals are influenced by their networks, and also simultaneously comprise the networks that influence others. When individuals who belong to the same network influence each other, they generate change in their network as a whole. The influence that one person exerts over another has the effect of changing their social network, such that individuals influence their social networks just as they are influenced by their networks. Hence, the findings reviewed in prior sections regarding social networks' impact on individuals may be interpreted in the opposite direction. Each time an individual receives advice from a network member, or a network member laughs at an antisocial comment, remains silent about an individuals' use of violence, or exhibits any attitude or behavior that is perceptible by others, that network member potentially has exerted influence upon the other individual, and therefore, their own network. The empirical evidence regarding social networks' impact on the perpetration of IPV need not be restated from the opposite perspective. Instead, the theoretical basis for understanding individuals' influence on their social networks is reviewed below. 


\section{SOCIAL NETWORKS OF INTIMATE PARTNER VIOLENCE PERPETRATORS}

Individual network members, whether intentionally or not, influence changes in the attitudes and behaviors of other members of the network. Cartwright (1965) introduced the idea of "ecological control," or taking action over another person's social or physical environment, ultimately determining the constraints placed on that person. As social networks are collections of individuals, the attitudes and behaviors of those individuals that comprise a network determine the content of that network as a whole, and hence the social environment that surrounds all of its other members (Marsden \& Friedkin, 1993). Features of any individual who belongs to a social network contributes to their ecological control over other network members. Social groups are often defined by the common belief systems shared among their members (Erickson, 1982). Shifts in an individual network member's beliefs may be sufficient to alter the network's definitional belief system, if only slightly, thereby changing the aggregate of the attitudes and beliefs that surround network members, and which network members consider normative. Creating changes in the environment to which individuals react generates changes in the individuals themselves (Marsden \& Friedkin, 1993).

An intervention that directly engages only a limited number of individuals may impact the entirety of those individuals' social networks. Hawe, Shiell and Riley (2009) recommend conceptualizing contexts, particularly contexts where interventions are to be implemented, as the interconnected collection of activity settings (physical spaces), the social networks that exist within those physical spaces, and time. Interventions are critical events in settings' histories, spurring new interactions among the settings' 


\section{SOCIAL NETWORKS OF INTIMATE PARTNER VIOLENCE PERPETRATORS}

components and subcomponents, and generating new and shared meanings, patterns of relationships, activities, and distributions of resources within the settings (Hawe, Shiell \& Riley, 2009). Regardless of how interventions are introduced to systems, they create new channels for the distribution of information, resources, and social support (Hawe, Shiell \& Riley, 2009), enabling network members within those settings to adopt new attitudes and beliefs. Therefore, even if only a limited number of network members participate in an intervention program, so long as they internalize the content of that program or react to it any way (positively or otherwise), they enable change to occur within other aspects of the setting, providing opportunities for other network members to change their attitudes and behaviors.

Participating in intervention programs can change individuals' relational patterns (Humphreys et al., 1999). Individuals who participate in intervention groups tend to form relationships with other participants, impacting the amount of time that they have to spend with other network members, and potentially, the dynamics of their relationships with pre-existing network connections: individuals draw upon, seek out, and engage in relationships that they initially develop within intervention group meetings outside of the intervention context (Humphreys et al., 1999). Thus, a single network member's participation in an intervention program may have ripple effects on the structure and intensity of their relationships with former network members, and introduce new attitudes, beliefs, and peripheral network members into the network. 


\section{SOCIAL NETWORKS OF INTIMATE PARTNER VIOLENCE PERPETRATORS}

Individual intervention participants may also create ripples throughout their networks without changing the structure of those social networks. Attitudes, beliefs and information to which individual network members are exposed through their participation in intervention programs may permeate their pre-existing social networks. Hawe, Shiell and Riley (2009) describe how a few individuals' exposure to an intervention curriculum or new information may inadvertently generate network-level changes, though at this point, there is little if any empirical evidence to verify that these processes do occur as described: when individuals leave the physical context in which an intervention has occurred, they continue to process, discuss, and perhaps complain about the intervention, the language and philosophy of which may eventually seep into other realms of participants' lives. This process may result in their network members' adoption of innovations, novel attitudes or behaviors, which the intervention program introduces.

Individuals may facilitate the adoption of an innovation, whether it is a piece of technology, an attitude, a belief, or a piece of information, throughout their network. There are two primary reasons that individuals may not adopt and enact attitudes, beliefs, or information that is common in other segments of society: they may be actively resistant to doing so, or their networks may have never facilitated their access to those attitudes, beliefs or information (Valente, 1996). In the latter case, casual conversation or even complaining, or the unintended use of intervention program lingo among friends, may provide participants' network members' first exposure to ideas that they may subsequently embrace. While it may be tempting to assume that casual complaining 


\section{SOCIAL NETWORKS OF INTIMATE PARTNER VIOLENCE PERPETRATORS}

about BIP participation is inconsequential for network members' attitudes and behaviors, friends' griping about required BIP attendance may be network members' first exposure to information about the consequences of IPV, or the first platform that they have ever been provided for discussing abuse.

Individual intervention participants may provide their network members' first exposure to ideas that ultimately result in those network members' behavior change. Before an individual can even consider changing a particular behavior, they must be triggered to think about that behavior and its potential negative consequences (Roffman, Edleson, Neighbors, Mbilinyi \& Walker, 2008). Until a member of a network brings a particular piece of information to their network's attention, that information will never be the topic of conversation within the network, and network members will not receive cues to think about that information or its relevance to their experience (Larson, 1997). A friend's description or allusion to the behavior that prompted their BIP participation or arrest, or mention of behaviors that they have discussed in their BIP may be sufficient to encourage peers' reflection on their own abusive behaviors.

Even if individuals have already been exposed to a particular attitude or behavior through their contact with media, campaigns, or targeted literature, interpersonal contact with network members who embrace that attitude or behavior is often necessary to lead the individual to adopt it (Valente, 1996). One of the mechanisms of influence that Borgatti, Mehra, Brass and Labianca (2009) note is adaptation, the process by which individuals in a social network adjust their attitudes and behaviors to meet the constraints 


\section{SOCIAL NETWORKS OF INTIMATE PARTNER VIOLENCE PERPETRATORS}

of their social environments. The more individuals within a social network who maintain a certain attitude or behavior, the more likely it is that other network members will adopt that attitude or behavior (Valente, 1996) as the constraints upon network members become better defined (Borgatti et al., 2009).

Though a lone network member's participation in a BIP may not single-handedly facilitate all of their peers' reflection on their abusive behavior or transform their network's culture as it pertains to IPV, individual system-parts (or members of a social network) shape the network's definitional belief system (Foster-Fishman, Nowell \& Yang, 2007). Especially if network members maintain high-quality relationships with their network members, they may be particularly well-placed to influence the attitudes and behaviors of other members of their networks (Ajzen \& Fishbein, 1970; FosterFishman, Nowell \& Yang, 2007).

Individuals' membership in a social network is not fatalistic. Through direct communication with network members, spending more or less time with new and preexisting network members, discussing novel ideas with social network members, or merely changing their own behaviors, individuals may change their social networks. BIP participants may, knowingly or otherwise, influence the members of their social networks.

In summary, men's perpetration of violence against women is related to their social network members' attitudes and behaviors regarding abuse. Direct communication between individuals and the members of their social networks, and social norms 


\section{SOCIAL NETWORKS OF INTIMATE PARTNER VIOLENCE PERPETRATORS}

manifested within networks, are mechanisms that may be responsible for this relationship. The impacts of both of these processes depend on the quality of the relationships in which they occur. Thus, a more complete description of BIP participants' social networks would include multiple relational ties (as opposed to only family or only friends), the quality of participants' relationship with each network member, and the discrete behaviors in which both participants and their network members engage that convey their IPV-related attitudes and behaviors, through either direct communication or through social norms.

\section{Rationale and Significance}

Summary of Known and Unknown Information

Before describing the methodology of the proposed study, the previously reviewed literature that provides the rationale for the proposed study is summarized. Gaps in the existing literature, which the proposed study is designed to address, are highlighted.

The perpetration of IPV, or behaviors within the context of intimate relationships that cause physical, psychological, or sexual harm to one's partner (Krug, Dahlberg, Mercy, Zwi \& Lsano, 2002) represents a significant problem in the United States, effecting 1.3 million women each year (Tjaden \& Thoennes, 2000). Many of the men who are arrested for IPV also have histories of antisocial behavior (Capaldi \& Crosby, 1997; Harrison, Hilton \& Rice, 1997; Magdol, Moffitt, Caspi, Newman, Fagan, \& Silva, 


\section{SOCIAL NETWORKS OF INTIMATE PARTNER VIOLENCE PERPETRATORS}

1997), which has been associated with belonging to peer groups that also engage antisocial behavior (Dishion, Andrews \& Crosby, 1995; Dishion, Capaldi, Spracklen \& Li, 1995; Dishion, Patterson \& Griesler, 1994; Patterson, Dishion \& Yoerger, 2000; Warr, 2006). However, a portion of BIP participants do not engage in antisocial behavior outside of their intimate relationships, indicating that not all BIP participants necessarily have social networks that support antisocial behavior. Is this so? Are there abusive men whose networks make no allusions to IPV?

Batterer intervention programs (BIPs) are group-based intervention programs that utilize a combination of cognitive-behavioral therapy (Saunders, 2008), gender resocialization (Saunders, 2008), didactic information about IPV (Rosenbaum \& Leisring, 2001) and self-reflection (Rosenbauam \& Leisring, 2001), intended to address perpetrators' use of abuse. Reports of BIPs' efficacy are varied, reflecting inconsistencies in how pre-existing differences among program participants (Hanson \& WallaceCapretta, 2000), participants' drop-out from the program (Feder \& Wilson, 2005; Hanson \& Wallace-Capretta, 2000), and metrics of program success (Taylor, Davis \& Maxwell, 2001) are defined. Of men who are deemed most successful in their BIPs, many begin program participation under pressure from their friends and family (particularly outside the U.S; Rothman, Buchart, \& Cerda, 2003), and develop relationships with BIP facilitators and participants through their program involvement (Sheehan, Thakor \& Stewart, 2012). 


\section{SOCIAL NETWORKS OF INTIMATE PARTNER VIOLENCE PERPETRATORS}

Social networks are sets of individuals who are connected to each other through known, or potentially known, relational ties (Wasserman \& Faust, 1994). Relational ties refer to the types of affiliation between two people, which may include being one another's acquaintance, friend, parent, partner, employer, or neighbor, etc. Individuals' social networks have characteristic norms and values (Wassertman \& Faust, 1994; Wellman, 1982), which shape their attitudes and behaviors (Borgatti, Mehra, Brass \& Labianca, 2009; Erickson, 1988) through processes of influence.

In the general population, individuals have an average of 7.5 social network members, only .7 of whom are friends, as opposed to family members, coworkers, neighbors, and other social contacts (Christakis \& Fowler, 2007). Young men who, at the age of 16 , belong to social networks that are almost exclusively male and contain dense patterns of relational ties between members, are most likely to have perpetrated IPV by the time they reach age 22 (Casey \& Beadnell, 2010). This indicates that, at least during their adolescence, men who perpetrate IPV may have smaller social networks comprised more densely of men than those who do not perpetrate IPV. However, we do not know whether adult men who perpetrate IPV also have smaller networks, or networks that are more densely male, than the general population. Additionally, studies of networks' influence on the perpetration of violence against women have either defined networks as those who provide social support (Raghavan et al., 2009) or as participants' friends (Abbey et al., 2001; DeKeseredy, 1988; DeKeseredy, 1990b; Gidycz, Orchowski \& Berkowitz, 2011), excluding other relational ties that may be present in social networks. 


\section{SOCIAL NETWORKS OF INTIMATE PARTNER VIOLENCE PERPETRATORS}

Influence is the impact of individuals' attitudes or behavior on the attitude or behavior of others (Lippitt, Polansky \& Rosen, 1952), which may occur through direct communication about those attitudes or behaviors, or through the implications of social norms within networks (Lippitt, Polansky \& Rosen, 1952; Marsden \& Friedkin, 1993). Network members with whom individuals have higher quality relationships or more satisfying relationships are more influential in shaping their attitudes and behaviors (Ajzen \& Fishbein, 1970; Priester \& Petty, 2001; Terry \& Hogg, 1996). We do not know which social network members with whom BIP participants have high quality relationships, and whether or how those social network members behave in ways that indicate their attitudes about, or perpetration of, IPV. We do not know whether BIP participants' social network members allude to the perpetration of IPV in their interactions with BIP participants at all.

Research regarding the social networks of those seeking treatment for alcohol abuse indicates that treatment is more successful for individuals whose social networks are larger (Zywiak, Longabaugh \& Wirtz, 2002), contain more non-family members (Gordon \& Zrull, 1991), and actively support the individuals' recovery (Beattie \& Longabaugh, 1997; Beattie \& Longabaugh, 1999; Humphreys et al., 1999; Humphreys \& Noke, 1997; Longabaugh \& Wirtz, 2002). As individuals participate in treatment programs and alter their drinking behavior, the alcohol-specific attitudes and behaviors of their networks change as well, though many of the network members themselves stay the same (Beatttie \& Longabaugh, 1999; Kelly et al., 2011; Humphreys et al., 1999; Mohr et 


\section{SOCIAL NETWORKS OF INTIMATE PARTNER VIOLENCE PERPETRATORS}

al., 2001): changing the alcohol-specific attitudes of pre-existing network members appears to support individuals' recovery from alcohol abuse. It is unclear whether the social networks of BIP participants maintain the structure and content that could, ultimately, enable similar processes of change.

However, substance abuse and IPV are distinct social problems that carry with them different stigmas, which shape the ways that these behaviors are or are not made known to, and acknowledged by, social network members. Even while friends may not necessarily drink together, mere awareness of important network members' use of alcohol may be enough to reinforce one's own drinking behavior (Mohr et al., 2001). The same may be true of IPV, however, the secrecy that often surrounds partner violence (Cooney, 1998) likely reduces network members' knowledge of each others' perpetration of IPV. For example, Holtzworth-Munroe and Stuart (1994) identified three typologies of men who perpetrate IPV, two of which, family-only batterers and dysphoric or borderline batters, mostly confine their use of violence to their families, and whose abusive behavior may therefore be less visible to others in their communities. Familyonly batterers in particular feel guilt and remorse about their use of violence (HoltzworthMunroe \& Stuart, 1994), and may be especially inclined to keep their abusive behavior secret. Thus, prior to intervention, these batterers may make concerted efforts to avoid indicating to their social networks that they engage in IPV, which prevents dialogue about abuse. Additionally, perpetrators' social networks may intentionally avoid the topic of IPV, regardless of their own perpetration, as a result of North American social norms 


\section{SOCIAL NETWORKS OF INTIMATE PARTNER VIOLENCE PERPETRATORS}

that support familial privacy (Lehrer \& Allen, 2008). Addressing the topic of someone else's involvement in IPV may be deterred by the belief that doing so would be a violation of social norms. We do not know the extent to which BIP participants actually discuss IPV with the members of their social networks, whether generally or in reference to their own experiences.

Furthermore, individuals seeking treatment for substance abuse are encouraged to rely on new friendships with members of their treatment programs as they distance themselves from substance-using friends (Humphreys \& Noke, 1997), whereas fear of collusion among perpetrators prevents BIP providers from encouraging the development of friendships between their participants (Viola \& Huffine, 2012). Subsequently, the specific individuals who comprise BIP participants' social networks may remain relatively constant, compared to those of individuals in treatment for substance abuse, and BIP participants may be subject to the influence of a more consistent set of network members. We do not know whether BIP participants consider other BIP group members or facilitators important in their lives.

Social networks also influence individuals' antisocial behavior, such that a model for preventing recidivism within the criminal justice field explicitly recognizes antisocial peer affiliates as a risk factor for re-offense (Andrews \& Bonta, 2010; Bonta \& Andrews, 2007). Among juvenile delinquents, the process of "deviancy training," whereby youths' social networks selectively reinforce antisocial statements and behaviors (Dishion, Andrews \& Crosby, 1995; Dishion, Patterson \& Griesler, 1994) appears partially 


\section{SOCIAL NETWORKS OF INTIMATE PARTNER VIOLENCE PERPETRATORS}

responsible for participation in antisocial behavior. Many, though not all, of the men who are arrested for the perpetration of IPV have antisocial tendencies outside the realm of their intimate relationships (Capaldi \& Crosby, 1997; Holtzwoth-Munroe \& Stuart, 1994; Magdol et al., 1997; Harris, Hilton \& Rice, 2011). Among children and adolescents, specific interactions within their social networks reinforce their talk of antisocial behavior, as well as their engagement therein (Dishion, Andrews \& Crosby, 1995; Dishion, Capaldi, Spracklen \& Li, 1995; Dishion, Patterson \& Griesler, 1994; Patterson, Dishion \& Yoerger, 2000; Warr, 2006). Having relationships with social network members who display antisocial behaviors is considered a risk factor for re-offense, among men who have been previously arrested (Andrews \& Bonta, 2010; Bonta \& Andrews, 2007). But, we do not know whether BIP participants and the members of their social networks reinforce each other's perpetration of IPV in a similar manner to adolescents' general antisocial behavior, or the specific interactions through which they do so. Nor do we know which social network members BIP participants may engage in this way. IPV is a unique form of antisocial behavior, one that may be perpetrated in private (Cooney, 1998), and has direct implications for one member of the individual's social network (their intimate partner).

Social networks have also been implicated in the perpetration of IPV and sexual assault more specifically: IPV among one's parents (Arriaga \& Foshee, 2004; Doumas, Margolin \& John, 1994; Silverman \& Williamson, 1997), peer groups that express hostility towards women (Capaldi et al., 2001; Reed et al., 2008), and perceptions of 


\section{SOCIAL NETWORKS OF INTIMATE PARTNER VIOLENCE PERPETRATORS}

social norms that condone violence against women (Abbey et al., 2001; Brown \& Messman-Moore, 2010; Raghavan et al., 2009; Silverman \& Williamson, 1997) are also related to the perpetration of sexual assault and IPV. While some studies have indicated that attending to BIP participants' social networks as a means of improving programs' efficacy (Almeida \& Bograd, 1991; Maxwell, Davis \& Taylor, 2010; Neighbors et al., 2008), no research to date has evaluated this possibility. A first step towards assessing the potential of incorporating an emphasis on BIP program participants' social networks into program curricula is describing the members of participants' social networks, and their IPV-specific interactions, to determine whether and how BIP participants and the members of their social networks interact about IPV.

Among adult men on college campuses, social networks may influence the perpetration of IPV through direct communication and informational support that condones or actively encourages the use of violence against women, in the context of intimate relationships and more casual dating relationships (DeKeseredy, 1988; DeKeseredy, 1990b, DeKeseredy, 1997). Norms within social networks may also encourage the perpetration of violence against women (Berkowitz, 2004; DeKeseredy, 1990a; Gidycz, Orchowski \& Berkowitz, 2011; Kilmartin et al., 2008; Lewis, 2004; Neighbors et al., 2010; Schwartz \& DeKeseredy, 1997; Silverman \& Williamson, 1997). We do not know the extent to which men in BIPs engage in direct communication about IPV with their network members, or how they or their network members contribute to norms regarding the perpetration of IPV. While DeKeseredy's model has been validated 


\section{SOCIAL NETWORKS OF INTIMATE PARTNER VIOLENCE PERPETRATORS}

for a college student population, it may not apply to BIP participants. BIP participants likely have a different demographic profile than the $18-22$ year old Canadian university students upon whom the model was based and validated, and live within a markedly different context (in the community, as opposed to a relatively homogenous and isolated university campus). BIP participants may be more likely to live with their families and/or partners, and to potentially seek support from these social network members, than with fraternity brothers, and are likely exposed to individuals from different age groups and backgrounds than may be the case for university students.

Just as social networks shape the attitudes and behaviors of their members, through transactional relational processes, individuals also influence the social networks that they comprise (Cartwright, 1965; Kandel, 1978; Marsden \& Friedkin, 1993). An intervention in which only a limited number of social network members participate may ultimately have the effect of impacting their network as a whole (Hawe, Shiell \& Riley, 2009): participation in an intervention may change the structure of an individual's social network (Humphreys et al., 1999), facilitate the spread of an innovation throughout a network (Valente, 1996), or spur other network members to reconsider their own behavior (Roffman et al., 2008). As perpetrators of IPV participate in BIPs, it is possible that they may change the norms of their social networks such that IPV becomes less commonplace. We do not know whether, or how, BIP participants address the issue of IPV with the members of their social networks, or the extent to which the influence of BIPs are communicated to the community beyond their immediate participants. 


\section{SOCIAL NETWORKS OF INTIMATE PARTNER VIOLENCE PERPETRATORS}

Measurement of Social Networks' Relationship to Violence Against Women

In the process of attempting to address the questions posed above, the current study also included the development of two new behavioral inventories: one assessing the behaviors social network members use in their interactions that potentially influence BIP participants regarding IPV, and one assessing the behaviors that BIP participants' use in their interactions with network members that potentially influence the behavior of their social network members. DeKeseredy and colleagues (DeKeseredy \& Schwartz, 1993; Schwartz \& DeKeseredy, 1997) designed a measure to assess the behaviors in which young men's social network members engage, with the effect of influencing their perpetration of sexual assault. However, the measure is designed to measure behaviors specific to influencing others' perpetration of sexual assault and is not valid for the assessment of network influences on the perpetration of IPV more broadly. Additionally, the behavioral indicators included in DeKeseredy and colleagues' (DeKeseredy \& Schwartz, 1993; Schwartz \& DeKeseredy, 1997) measure are largely specific to university culture, and do not seem relevant to a community population.

Several studies have assessed social networks' support for violence against women by asking participants to report on their perceptions of others' attitudes or behaviors, or speculations about their social network members' perpetration of IPV or sexual assault. Neighbors and colleagues (2010) assessed IPV perpetrators' perceptions of others' perpetration in IPV, using a tool that reflects participants' perceptions of social norms. Similarly, Brown and Messman-Moore (2010) measured individuals’ peer 


\section{SOCIAL NETWORKS OF INTIMATE PARTNER VIOLENCE PERPETRATORS}

groups' attitudes towards sexual assault by asking participants to report their perceptions of their social network members' attitudes. Abbey and colleagues (2001) also asked participants to speculate about their friends' reactions to sexual assault, and how much pressure they had felt from their friends to perpetrate sexual assault. Raghavan and colleagues (2009) asked participants whether any men who provide them with social support had engaged in IPV in the six months prior to the survey. Network members' actual perpetration of sexual assault and IPV, perceptions of network members' perpetration of these behaviors, and speculations about network members' reactions to these behaviors may reflect network-wide social norms and participants' perceptions of these norms. However, this metric does not capture direct communication between social network members about IPV. Additionally, responses to such measures may be more indicative of participants' normative misperceptions, which Neighbors and colleagues (2010) have established are substantial, rather than network members' actual behavior. Currently, no inventory of behaviors that BIP participants may use to influence potentially their social network members exists. Thus, an additional aspect of this study is the development of these two inventories of the behaviors that BIP participants and their social network members may use to convey their attitudes about, or participation in, IPV, through a series of focus groups with BIP facilitators and participants. 


\section{SOCIAL NETWORKS OF INTIMATE PARTNER VIOLENCE PERPETRATORS}

\section{Chapter 2. Present Study}

\section{Purpose}

The study has two main purposes. First, to describe the members of BIP participants' social networks, and the ways in which they engage in direct communication and convey network norms about IPV to BIP participants. While it has been established that individuals' families (Capaldi \& Clark, 1998; Cazenave \& Straus, 1995; Collins, Maccoby, Steinberg, Hetherington, \& Bornstein, 2000; Doumas, Margolin \& John, 1994; Dishion, Capaldi, Spracklen \& Li, 1995; Silverman \& Williamson, 1997), adolescent peer groups (Arriaga \& Foshee, 2004; Capaldi et al., 2001; Schwartz \& DeKeseredy, 1997; Silverman \& Williamson, 1997), and adult social networks (Abbey et al., 2001; Almeida \& Bograd, 1991; Coker, 2002; Hearn \& Whitehead, 2006; Neighbors et al., 2008; Raghavan et al., 2009; Schwartz \& DeKeseredy, 1997; Silverman \& Williamson, 1997) shape individuals' perpetration of sexual assault and IPV, whether these individuals belong to BIP participants' social networks, and their IPV-specific interactions, have yet to be documented. The study provides an initial description of the individuals that belong to BIP participants' social networks and the ways and extent to which they convey their IPV-specific attitudes and behaviors to BIP participants. Identifying the extent to which BIP participants are exposed to IPV-relevant attitudes and behaviors in their social networks may inform how BIP providers understand and support participants through their process of altering their patterns of abuse, ultimately contributing to an increase in the effectiveness of these interventions 


\section{SOCIAL NETWORKS OF INTIMATE PARTNER VIOLENCE PERPETRATORS}

The second main purpose of the proposed study is to describe how BIP participants address IPV with the members of their social networks, and the social network members with whom they do so. These data may illustrate both the initiative that BIP participants may be taking to alter their social networks for their own sake, as well as the potential of BIPs' impact to extend beyond their participants, into the broader community. While findings of the current study may have implications for BIPs' efficacy and program activities, it is not intended to be a program evaluation.

To accomplish the study's two primary aims, data bearing on four main research questions and two hypotheses were collected.

\section{Research Questions and Hypotheses}

Research Question One

The first research question that the study addresses is: What are the characteristics of BIP participants' social networks? Three sub-questions are: how many social network members do BIP participants report (RQ 1.a)? What are the genders of participants' reported network members (RQ 1.b)? and what are the relational ties that connect participants to their network members (RQ 1.c)?

\section{Research Question Two}

The second research question that the study addresses is: How do BIP participants perceive the quality of their relations with their social network members? Specific sub- 


\section{SOCIAL NETWORKS OF INTIMATE PARTNER VIOLENCE PERPETRATORS}

questions ask: what is the quality of participants' relationships with their network members overall? (RQ 2.a), what is the quality of participants' relationships with their male and female network members? (RQ 2.b), and what is the quality of participants' relationships with network members to whom they have various relational ties? (RQ 2.c).

Research Question Three

The third research question asks how BIP participants' network members communicate that they condone IPV. Specific sub-questions are: how do participants' network members communicate that they condone IPV to BIP participants? (RQ 3.a), is the type of relational tie that participants have to their network members related to the number of times that the network members engage in behaviors that indicate that they condone IPV? (RQ 3.b), and do network members to whom participants have different relational ties communicate that they condone IPV in different ways? (RQ 3.c).

\section{Research Question Four}

The fourth research question addresses participants' possible attempts to influence their network members. Specific sub-questions are: what behaviors do participants engage in, with the intention or effect of influencing their network members? (RQ 4.a), does the number of times that BIP participants engage in behaviors with the intention or effect of influencing their network members differ depending on the relational tie? (RQ 


\section{SOCIAL NETWORKS OF INTIMATE PARTNER VIOLENCE PERPETRATORS}

4.b), and do participants use different behaviors to influence network members with whom they have different relational ties? (RQ 4.c).

\section{Hypotheses}

Two hypotheses about the relationships between network members' condoning of IPV, the quality of participants' relationships with network members, and participants' attempts to influence their network members are tested. Hypothesis 1 states that there is a negative relationship between network members' expressions of condoning IPV and the quality of participants' relationships with their network members (H 1). Hypothesis 2 states that there is a positive relationship between network members' condoning of IPV and the number of times that participants engage in behaviors with the intention or effect of influencing those network members' IPV-specific attitudes or behaviors (H 2).

\section{Moderating Variables}

The size and composition of BIP participants' social networks, and the use of influence to alter social networks, may vary depending on the number of weeks that BIP participants have been attending the program at the time of their survey completion, and whether or not they are enrolled in a group specifically for criminally oriented men. It may take several weeks or months of BIP participation for the contents of the curricula to begin resonating with participants; those early in their participation are unlikely to have sufficiently absorbed the messages conveyed by the program, and are therefore unlikely 


\section{SOCIAL NETWORKS OF INTIMATE PARTNER VIOLENCE PERPETRATORS}

to actively attempt to their network members' support for IPV. The BIP from which participants will be drawn has created several groups for clients whom they deem criminally oriented, or who they believe to be less responsive to the program's standard curriculum. This group of men, and the intervention that they receive, are considered qualitatively different by the BIP responsible for their treatment. Thus, two additional variations of research questions $3 \mathrm{a}, 3 \mathrm{~b}, 4 \mathrm{a}$, and $4 \mathrm{~b}$ and both hypotheses are pursued, one in which participants' attendance is included in the model, and one in which participants' enrollment in a group for criminally oriented men is included in the model. Participants' attendance and enrollment in a group for criminally oriented men are examined as predictors of how their network members communicate support for IPV to BIP participants. Attendance and enrollment in a criminally oriented group are also examined as potential moderators of the relationship between the types of relational ties that participants have to their network members and the number of times that network members express their support for IPV. Similarly, participants' attendance and enrollment in a group for criminally oriented men are examined as predictors of the behaviors that participants engage in, with the intention or effect of influencing their network members, and as potential moderators of the relationship between the number of influence behaviors that participants use with network members with whom they have different relational ties. Additionally, participants' attendance and enrollment in a group for criminally oriented men are examined as potential moderators of the following relationships: the hypothesized negative relationship between the number of times that 


\section{SOCIAL NETWORKS OF INTIMATE PARTNER VIOLENCE PERPETRATORS}

network members express their support for IPV and the quality of their relationship with participants (1) and the hypothesized positive relationship between the number of times that network members express their support for IPV and the number of times that participants engage with them about IPV (2).

\section{Method}

Participants

Participants in three of the study's four focus groups and the survey portion of the current study were men enrolled in the Allies in Change Counseling Center's BIP in Portland, OR. Allies in Change provides individual, couples, and group counseling services to both men and women. Their programs serve men who are court mandated to attend BIPs, as well as men who enroll voluntarily. The program has three locations in Oregon, in Beaverton, Northeast Portland, and Oregon City. Participants were drawn from all three of these locations. Further information about the people who participated in each of the focus groups and the survey portion of the study is provided in the description of each stage of the study.

Allies in Change is a relatively unique BIP in its mission and orientation towards working with perpetrators of IPV. The program describes itself as a "non-profit social activist organization and psychological services center," and strives to raise community awareness about subtle forms of abuse, offering training and outreach to other organizations and community members, in addition to BIP groups (Allies in Change, 


\section{SOCIAL NETWORKS OF INTIMATE PARTNER VIOLENCE PERPETRATORS}

2014). Conversely, many BIPs offer more narrow services, and are primarily focused on curbing the physical violence perpetrated by their participants (Viola \& Huffine, March 11, 2014). The orientation of Allies in Change is that culturally engrained conceptions of gender roles, power and control contribute to the perpetration of abuse (Allies in Change, 2014), whereas a portion of BIPs do not consider participants' contexts to such an extent (Viola \& Huffine, March 11, 2014). BIP facilitators at Allies in Change attempt to hold participants accountable for their behavior and encourage participants to conceptualize their partners as their allies, as opposed to their adversaries, while maintaining a respectful and supportive stance (Allies in Change, 2014). This often takes the form of thoroughly developing rapport with participants before confronting them directly about their denial or pro-abuse beliefs (Viola \& Huffine, March 11, 2014), while it is common for BIPs to maintain a more punitive orientation towards working with men who have perpetrated IPV (Viola \& Huffine, May 13, 2014).

The specific practices that Allies in Change utilizes are also noteworthy and potentially distinct. The program's batterer intervention curricula are largely based on the Duluth curriculum, which is the most common curriculum among American BIPs (Price \& Rosenbaum, 2009), and include some discussion of both anger management and substance abuse, topics that are addressed within $76 \%$ and $55 \%$ of American BIPs, respectively (Price \& Rosenbaum, 2009). However, the program offers a number of specialized groups, an approach endorsed by only $10 \%$ of BIPs nationwide (Price \& Rosenbaum, 2009). Allies in Change's specialized groups include those that are tailored 


\section{SOCIAL NETWORKS OF INTIMATE PARTNER VIOLENCE PERPETRATORS}

to abusive fathers, emotionally intense participants, participants with cognitive deficits, men who have perpetrated sexual offenses, participants with criminal histories, participants who have enrolled in the program voluntarily, and long-time voluntary program participants, all of which utilize different curricula (Allies in Change, 2014). As a result, participants are often referred to Allies in Change, specifically, if staff at other programs, mental health professionals, or members of the criminal justice system believe that they would benefit from these specialty groups (Viola \& Huffine, May 13, 2014). Thus, Allies in Change may serve greater proportions of participants who fall into these categories than other BIPs. Additionally, the provision of such specialized groups facilitates the use of different program curricula with participants with specific needs, such that Allies in Change's curricula are distinct from each other, as well as from those used by other programs (Viola \& Huffine, May 13, 2014). Allies in Change participants are also asked to complete weekly journaling exercises, to reflect on their current struggles with power and control (Viola \& Huffine, May 13, 2014), which may be an additional unique program feature.

Allies in Change offers a 40-hour training for BIP facilitators to meet the necessary requirements to conduct BIP groups in Oregon (Allies in Change, 2014). The executive director of Allies in Change also facilitates the monthly meetings of the Tri County Batterer Intervention Providers Network, regularly attends academic and professional conferences on abuse intervention, and both conducts and attends additional training opportunities across the country, whereas the majority of BIPs have limited 


\section{SOCIAL NETWORKS OF INTIMATE PARTNER VIOLENCE PERPETRATORS}

resources for their staff members to have the same exposure to relevant education and developments in the field batterer intervention (Viola \& Huffine, Jan. 14, 2014). Allies in Change's unique orientation to batterer intervention work, provision of a range of specialized BIP groups, and exposure to training and education make this a unique BIP, at least within the state of Oregon. More pertinent to the content of the current study, the executive director of Allies in Change has been involved in the conceptualization and development of the current study, and the researcher discussed the current study with all of the BIP facilitators at Allies in Change several weeks prior to collecting data from program participants. As a result, it is possible that staff at Allies in Change were more attuned to participants' interactions with their social networks and abuse-relevant communication therein, and may have discussed these ideas with their groups in the weeks leading up to data collection. This context may have implications for the generalizability of current findings to participants in other BIPs.

Protection of human subjects. Before initiating the current study, the Portland State University Human Subjects Research Review Committee reviewed proposed protocols, and several adjustments were made to the proposed procedure. All participants completed informed consent forms prior to participating in focus groups or completing surveys (see Appendices C, H, M, Q, and R).

Focus group recordings are, and have been, stored in a locked laboratory on the Portland State University campus, as have completed paper surveys. Data from the paper surveys were entered electronically. Research assistants helping with the data entry 


\section{SOCIAL NETWORKS OF INTIMATE PARTNER VIOLENCE PERPETRATORS}

reviewed the importance of confidentiality and means of ensuring confidentiality, before beginning to enter data. Electronic data files will are stored on Portland State University's I-drive, and only individuals on Dr. Eric Mankowski's research team have access to the files.

Paper surveys administered to participants are identified by a unique code, which was written on the first page of each survey by the research team before arriving at the data collection location. Two consent forms were distributed to participants, along with the paper survey: one consent form, also marked with the same unique code as the survey, explained the purpose of the study and asked for participants' consent to participate. The second form, which was not marked with the survey code, asked participants for their permission for Allies in Change to share their administrative records with the research team. Specifically, participants were asked to permit Allies in Change to share the number of groups that they had attended as of the date of the survey administration, their referral source to the program, and their contact information, in perpetuity. Written and verbal instructions were provided to participants, explaining that they could permit Allies in Change to share any combination of these pieces of information with the research team. Additionally, participants were encouraged to sign their names illegibly if they wished to participate in the study, but did not want their identities to be known to the research team. Participants' printed names were used to match their two consent forms to each other, and to their survey ID number. A key was compiled, listing participants' names, survey ID numbers, the date of their survey 


\section{SOCIAL NETWORKS OF INTIMATE PARTNER VIOLENCE PERPETRATORS}

participation, and the administrative records that they permitted Allies in Change to share with the research team. This key was sent to Allies in Change, to fill in with the indicated administrative records. Once this information was inputted into the key, participants' names were removed from the file. Participants' survey ID numbers were then used to link their administrative records to their survey data. All paper surveys are stored in a filing cabinet on the Portland State campus, separate from the signed consent forms in a locked research laboratory.

\section{Design}

The current study utilizes a cross-sectional design to describe participants' social networks and the behaviors that they use to communicate about abuse. All participants were surveyed on a single occasion. Participants enrolled in Allies in Change at different times, and had attended the program for different durations at the time of the survey administration. In the language of Morgan's (1998) procedural options for combining qualitative and quantitative methodology, the current research utilized preliminary qualitative methods in a quantitative study, with the additional of a follow-up qualitative portion. 


\section{SOCIAL NETWORKS OF INTIMATE PARTNER VIOLENCE PERPETRATORS}

Procedure

In the current study, data were collected in four sequential phases. The goals of each phase of data collection, and the methods that were used, are outlined in Figure 2, below, and elaborated in greater detail in the sections that follow.

\begin{tabular}{|c|c|c|c|c|}
\hline & Phase I & Phase 2 & Phase 3 & Phase 4 \\
\hline $\begin{array}{l}\overline{0} \\
0\end{array}$ & $\begin{array}{c}\text { Measure } \\
\text { Development }\end{array}$ & $\begin{array}{c}\text { Survey Pilot } \\
\text { Testing }\end{array}$ & $\begin{array}{l}\text { Survey Data } \\
\text { Collection }\end{array}$ & $\begin{array}{c}\text { Member } \\
\text { Checking and } \\
\text { Reporting }\end{array}$ \\
\hline 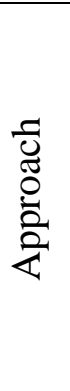 & $\begin{array}{l}\text { - Focus } \\
\text { group with } \\
\text { BIP } \\
\text { facilitators } \\
\text { - Focus } \\
\text { group with } \\
\text { BIP } \\
\text { participants }\end{array}$ & $\begin{array}{l}\text { Focus group } \\
\text { with BIP } \\
\text { participants }\end{array}$ & $\begin{array}{l}\text { Survey } \\
\text { administration } \\
\text { with BIP } \\
\text { participants }\end{array}$ & $\begin{array}{l}\text { Focus group } \\
\text { with BIP } \\
\text { facilitators and } \\
\text { participants }\end{array}$ \\
\hline
\end{tabular}

Figure 2. Phases, goals, and corresponding approaches, to data collection.

Measure development. Focus groups with individuals who are enmeshed in a

phenomenon of interest are an effective method of identifying language to use in subsequent survey instruments addressing that phenomenon (O’Brien, 1993). Based on O'Brien (1993)'s example of using focus groups to inform the construction of a survey instrument, the first step in the current project was conducting a set of focus groups. The focus groups were used to iteratively generate and refine a list of ways that BIP participants' network members communicate about abuse, and a list of the ways that BIP participants convey their attitudes and behaviors about IPV to the members of their social networks. The first focus group was conducted with BIP facilitators, and a second focus group was conducted with BIP participants at Allies in Change. 


\section{SOCIAL NETWORKS OF INTIMATE PARTNER VIOLENCE PERPETRATORS}

BIP facilitators were recruited from the Tri County Batterer Intervention Program Providers' Network (TCBIPPN) to participate in the first focus group. The TCBIPPN is a group of BIP providers and victim advocates from Multnomah, Clackamas, and Washington Counties, which assembles in Portland each month to discuss issues relevant to BIP facilitation. Three TCBIPPN attendees who work in BIP facilitation were recruited to participate in a focus group addressing BIP participants' communication about IPV outside of their groups. Participants were recruited in person from the July, 2013 TCBIPPN meeting, via email over a list-serve of BIP providers in Oregon, and phone calls to BIPs in the Portland metro area. The flier and email that were used to recruit focus group participants are located in appendices A and B, respectively.

While focus groups are typically composed of 4 to 15 participants, two participants are considered the bare minimum (Morgan, 1992). As the focus group was convened to compile specific and detailed anecdotes from the participating facilitators, the smaller group size was preferable (Morgan, 1992). Additionally, the participants in the current focus group represented a great diversity of perspectives and experiences, despite their limited number. Between the three participants, they had specializations in working with the following groups of perpetrators: those in their late teens and twenties, groups of criminally oriented perpetrators in urban areas who are almost exclusively court-mandated to BIP participation, residents of rural areas, those who have immigrated from Latin American countries, and faith-based BIP groups for Christian participants, many of whom attend voluntarily. Thus, the varied expertise of the focus group 


\section{SOCIAL NETWORKS OF INTIMATE PARTNER VIOLENCE PERPETRATORS}

participants enabled them to speak about having worked with a wide and diverse group of BIP participants in Oregon. While the number of focus group participants was relatively small, they possessed collective knowledge about BIP participants from a wide variety of backgrounds. The researcher, who facilitated the focus group, had previously interacted with all of the focus group participants at multiple TCBIPPN meetings before beginning focus group recruitment. The focus group participants had also met each other at TCBIPPN meetings on numerous occasions prior to the focus group.

The focus group of program providers was convened on the Portland State University campus on July 23, 2013. Participating BIP providers were asked to sign informed consent forms indicating their willingness to participate in the focus group and their permission for the researcher to audio-record the focus group (Appendix C). Focus group participants were asked to describe the ways that they thought that their clients are influenced by members of their social networks, and discrete behaviors that they believe the clients' social network members engage in, which impact the perpetration of IPV. Participants were also asked about behaviors that they believed that their clients engage in, which have the effect of shaping the attitudes and behaviors of those in their lives (see Appendix D for the script that was used to guide the focus group). Participants were then asked for their feedback on two pools of sample items: one pool of 33 items representing discrete behaviors that BIP participants' network members may engage in, and one pool of 34 items representing behaviors that BIP participants may engage in (see Appendix E for the initial item pools). These items were either drawn directly or adapted from the 


\section{SOCIAL NETWORKS OF INTIMATE PARTNER VIOLENCE PERPETRATORS}

following scales: Peers' Informational Support Regarding Sexual Assault (DeKeseredy, 1990b), the Psychological Maltreatment of Women Inventory (Modified; Tolman, 1995), the Helping Attitudes Scale (Banyard, Plante \& Moynihan, 2005), the Bystander Behaviors Scale (Banyard, Plante \& Moynihan, 2005), the Bystander Efficacy Scale (Banyard, Plante \& Moynihan, 2005), and the forms of Work Related Intimate Partner Violence (Galvez, Mankowski, McGlade, Ruiz \& Glass, 2011) or developed by the researcher. Items were drawn from these specific scales because they include discrete, IPV-relevant behaviors. With the exception of the Psychological Maltreatment of Women Inventory (Modified; Tolman, 1995), all of the aforementioned scales include examples of behaviors that network members or other bystanders may engage in. The Psychological Maltreatment of Women Inventory (Modified; Tolman, 1995) includes discrete psychologically or emotionally abusive behaviors. Items from this scale represented abusive behaviors that network members may demonstrate in the presence of BIP participants. The specific items that were drawn or modified from these scales were chosen on the basis of their face validity, their relevance to IPV (as opposed to sexual assault more generally), and their applicability to a community sample (versus a college student sample). See Appendix D for questions that were used to guide the focus group discussion and to elicit participants' feedback on the sample items.

The researcher facilitated the 75-minute focus group, while a co-moderator took notes on the content of participants' comments. Immediately following the focus group, the researcher wrote down her own notes and reflections on the group and listened to the 


\section{SOCIAL NETWORKS OF INTIMATE PARTNER VIOLENCE PERPETRATORS}

audio recording of the group twice over, taking extensive notes. The researcher then reviewed the notes that she made during the focus group and immediately afterwards, the co-moderator's notes from the focus group, and her notes on the audio recording to identify relevant examples of discrete behaviors. Reviewing the multiple sources of notes and recordings served to triangulate the occurrence of the discrete behaviors in the focus group and the contexts in which they were mentioned, contributing to the credibility and confirmability of the researcher's interpretations (Lincoln \& Guba,1985). The researcher identified specific examples of the following, as reported by participating BIP facilitators: the behaviors that BIP participants' social network members use to contribute to their perpetration of IPV; how BIP participants respond to their social network members' provocation of anger or distrust of their partners; and BIP participants' strategies for sharing what they learn in BIPs. As per O’Brien's (1993) example, specific anecdotes and examples that the BIP providers shared were rephrased into a format that matched the existing survey items, such that survey participants would be able to indicate how many times the specific behavior had occurred. The researcher then reviewed the focus group participants' feedback on the initial pools of items, identifying specific items that participating BIP facilitators believed were unrealistic or exceedingly rare among their participants, alternative items that BIP facilitators believed would be more applicable to their participants, and general suggestions about topics, behaviors, and interaction styles that would make the items more relevant to their participants. The researcher collected 


\section{SOCIAL NETWORKS OF INTIMATE PARTNER VIOLENCE PERPETRATORS}

these points into a list of important points to integrate into the next version of the item pool (see Appendix F).

The researcher used this list of important points to revise the two item pools, removing items that the BIP facilitators did not believe that participants would endorse, modifying the phrasing of a number of items, and creating new items based on the BIP facilitators' suggestions, resulting in a total of 74 items between the two inventories, 44 behaviors that participants' network members may have engaged in, and 30 behaviors that participants may have engaged in. See Appendix G for the resulting inventories. The researcher then brought these resulting sets of items to a focus group of BIP participants for further feedback and revision.

One of Allies in Change's regularly scheduled counseling groups acted as a second focus group. The second focus group was conducted to prolong the researcher's engagement at Allies in Change and provide another opportunity for relevant observation, both of which contribute to the credibility of qualitative research (Lincoln \& Guba, 1985). The focus group also allowed BIP participants to respond and contribute to the BIP facilitators' perspectives, essentially member-checking the initial inventory development, which is another method for establishing credibility (Lincoln \& Guba, 1985). The focus group of BIP participants was held at Allies in Change Counseling Center's Beaverton location on August 8, 2013. The focus group was facilitated by the researcher, and co-moderated by another female graduate student. For three consecutive weeks prior to the focus group, the group facilitator announced that the researcher would 


\section{SOCIAL NETWORKS OF INTIMATE PARTNER VIOLENCE PERPETRATORS}

be attending the August $8^{\text {th }}$ group meeting for the purpose of conducting a focus group with the group members, and that those who wished not to participate would be excused from the group for the evening. The focus group consisted of 5 participants, all of who were voluntarily enrolled at Allies in Change. Participants indicated that this particular group of men had been meeting for over a year, and two participants explained that they had been attending Allies in Change of over a decade. All of the participants alluded to having children, and all but one of the participants expressed that their children are adults.

Participants were asked to sign an informed consent form (see Appendix H) indicating their willingness to participate in the focus group, and their permission to audio-record the group. The group was asked about the people who are important in their lives, interactions that they had had with members of their social networks around IPV and the ways in which they have responded to those interactions (see Appendix I for the script that was used to facilitate the focus group). Participants were also asked to look over and provide feedback on the second version of the two item pools, which had been revised on the basis of the BIP providers' feedback (see Appendix G). The same procedures that were used to conduct and review the initial focus group of BIP facilitators were used to conduct the second focus group and synthesize participants' comments.

The participants in the current focus group already had a high degree of rapport with each other, as this group of men had been meeting for over a year at the time of the focus group. The one female BIP staff member who was present during the group 


\section{SOCIAL NETWORKS OF INTIMATE PARTNER VIOLENCE PERPETRATORS}

meeting, and who remained in the room while the focus group was underway, had also been meeting with this group of men for a year prior. Participants demonstrated a clear understanding of the purpose for the focus group, and were able to provide concrete examples of ways that they have discussed IPV and their work at Allies in Change with others in their lives. Participants focused on emotionally or psychologically abusive behavior and the survey items that pertained to these forms of abuse, as opposed to physical or sexual abuse. Participants indicated that, at least among other men who attend Allies in Change voluntarily, emotional and psychological abuse is more common than physical or sexual abuse, and therefore more likely to emerge in conversations with their social network members. Accordingly, focus group participants provided examples of interactions that they have had, or could imagine having, with their social network members around emotional or psychological abuse. Participants recommended items and revisions to items that made them more nuanced; participants indicated that they are more likely to engage with their social network members around abuse less directly than talking more explicitly about abuse that they had perpetrated or suspect that their social network members perpetrate.

Appendix J contains a list of important points that emerged from the current focus group, which suggested modifications to the item pools that the focus group reviewed. Again, items that focus group participants identified as unrealistic or exceedingly rare were removed from the item pool, several items were rephrased, and a number of new items were developed, based on explicit examples and quotes provided by focus group 


\section{SOCIAL NETWORKS OF INTIMATE PARTNER VIOLENCE PERPETRATORS}

participants about their interactions with members of their social networks. The focus group of BIP participants produced 67 items: 34 behaviors that participants' social network members may have engaged in, and 33 behaviors that participants may have engaged in with the members of their social networks (see Appendix K).

At this point, after both focus groups were completed, the researcher met with the dissertation committee chair to determine whether the groups produced enough information to select items to include in the two behavioral inventories for pilot testing. The researcher and committee chair decided that the researcher had enough information from the two focus groups to narrow down the two inventories. Items generated by the BIP facilitator and participant focus groups, focus group participants' responses to the initial and revised item pools, and focus group participants' perceptions of the items that would be least commonly endorsed by other participants were considered in paring down the two behavioral inventories. Consulting these multiple sources enabled the researcher to triangulate her identification of items to remove from the inventory. Items that participants indicated were unlikely to be endorsed by their peers were removed. The remaining items were organized by thematic category within each of the two inventories, for the purpose of identifying conceptually similar items. Items from the inventory of network members' behavior were sorted into four categories: provoking participants' abusive behavior towards their partners; justifying participants' use of abuse, explicitly supporting or providing advice regarding abuse; and expressing their general orientation towards abuse. The inventory of participants' own behavior towards their network 


\section{SOCIAL NETWORKS OF INTIMATE PARTNER VIOLENCE PERPETRATORS}

members also consisted of four thematic categories: direct intervention in others' behavior; speaking theoretically about abuse, sharing information or resources regarding abuse, and making self-disclosures about abuse. Within each thematic category, items that were very similar or redundant were consolidated or removed, to allow for a wider range of items that would maximize the inventories' coverage. Items with the greatest face validity and clearest interpretation were retained, as were items that came most directly from the content of the two focus groups. To ensure the inventories' coverage, an additional item was added to each of the two inventories, asking participants whether their network members had engaged in any other behaviors that had made them think about IPV, or whether they had engaged in any other behaviors with their network members that may have made their network members think about IPV. The resulting inventories each consisted of 16 items. See Appendix L for the resulting version of the survey.

Survey pilot testing. Once the two behavioral inventories were established, a third focus group of Allies in Change participants was conducted to pilot test the survey and solicit BIP participants' feedback on it. A second regularly scheduled group of program participants at Allies in Change was selected to pilot test the survey. Pilot testing was conducted at Allies in Change's Beaverton location on August $20^{\text {th }}, 2013$. The researcher facilitated the focus group, and a female undergraduate research assistant acted as the comoderator. For three consecutive weeks prior to the focus group, the group facilitator announced that the researcher would be attending the August $20^{\text {th }}$ group meeting for the 


\section{SOCIAL NETWORKS OF INTIMATE PARTNER VIOLENCE PERPETRATORS}

purpose of administering the survey and conducting a focus group with the group members, and that those who wished not to participate would be excused from the group for the evening. The focus group consisted of 9 participants, all of whom were courtmandated to attend the program. A group of court-mandated participants was selected to act as the third focus group, to ensure that court mandated participants' perspectives were represented in the survey development phase of the study, in addition to the perspectives

of voluntary participants. Before the group began, participants chatted among themselves about their work in the construction industry.

The batterer intervention group's regular two facilitators were present at the outset of the group. The researcher explained the purpose and procedure for the focus group. Participants completed informed consent forms before the group began, indicating their consent to complete the survey, to participate in a facilitated conversation about the survey, and for the conversation to be audio-recorded (see Appendix M). One group member negotiated their focus group participation with the male group facilitator, asking that they receive credit for completing two class assignments in exchange for their participation in the focus group. The facilitator agreed. A number of participants expressed concerns about being audio-recorded, however, once the researcher verbally explained the recording's intended use, which individuals who would hear the recording, and the confidentiality of the participants' names, all of the participants signed the informed consent documents and stayed in the room to participate in the focus group. After the informed consent documents were collected, the researcher distributed the 


\section{SOCIAL NETWORKS OF INTIMATE PARTNER VIOLENCE PERPETRATORS}

surveys and asked participants to complete them, paying attention to the survey's clarity and relevance to them. Participants were asked to complete prototypes of the entire survey (see Appendix M), which included the two behavioral inventories that were under development, as well as the measures the quality of participants' relationships with each of their network members, their stage of change regarding their perpetration of IPV, and their actual perpetration of abuse.

While participants were working on the survey, and throughout the conversation that followed, the two group facilitators came and went from the room. Several participants asked the researcher clarifying questions about particular phrases that were used in the survey as they worked through it. Specifically, participants were confused by the use of the phrase "contact" to refer to individual network members. They inquired about the number of contacts or network members for whom they should complete the measure of relationship quality and the behavioral inventories. One participant also asked for clarification about the phrase "contented," as opposed to "content." Participants were also unclear about whether the phrase "partner" referred to their current partner, their former partner, both their current and former partners, or one but not the other.

Two participants finished the survey within approximately 10 minutes, one participant finished the survey after roughly 15 minutes, and two more participants were done within 25 minutes of beginning the survey. While participants waited for their group members to finish the survey, they entertained themselves on their cell phones and wandered back to Allies in Change's waiting area. After 40 minutes, all of the 


\section{SOCIAL NETWORKS OF INTIMATE PARTNER VIOLENCE PERPETRATORS}

participants were done with the survey and had returned to the room and the researcher initiated the group conversation (see Appendix $\mathrm{N}$ for focus group guide).

This group of participants had a strong and negative reaction to the survey. One participant stated that "this whole survey is just meant to make us look screwed up and figure out how screwed up we are." Upon further questioning, participants explained that these feelings were generated by the measures of participants' stage of change and perpetration of abuse, both of which were pre-existing measures and were included in the current survey for later analysis outside the context of the current dissertation.

Participants explained that the scales' lack of a "not applicable" option communicated an assumption that all of the participants had perpetrated abuse in their current relationship. Participants felt that this assumption was not valid, and they did not know how to respond to these scales when the items were not applicable to them. The lack of a "not applicable" option and the assumption that it implied to participants also made them defensive. One participant explained that these scales made them feel that they were being put in a box. Participants suggested including a "not applicable" option and phrasing the items from these scales in the third person or using conditional tense, as opposed to the original first person.

The researcher asked specifically whether participants had the same negative reactions to the behavioral inventories that were being developed. The participants clarified that these items did not make them feel as guarded as the stage of change measure and the measure of abusive behavior. Participants felt that the items from the 


\section{SOCIAL NETWORKS OF INTIMATE PARTNER VIOLENCE PERPETRATORS}

behavioral inventories that were under development were realistic, though not all of them were applicable for all of the participants, or for participants' relationships with all of their network members. Participants did not offer any suggestions about modifications to specific items, or any new behaviors that would be relevant for either inventory.

Following the focus group, the researcher reviewed her own notes from the group, the co-moderator's notes, and notes that she made while listening to the audio recording of the focus group twice over to triangulate her impressions of the group. The researcher also compiled participants' responses to the inventories of participants' behaviors with their network members, and network members' behaviors with the participants. She also reviewed prior drafts of the inventories, to trace the evolution of the inventories, essentially conducting an inquiry audit to support the measures' dependability and confirmability (Lincoln \& Guba, 1985). Each item on the inventory of participants' own behaviors was endorsed by at least one participant, so all of these items were retained. All but one of the items on the inventory of network members' behaviors was also endorsed by at least one participant. The one item that was not endorsed ("Contact your partner to harass or monitor them") has face validity, and was introduced explicitly by participants in focus group of BIP providers, so all of the items on this inventory were also retained. The language of a number of items was simplified (i.e. "Confront this person if you saw them being insulting, grouchy, snapping, or ignoring their partner" was changed to "Call this person out if you saw them ignoring or being rude to their partner"). During the focus group, participants explained that the phrase "I never had the chance" was not always a 


\section{SOCIAL NETWORKS OF INTIMATE PARTNER VIOLENCE PERPETRATORS}

relevant replacement for "not applicable," so "I never had the chance" was replaced with "Not applicable." None of the participants indicated that they, or any of their network members, had engaged in any behavior over 20 times, so the response options were reduced from "I never had the chance," "0 times," "1 - 5 times," "6 - 10 times," "11 - 20 times" and "Over 20 times" to "0 times," "1 to 5 times," "6 - 10 times," "11 times or more," and "Not applicable." The survey was reformatted to appear less congested and overwhelming.

Upon consultation with the dissertation committee chair, the following statement was added to the instructions for the measure of participants' stage of change, in an attempt to reduce participants' reactivity to the measure: "The following statements assume that you are currently in a relationship where abuse has occurred in the past. If you are not currently in a relationship, or if you are not in a relationship where there has been abuse, respond to these statements imagining that you are still in your most recent relationship where there had been abuse". The researcher also used participants' reactions to the survey to draft the statement that was used to introduce the survey to subsequent groups of participants. The final version of the survey is located in Appendix O.

Survey data collection. On October $1^{\text {st }}, 2013$, the researcher attended an agencywide staff meeting at Allies in Change to explain the study and tentative survey administration procedures, and to share the schedule for survey administration, the consent forms that participants would be asked to complete, and example pages of the 


\section{SOCIAL NETWORKS OF INTIMATE PARTNER VIOLENCE PERPETRATORS}

survey. The researcher distributed copies of the schedule for survey administration and the dates on which each BIP group should begin hearing announcements about the upcoming research activities. Facilitators were instructed to begin making announcements about survey administration three weeks before the researcher was scheduled to attend the group, and every week thereafter until the researcher's visit. Facilitators were also asked to circulate a copy of the example page of the survey among the participants each week, so that they would have a sense of the reading level that would be required to complete the survey. Both of these measures were taken to allow participants enough advanced warning to avoid their group on the day of the survey administration if they would be uncomfortable being asked to complete the survey. Group facilitators were also asked to explain the following to participants, each time they announced the upcoming research activities: participants would receive an excused absence if they missed meeting during which the surveys would be administered; if they did not attend the group, they would not receive credit towards their court-mandated minimum number of sessions, but they would not be penalized for their absence; and participants would receive credit for having attended the group if they did come to Allies in Change for the survey administration, but declined to participate in the research activities. If participants did come to Allies in Change during the survey administration but decided not to participate, their facilitators would have "journals" for them to work on, program worksheets that are assigned as homework. The researcher fielded questions 


\section{SOCIAL NETWORKS OF INTIMATE PARTNER VIOLENCE PERPETRATORS}

about the study and procedure, and agreed to one facilitators' request to include participants' place of birth in the survey.

Between October $22^{\text {nd }}, 2013$ and November $21^{\text {st }}, 2013$, the researcher attended 22 regularly scheduled groups at Allies in Change's three locations. The only groups that the researcher did not visit were those that had previously participated in focus groups, or would participate in a focus group during the final stage of the study. The researcher and a female research assistant attended each group. In most, but not all of the groups that the researcher attended, the participants and group facilitators held check-ins, the usual opening to the group, before the researcher entered the group. At the facilitators' indication that they were ready to begin the survey, the researcher and a research assistant entered the room where the group was held. The researcher introduced herself and the research assistant, and explained that they were there to distribute a survey. They explained that they were interested in the people who were important to the group members and with whom they had spent the most time in the last three months, and how they communicated about abuse. The researcher elaborated that she was interested in the ways that these people might communicate their own attitudes about abuse to group members, and how group members might spread some of the information that they are learning at Allies in Change to the people in their communities. The researcher explained that the survey contains the same set of questions repeated eight times over, and that participants should complete a set of questions for each of the people with whom they spend the most time. The researcher clarified that it may make sense for some 


\section{SOCIAL NETWORKS OF INTIMATE PARTNER VIOLENCE PERPETRATORS}

participants to complete these questions eight times over, while others might only spend time with one or two people; participants were encouraged to fill out the questionnaire for as many network members as made sense for them. The researcher also pointed out that the last four pages of the survey were different than the first several, and that, even if participants skipped over several repetitions of the questions about their network members, they should take a look at the last few pages of their survey packet.

The researcher then told the participants that she would distribute packets to each of the group members in a moment, and that the packets would each contain the survey and two consent forms. The researcher explained that the consent form on the top of the packet asked participants for their willingness to complete the survey, and that this consent form was marked with a code that matched the code written on the top of their survey (see Appendix P). The second consent form asked participants to allow Allies in Change to share their attendance records, referral source, and, at some point in the future, their contact information, with the research team (see Appendix Q). The researcher presented the back of this consent form to the group, and pointed out that participants could allow each individual piece of information to be shared with the research team, or not, so they could pick and choose the specific administrative records that they would permit the organization to release. The researcher then explained how the codes that were written on the surveys and consent forms would be used: the researcher would compile a spreadsheet that listed participants' names (taken from their consent forms), the code from their surveys and consent forms, whether they had consented to complete the 


\section{SOCIAL NETWORKS OF INTIMATE PARTNER VIOLENCE PERPETRATORS}

survey, and which administrative records they permit Allies in Change to release. The researcher would send this spreadsheet to Allies in Change, and they would fill in participants' attendance and referral sources, if they had indicated that this information could be shared with the research team. Allies in Change would then delete the column of the spreadsheet that contained participants' names, and send the remaining information back to the research team. Thus, participants' names would never be matched to the contents of their surveys, and no one at Allies in Change would ever have access to their completed surveys. The researcher then noted that there was an extra copy of each consent form on the very bottom of the packet, which participants could keep for their own records.

After explaining the purpose of the survey and the purpose and content of the two consent forms, the researcher asked if anyone in the group had any questions. After answering participants' questions, the researcher distributed a clipboard, a survey packet, and a pen to each participant. Participants were welcomed to ask questions while they worked through the survey. In some cases, group members who wished not to participate completed journals. Others who declined to participate in the study left the room to sit in the waiting room, have a cigarette, or speak with a group facilitator in another room. At least one facilitator remained in the room while participants were completing the surveys, and always left at least one empty seat on either side of them, or sat between the researcher and an empty chair so that they would not be able to see any of the participants' survey responses. As participants completed the surveys, they returned their 


\section{SOCIAL NETWORKS OF INTIMATE PARTNER VIOLENCE PERPETRATORS}

survey, consent forms, clipboard, and pen to the researcher. Upon finishing the survey, participants returned to their seats to play with their cell phones, read the newspaper, work on a journal, or chat quietly with other participants or their facilitators, or left the room.

During each of the first two groups that the researcher attended, all but one of the participants completed and returned their surveys within forty minutes, while one participant in each group worked on the survey for an additional half hour to forty minutes and the rest of the group waited. In the remaining twenty groups, the researcher told the participants, upon distributing the surveys, that they would take about forty minutes to work on the surveys. The researcher told the group when they had spent twenty minutes, and then half an hour on the survey. The participants were able to pace themselves, and the researcher never had ask for participants to return their surveys before everyone in the group was done. Once all of the participants had returned their materials, she thanked them for their time and their willingness to participate, and let them know that she'd eventually share her findings with the staff at Allies in Change, who would be happy to pass along this information if they were interested. The researcher then left the room, and the facilitators began to engage the group in a conversation about their reactions to the survey.

Member checking and reporting. Following survey completion and quantitative data analysis, a fourth and final focus group was conducted. The intention of the focus group was to member-check the quantitative findings, to enhance the credibility of the 


\section{SOCIAL NETWORKS OF INTIMATE PARTNER VIOLENCE PERPETRATORS}

researcher's interpretations of the quantitative results (Lincoln \& Guba, 1985; Morgan, 1998).

The researcher and a research assistant co-moderator attended a regularly scheduled meeting of voluntary participants at Allies in Change on the evening of February $26^{\text {th }}, 2014$. The focus group consisted of 5 participants, all of whom were voluntarily enrolled at Allies in Change, as well as the two staff members who regularly facilitate this group. The facilitator indicated that this particular group of men had been meeting for over a year. For three consecutive weeks prior to the focus group, the group facilitator announced that the researcher would be attending the February $26^{\text {th }}$ group meeting to discuss her preliminary findings, and that those who wished not to participate would be excused from the group for the evening.

The researcher explained the purpose of the focus group and the history of the project before distributing informed consent documents to the participants (See Appendix $\mathrm{R}$ for consent form). Participants, including the group facilitators, who also intended to participate in the conversation, were asked to sign the document, indicating their willingness to participate in the focus group and their permission to be audio-recorded. Once the consent documents were signed and returned to the researcher, she turned on the audio-recorder and distributed a handout summarizing the quantitative findings (See Appendix S). The handout intentionally excluded research questions regarding criminally oriented groups, as Allies in Change does not regularly discuss these groups with participants. 


\section{SOCIAL NETWORKS OF INTIMATE PARTNER VIOLENCE PERPETRATORS}

The researcher began by explaining how the quantitative research was conducted, and then walked participants through the handout, explaining each finding (See Appendix $\mathrm{T}$ for the focus group script). The researcher encouraged participants to voice comments and questions as they went through the handout. She also explained her thoughts about what might have caused certain findings, and asked participants to talk about whether her conjectures resonated with their personal experiences. Both facilitators also shared relevant knowledge about the findings from their experiences working with many participants at Allies in Change. One of the facilitators elaborated upon many of the researcher's questions, posing them in different ways to solicit more detailed responses from the group. The facilitator also probed participants to elaborate on their responses, and occasionally asked specific group members to reflect on relevant experiences that they had discussed in the group on prior occasions. The group members were very articulate, and forthcoming with their interpretations of the data and illustrative personal experiences. The group facilitator's presence and facilitation throughout the group contributed greatly to the depth of participants' responses: the facilitator was able to refer to relevant aspects of participants' histories and ask them to consider the researcher's questions in the context of specific situations that they had previously discussed.

As in the analysis of the three prior focus groups, the researcher listened to the recording of the focus group twice through, making notes on the recording. She reviewed these notes, the notes she made during and immediately following the focus group, and the co-moderator's notes on the focus group, to triangulate her perceptions of the group. 


\section{SOCIAL NETWORKS OF INTIMATE PARTNER VIOLENCE PERPETRATORS}

Synthesizing these three sources, the researcher organized the contents of the focus group into a set of themes that speak to the study's quantitative findings and the theoretical constructs that contributed to the foundation for the current study (See Appendix U). Relevant themes are discussed in conjunction with the quantitative findings in the Discussion section of the present document.

Measures

All of the measures described below are included in the final version of the survey instrument, located in Appendix O. In addition to the measures described, two additional measures were also included at the end of the survey instrument just prior to participants' demographic information: one of participants' stages of change regarding their perpetration of abuse, and one regarding their actual perpetration of abuse in the prior year. These measures are not analyzed in the current dissertation.

Network members. Participants were asked to nominate the individuals with whom they spent the most time in the last three months, and indicate how frequently they interact with them (less than once a year, about once a year, a few times a year, about every month, twice - three times a month, about once a week, almost every day, more than once a day). Surveys included spaces for listing up to eight network members, but participants were given the instruction to only list as many network members as they spend time with on a regular basis. Participants recorded each network members' gender, and were provided space to write in their relational tie to each network member, as per 


\section{SOCIAL NETWORKS OF INTIMATE PARTNER VIOLENCE PERPETRATORS}

the following prompt: "What is your relationship to this person? (for example, are they your parent? Your boss or coworker? A friend from high school?).” Clifford and Longabaugh's (1991) Important People and Activities inventory was considered in the development of this measure.

Network members' IPV-relevant behaviors. The items that were used to assess each network member's communication about IPV were generated during the focus groups with BIP facilitators and participants conducted at the beginning of the study. An unexpected finding from the focus groups was that participants' network members expressed both support for IPV, as well as support for increased accountability and nonabusive attitudes and behaviors. Behaviors that can be interpreted as pro-abuse as well as behaviors that are interpreted as pro-accountability or anti-abuse were both included in the inventory, for two reasons: (1) the three initial focus groups revealed that participants do experience support for accountability from their network members. Examining only behaviors that convey pro-abuse attitudes would result in an incomplete picture of participants' network members' IPV-relevant behavior. (2) The reactions of BIP participants who pilot tested the survey indicated that participants were sensitive to implications or perceived assumptions about their character. The inclusion of items that tap into network members' anti-abuse attitudes was intended to both reduce participants' negative reactivity to the survey, and to acknowledge that participants may have friends and family members who are pro-social influences. 


\section{SOCIAL NETWORKS OF INTIMATE PARTNER VIOLENCE PERPETRATORS}

Items were intended to represent discrete behaviors that convey support for either IPV or avoiding the perpetration of abuse. The inventory consists of a total of 16 items: 10 behaviors that indicate support for abuse or forms of provocation towards perpetrating abuse, 4 behaviors that convey anti-abuse attitudes, one item with an ambiguous interpretation ("told you ways to avoid the consequences of abuse"), and one open-ended item, which invited participants to fill in any other behaviors that their network members engaged in that made them think about abuse. Examples of behaviors that represent support for abuse or provocation towards abuse are having "been abusive to their partner in front of you" or having "accused your current/former partner of trying to harm your relationship with your kids.” An example of a behavior that represents an anti-abuse attitude or support for accountability is "did or said something that supported your participation at Allies in Change."

Participants indicated, on a Likert-type scale the approximate number of occasions on which each network member engaged in each behavior during the prior three months: 0 times, $1-5$ times, $6-10$ times, 11 times or more, or not applicable. Studies in the area of substance abuse often use retrospective reports of up to 90 days prior to the survey (e.g. Mohr et al., 2001), such that participants should have been able to report on interactions with network members occurring in the three months prior to measurement with little trouble.

Relationship quality. Relationship quality was measured using a subscale of the McGill Friendship Questionnaire - Respondent's Affection (MFQ-RA; Mendelson \& 


\section{SOCIAL NETWORKS OF INTIMATE PARTNER VIOLENCE PERPETRATORS}

Aboud, 1999) measure. The original measure consists of 16 items that assess respondents' positive feelings towards important others and satisfaction with their relationships. The current study utilizes the seven items of the "Satisfaction" subscale, which assesses participants' satisfaction with their relationship with a specific other person. Original items are phrased in terms of "my friendship with." As participants in the current study were expected to nominate partners, family members and coworkers, in addition to friends, items were rephrased in terms of "my relationship with." Participants were asked to rate their agreement with each statement on a nine-point scale, ranging from -4 to 4 , with higher values representing greater agreement with the positively-worded statements. Example items include "I like this person a lot" and "I hope that this person will stay in my life." Mendelson and Aboud (1999) validated the scale using a sample of 227 junior-college students (118 women and 109 men), ranging in age from 16 to 21 years. Asking participants to complete the measure in reference to their best friend, the satisfaction subscale had a coefficient alpha of .96, a range from -2.6 to 4 , a mean of 3.1 , and a standard deviation of 1.2. Additionally, the subscale significantly covaried with the length of the best friendship about which participants were reporting, and were more highly correlated with a measure of participants' self esteem with regard to close friendships than any other aspects of self esteem that were assessed (Mendelson \& Aboud, 1999). The 7-item measure was reliable in the current sample, ( $\alpha$ $=.975)$. 


\section{SOCIAL NETWORKS OF INTIMATE PARTNER VIOLENCE PERPETRATORS}

Participants' IPV-relevant behaviors. The focus groups with BIP facilitators and participants conducted at the start of the study generated a list of ways that BIP participants communicate with their network members about IPV, either in direct conversation or through less direct actions that may still contribute to their networks' social norms. Examples include having "stuck up for this person's partner if they were talking badly about them," having "called this person out if you saw them ignoring or being rude to their partner" and having "shared your story about abuse with this person." The measure includes a total of 16 items, 15 of which are discrete behaviors, and one of which is open ended and asks participants to specify any other behaviors that they may have engaged in that might have made their network member think about abuse. Participants indicated, on a Likert-type scale, the approximate number of occasions on which they engaged in each of these behaviors with each of their network members during the prior month: 0 times, $1-5$ times, $6-10$ times, 11 times or more, or not applicable.

Potential moderating variables. Allies in Change provided information regarding the number of weeks that each participant has attended the program. Seventy participants allowed Allies in Change to share their official attendance records. Those 70 participants had attended an average of 23.76 group meetings $(\min =0, \max =87, s d=18.91)$, as per Allies in Change's official records. Participants were also asked to indicate the number of weeks that they had been attending the Allies in Change BIP on the surveys that they completed, such that approximate information regarding participants' attendance would 


\section{SOCIAL NETWORKS OF INTIMATE PARTNER VIOLENCE PERPETRATORS}

be available even if they failed to provide identifying information that would allow their survey responses to be matched with Allies in Changes' official attendance records. Ninety participants indicated the number of groups that they had at Allies in Change. According to their self reports, these 90 participants had attended an average of 25.14 groups $(\min =1, \max =225, s d=27.16)$.

The surveys that were collected in each BIP group were kept separate from each other, and the date, the day of the week, and time of the group meeting from which they were collected was recorded. Allies in Change administration provided information about which of their regularly scheduled groups consisted of men who they identified as criminally oriented or necessitating a different curriculum, so that surveys from those groups were identified as such. Of the 22 groups that the research team visited, 4 groups served criminally oriented participants. Across the 4 groups for men who Allies in Change has designated as criminally oriented, a total of 17 participants completed surveys. Ninety participants from the other 18 groups completed surveys.

Additional descriptive information. For the purposes of describing the sample, participants were asked to indicate their age in years. They were also asked whether they currently have a romantic partner, and if so, how often they have contact with their partner (daily, weekly, monthly, or never). Participants were also asked to indicate whether their current/former partner has a no-contact order against them. Participants also indicated the racial/ethnic grouping(s) with which they identify: Asian/Asian American, Black/African American, Latino/Hispanic, Middle Eastern, Native American/First 


\section{SOCIAL NETWORKS OF INTIMATE PARTNER VIOLENCE PERPETRATORS}

Nation, White. Participants were also asked write in the languages that they speak and their place of birth. Surveys also asked participants to report the source of their referral to the program: a judge, their partner, parole or probation, children's services, or other. Participants were also asked to indicate their income (under $\$ 10,000 ; \$ 10,000$ - \$25,000; $\$ 25,000$ - $\$ 50,000 ; \$ 50,000$ - $\$ 75,000$; over $\$ 75,000)$, level of education (less than high school; high school education/GED; some college/Associates degree/Technical degree; Bachelors' degree; Professional degree or higher), religious affiliation (Atheism, Buddhism; Christianity - Catholic; Christianity - Orthodox; Christianity- Protestant; Christianity - Other; Hinduism; Judaism; Islam; Sikh; Nonreligious), and their relational ties to those that they live with, if they do not live alone (family of origin; extended family; partner only; partner and biological children; partner and partner's children from a different relationship; non-family roommates - friends; non-family roommates unknown before living together; non-family roommates - group home; lives alone).

\section{Survey Participants}

One hundred and seven male participants at the Allies in Change Counseling Center completed surveys. These 107 participants represent an $86.29 \%$ overall response rate: between the 22 Allies in Change groups that the researcher surveyed, a total of 124 men were given the opportunity to participate in the study. An average of 5.64 men were present in each group $(\min =3.00, \max =10.00, S D=1.99)$, and an average of 4.86 surveys were completed in each group $(\min =2.00, \max =9.00, S D=1.78)$. These 


\section{SOCIAL NETWORKS OF INTIMATE PARTNER VIOLENCE PERPETRATORS}

figures are a deviation from the number of participants that was originally expected. As of October 7, 2013, a total of 222 participants were enrolled in the 22 Allies in Change groups that were surveyed $(M$ group size $=10.57, \min =4.00, \max =20.00, S D=3.46$ ). The low attendance on survey administration days may be a result of group facilitators' three weekly warnings about the upcoming research activities. Participants who knew in advance that they did not want to participate in the research may have intentionally avoided Allies in Change on the day that the survey was administered to their group. However, conversation with group facilitators at Allies in Change revealed that participants' inability to pay the weekly program fee negatively impacts their attendance. Despite the program's sliding fee and some participants' subsidies from the Department of Human Services, insurance agencies, and other social services, many men who are enrolled at Allies in Change find the cost prohibitive of consistent attendance. While many of the men who are enrolled at Allies in Change are court mandated to attend the program, they are subject to "financial leave," or a sustained period of absence from the program, if they can prove that they are financially unable to attend. Facilitators indicated, in conversation with the researcher, that group attendance is generally much lower than group enrollment as a result of participants' financial situations, and that group attendance was often not much different than usual during the researcher's visits. Thus, participants' absence from Allies in Change on the days of survey administration may have been unrelated to the research activities. 


\section{SOCIAL NETWORKS OF INTIMATE PARTNER VIOLENCE PERPETRATORS}

Participants had an average self-reported age of $36.71(n=91, \min =20, \max =$ $65, S D=10.18)$. A total of 90 participants also self-reported their racial/ethnic identity, the number and percentage of participants who indicated each racial/ethnic identity provided on the survey are listed in table 1 , below.

Table 1

\begin{tabular}{lrr} 
Participants' Racial/Ethnic Identity & \\
\hline Racial/Ethnic Identity & $\underline{\mathrm{N}}$ & $\underline{\text { Percent }}$ \\
\hline White & 60 & 56.07 \\
Multiple Ethnic Identities & 12 & 11.21 \\
African American/Black & 10 & 9.35 \\
Latino/Hispanic & 6 & 5.61 \\
Native American/First Nation & 1 & 0.93 \\
Pacific Islander & 1 & 0.93 \\
& 90 & 84.11 \\
Did Not Indicate Racial/Ethnic ID & 17 & 15.89 \\
Total & 107 & 100.00 \\
\hline
\end{tabular}

Eighty-seven participants also reported the source of their referrals to Allies in Change. Of these 87 participants, 67 reported referral sources that may have mandated them to attend the program (parole and probation, judges, Children's Services, or combinations of sources). Participants' self-reported referral sources to Allies in Change are listed in table 2 below. 


\section{SOCIAL NETWORKS OF INTIMATE PARTNER VIOLENCE PERPETRATORS}

Table 2

Participants' Referral Source to Allies in Change

\begin{tabular}{lrr}
\hline Referral Source & $\underline{N}$ & $\underline{\text { Percent }}$ \\
Parole or Probation & 33 & 30.84 \\
A judge & 26 & 24.30 \\
Children's Services & 4 & 3.74 \\
A judge and Parole or Probation & 4 & 3.74 \\
Partner & 3 & 2.80 \\
Other Referral Source & 17 & 15.89 \\
& 87 & 81.30 \\
Did Not Indicate Referral Source & 20 & 18.69 \\
Total & 107 & 100.00 \\
\hline
\end{tabular}

Seventy-eight participants reported their annual income. The modal income bracket reported was $\$ 25,000$ - $\$ 50,000$ per year, with 18 participants reporting incomes in this range. The number and percent of participants indicating that their annual income falls within each bracket are presented in table 3, below.

Table 3

Participants'Self-Reported Income

\begin{tabular}{lrr}
\hline Income Bracket & $\underline{\mathrm{N}}$ & $\frac{\text { Percent }}{14.02}$ \\
Under $\$ 10,000$ & 15 & 15.89 \\
$\$ 10,000-\$ 25,000$ & 17 & 16.82 \\
$\$ 25,000-\$ 50,000$ & 18 & 14.02 \\
$\$ 50,000-\$ 75,000$ & 15 & 3.74 \\
$\$ 75,000-\$ 100,000$ & 4 & 8.41 \\
Over $\$ 100,000 \quad$ Total & 9 & 72.90 \\
& 78 & 27.10 \\
Did Not Indicate Income & 29 & 100.00 \\
Total & 107 & \\
\hline
\end{tabular}




\section{SOCIAL NETWORKS OF INTIMATE PARTNER VIOLENCE PERPETRATORS}

Participants were also asked to indicate the highest level of education that they had received. Of the 77 participants who reported on their educational attainment, 60 had completed education up to and including an associate's degree or a technical degree, while 17 participants reported having earned a bachelor's degree, a professional degree, or higher. See table 4 below.

Table 4

Participants' Highest Level of Education Completed

\begin{tabular}{lrrr}
\hline Highest level of education completed & & $\mathrm{N}$ & Percent \\
\cline { 2 - 3 } Less than high school & 3 & 2.80 \\
High school education/GED & 22 & 20.56 \\
$\begin{array}{l}\text { Some college/Associate's } \\
\text { degree/Technical degree }\end{array}$ & 35 & 32.71 \\
Bachelor's degree & 10 & 9.35 \\
Professional degree or higher & 7 & 6.54 \\
& 77 & 71.96 \\
Did not indicate highest level of & 30 & 28.04 \\
education completed & 107 & 100.00 \\
Total & & \\
\hline
\end{tabular}

Of the participants who reported their religious affiliation $(n=91)$, over half $(n=$ 49) reported that they are affiliated with some form of Christianity. Twelve participants indicated that they identify with a religious group other than those listed. Examples of “other" religious affiliations include spiritual, Eckankar, Mongolian shamanism, and New Age. See table 5, below, for the numbers and percent of participants who indicated that they subscribe to each religious affiliation listed on the survey. Additional options for 


\section{SOCIAL NETWORKS OF INTIMATE PARTNER VIOLENCE PERPETRATORS}

religious affiliation, which were listed on the survey but which were not indicated by any participants, included Hinduism, Judaism, Islam, and Sikh.

Table 5

Participants' Self-Reported Religious Affiliation

\begin{tabular}{|c|c|c|}
\hline Religious Affiliation & $\underline{\mathrm{N}}$ & Percent \\
\hline Atheism & $\overline{5}$ & 4.67 \\
\hline Agnostic & 3 & 2.80 \\
\hline Buddhism & 3 & 2.80 \\
\hline Christianity - Catholic & 12 & 11.21 \\
\hline Christianity - Orthodox & 4 & 3.74 \\
\hline Christianity - Protestant & 5 & 4.67 \\
\hline Christianity - Other & 28 & 26.17 \\
\hline Native Traditionalism & 1 & 0.93 \\
\hline Nonreligious & 12 & 11.21 \\
\hline Other religion & 12 & 11.21 \\
\hline Multiple religious affiliations & 6 & 5.61 \\
\hline Total & 91 & 85.05 \\
\hline Did not indicate religious affiliation & 16 & 14.95 \\
\hline Total & 107 & 100.00 \\
\hline
\end{tabular}

Twenty participants reported that they live by themselves, while 74 indicated that they live with other people (13 participants did not indicate whether or not they live with others). Of those participants who live with others, the modal response option was their family of origin $(n=18)$. Nineteen participants indicated that they live with their partners, whether they live with just their partners, their partners and the partners' children from a current relationship, or their partners and their own children. Fourteen participants lived with a combination of others from the list provided (i.e., their partner and their in-laws). See table 6, below. 


\section{SOCIAL NETWORKS OF INTIMATE PARTNER VIOLENCE PERPETRATORS}

Table 6

Participants' relational ties to the people that they live with

\begin{tabular}{lrr}
\hline Relational ties that participants live with & N & Percent \\
Alone & 20 & 18.69 \\
Family of origin & 18 & 16.82 \\
Extended family & 2 & 1.87 \\
Partner, only & 5 & 4.67 \\
Partner, partner's children from another relationship & 2 & 1.87 \\
Partner, own children & 12 & 11.21 \\
Children, only & 4 & 3.74 \\
Group home or halfway house & 2 & 1.87 \\
Non-family roommates they knew prior to cohabitating & 12 & 11.21 \\
Non-family roommates they did not know prior to & 3 & 2.8 \\
cohabitating & 14 & 13.08 \\
Lives with others from multiple categories & 94 & 87.85 \\
& 13 & 12.15 \\
Did not indicate whether they live with others & 107 & 100.00 \\
Total & Total &
\end{tabular}

Fifty-seven participants indicated that they were in a romantic relationship at the time that they completed the survey. Forty-four participants indicated that they had daily contact with their partner, and 8 had contact with their partner approximately weekly, and five indicated that they "never" had contact with their partner. A total of 29 participants indicated that their partners had no-contact orders against them at the time of survey administration, including nine of the 57 participants who indicated that they were currently in romantic relationships. Of the 57 participants who were in romantic relationships when they completed the survey, 38 nominated their romantic partner among their social network members, including three participants whose romantic partners currently had no-contact orders against them. It should be noted, however, that participants may have no-contact orders from prior relationships: the romantic partners 


\section{SOCIAL NETWORKS OF INTIMATE PARTNER VIOLENCE PERPETRATORS}

that participants listed among their social network members may not be the same individuals who have taken out no-contact orders against them. No-contact orders may be concentrated among BIP participants with lower attendance: no-contact orders taken out against participants prior to their enrollment at Allies in Change may expire over the course of their program participation, and current participants are ideally less likely to accrue no-contact orders than men who are yet to begin the program.

\section{Survey Findings}

Data Preparation and Screening

All of the survey data were entered into SPSS twice: once by the researcher and once by one of three research assistants. The two complete datasets were compared using the SPSS “compare datasets" procedure to identify discrepancies. All discrepancies between the two datasets were resolved by re-consulting the hard copies of the surveys and conferring with the researcher who had entered the data. Frequencies and descriptive statistics were examined for each variable in the data set to check for data entry errors and identify any variables that may have been improperly re-coded. Additionally, throughout the data entry process, surveys were flagged for exclusion from hypothesis testing, on the basis of response patterns that indicated a potential lack of validity. Five surveys were identified for exclusion from the following analyses: one participant nominated "myself" as 5 network members, and 4 participants appear to have been considering multiple individuals in responding to items intended to reflect a single 


\section{SOCIAL NETWORKS OF INTIMATE PARTNER VIOLENCE PERPETRATORS}

network member. Thus, the following analyses are based on a sample size of 102 participants, who together, nominated a total of 360 network members.

As participants' relational ties to each of their social network members were asked in an open-ended format, participants' responses were coded prior to analysis. The frequencies of each variable in which participants indicated their relationships to their network members were examined. Participants nominated friends, best friends, coworkers, bosses, roommates/landlords, mothers, fathers, daughters/stepdaughters/nieces, sons, brothers, sisters, partners, former partners, mothers-in-law, fathers-in-law, sisters-in-law, brothers-in-law, and a small handful of other relational ties. These more specific categories were collapsed into seven broader categories of relational ties: friends/roommates, bosses/coworkers, family of origin, children, in laws, partners/former partners, and other relational ties.

\section{Research Question One}

$R Q$ 1.a. The aim of the first research question was to explore the characteristics of BIP participants' social networks, in terms the number of social network members that they nominated, the genders of participants' reported network members, and the relational ties that connect participants to their network members. The 102 participants nominated a total of 360 network members. The number of network members that BIP participants reported was determined by taking an average, across participants, of the number of network members nominated. Participants nominated an average of 3.53 


\section{SOCIAL NETWORKS OF INTIMATE PARTNER VIOLENCE PERPETRATORS}

network members $(\min =0.00, \max =8.00, S D=2.27)$. The distribution of the number of network members nominated is depicted in Figure 3, below.

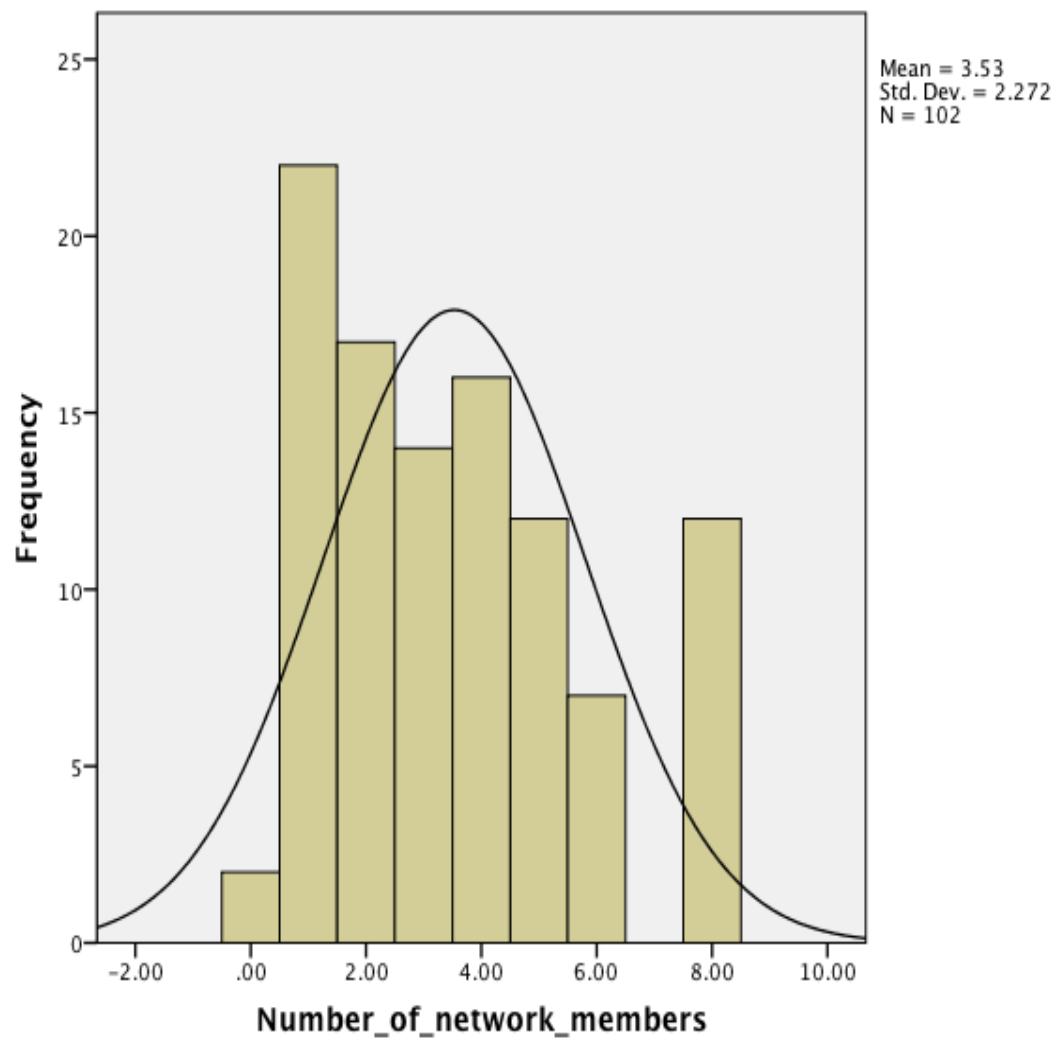

Figure 3. Distribution of number of network members nominated. This figure illustrates the frequency of the total number of network members nominated by participants.

$R Q$ 1.b. Participants nominated approximately equal numbers of male and female network members. The average number of male and female network members nominated by each participant was calculated: the 102 participants nominated a total of 180 male network members and 177 female network members (three network members' genders were not specified), resulting in an average of 1.77 male network members ( $\min =0, .00$ $\max =6.00, S D=1.46)$ and 1.74 female network members $(\min =0, \max =5, S D=1.29)$ 


\section{SOCIAL NETWORKS OF INTIMATE PARTNER VIOLENCE PERPETRATORS}

each. A matched-pairs t-test was used to explore whether there were gender differences among the network members who were nominated: there were was not, $t(101)=.189, p=$ .850 .

$R Q$ 1.c. The average number of times that each type of relational tie connecting a participant to a network member was calculated, across network members. The frequency with which relational ties were nominated ranges from .09 ("other" relational ties, $S D=$ .32 ) to .98 (friends/roommates, $S D=1.27$ ), with participants nominating over eight times as many friends/roommates as in-laws $(M=.12, S D=.41)$ The minimum, maximum, mean, and standard deviations of the number of each relational tie nominated by participants are displayed in table 7 below, as is the total number of relational ties nominated, summing across all 102 participants. Participants did not indicate their relational ties to a total of 31 network members.

Table 7

Participants' relational ties to their social network members

\begin{tabular}{|c|c|c|c|c|c|}
\hline$\frac{\text { Relational ties to social }}{\text { network members }}$ & $\begin{array}{l}\text { Total N, summing } \\
\text { across participants }\end{array}$ & $\underline{M}$ & $\underline{S D}$ & $\underline{\text { Min }}$ & $\underline{\operatorname{Max}}$ \\
\hline Friends/roommates & 100 & .98 & 1.27 & .00 & 6.00 \\
\hline Bosses/Coworkers & 41 & .40 & .76 & .00 & 4.00 \\
\hline Family of origin & 83 & .81 & 1.01 & .00 & 5.00 \\
\hline Children & 32 & .31 & .68 & .00 & 4.00 \\
\hline In-laws & 12 & .12 & .41 & .00 & 2.00 \\
\hline Partners/former partners & 52 & .51 & .64 & .00 & 4.00 \\
\hline Other relational ties & 9 & .09 & .32 & .00 & 2.00 \\
\hline Total & 329 & & & & \\
\hline
\end{tabular}

Note. The 329 network members were nominated by 102 participants. 


\section{SOCIAL NETWORKS OF INTIMATE PARTNER VIOLENCE PERPETRATORS}

Further description of participants' social networks. Participants had contact with the majority of their network members at least daily. Most participants nominated a current/former partner, regardless of the number of network members that they nominated, and no participants indicating fewer than four social network members listed an in-law among the members of their networks; the larger participants' networks, the more diverse their relational ties to their network members. The average numbers of network members with whom participants have contact (1) almost once a day or more than daily, (2) between twice per month and almost once a week (3) approximately monthly, and (4) a few times a year or less were calculated. For each participant, the number of network members with whom they have contact approximately daily, weekly,

monthly, and annually, as per the categories specified above, was divided by the total number of network members that they nominated, to establish the percent of each participants' network members with whom they have contact at each interval. These percentages were averaged across the 102 participants. Participants nominated an average of 1.86 network members with whom they have contact almost daily or more than once a day $(\min =0.00, \max =6.00, S D=1.34)$, representing an average of $62.5 \%$ of their network members. On average, participants had contact with 1.16 network members, or $25.8 \%$ of their social network members, between twice per month and weekly $(\mathrm{min}=$ $0.00, \max =7.00, S D=1.51)$. Participants had contact with an average of .23 network members approximately monthly $(\min =0.00, \max =4.00, S D=.64$ ); participants had approximately monthly contact with a mean of $4.6 \%$ of their social network. On average, 


\section{SOCIAL NETWORKS OF INTIMATE PARTNER VIOLENCE PERPETRATORS}

the 102 participants had contact with .11 network members, or $2.3 \%$ of their social network, a few times a year or less $(\min =0.00, \max =2.00, S D=0.37)$. Looking across participants, $87.3 \%$ indicated that they had contact with at least one network member almost daily or more than once a day, $52.0 \%$ of participants indicated having contact with at least one network member between twice per month and weekly, $14.7 \%$ nominated at least one network member with whom they had contact approximately monthly, and $8.8 \%$ of participants nominated at least one network member with whom they had contact only annually. Among participants who nominated one through eight network members, the percent of participants who nominated a network member with whom they had each type of relational tie was calculated. These results are presented in table 8 below. 


\section{SOCIAL NETWORKS OF INTIMATE PARTNER VIOLENCE PERPETRATORS}

Table 8.

Percent of relational ties nominated by participants nominating 1 thru 8 network

members

\begin{tabular}{|c|c|c|c|c|c|c|c|c|}
\hline \multirow[b]{2}{*}{$\begin{array}{l}\frac{\text { Number of }}{\text { network }} \\
\underline{\text { members }} \\
\underline{\text { nominated }}\end{array}$} & \multicolumn{8}{|c|}{$\frac{\text { Percent of participants who nominated at least one of the }}{\text { following relational ties }}$} \\
\hline & $\underline{\mathrm{N}}$ & $\frac{\text { Friends/ }}{\text { roommates }}$ & $\begin{array}{l}\text { Bosses/ } \\
\text { coworkers }\end{array}$ & $\begin{array}{l}\frac{\text { Family }}{\text { of }} \\
\underline{\text { origin }}\end{array}$ & $\underline{\text { Children }}$ & $\underline{\underline{\text { In- }}} \underline{\underline{\text { laws }}}$ & $\frac{\text { Partners/ }}{\underline{\text { former }}}$ & $\begin{array}{l}\frac{\text { Other }}{\text { relational }} \\
\underline{\text { ties }}\end{array}$ \\
\hline 0 & 2 & 0 & 0 & 0 & 0 & 0 & 0 & 0 \\
\hline 1 & 22 & 27.3 & 4.5 & 18.2 & 9.1 & 0 & 36.4 & 4.5 \\
\hline 2 & 17 & 47.1 & 1.0 & 47.1 & 5.9 & 0 & 52.9 & 5.9 \\
\hline 3 & 14 & 35.7 & 50.0 & 57.1 & 28.6 & 0 & 50.0 & 7.1 \\
\hline 4 & 16 & 75.0 & 31.3 & 50.0 & 31.3 & 12.5 & 56.3 & 6.3 \\
\hline 5 & 12 & 58.3 & 41.7 & 75.0 & 33.3 & 16.7 & 16.7 & 8.3 \\
\hline 6 & 7 & 57.1 & 57.1 & 85.7 & 71.4 & 28.6 & 71.4 & 0 \\
\hline 7 & 0 & . & • & & . & • & . & . \\
\hline 8 & 12 & 75.0 & 41.7 & 75.0 & 25.0 & 25.0 & 58.3 & 25.0 \\
\hline Average & & 46.9 & 28.4 & 51.0 & 25.6 & 10.4 & 42.8 & 7.2 \\
\hline
\end{tabular}

Note. $N=102$ participants, nominating a total of 329 network members.

\section{Research Question Two}

$R Q$ 2.a. The average quality of participants' relationships with their network

members was assessed. An intercepts-only model was tested to account for the nesting of the 359 network members within the 100 participants who nominated them (the measure of relationship quality was not completed for one of the 360 network members, and two of the 102 participants did not nominate any network members). The grand mean score on the McGill Friendship Quality - Respondents' Affection (MFQ-RA) scale was 2.43 


\section{SOCIAL NETWORKS OF INTIMATE PARTNER VIOLENCE PERPETRATORS}

$(S E=.12)$. Individual network members received MFQ-RA scores ranging from -4.00 to 4.00, and group (participant) mean MFQ-RA scores ranged from -1.29 to 4.00. The value of 2.43 falls between the ordinal response options of "somewhat agree" and "very much agree." All of the items on the scale were positively phrased, such that this value represents moderate affection for the nominated network members. The intraclass correlation for network members' scores on the MFQ-RA was .20, indicating that approximately $20 \%$ of the variation in network members' MFQ-RA scores are due to the participant who nominated them. This between-participant variance was significant, intercept variance $=0.584$, Wald $\mathrm{Z}=3.254, p<.001$.

$R Q 2 . b$. The average qualities of participants' relationships with their male and female network members were also calculated. Three network members' genders were not specified, and the MFQ-RA was left blank for an additional network member, so 356 network members were used in the current analysis. One multilevel model was tested, in which the 356 network members were nested within the participants who had nominated them. Network members' gender was used to predict the scores that they had received on the MFQ-RA. The grand mean score for male network members was $2.54(S E=.14)$, and the grand mean score for female network members was $2.32(S E=.14)$. The 0.23 -point difference in the satisfaction scores for male and female network members was not statistically significant, $\beta=0.23, t(321.434)=1.353, p=.177$. Both of these averages again fall between the response options of "somewhat agree" and "very much agree" on the positively phrased scale. The variance in participants' satisfaction with their network 


\section{SOCIAL NETWORKS OF INTIMATE PARTNER VIOLENCE PERPETRATORS}

members remained significant after accounting for their network members' genders, intercept variance $=0.591$, Wald $\mathrm{Z}=3.245, p<.001$.

$R Q$ 2.c. To determine the quality of participants' relationships with network members to whom they have various relational ties, an additional multilevel model was tested. The 359 network members with scores on the MFQ-RA were again nested within 100 participants. Network members' relational ties to participants were used to predict their scores on the MFQ-RA. Participants rated their friends/roommates most highly on the MFQ-RA, $(M=2.82, S E=.17)$, followed by members of their families of origin $(M=2.53, S E=.19)$, "other" relational ties $(M=2.48, S E=.56)$, and their children $(M=2.46, S E=.30)$. Participants' bosses/coworkers had an average MFQ-RA score of $2.06(S E=.26)$. Participants assigned the lowest scores on the MFQ-RA to their partners/former partners $(M=1.82, S E=.24)$ and their in-laws $(M=1.75, S E=.49)$. All of these average scores are positive values, on a scale that ranges from -4 to 4 , indicating that participants generally feel more positively than negatively towards the members of their social networks, regardless of their relationships to their social network members. Including network members' relationships to the participant in the model, the between-participant variance in their satisfaction with their network members was reduced, though still significant, intercept variance $=0.491$, Wald $\mathrm{Z}=2.677, p=.004$.

Using the least significant difference to assess pairwise comparisons, participants rated their friends/roommates significantly higher on the MFQ-RA than their bosses/coworkers $(p=.016)$, their in laws $(p=.039)$, and their partners/former partners 


\section{SOCIAL NETWORKS OF INTIMATE PARTNER VIOLENCE PERPETRATORS}

$(p=.001)$. Participants also scored members of their families of origin significantly higher than their partners/former partners $(p=.019)$. Each relational tie's means and standard errors on the MFQ-RA are listed in table 9 below.

Table 9.

Average MFQ-RA scores of network members with various relational ties to participants

\begin{tabular}{|c|c|c|c|}
\hline Network members' relational tie & $\underline{\mathrm{N}}$ & $\underline{M}$ & $\underline{S E}$ \\
\hline Friend/Roommate & 100 & $2 . \overline{82}$ & .17 \\
\hline Boss/Coworker & 41 & 2.06 & .26 \\
\hline Family of origin & 83 & 2.58 & .19 \\
\hline Child & 32 & 2.46 & .30 \\
\hline In- law & 12 & 1.75 & .49 \\
\hline Partner/ former partner & 52 & 1.82 & .24 \\
\hline Other & 9 & 2.48 & .56 \\
\hline
\end{tabular}

Note. The 359 network members were nominated by 100 participants.

Research Question 3

$R Q$ 3.a. The number of times that social network members used each abuserelevant behavior during the three months prior to data collection was examined. Participants' responses for each behavior ( 0 times, $1-5$ times, $6-10$ times, 11 times or more, or not applicable) were recoded to $0,2.5,8,12$, or missing, accordingly. This method of recoding original responses using the midpoint of each response option is also used in the scoring of the Conflict Tactics Scale (Straus, Hamby, Boney-McCoy \& Sugarman, 1996), a measure commonly used to assess BIP participants' perpetration of IPV. Only network members with whom participants were in contact at least several 


\section{SOCIAL NETWORKS OF INTIMATE PARTNER VIOLENCE PERPETRATORS}

times a year were used in the following analyses; this resulted in the removal of one additional participant from the analysis: the following analyses are based on a sample of 99 participants.

Due to the positive skew of the outcome data (mean skewness statistic across the 16 behaviors $=2.86$ ); multiple outliers on each behavior in the inventory; significant differences in the variances associated with each behavior; the inability to produce results for Box's test of equality of covariance matrices or Mauchly's test of sphericity; and missing data from all but 58 inventories of network members' behaviors, several approaches were used to determine the significance of the differences in the frequencies of network members' use of the behaviors. Convergence in the findings of these approaches is meant to confirm the reliability of the pattern of results, despite violations

of the statistical assumptions on which the approaches are based. The omnibus results of each of the four approaches are summarized below, followed by a description of the follow-up pair-wise comparisons between behaviors that appeared significant across all four approaches.

The first approach that was used to determine differences in the number of times that network members use each of the 16 behaviors from the inventory during the prior three months was a mixed-modeling approach. While this approach does rely on the assumption of normality of outcome data (which is violated in the current analysis), this approach does not necessitate equal numbers of observations per higher-level unit (Tabachnick \& Fidell, 2007), meaning that the 73 participants who did not provide 


\section{SOCIAL NETWORKS OF INTIMATE PARTNER VIOLENCE PERPETRATORS}

complete data for each of the network members that they nominated were included in the analysis. Additionally, sphericity is not assumed (Tabachnick \& Fidell, 2007). A threelevel mixed model was tested, wherein behaviors from the inventory were nested within network members, who were considered nested within the participant who nominated them. The 99 participants nominated 343 network members with whom they had contact at least several times a year. Across these 343 network members, participants provided data on a total of 4,945 behaviors from the inventory of network members' behaviors. The ICC for behaviors' nesting within network members was .13 [Var(intercepts) $=$ 1.068, Wald $\mathrm{Z}=6.314, p<.001]$, and the ICC corresponding to behaviors' nesting within participants was $.21[\operatorname{Var}($ intercepts $)=1.917, \mathrm{Wald} \mathrm{Z}=4.645, p<.001]$, indicating that a total of $34 \%$ of the variance in use of the behaviors was the result of the nesting structure of the data. Results indicated that the use of behaviors did vary significantly across the 16 discrete types of behaviors, $F(15,4019.17)=44.70, p<.001$, controlling for behaviors' nesting within network members, and network members' nesting within participants. The initial mixed model was followed up with pairwise comparisons of mean differences, using a Bonferroni comparison to control the type I error rate. The mean differences that were significant in this set of comparisons, as well as the follow-up pairwise comparisons conducted in each of the other three approaches, are reported below. The average number of times that each behavior was used by nominated network members and associated standard errors are indicated in table 10 below, as calculated in an intercepts-only model. These means and standard errors were computed as part of the mixed model analysis, and 


\section{SOCIAL NETWORKS OF INTIMATE PARTNER VIOLENCE PERPETRATORS}

are thus based on all 343 network members that were nominated and with whom participants interacted at least several times a year.

\section{Table 10.}

\section{Network Members' Average Use of Each IPV-Relevant Behavior}

\begin{tabular}{|c|c|c|}
\hline$\underline{\text { Network Members' Behaviors }}$ & $\underline{M}$ & $\underline{S E}$ \\
\hline Supported you in being more accountable? & 4.29 & 0.21 \\
\hline Did or said something that supported your participation at Allies in Change? & 3.16 & 0.21 \\
\hline $\begin{array}{l}\text { Told you that your current/former partner was taking advantage of you or } \\
\text { disrespecting you? }\end{array}$ & 3.15 & 0.21 \\
\hline $\begin{array}{l}\text { Accused your current/former partner of trying to harm your relationship with } \\
\text { your kids? }\end{array}$ & 2.12 & 0.22 \\
\hline Pointed out the effects of abuse on children or other people? & 2.02 & 0.21 \\
\hline Tried to make amends with you for their abusive behavior? & 2.00 & 0.21 \\
\hline $\begin{array}{l}\text { Told you that they wouldn't let their own partner get away with the things that } \\
\text { your current/former partner does to you? }\end{array}$ & 1.95 & 0.21 \\
\hline Supported you in taking legal action against your current/former partner? & 1.89 & 0.22 \\
\hline Has this person done anything else that made you think about abuse? & 1.70 & 0.30 \\
\hline Blamed their partner for their own problems? & 1.68 & 0.22 \\
\hline Been abusive towards their partner in front of you? & 1.46 & 0.22 \\
\hline Told you ways to avoid the consequences of abuse? & 1.31 & 0.21 \\
\hline $\begin{array}{l}\text { Made fun of you for letting your current/former partner call the shots in your } \\
\text { relationship? }\end{array}$ & 1.20 & 0.21 \\
\hline Refused to accept that you have been abusive? & 1.02 & 0.21 \\
\hline Told you that your current/former partner deserved your abusive behavior? & 0.77 & 0.21 \\
\hline Contacted your current/former partner to harass or monitor them? & 0.60 & 0.21 \\
\hline
\end{tabular}

Note. The average use of each behavior was based on a sample of 343 network members, nominated by 99 participants. 


\section{SOCIAL NETWORKS OF INTIMATE PARTNER VIOLENCE PERPETRATORS}

The second approach that was used to explore mean differences in the number of times that participants' network members used each type of behavior in the three months prior to data collection was a mixed ANOVA. This approach was used due to its robustness against violations of the assumption of homogeneity of variance between subjects (Collier, Baker \& Mandeville, 1967, as cited in Howell, 2007). However, mixed ANOVA cannot handle unequal group sizes (Howell, 2007); any network member who was missing any data from the inventory of network members' behaviors was excluded from the analysis, resulting in the inclusion of only 58 network members, nested within 24 participants, in the analysis. The current behavioral inventory included the option of "not applicable," the frequent use of which contributed to the high numbers of network members with missing data. Network members' use of each behavior was considered the within-subjects variable, which was repeated within each network member. The participants who nominated the network members were considered a between-subjects factor. Controlling for the participant who had nominated each network member, significant differences in the mean number of times that network members use each behavior were found, $F(1,15)=18.73, p<.001$, partial $\eta^{2}=.36$. These results did not vary depending on whether or not sphericity was assumed or which adjustment was used to correct for sphericity. Averaging across the 16 behaviors from the inventory, there was also a significant main effect of the participant who nominated the network member, $F(1$, 23) $=10.63, p<.001$, partial $\eta^{2}=.88$. The significant main effect of type of behavior 


\section{SOCIAL NETWORKS OF INTIMATE PARTNER VIOLENCE PERPETRATORS}

was followed up with pairwise comparisons of mean differences, using a Bonferroni correction for multiple comparisons.

To improve the distributions of each of the outcome variables, which were all positively skewed, the outcome variables were also recoded to be dichotomous, such that network members received a score of one if participants indicated that they had ever engaged in a given behavior, and a score of zero if they had not. Using these binary outcomes, another mixed ANOVA was conducted. Again, network members' use of each behavior was considered the within-subjects variable, which was repeated within each network member. The participants who nominated the network members were considered a between-subjects factor. Again, the analysis included only 58 network members, nested within 24 participants. The results of the current analysis are quite similar to those of the prior analysis. Significant differences in the number of times that network members use each behavior from the inventory were found, controlling for the participant who had nominated them, $F(1,15)=18.06, p<.001$, partial $\eta^{2}=.35$. These results did not vary depending on whether or not sphericity was assumed. Averaging across the specific behaviors, there was also a main effect of the participant who had nominated each network member, $F(1,23)=8.88, p<.001$, partial $\eta^{2}=.86$. Again, pairwise comparisons of mean differences in network members' use of each behavior were conducted, using a Bonferroni correction for multiple comparisons.

The fourth and final approach that was tested to identify differences in the number of times that network members used each behavior during the prior three months was a 


\section{SOCIAL NETWORKS OF INTIMATE PARTNER VIOLENCE PERPETRATORS}

non-parametric approach. A Friedman test was conducted to assess differences in the median number of times that network members used each behavior from the inventory. Again, only the 58 network members for whom the entire inventory was completed without any missing data were used. As the Friedman test is not able to integrate between-subjects variables (Howell, 2007), no attempt was made to control for the nesting structure of network members within participants. The test was significant, $X^{2}$ $(15, \mathrm{~N}=58)=192.27, p<.001$. This significant omnibus test was followed by a series of pairwise comparisons. The median of each behavior in the inventory was compared to the median score of every other behavior in the inventory, using Wilcoxon tests. The results of these tests were compared to the results of the pairwise comparisons that followed each of the other three omnibus analyses described above.

The post-hoc pairwise comparisons that followed each of the four omnibus approaches described above were compared to each other. Only those pairwise comparisons that were significant across all four approaches are listed here, in table 11. The behavior on the left side of the table occurred significantly more often than the behavior on the right. The average number of times that each network member used each of the behaviors during the three months prior to data collection, accounting for the nesting structure of the data, is included in parentheses. The behaviors that occurred significantly more often than others were: (1) told you that your current/former partner was taking advantage of you or disrespecting you; (2) accused your current/former partner of trying to harm your relationship with your kids; (3) told you that they wouldn't 


\section{SOCIAL NETWORKS OF INTIMATE PARTNER VIOLENCE PERPETRATORS}

let their own partner get away with the things that your current/former partner does to you; (4) supported you in being more accountable; (5) supported you in taking legal action against your current/former partner; (6) blamed their partner for their own problems, and; (7) did or said something that supported your participation at Allies in Change. Five of these seven behaviors involve villainizing participants' or their own current/former partners, and two of these behaviors involve supporting participants' accountability and BIP participation. 


\title{
SOCIAL NETWORKS OF INTIMATE PARTNER VIOLENCE PERPETRATORS
}

\author{
Table 11.
}

\section{Significant Comparisons of Pairwise Differences in Network Members' Use of Behaviors}

Behavior occurring significantly more often

Told you that your current/former partner was taking advantage of you or disrespecting you? ( $M$

$$
=3.15)
$$

Told you that your current/former partner was taking advantage of you or disrespecting you? $(M$

$$
=3.15)
$$

Told you that your current/former partner was taking advantage of you or disrespecting you? $(M$

$$
=3.15)
$$

Told you that your current/former partner was taking advantage of you or disrespecting you? ( $M$

$$
=3.15 \text { ) }
$$

Told you that your current/former partner was taking advantage of you or disrespecting you? ( $M$

$$
=3.15 \text { ) }
$$

Told you that your current/former partner was taking advantage of you or disrespecting you? ( $M$

$$
=3.15 \text { ) }
$$

Told you that your current/former partner was taking advantage of you or disrespecting you? ( $M$

$$
=3.15 \text { ) }
$$

Told you that your current/former partner was taking advantage of you or disrespecting you? ( $M$

$$
=3.15)
$$

Accused your current/former partner of trying to harm your relationship with your kids? $(M=$

$$
\text { 2.12) }
$$

Accused your current/former partner of trying to harm your relationship with your kids? $(M=$
Behavior occurring significantly less often

Told you that your current/former partner deserved your abusive behavior? $(M=.77)$

Refused to accept that you have been abusive?

$$
(M=1.02)
$$

Told you ways to avoid the consequences of abuse? $(M=1.31)$

Supported you in taking legal action against your current/former partner? $(M=1.89)$

Contacted your current/former partner to harass or monitor them? $(M=.60)$

Made fun of you for letting your current/former partner call the shots in your relationship? $(M=1.20)$

Tried to make amends with you for their abusive behavior? $(M=2.00)$

Has this person done anything else that made you think about abuse? $(M=1.70)$

Told you that your current/former partner deserved your abusive behavior? $(M=.77)$

Refused to accept that you have been abusive?

$$
(M=1.02)
$$




\section{SOCIAL NETWORKS OF INTIMATE PARTNER VIOLENCE PERPETRATORS}

Accused your current/former partner of trying to harm your relationship with your kids? $(M=$

$$
\text { 2.12) }
$$

Accused your current/former partner of trying to harm your relationship with your kids? $(M=$

Told you that they wouldn't let their own partner get away with the things that your current/former partner does to you? $(M=1.95)$

Told you that they wouldn't let their own partner get away with the things that your current/former partner does to you? $(M=1.95)$

Told you that they wouldn't let their own partner get away with the things that your current/former partner does to you? $(M=1.95)$

Supported you in being more accountable? $(M=$

Supported you in being more accountable? $(M=$

Supported you in being more accountable? $(M=$ 4.29)

Supported you in being more accountable? $(M=$ 4.29)

Supported you in being more accountable? $(M=$ 4.29)

Supported you in being more accountable? $(M=$ 4.29)

Supported you in being more accountable? $(M=$ 4.29)

Supported you in being more accountable? $(M=$ 4.29)

\section{Contacted your current/former partner to} harass or monitor them? $(M=.60)$

Made fun of you for letting your current/former partner call the shots in your relationship? $(M=1.20)$

Told you that your current/former partner deserved your abusive behavior? $(M=.77)$

Refused to accept that you have been abusive?

$$
(M=1.02)
$$

Made fun of you for letting your current/former partner call the shots in your

$$
\text { relationship? }(M=1.20)
$$

Told you that they wouldn't let their own partner get away with the things that your current/former partner does to you? $(M=1.95)$

Told you that your current/former partner deserved your abusive behavior? $(M=.77)$ Refused to accept that you have been abusive?

$$
(M=1.02)
$$

Been abusive towards their partner in front of

$$
\text { you? }(M=1.46)
$$

Told you ways to avoid the consequences of

$$
\text { abuse? }(M=1.31)
$$

Supported you in taking legal action against your current/former partner? $(M=1.89)$

Contacted your current/former partner to harass or monitor them? $(M=.60)$

Made fun of you for letting your current/former partner call the shots in your 


\section{SOCIAL NETWORKS OF INTIMATE PARTNER VIOLENCE PERPETRATORS}

relationship? $(M=1.20)$

Supported you in being more accountable? $(M=$ 4.29)

Supported you in being more accountable? $(M=$

$$
\text { 4.29) }
$$

Supported you in being more accountable? $(M=$

Supported you in being more accountable? $(M=$

$$
\text { 4.29) }
$$

Supported you in taking legal action against your current/former partner? $(M=1.89)$

Supported you in taking legal action against your current/former partner? $(M=1.89)$

Blamed their partner for their own problems? ( $M$

$$
=1.68)
$$

Did or said something that supported your participation at Allies in Change? $(M=3.16)$

Did or said something that supported your participation at Allies in Change? $(M=3.16)$

Did or said something that supported your participation at Allies in Change? $(M=3.16)$

Did or said something that supported your participation at Allies in Change? $(M=3.16)$

Did or said something that supported your participation at Allies in Change? $(M=3.16)$
Pointed out the effects of abuse on children or other people? $(M=2.02)$

Tried to make amends with you for their abusive behavior? $(M=2.00)$

Has this person done anything else that made you think about abuse? $(M=1.70)$

Accused your current/former partner of trying to harm your relationship with your kids? $(M$

$$
=2.12 \text { ) }
$$

Told you that your current/former partner deserved your abusive behavior? $(M=.77)$

Contacted your current/former partner to harass or monitor them? $(M=.60)$

Contacted your current/former partner to harass or monitor them? $(M=.60)$

Told you that your current/former partner deserved your abusive behavior? $(M=.77)$

Refused to accept that you have been abusive?

$$
(M=1.02)
$$

Told you ways to avoid the consequences of

$$
\text { abuse? }(M=1.31)
$$

Contacted your current/former partner to harass or monitor them? $(M=.60)$

Made fun of you for letting your current/former partner call the shots in your relationship? $(M=1.20)$

Note. Averages based on a sample of 343 network members, nominated by 99

participants. 
Two exploratory analyses were conducted, to determine whether participants' attendance and participation in a group for criminally oriented men were related to the number of times that their network members used each behavior from the inventory during the prior three months. Two mixed models were tested, one in which participants' attendance was included, and one in which participants' participation in a group for criminally oriented men was included. The mixed modeling approach was selected because of its ability to handle missing data. However, both of these models included only two levels: behaviors were nested within network members. The participant who nominated each network member was not included as a level-three variable in either model, due to the collinearity between participants and their attendance $\left(\eta^{2}=1.00\right)$, as well as the collinearity between participants and their participation in groups for criminally oriented men $\left(\eta^{2}=1.00\right)$, which prohibited SPSS from producing parameter estimates when participants' identifiers were also included in the model. Thus, each model utilized the 4,945 behaviors from the inventory of network members' behaviors over the three months prior, which were nested within the 343 network members with whom participants had contact at least several times a year. The 16 behaviors in the inventory of network members' behaviors were dummy coded. For those participants who gave consent for Allies in Change to share their attendance records, their official records were used in the creation of the attendance variable, and the remaining participants' self-reported attendance was used in the creation of this variable.

In the first exploratory model, the number of times that network members engaged in behaviors was predicted by the interaction of their associated participants' 


\section{SOCIAL NETWORKS OF INTIMATE PARTNER VIOLENCE PERPETRATORS}

grand mean centered attendance and the specific behavior, controlling for network

member. Controlling for the network member who had engaged in the behavior,

participants' centered attendance significantly interacted with six of the 16 behaviors

from the inventory to predict network members' use of the behavior. These behaviors that significantly interacted with centered attendance, controlling for network member, are: (1) supported you in being more accountable, $\beta=.02, t(1859)=2.09 p=.037$; (2) told you that your current/former partner deserved your abusive behavior, $\beta=-.03$, $t(2031)=-2.64 p=.008 ;$ (3) refused to accept that you have been abusive, $\beta=-.03$, $t(1928)=-2.80 p=.005 ;$ (4) contacted your current/former partner to harass or monitor them, $\beta=-.03, t(2155)=-2.81, p=.005 ;$ (5) made fun of you for letting your current/former partner call the shots in your relationship, $\beta=-.02, t(2191)=-1.99, p=$ .047 , and (6) done or said anything else that has made you think about abuse, $\beta=-.04$, $t(4101)=-2.37, p=.018 .{ }^{1}$ While all of the regression coefficients associated with the interactions of centered attendance and behavior type are small (less than $|0.05|$ ), their signs indicate that the longer participants have been attending Allies in Change, the more often their network members support them in being accountable, the less often their network members engage in five behaviors that express support for IPV, and the less often their network members engage in additional behaviors that may or may not indicate support for IPV.

\footnotetext{
${ }^{1}$ Including the interaction of centered attendance and each behavior in the model, there was still significant network-member-level variance in their use of behaviors: at the mean of attendance, intercept variance $=2.680, \mathrm{Wald} \mathrm{Z}=9.746, p<.001$.
} 


\section{SOCIAL NETWORKS OF INTIMATE PARTNER VIOLENCE PERPETRATORS}

In the second exploratory model, the number of times that network members engaged in behaviors during the prior three months was predicted by the interaction of their associated participants' enrollment in a group for criminally oriented men and the specific type behavior, controlling for network member. Averaging across the 16 specific behaviors and controlling for the network member who had engaged in the behavior, network members of participants in criminally oriented groups used significantly more behaviors $(M=3.42, S E=0.41)$ than network members of participants in other groups $(M=1.66, S E=0.10), F(1,348.844)=17.70 p<.001 .^{2}$ Specifically, controlling for network member, network members of men in criminally oriented groups used the following nine behaviors significantly more often than network members of men in other groups: told you that your current/former partner was taking advantage of you or disrespecting you; accused your current/former partner of trying to harm your relationship with your kids; refused to accept that you had been abusive; blamed their partner for their own problems; told you ways to avoid the consequences of abuse; supported you in taking legal action against your current/former partner; pointed out the effects of abuse on children or other people; did or said something that supported your participation at Allies in Change; and done anything else that made you think about abuse. A Bonferonni correction was used in assessing these pair-wise differences. The

\footnotetext{
${ }^{2}$ Including the interaction of participation in a criminally oriented group and each behavior in the model, there was still significant network-member-level variance in their use of behaviors: for participants in non-criminally oriented groups, intercept variance = 2.643, Wald $\mathrm{Z}=9.948, p<.001$.
} 


\section{SOCIAL NETWORKS OF INTIMATE PARTNER VIOLENCE PERPETRATORS}

averages, standard errors, t-statistics, and p-values associated with the use of each behavior by network members of men in criminally oriented groups and other groups are listed in table 12 below. Five of these behaviors may be considered pro-abuse, two of these behaviors may be considered anti-abuse, and two of the behaviors are neither explicitly pro-abuse nor anti-abuse. In the case of all nine behaviors that were significantly related to participants' enrollment in a group for criminally oriented men, network members of those in criminally oriented groups used behaviors more often than network members of men in other groups. 


\section{SOCIAL NETWORKS OF INTIMATE PARTNER VIOLENCE PERPETRATORS}

Table 12.

Use of Each Behavior by Network Members of Participants in Criminally Oriented and Non

\section{Criminally Oriented Groups}

\begin{tabular}{|c|c|c|c|c|c|c|c|}
\hline \multirow[t]{2}{*}{ Behavior } & \multicolumn{2}{|c|}{$\begin{array}{l}\text { Non } \\
\text { Criminally } \\
\text { Oriented }\end{array}$} & \multicolumn{2}{|c|}{$\begin{array}{l}\text { Criminally } \\
\text { Oriented } \\
\text { Group }\end{array}$} & \multirow[t]{2}{*}{$d f$} & \multirow[t]{2}{*}{$t$} & \multirow[t]{2}{*}{$p$} \\
\hline & Mean & $\begin{array}{l}\text { Std. } \\
\text { Error }\end{array}$ & Mean & $\begin{array}{l}\text { Std. } \\
\text { Error }\end{array}$ & & & \\
\hline $\begin{array}{l}\text { Told you that your current/former } \\
\text { partner was taking advantage of you or } \\
\text { disrespecting you? }\end{array}$ & 2.85 & .18 & 6.18 & .69 & 2222.30 & 4.703 & $.000 *$ \\
\hline $\begin{array}{l}\text { Accused your current/former partner of } \\
\text { trying to harm your relationship with } \\
\text { your kids? }\end{array}$ & 1.83 & .18 & 4.79 & .69 & 2235.69 & 4.179 & $.000 *$ \\
\hline $\begin{array}{l}\text { Told you that they wouldn't let their own } \\
\text { partner get away with the things that } \\
\text { your current/former partner does to you? }\end{array}$ & 1.81 & .18 & 2.62 & .70 & 2336.21 & 1.123 & .261 \\
\hline $\begin{array}{l}\text { Supported you in being more } \\
\text { accountable? }\end{array}$ & 4.13 & .17 & 4.67 & .70 & 2323.03 & 0.751 & .453 \\
\hline $\begin{array}{l}\text { Told you that your current/former } \\
\text { partner deserved your abusive behavior? }\end{array}$ & .64 & .18 & .42 & .76 & 2723.33 & 0.276 & .782 \\
\hline $\begin{array}{l}\text { Refused to accept that you have been } \\
\text { abusive? }\end{array}$ & .69 & .17 & 4.18 & .70 & 2340.51 & 4.835 & $.000 *$ \\
\hline $\begin{array}{l}\text { Been abusive towards their partner in } \\
\text { front of you? }\end{array}$ & 1.28 & .18 & 2.19 & .92 & 3575.67 & 0.976 & .329 \\
\hline $\begin{array}{l}\text { Blamed their partner for their own } \\
\text { problems? }\end{array}$ & 1.45 & .18 & 3.31 & .88 & 3382.18 & 2.093 & $.036^{*}$ \\
\hline $\begin{array}{l}\text { Told you ways to avoid the } \\
\text { consequences of abuse? }\end{array}$ & 1.08 & .17 & 2.78 & .76 & 2711.29 & 2.181 & $.029 *$ \\
\hline $\begin{array}{l}\text { Supported you in taking legal action } \\
\text { against your current/former partner? }\end{array}$ & 1.65 & .18 & 3.97 & .74 & 2592.47 & 3.049 & $.002 *$ \\
\hline $\begin{array}{l}\text { Contacted your current/former partner to } \\
\text { harass or monitor them? }\end{array}$ & .40 & .18 & 1.51 & .88 & 3388.03 & 1.239 & .216 \\
\hline $\begin{array}{l}\text { Made fun of you for letting your } \\
\text { current/former partner call the shots in } \\
\text { your relationship? }\end{array}$ & .99 & .18 & 2.23 & .84 & 3201.22 & 1.443 & .149 \\
\hline $\begin{array}{l}\text { Pointed out effects of abuse on children } \\
\text { or other people? }\end{array}$ & 1.78 & .17 & 3.42 & .740 & 2565.18 & 2.162 & $.031^{*}$ \\
\hline $\begin{array}{l}\text { Did or said something that supported } \\
\text { your participation at Allies in Change? }\end{array}$ & 2.92 & .17 & 4.87 & .70 & 2316.56 & 2.698 & $.007 *$ \\
\hline $\begin{array}{l}\text { Tried to make amends with you for their } \\
\text { abusive behavior? }\end{array}$ & 1.83 & .18 & 2.17 & .78 & 2866.65 & 0.422 & .673 \\
\hline $\begin{array}{l}\text { Has this person done anything else that } \\
\text { made you think about abuse? }\end{array}$ & 1.32 & .28 & 5.40 & 1.19 & 4241.81 & 3.345 & $.001 *$ \\
\hline
\end{tabular}




\section{SOCIAL NETWORKS OF INTIMATE PARTNER VIOLENCE PERPETRATORS}

Note. Averages and standard errors are based on a sample of 4,679 behaviors used by 320 network members of 87 participants in non-criminally oriented groups and 266 behaviors used by 23 network members of 12 participants in criminally oriented groups.

$R Q$ 3.b. A two-level mixed model was tested to examine the relationship between network members' relationship to participants and their total use of behaviors from the inventory of network members' behaviors during the three months prior to the study. Use of each behavior from the inventory was summed for each network member individually (recalling that original response options were recoded from 0 times, $1-5$ times, $6-10$ times, 11 times or more, or not applicable to $0,2.5,8,12$, or missing, accordingly). Network members' relational tie to participants was the factor. The 343 network members were the level-one variable, nested within the 99 participants, the level-two variable. From an intercepts-only model, the ICC for network members' total behavior, nested within participants, was .47 , indicating that $47 \%$ of the variance in network members' total use of behaviors was dependent upon the participant who nominated them $[\operatorname{Var}($ Intercepts $)=200.401, \mathrm{Wald} Z=5.044, p<001)]$. From an intercepts-only model, controlling for network members' nesting within participants, network members engaged in an average of 22.09 behaviors from the inventory $(S E=1.72)$. Network members' total use of behaviors from the inventory was compared across the seven relational ties, controlling for the participant who nominated them, and using a Bonferonni correction to assess significance. Controlling for participants, partners and former partners used significantly more behaviors $(M=32.41, S E=2.61)$ than friends and roommates $(M=$ $17.96, S E=2.23, t(283.95)=4.88, p<.001)$, bosses and coworkers $(M=15.57, S E=$ 


\section{SOCIAL NETWORKS OF INTIMATE PARTNER VIOLENCE PERPETRATORS}

$3.01, t(268.12)=4.82, p<.001)$, children $(M=15.30, S E=3.57, t(265.48)=4.34, p<$ $.001)$, and in-laws $(M=11.46, S E=4.87, t(250.90)=4.06, p=.001)$. Among participants' friends and roommates, bosses and coworkers, children, and in-laws, there were no significant differences in the total number of times that each time of relational tie used any behaviors from the inventory. Members of participants' families of origin $(M=$ $25.51, S E=2.31)$ and "other" relational ties $(M=22.60, S E=5.61)$ did not use significantly more or fewer behaviors than other types of relational ties ${ }^{3}$. See table 13 below for the average number of times that each type of relational tie used any behavior from the inventory with participants, controlling for network members' nesting in participants.

Table 13.

Network Members' Total Use of Behaviors by Relational Tie

\begin{tabular}{|c|c|c|}
\hline$\frac{\text { Network members' }}{\underline{\text { relational tie }}}$ & $\underline{M}$ & $\underline{S E}$ \\
\hline$\overline{\text { Friend/Roommate }}$ & 17.96 & 2.23 \\
\hline Boss/Coworker & 15.57 & 3.01 \\
\hline Family of origin & 25.51 & 2.31 \\
\hline Child & 15.30 & 3.57 \\
\hline In- law & 11.46 & 4.87 \\
\hline Partner/ former partner & 32.41 & 2.61 \\
\hline Other & 22.60 & 5.61 \\
\hline
\end{tabular}

Note. Averages based on a sample of 343 network members, nominated by 99 participants.

${ }^{3}$ Accounting for network members' relational ties to participants, the variance in network members' use of behaviors remained significant, $\operatorname{Var}$ (intercepts) $=169.719, \mathrm{Wald} \mathrm{Z}=$ $4.790, p<.001$. 


\section{SOCIAL NETWORKS OF INTIMATE PARTNER VIOLENCE PERPETRATORS}

Two exploratory mixed models were tested, to determine whether different relational ties' total use of behaviors from the inventory of network members' behaviors were related to participants' attendance at Allies in Change, or their enrollment in a group for criminally oriented men. The 343 network members were again nested within 99 participants. In the first exploratory model, network members' total use of behaviors from the inventory were predicted by the interaction of their relational tie to participants and participants' grand mean centered attendance. Controlling for the participant by whom they were nominated, the interaction of centered attendance and network members' relational ties was significantly related to the number of behaviors that participants' children used: participants' children used approximately one fewer behavior for every two weeks that participants had been attending Allies in Change $(\beta=-.55, t(294.154)=-$ $2.38, p=.018)$. None of the other relational ties' total use of behaviors varied significantly with their associated participants' attendance.

In the second exploratory model that was tested, network members' total use of behaviors was predicted by the interaction of their relational ties and their associated participants' enrollment in a group for criminally oriented men. Controlling for the participant who had nominated the network member and using a Bonferonni correction to assess the significance of pairwise comparisons, participants' family of origin engaged in significantly more behaviors when participants were enrolled in groups for criminally oriented men $(M=54.22, S E=10.38)$, than when they were not $(M=23.99, S E=2.30)$, $t(291.230)=2.82, p=.005$. Participants' children also engaged in significantly more 


\section{SOCIAL NETWORKS OF INTIMATE PARTNER VIOLENCE PERPETRATORS}

behaviors when participants were enrolled in groups for criminally oriented men $(M=$ 47.17, $S E=10.45)$ than when they were not $(M=11.43, S E=3.69), t(259.243)=3.23, p$ $=.001$. In both instances of significant differences between participants in criminally oriented groups and other groups, much larger standard errors were associated with the criminally oriented group, reflecting the substantially smaller number of participants in criminally oriented groups $(N=12)$ than non-criminally oriented groups $(N=87)$, and potentially indicating more variation among men assigned to criminally oriented groups than participants in other groups at Allies in Change. None of the other interactions of participants' enrollment in a group for criminally oriented men and network members' relational ties to participants were significantly related to network members' total use of behaviors, indicating that whether or not a participant attends a group for criminally oriented men is only significantly related to the number of behaviors used by their family of origin and their children.

$R Q$ 3.c. An additional mixed model was tested to determine whether network members to whom participants have different relational ties engage in different behaviors from the inventory to different extents during the three months prior to data collection. Instead of examining interactions between each type of relational tie and each of the 16 behaviors from the inventory, two composite scores were computed: the number of times that network members engaged in each of the 10 behaviors that were explicitly pro-abuse were averaged to create a score of their average use of pro-abuse behaviors, and the number of times that network members engaged in the four behaviors that were explicitly 


\section{SOCIAL NETWORKS OF INTIMATE PARTNER VIOLENCE PERPETRATORS}

anti-abuse were averaged to create a score of for their average use of anti-abuse behaviors. The two behaviors that were more ambiguous in terms of being either proabuse or anti-abuse ("told you ways to avoid the consequences of abuse" and "done or said anything else that made you think about abuse") were not included in the creation of either of these composite scores. In an intercepts-only model, the nesting of these composite scores within network member was responsible for $10.33 \%$ of the variance between scores $(\mathrm{ICC}=0.1033)[\operatorname{var}($ intercepts $)=0.501$, Wald $\mathrm{Z}=1.802, p=.072] . \mathrm{A}$ two-level mixed model was tested to examine whether the interaction of the type of behavior (either pro-abuse or anti-abuse) and network members' relationship to the participant significantly predicted network members' use of the behaviors. Across the 343 network members, there was a total of 655 scores between the two composites. These 655 scores were nested within the 343 network members (the level-two variable). The model would not converge when participants were included as a level-three variable. Network members' scores on the composite variables were predicted by the interaction of the type of composite score (either pro-abuse or anti-abuse), and their relational tie to the participant who nominated them. Accounting for scores' nesting within network members, network members used each anti-abuse behavior an average of $2.61(S E=.16)$ times, and each pro-abuse behavior an average of $0.98(S E=.16)$ times, across relational ties. This translates to total of 10.44 anti-abuse behaviors and 9.80 pro-abuse behaviors per network member, averaging across relational ties and controlling for behaviors' nesting within network members. Controlling for scores' nesting within network 


\section{SOCIAL NETWORKS OF INTIMATE PARTNER VIOLENCE PERPETRATORS}

members, the interaction of the type of behavioral composite (anti-abuse or pro-abuse) and network members' relational ties to participants significantly predicted network members' scores on those composites, $F(13,320.21)=14.523, p<.001$. Controlling for network member, five interactions of type of composite and network members' relational tie to participants were significant. Participants' friends/roommates, bosses/coworkers, family of origin, partners/former partners, and "other" relational ties all used significantly each anti-abuse behavior more frequently than they used each pro-abuse behavior. There were no significant differences in the frequencies with which participants' children and in-laws used pro-abuse and anti-abuse behaviors, accounting for the nesting of pro-abuse and anti-abuse behaviors within network members. The averages and standard errors associated with relational ties' use of pro-abuse and anti-abuse behaviors, and associated t-statistics, and p-values, are presented in table 14 below. Again, a Bonferonni correction was used to assess the significance of pairwise comparisons (use of pro-abuse versus anti-abuse behaviors by each relational tie). 


\section{SOCIAL NETWORKS OF INTIMATE PARTNER VIOLENCE PERPETRATORS}

Table 14.

Network Members' Use of Pro-Abuse and Anti-Abuse Behaviors by Relational Tie

\begin{tabular}{|l|c|c|c|c|c|c|c|}
\hline \multirow{2}{*}{$\begin{array}{l}\text { Network members' } \\
\text { relational tie }\end{array}$} & \multicolumn{2}{|c|}{ Pro-Abuse } & \multicolumn{2}{|c|}{$\begin{array}{c}\text { Anti- Abuse } \\
\text { Behaviors }\end{array}$} & & \\
\cline { 2 - 8 } Friend/Roommate & 1.10 & .21 & 1.79 & .20 & 290.76 & 2.669 & $.008^{*}$ \\
\hline Boss/Coworker & .83 & .32 & 2.36 & .32 & 290.56 & 3.786 & $.000^{*}$ \\
\hline Family of origin & 1.25 & .22 & 2.60 & .22 & 283.06 & 4.739 & $.000^{*}$ \\
\hline Child & .96 & .41 & 1.62 & .41 & 295.60 & -1.274 & .204 \\
\hline In- law & .50 & .57 & 1.53 & .57 & 283.06 & -1.4371 & .152 \\
\hline $\begin{array}{l}\text { Partner/ former } \\
\text { partner }\end{array}$ & 1.31 & .29 & 4.64 & .28 & 294.87 & 9.191 & $.000^{*}$ \\
\hline Other & .92 & .66 & 3.71 & .66 & 283.06 & 3.349 & $.001^{*}$ \\
\hline
\end{tabular}

Note. Statistics based on a sample of 343 network members, nominated by 99 participants.

\section{Research Question 4}

$R Q$ 4.a. The number of times that participants used each behavior from the inventory of their own behaviors during the three months prior to the study was examined. Participants' responses to the inventories of their own behaviors with each network member were also recoded, just the same as their responses to the inventories of their network members' behaviors. Their responses of 0 times, $1-5$ times, $6-10$ times, 11 times or more, or not applicable were recoded to $0,2.5,8,12$, or missing, accordingly. Again, only network members with whom participants were in contact at least several times a year were used in the following analyses, resulting in a total of 99 participants in the current sample. 


\section{SOCIAL NETWORKS OF INTIMATE PARTNER VIOLENCE PERPETRATORS}

These outcome data were also positively skewed, though less so than the data reflecting network members' behavior (mean skewness statistic across the 16 behaviors $=$ 2.05). Again, almost all of the behaviors in the inventory had several outliers; significant differences in the variances associated with each behavior were found, and Box's test of equality of covariance matrices was not produced. Mauchly's test of sphericity was significant, $W=.006, X^{2}(119, N=62)=147.82, p<.050$. Participants only completed the inventory of their own behaviors with their network members a total of 62 times without missing any items or marking a behavior as "not applicable". These 62 network members, for whom participants had completed inventories of their own behaviors, were nested within 28 participants. Hence, the same four approaches that were used to detect differences in the use of behaviors from the inventory of network members' behaviors were used to detect differences in the use of participants' behaviors. The omnibus results of each of the four approaches are summarized below, followed by a description of the follow-up pair-wise comparisons between behaviors that appeared significant across all four approaches.

The first approach that was used to determine differences in the number of times that participants used each of the 16 behaviors from the inventory was a mixed-modeling approach. Again, the assumption of normality, upon which this test relies, was violated. However, this approach does not necessitate equal numbers of observations per higher-level unit, meaning that the network members for whom inventories of participants' behaviors were missing data were included in the analysis, and sphericity is not assumed (Tabachnick \& Fidell, 2007). A three-level mixed model was tested, wherein behaviors from the inventory 


\section{SOCIAL NETWORKS OF INTIMATE PARTNER VIOLENCE PERPETRATORS}

were nested within network members, who were considered nested within the participant who nominated them. The 99 participants nominated 343 network members with whom they had contact at least several times a year. Across these 343 network members, participants provided data on a total of 4,459 behaviors from the inventory of participants' own behaviors. In an intercepts-only model, the ICC for behaviors' nesting within network members was .20, and the ICC corresponding to behaviors' nesting within participants was .29 , indicating that a total of $49 \%$ of the variance in participants' use of behaviors from the inventory was the result of the nesting structure of the data [Var(Network Member Intercepts $)=1.736, \mathrm{Wald} Z=8.153, p<.001 ; \operatorname{Var}($ Participant Intercepts $)=2.732$, Wald $\mathrm{Z}=$ $4.805, p<.001]$. Upon adding the type of behavior from the inventory as a predictor, results indicated that participants did report using the 16 discrete behaviors from the inventory to different extents during the three months preceding data collection, $F(15,4119.86)=38.14, p$ $<.001$. Including the type of behavior in the model, there remained significant variance in the intercepts at both the level of the network member [ $\operatorname{Var}$ (Network Member Intercepts) $=1.77$, Wald $\mathrm{Z}=8.429, p<.001]$ and the participant $[\operatorname{Var}($ Participant Intercepts $)=2.563$, Wald $\mathrm{Z}=$ $4.758, p<.001]$. The average number of times that participants engaged in each behavior from the inventory with their network members, and associated standard errors, are indicated in table 15 below. These means and standard errors were computed from the intercepts-only model used to build the mixed model analysis, and are thus based on participants' interactions with all 343 network members that were nominated and with whom they interacted at least several times a year, accounting for their nesting within participants. 


\section{SOCIAL NETWORKS OF INTIMATE PARTNER VIOLENCE PERPETRATORS}

Table 15.

Participants' Average Use of Each IPV-Relevant Behavior with Network Members

\begin{tabular}{|c|c|c|}
\hline Participants' Behaviors & $\underline{M}$ & $\underline{S E}$ \\
\hline Told this person that you go to Allies in Change? & 4.56 & .19 \\
\hline Shared your story about abuse with this person? & 4.09 & .32 \\
\hline $\begin{array}{l}\text { Shared information about abuse, and/or resources for victims of abuse with } \\
\text { this person? }\end{array}$ & 2.94 & .34 \\
\hline Challenged this person about their controlling behavior? & 2.49 & .36 \\
\hline Apologized to this person for demonstrating abusive behavior in the past? & 2.42 & .22 \\
\hline Talked with this person about the consequences of being abusive? & 2.35 & .25 \\
\hline $\begin{array}{l}\text { Have you done anything else with this person that might have made them } \\
\text { think about abuse? }\end{array}$ & 2.31 & .42 \\
\hline Talked with this person about the effects of abuse on children? & 2.29 & .30 \\
\hline $\begin{array}{l}\text { Called this person out if you saw them ignoring or being rude to their } \\
\text { partner? }\end{array}$ & 2.10 & .37 \\
\hline Stuck up for this person's partner if they were talking badly about them? & 1.97 & .24 \\
\hline Made amends with this person for your abusive behavior? & 1.67 & .13 \\
\hline Encouraged this person to be accountable for their abusive behavior? & 1.47 & .24 \\
\hline Shared books or other materials from Allies in Change with this person? & 1.25 & .11 \\
\hline Asked this person not to talk about abuse or act abusively around you? & 1.20 & .19 \\
\hline $\begin{array}{l}\text { Spoken up against sexist jokes or jokes about abuse while you were with } \\
\text { this person? }\end{array}$ & .79 & .13 \\
\hline Recommended Allies in Change or a similar program to this person? & .33 & .11 \\
\hline
\end{tabular}

Note. Averages based on 99 participants' use of behaviors with 343 network members. 
Again, this analysis was followed by a mixed ANOVA analysis, in which the 16 behaviors from the inventory were the repeated measures across each of the 62 network members for whom the inventory was completed without any missing data or use of the "not applicable" option. The between-subjects factor was the participant who had nominated each network member. Controlling for the participant who had nominated each network member, significant differences in the average number of times that participants use each behavior with their network members during the prior three months were found, $F(1,15)=19.55, p<$ .001 , partial $\eta^{2}=.37$. These results did not vary depending on whether or not sphericity was assumed or which adjustment was used to correct for sphericity. Averaging across the 16 behaviors from the inventory, there was also a significant main effect of the participant who nominated the network member, $F(1,27)=11.09, p<.001$, partial $\eta^{2}=.90$. The significant main effect of behavior type was followed up with pairwise comparisons of mean differences, using a Bonferroni correction for multiple comparisons.

Again, participants' use of each behavior during the prior three months was recoded to be dichotomous, such that network members received a score of one if participants had ever engaged in a given behavior with that network member, and a score of zero if they had not. Using these binary outcomes, another mixed ANOVA was conducted. Again, participants' use of each behavior with their network member was considered the withinsubjects variable, which was repeated within each network member. The participants who nominated the network members were considered a between-subjects factor. Again, the analysis included only 62 network members, nested within 28 participants. For participants' behaviors as well, the results of the current analysis are quite similar to those of the prior 


\section{SOCIAL NETWORKS OF INTIMATE PARTNER VIOLENCE PERPETRATORS}

analysis. Significant differences in the number of times that participants use each behavior from the inventory were found, controlling for the participant, $F(1,15)=13.61, p<.001$, partial $\eta^{2}=.29$. These results did not vary depending on whether or not sphericity was assumed or which adjustment was used to correct for sphericity. Averaging across the specific behaviors, there was also a main effect of the participant who had nominated each network member, $F(1,27)=3.92, p<.001$, partial $\eta^{2}=.76$. Again, pairwise comparisons of mean differences in the use of each behavior were conducted, using a Bonferroni correction for multiple comparisons.

The fourth and final approach used to identify differences in the number of times that participants use each behavior from the inventory during the prior three months was nonparametric. A Friedman test was conducted to assess differences in the median number of times that participants use each behavior from the inventory of IPV-relevant behaviors with their network members. Only the 62 network members for whom participants had completed the entire inventory of their own behaviors were included in the analysis. As in the corresponding analysis conducted to analyze Research Question 3a, no attempt was made to control for the nesting structure of network members within participants. This test was also significant, $X^{2}(15, \mathrm{~N}=62)=198.86, p<.001$ (descriptive statistics reflecting participants' use of each behavior from the inventory are located in table 15). This significant omnibus test was followed by a series of pariwise comparisons. The median of each behavior in the inventory was compared to the median score of every other behavior in the inventory, using 


\section{SOCIAL NETWORKS OF INTIMATE PARTNER VIOLENCE PERPETRATORS}

Wilcoxon tests. The results of these tests were compared to the results of the pairwise comparisons that followed each of the other three omnibus analyses described above.

The post-hoc pairwise comparisons that followed each of the four omnibus approaches described above were compared to each other. Only those pairwise comparisons that were significant across all four approaches are listed here, in table 16. The behavior on the left side of the table occurred significantly more often than the behavior on the right. The mean number of times that participants used each behavior with their network members

during the three months prior to the study, accounting for the nesting structure of the data, is included in parentheses. 


\section{SOCIAL NETWORKS OF INTIMATE PARTNER VIOLENCE PERPETRATORS}

Table 16.

\section{Significant Comparisons of Pairwise Differences in Participants' Use of Behaviors}

Behavior occurring significantly more often

Called this person out if you saw them ignoring or

being rude to their partner? $(M=2.10)$

Told this person that you go to Allies in Change? (M

$$
=4.56)
$$

Shared information about abuse, and/or resources for

victims of abuse with this person? $(M=2.94)$

Shared information about abuse, and/or resources for

victims of abuse with this person? $(M=2.94)$

Shared information about abuse, and/or resources for victims of abuse with this person? $(M=2.94)$

Told this person that you go to Allies in Change? ( $M$

$$
=4.56)
$$

Stuck up for this person's partner if they were talking badly about them? $(M=1.97)$

Talked with this person about the effects of abuse on

$$
\text { children? }(M=2.29)
$$

Shared your story about abuse with this person? $(M=$

Told this person that you go to Allies in Change? ( $M$

$$
=4.56)
$$

Challenged this person about their controlling

behavior? $(M=2.49)$

Challenged this person about their controlling behavior? $(M=2.49)$

Challenged this person about their controlling behavior? $(M=2.49)$
Behavior occurring significantly less often

Recommended Allies in Change or a similar program to this person? $(M=.33)$

Called this person out if you saw them ignoring or being rude to their partner? $(M=2.10)$

Recommended Allies in Change or a similar program to this person? $(M=.33)$

Spoken up against sexist jokes or jokes about abuse while you were with this person? $(M=$

Shared books or other materials from Allies in

Change with this person? $(M=1.25)$

Shared information about abuse, and/or resources for victims of abuse with this person?

$$
(M=2.94)
$$

Recommended Allies in Change or a similar program to this person? $(M=.33)$

Recommended Allies in Change or a similar program to this person? $(M=.33)$

Talked with this person about the effects of abuse on children? $(M=2.29)$

Talked with this person about the effects of abuse on children? $(M=2.29)$

Recommended Allies in Change or a similar program to this person? $(M=.33)$

Spoken up against sexist jokes or jokes about abuse while you were with this person? $(M=$ .79)

Shared books or other materials from Allies in Change with this person? $(M=1.25)$ 


\section{SOCIAL NETWORKS OF INTIMATE PARTNER VIOLENCE PERPETRATORS}

Asked this person not to talk about abuse or act

abusively around you? $(M=1.20)$

Encouraged this person to be accountable for their abusive behavior? $(M=1.47)$

Talked with this person about the consequences of

$$
\text { being abusive? }(M=2.35)
$$

Shared your story about abuse with this person? $(M=$ 4.09)

Told this person that you go to Allies in Change? ( $M$

$$
=4.56)
$$

Made amends with this person for your abusive

$$
\text { behavior? }(M=1.67)
$$

Apologized to this person for demonstrating abusive

$$
\text { behavior in the past? }(M=2.42)
$$

Have you done anything else with this person that might have made them think about abuse? $(M=2.31)$

Talked with this person about the consequences of being abusive? $(M=2.35)$

Shared your story about abuse with this person? $(M=$ 4.09)

Told this person that you go to Allies in Change? ( $M$

$$
=4.56)
$$

Apologized to this person for demonstrating abusive behavior in the past? $(M=2.42)$

Talked with this person about the consequences of being abusive? $(M=2.35)$

Shared your story about abuse with this person? $(M=$ 4.09)

Told this person that you go to Allies in Change? ( $M$

$$
=4.56)
$$

Recommended Allies in Change or a similar program to this person? $(M=.33)$

Recommended Allies in Change or a similar program to this person? $(M=.33)$

Recommended Allies in Change or a similar program to this person? $(M=.33)$

Recommended Allies in Change or a similar program to this person? $(M=.33)$

Recommended Allies in Change or a similar program to this person? $(M=.33)$

Recommended Allies in Change or a similar program to this person? $(M=.33)$

Recommended Allies in Change or a similar program to this person? $(M=.33)$

Recommended Allies in Change or a similar program to this person? $(M=.33)$

Spoken up against sexist jokes or jokes about abuse while you were with this person? $(M=$ .79)

Spoken up against sexist jokes or jokes about abuse while you were with this person? $(M=$

Spoken up against sexist jokes or jokes about abuse while you were with this person? $(M=$

Spoken up against sexist jokes or jokes about abuse while you were with this person? $(M=$

Shared books or other materials from Allies in Change with this person? $(M=1.25)$

Shared books or other materials from Allies in Change with this person? $(M=1.25)$ Shared books or other materials from Allies in Change with this person? $(M=1.25)$ 


\section{SOCIAL NETWORKS OF INTIMATE PARTNER VIOLENCE PERPETRATORS}

Apologized to this person for demonstrating abusive behavior in the past? $(M=2.42)$

Shared your story about abuse with this person? $(M=$ 4.09)

Told this person that you go to Allies in Change? ( $M$

$$
=4.56)
$$

Shared your story about abuse with this person? $(M=$

Told this person that you go to Allies in Change? ( $M$

$$
=4.56)
$$

Shared your story about abuse with this person? $(M=$ 4.09)

Told this person that you go to Allies in Change? ( $M$

$$
=4.56)
$$

Told this person that you go to Allies in Change? ( $M$

$$
=4.56)
$$

Shared books or other materials from Allies in Change with this person? $(M=1.25)$

Asked this person not to talk about abuse or act abusively around you? $(M=1.20)$

Asked this person not to talk about abuse or act abusively around you? $(M=1.20)$

Encouraged this person to be accountable for their abusive behavior? $(M=1.47)$

Encouraged this person to be accountable for their abusive behavior? $(M=1.47)$

Made amends with this person for your abusive

$$
\text { behavior? }(M=1.67)
$$

Made amends with this person for your abusive

$$
\text { behavior? }(M=1.67)
$$

Have you done anything else with this person that might have made them think about abuse?

$$
(M=2.31)
$$

Note. Averages based on 99 participants' use of behaviors with 343 network members. 
As in the case of Research Question 3a, two exploratory models were tested, to determine whether participants' attendance and enrollment in a group for criminally oriented men were related to the number of times that they used each behavior from the inventory of participants' behaviors with their network members during the preceding three months. Again, the mixed modeling approach was used to enable the inclusion of the greatest amount of data, and only two levels were included in each model, due to the collinearity between participants and their attendance $\left(\eta^{2}=1.00\right)$ as well as the collinearity between participants and their enrollment in groups for criminally oriented men $\left(\eta^{2}=1.00\right)$. Thus, in the models described below, the 4,459 participant behaviors were considered the level-one variable, nested within the 343 network members, the level-two variable. Participants' attendance records (either those provided by Allies in Change, where available, or those self-reported by participants) were grand mean centered. Participants' enrollment in a group for criminally oriented men was coded dichotomously.

In the first exploratory model, the number of times that participants engaged in a behavior was predicted by the interaction of their centered attendance and the specific type of behavior, controlling for the network members with whom participants engaged in the behaviors (the model would not converge when participants were also entered into the model, so they were not controlled for). Controlling for network member, participants' attendance significantly interacted with the specific type of behavior to 


\section{SOCIAL NETWORKS OF INTIMATE PARTNER VIOLENCE PERPETRATORS}

predict participants' use of behaviors, $F(16,2338.27)=4.94, p<.001^{4}$. Specifically, participants' centered attendance significantly interacted with 7 of the 16 behaviors from the inventory to predict participants' use of the behavior. The behavior types that significantly interacted with participants' attendance, controlling for network members, are: (1) shared information about abuse, and/or resources for victims of abuse with this person, $\beta=.02, t(1645)=2.14, p=.032 ;(2)$ recommended Allies in Change or a similar program to this person, $\beta=-.03 t(1852)=-2.90, p=.004 ;$ (3) spoken up against sexist jokes or jokes about abuse while you were with this person, $\beta=-.03, t(2031)=-2.34, p=$ .020 ; (4) asked this person not to talk about abuse or act abusively around you, $\beta=-.02$, $t(1741)=-2.12, p=.034 ;(5)$ told this person that you go to Allies in Change, $\beta=.03$, $t(1650)=3.4,1 p=.001 ;(6)$ made amends with this person for your abusive behavior, $\beta$ $=.02, t(1823)=2.12, p=.035$; and $(7)$ apologized to this person for demonstrating abusive behavior in the past, $\beta=.02, t(1791)=2.17, p=.030$. As was the case for Research Question 3a, the significant coefficients associated with the interaction of centered attendance and behavior type are quite small, (|0.03| or smaller). The signs of the coefficients indicate that, as participants' attendance at Allies in Change increases, they engage in four behaviors that indicate anti-abuse attitudes more often, and they engage in three behaviors that indicate anti-abuse attitudes less often.

\footnotetext{
${ }^{4}$ Including the interaction of participants' centered attendance and the specific type of behavior, the variance in network members' use of behaviors remained significant, $\operatorname{var}($ Intercepts $)=3.27$, Wald $\mathrm{Z}=10.77, p<.001$.
} 


\section{SOCIAL NETWORKS OF INTIMATE PARTNER VIOLENCE PERPETRATORS}

In the second exploratory model, the number of times that participants engaged in each behavior was predicted by the interaction of their enrollment in a group for criminally oriented men and the variable indicating the specific behavior, controlling for network member. Controlling for the network member with whom participants had engaged in behaviors during the prior three months, participants' enrollment in a group for criminally oriented men significantly interacted with the specific type of behavior to predict the frequency of that behavior, $F(31,3274.41)=19.724, p<.001^{5}$. A Bonferonni correction was used to assess the significance of the 16 pairwise comparisons. Participants in groups for criminally oriented men used 8 of the 16 behaviors significantly more often than participants in other groups, controlling for the nesting of behaviors within network members. The specific behaviors participants in criminally oriented groups used significantly more often than participants in other groups were: called this person out if you saw them ignoring or being rude to their partner; talked with this person about the effects of abuse on children; recommended Allies in Change or a similar program to this person; spoken up against sexist jokes or jokes about abuse while you were with this person; shared books or other materials from Allies in Change with this person; shared your story about abuse with this person; told this person that you go to Allies in Change; and apologized to this person for demonstrating abusive behavior in the past. The average number of times that participants in groups for criminally oriented men

\footnotetext{
${ }^{5}$ Including the interaction of BIP participants' enrollment in a group for criminally oriented men and the type of behavior that they used with their network members, there remained significant variance in their use of each behavior with their network members, $\operatorname{var}($ Intercepts $)=3.696$, Wald $\mathrm{Z}=11.263, p<.001$.
} 


\section{SOCIAL NETWORKS OF INTIMATE PARTNER VIOLENCE PERPETRATORS}

and participants in other groups used each of the behaviors from the inventory, and associated standard errors, t-statistics, and p-values are listed in table 17 below. 


\section{SOCIAL NETWORKS OF INTIMATE PARTNER VIOLENCE PERPETRATORS}

Table 17.

Use of Each Behavior by Participants in Criminally Oriented and Non Criminally Oriented

\section{Groups}

\begin{tabular}{|c|c|c|c|c|c|c|c|}
\hline \multirow[t]{2}{*}{ Behavior } & \multicolumn{2}{|c|}{$\begin{array}{c}\text { Non } \\
\text { Criminally } \\
\text { Oriented } \\
\text { Group } \\
\end{array}$} & \multicolumn{2}{|c|}{$\begin{array}{c}\text { Criminally } \\
\text { Oriented } \\
\text { Group }\end{array}$} & \multirow[t]{2}{*}{$d f$} & \multirow[t]{2}{*}{$t$} & \multirow[t]{2}{*}{$p$} \\
\hline & Mean & $\begin{array}{l}\text { Std. } \\
\text { Error }\end{array}$ & Mean & $\begin{array}{l}\text { Std. } \\
\text { Error }\end{array}$ & & & \\
\hline $\begin{array}{l}\text { Called this person out if you saw them } \\
\text { ignoring or being rude to their partner? }\end{array}$ & 2.01 & .19 & 3.78 & .86 & 2741.54 & 2.011 & $0.044^{*}$ \\
\hline $\begin{array}{l}\text { Shared information about abuse, } \\
\text { and/or resources for victims of abuse } \\
\text { with this person? }\end{array}$ & 2.67 & .18 & 4.15 & .81 & 2387.12 & 1.798 & 0.072 \\
\hline $\begin{array}{l}\text { Stuck up for this person's partner if } \\
\text { they were talking badly about them? }\end{array}$ & 1.83 & .20 & 2.88 & .97 & 3380.39 & 1.057 & 0.291 \\
\hline $\begin{array}{l}\text { Talked with this person about the } \\
\text { effects of abuse on children? }\end{array}$ & 2.73 & .18 & 4.43 & .76 & 2114.88 & 2.17 & $0.03 *$ \\
\hline $\begin{array}{l}\text { Challenged this person about their } \\
\text { controlling behavior? }\end{array}$ & 2.80 & .18 & 2.85 & .78 & 2256.05 & 0.061 & 0.952 \\
\hline $\begin{array}{l}\text { Recommended Allies in Change or a } \\
\text { similar program to this person? }\end{array}$ & .57 & .19 & 2.24 & .83 & 2558.99 & 1.996 & $0.050 *$ \\
\hline $\begin{array}{l}\text { Spoken up against sexist jokes or } \\
\text { jokes about abuse while you were with } \\
\text { this person? }\end{array}$ & .99 & .19 & 2.84 & .83 & 2560.95 & 2.181 & $0.029 *$ \\
\hline $\begin{array}{l}\text { Shared books or other materials from } \\
\text { Allies in Change with this person? }\end{array}$ & 1.16 & .18 & 2.93 & .83 & 2549.83 & 2.088 & $0.037^{*}$ \\
\hline $\begin{array}{l}\text { Asked this person not to talk about } \\
\text { abuse or act abusively around you? }\end{array}$ & 1.37 & .18 & 1.77 & .81 & 2391.71 & 0.491 & 0.623 \\
\hline $\begin{array}{l}\text { Encouraged this person to be } \\
\text { accountable for their abusive } \\
\text { behavior? }\end{array}$ & 2.08 & .18 & 1.91 & .83 & 2554.28 & 0.207 & 0.836 \\
\hline $\begin{array}{l}\text { Talked with this person about the } \\
\text { consequences of being abusive? }\end{array}$ & 2.80 & .18 & 3.84 & .75 & 1989.31 & 1.354 & 0.176 \\
\hline $\begin{array}{l}\text { Shared your story about abuse with } \\
\text { this person? }\end{array}$ & 3.57 & .18 & 6.34 & .75 & 1987.21 & 3.614 & $0.000^{*}$ \\
\hline $\begin{array}{l}\text { Told this person that you go to Allies } \\
\text { in Change? }\end{array}$ & 3.47 & .18 & 6.26 & .67 & 1596.69 & 4.025 & $0.000 *$ \\
\hline $\begin{array}{l}\text { Made amends with this person for } \\
\text { your abusive behavior? }\end{array}$ & 2.54 & .18 & 3.86 & .75 & 2002.76 & 1.721 & 0.085 \\
\hline $\begin{array}{l}\text { Apologized to this person for } \\
\text { demonstrating abusive behavior in the } \\
\text { past? }\end{array}$ & 2.78 & .18 & 4.49 & .73 & 1892.30 & 2.281 & $0.023 *$ \\
\hline $\begin{array}{l}\text { Have you done anything else with this } \\
\text { person that might have made them } \\
\text { think about abuse? }\end{array}$ & 2.05 & .28 & 3.53 & 1.10 & 3892.56 & 1.307 & .191 \\
\hline
\end{tabular}




\section{SOCIAL NETWORKS OF INTIMATE PARTNER VIOLENCE PERPETRATORS}

Note. Averages and standard errors are based on a sample of 4,245 behaviors used by of 87 participants in non-criminally oriented groups with 320 network members, and 214 behaviors used by 12 participants in criminally oriented groups with 23 network members.

$R Q$ 4.b. A two-level mixed model was tested to examine the association between participants' relationships to their network members and participants' total use of behaviors from the inventory of participants' own behaviors during the three months prior to data collection. For each of the participants' one through eight network members, participants' use of each behavior from the inventory was summed (recalling that original response options were recoded from 0 times, $1-5$ times, 6 - 10 times, 11 times or more, or not applicable to $0,2.5,8,12$, or missing, accordingly). The 343 network members were the level -one variable, nested within the 99 participants, the level-two variable. The ICC corresponding to participants' total use of behaviors with each network member was .50 in an intercepts-only model, indicating that half of the variance in participants' total use of behaviors with each of their network members was dependent upon themselves, $\operatorname{Var}($ Intercepts $)=384.707, \mathrm{Wald} Z=4.841, p<.001^{6}$. From an intercepts-only model, controlling for network members' nesting within participants, participants engaged in an average of 31.77 behaviors from the inventory with each of their network members $(S E=$ 2.33). The relational tie between participants and network members was used to predict the total number of times that participants had engaged in behaviors from the inventory with their network members, using a Bonferonni correction for multiple comparisons.

\footnotetext{
${ }^{6}$ Including the variable representing network members' relational ties in the model, intercept variance remained significant, $\operatorname{var}($ Intercepts $)=276.851$, Wald $Z=4.222, \mathrm{p}<$ .001 .
} 


\section{SOCIAL NETWORKS OF INTIMATE PARTNER VIOLENCE PERPETRATORS}

Participants use of behaviors from the inventory varied significantly across their relational ties to participants, $F(6,253.688)=13.685, p<.001$. Participants engaged in significantly more behaviors with their partners and former partners $(M=53.59, S E=$ 3.22) than with their friends or roommates $(M=25.67, S E=2.75, t(277.78)=7.738, p<$ $.001)$, their bosses or coworkers $(M=22.82, S E=3.67, t(255.53)=30.771, p<.001)$, members of their family of origin $(M=28.23, S E=2.85, t(264.63)=6.974, p<.001)$, their children $(M=32.08, S E=4.23, t(252.90)=4.601, p<.001)$, or their in-laws $(M=$ 20.57, $S E=5.94, t(233.10)=5.27, p<.001)$. Among participants' friends and roommates, bosses and coworkers, family of origin, children, and in-laws, there were no significant differences in the total number of times that network members engaged in behaviors from the inventory with participants. There was not a significant difference between the average number of times that participants used behaviors from the inventory with their current or former partners and their "other" relational ties $(M=34.12, S E=$ 6.86), controlling for the nesting of network members within participants. See table 18 below for the average number of times that participants used IPV-relevant behaviors with each of their relational ties. 


\section{SOCIAL NETWORKS OF INTIMATE PARTNER VIOLENCE PERPETRATORS}

Table 18.

Participants’ Total Use of Behaviors with Network Members by Relational Tie

\begin{tabular}{lcc}
\hline Network members' & $\underline{M}$ & $\underline{S E}$ \\
relational tie & 25.67 & 2.75 \\
Friend/Roommate & 22.82 & 3.67 \\
Boss/Coworker & 28.23 & 2.85 \\
Family of origin & 32.08 & 4.23 \\
Child & 20.57 & 5.94 \\
In- law & 53.59 & 3.22 \\
Partner/ former partner & 34.12 & 6.86 \\
Other & Note. Averages based 99 participants' interaction with 343 network members.
\end{tabular}

Again, two exploratory mixed models were tested, with the 343 network members (the level-one variable) nested within the 99 participants (the level-two variable). In the first exploratory model, participants' grand mean centered attendance interacted with participants' relational ties to their network members to predict participants' total use of behaviors with their network members. Controlling for the participant, there was a significant interaction between participants' centered attendance and their network members' status as their partners or former partners, $\beta=0.62, t(267.962)=3.077, p=$ $.002^{7}$. Specifically, participants engaged in approximately two additional behaviors with their partners or former partners for every three additional weeks that they had attended Allies in Change compared to their peers. Participants' attendance did not significantly

\footnotetext{
${ }^{7}$ Including the interaction of centered attendance and behavior type in the model, there remained significant variance in the intercepts corresponding to participants' use of each behavior, $\operatorname{var}($ Intercepts $)=228.899, \mathrm{Z}=3.723, \mathrm{p}<.001)$.
} 


\section{SOCIAL NETWORKS OF INTIMATE PARTNER VIOLENCE PERPETRATORS}

predict their use of abuse-relevant behavior with network members other than their current/former partners.

In the second exploratory model that was tested, the interactions of participants' enrollment in a group for criminally oriented men and their relational tie to their network members were used to predict participants' total use of behaviors with each of their network members during the three months prior to data collection. Controlling for network members' nesting within participants, there were no significant differences between participants in groups for criminally oriented men and participants in other groups, in terms of their total use of behaviors with network members to whom they had different relational ties. Participants' total use of behaviors with network members to whom they had different relational ties did not vary significantly between participants in groups for criminally oriented men and participants in other groups.

$R Q$ 4.c. An additional mixed model was tested to determine whether participants engage in different types behaviors from the inventory of their own behaviors to different extents with network members to whom they have different relational ties. Instead of examining interactions between each type of relational tie and each of the 16 behaviors from the inventory, four composite scores were computed to assess the following categories of behavior: intervening in others' abusive behavior, talking theoretically about abuse, self-disclosure, or sharing information. Participants' use of the six behaviors that involve directly intervening in behavior were averaged within each network member that they nominated. These items were: “called this person out if you 


\section{SOCIAL NETWORKS OF INTIMATE PARTNER VIOLENCE PERPETRATORS}

saw them ignoring or being rude to their partner," "stuck up for this person's partner if they were talking badly about them," "challenged this person about their controlling behavior," "spoken up against sexist jokes or jokes about abuse while you were with this person," "encouraged this person to be accountable for their abusive behavior," and "asked this person not to talk about abuse or act abusively around you." The second composite score that was created represents participants' average use of the two behaviors that involve theoretically discussing abuse with each of their nominated network members ("talked with this person about the effects of abuse on children" and "talked with this person about the consequences of being abusive"). A third composite variable represents the average of participants' self-disclosure about IPV with each of their network members. This composite is the average of participants' responses to each of the following items, with each of their network members: "shared your story about abuse with this person," "told this person that you go to Allies in Change," "made amends with this person for your abusive behavior," and "apologized to this person for demonstrating abusive behavior in the past." The fourth composite score is an average of participants' information-sharing behaviors with each of their network members. The items that were averaged within each network member to create this score were "shared information about abuse, and/or resources for victims with this person," "recommended Allies in Change or a similar program to this person," and "shared books or other materials from Allies in Change with this person." One variable was created to represent participants' use of each composite type of behavior over the three months prior to data 


\section{SOCIAL NETWORKS OF INTIMATE PARTNER VIOLENCE PERPETRATORS}

collection. Across the four composite variables, there were a total of 1,314 level-one observations. These scores were nested within 343 network members (the level-two variable). In an intercepts-only model, the nesting of composite scores within network members accounted for $43.26 \%$ of the variance in scores $(\mathrm{ICC}=.4326, \operatorname{var}($ Intercepts $)=$ 2.553, Wald $\mathrm{Z}=9.639, p<.001)$. Participants' scores on each of these composites were predicted by the interaction of the variable representing the specific composite (intervening in behavior, talking theoretically about abuse, self-disclosure, or sharing information) and their relational tie to the network member with whom they used these sets of behaviors. Participants' use of intervening behaviors, theoretical discussions about abuse, self-disclosure, and information sharing were predicted by the interaction of the variable representing the type of behavior and the variable representing each relational tie linking participants and their network members. Averaging across relational ties and controlling for the nesting structure of the data, participants engaged in an average of $2.97(S E=.17)$ instances of self disclosure with each of their network members, 2.91 ( $S E$ $=.17)$ instances of speaking theoretically about abuse with each network member, 1.44 $(S E=.17)$ intervening behaviors with each network member, and $1.31(S E=.17)$ instances of sharing information about abuse with each of their network members during the preceding three months. Thus, it appears that participants engaged in both selfdisclosures about abuse and theoretical discussions of abuse about once per month, and used intervening behaviors and information sharing once every month and a half with each of their network members. The interaction of the type of composite and participants' 


\section{SOCIAL NETWORKS OF INTIMATE PARTNER VIOLENCE PERPETRATORS}

relational tie to their network member significantly predicted their score on the behavioral composite, $F(27,660.292)=11.978, p<.001$. The means and standard errors associated with participants' use of each type of behavior composite, with each of type of relational tie, controlling for the nesting of behavior composites within network members, are presented in table 19 below. Controlling for composite scores' nesting within network members and using a Bonferonni correction for multiple comparisons, participants did not use significantly different numbers of intervening behaviors, the first composite examined, with network members to whom they have different relational ties. Controlling for the nesting of composite scores within network members, participants engaged in significantly more theoretical discussions about abuse with their partners and former partners than with their friends and roommates $(t(808.379)=4.988, p<.001)$, their bosses and coworkers $(t(794.120)=3.814, p=.003)$, their families of origin $(t(804.33)=3.821, p=.003)$, and their in-laws $(t(794.120=3.154, p=.035)$. They also engaged in significantly more theoretical discussion about abuse with their "other" relational ties than with their friends and roommates $(t(797.734)=3.207, p=.029)$. Accounting for the nesting of composite scores within network members, participants made significantly more disclosures about their personal experiences regarding abuse to their current/former partners than to their friends/roommates $(t(794.120)=7.692, p<$ $.001)$, bosses/coworkers $(t(794.120)=6.474, p<.001)$, families of origin $(t(794.120)=$ $6.805, p<.001)$, children $(t(807.757)=4.275, p<.001)$, in-laws $(t(794.120)=4.008, p$ $=.001)$, and "other" relational ties $(t(794.120)=3.434 p=.013)$. Additionally, 


\section{SOCIAL NETWORKS OF INTIMATE PARTNER VIOLENCE PERPETRATORS}

controlling for the nesting structure of the data, participants shared information about abuse significantly more with their partners and former partners than with their friends/roommates $(t(820.558)=4.056, p=.001)$, family of origin $(t(814.569)=3.600, p$ $=.007)$, and children $(t(1.843)=3.381, p=.016)$.

Table 19.

Participants' Average Use of Behavior Composites by Relational Tie

\begin{tabular}{|l|c|c|c|c|c|c|c|c|}
\hline \multirow{2}{*}{$\begin{array}{l}\text { Network } \\
\text { members' } \\
\text { relational tie }\end{array}$} & \multicolumn{2}{|c|}{$\begin{array}{c}\text { Intervening } \\
\text { Behavior }\end{array}$} & \multicolumn{2}{c|}{$\begin{array}{c}\text { Theoretical } \\
\text { Discussions }\end{array}$} & \multicolumn{2}{c|}{$\begin{array}{c}\text { Self- } \\
\text { Disclosure }\end{array}$} & \multicolumn{2}{c|}{$\begin{array}{c}\text { Sharing } \\
\text { Information }\end{array}$} \\
\cline { 2 - 10 } & Mean & $\begin{array}{c}\text { Std. } \\
\text { Error }\end{array}$ & Mean & $\begin{array}{c}\text { Std. } \\
\text { Error }\end{array}$ & Mean & $\begin{array}{c}\text { Std. } \\
\text { Error }\end{array}$ & Mean & $\begin{array}{c}\text { Std. } \\
\text { Error }\end{array}$ \\
\hline Friend/Roommate & 1.29 & .23 & 2.11 & .28 & 2.39 & .22 & .98 & .23 \\
\hline Boss/Coworker & 1.28 & .35 & 2.26 & .34 & 2.32 & .34 & 1.28 & .34 \\
\hline Family of origin & 1.24 & .25 & 2.50 & .25 & 2.62 & .25 & 1.10 & .25 \\
\hline Child & 1.89 & .44 & 3.17 & .42 & 3.06 & .42 & .69 & .45 \\
\hline In- law & .63 & .62 & 1.81 & .62 & 2.50 & .62 & .64 & .62 \\
\hline $\begin{array}{l}\text { Partner/ former } \\
\text { partner }\end{array}$ & 2.42 & .31 & 4.01 & .31 & 5.29 & .31 & 2.53 & .31 \\
\hline Other & 1.31 & .75 & 4.53 & .72 & 2.60 & .72 & 1.96 & .75 \\
\hline
\end{tabular}

Note. Statistics based 99 participants' interaction with 343 network members. 


\section{Hypotheses}

The following analyses were conducted utilizing only those social network members that participants nominated, with whom they reported interacting at least once a year. Participants were asked to nominate network members on the basis of their importance to them, however, despite their importance in participants' lives, if they do not interact regularly, there will be little opportunity for them to communicate about IPV, particularly within the 3-month window on which the survey focused.

$H$ 1. Two series of hierarchical linear regression models were conducted to examine (1) whether there is a significant negative relationship between network members' expressed support for IPV and the quality of participants' relationships with their network members, and (2) whether there is a significant positive relationship between network members' expressed disapproval of IPV and the quality of participants' relationships with their network members. The frequency of network members' use of the 10 behaviors that indicate support for IPV over the preceding three months were averaged, to create a single score of their average use of pro-abuse behaviors, as in Research Question 3c. The ICC, intercept variance, and general descriptives of the relationship quality measure are provided in the analysis of Research Question 2. These scores were grand mean centered for inclusion in the first model. The 343 network members were considered the level-one variable, nested within the 99 participants. The average relationship quality score that participants assigned to each of their network members were predicted by network members' use of pro-abuse behaviors, grand mean centered. The data indicate that the more pro-abuse behaviors that network members 


\section{SOCIAL NETWORKS OF INTIMATE PARTNER VIOLENCE PERPETRATORS}

engaged in during the prior three months, the less affection participants felt towards them. These data are consistent with hypothesis 1 , indicating that network members' use of proabuse behaviors significantly and negatively predicted participants' affection for them, $(\beta=$ $.02, t(287)=-2.49, p=.014$. Two exploratory additions to the model were evaluated separately. The interaction of participants' grand mean centered attendance and network members' grand mean centered average use of pro-abuse behaviors was introduced to the model as an additional predictor. This interaction was not significant, $\beta=.0001, t(270)=.29$, $p=.773$. The interaction of participants' enrollment in a group for criminally oriented men and network members' use of pro-abuse behaviors was also entered into the model, and this interaction was also non-significant, $\beta=.03, t(310)=1.09, p=.275$. The more pro-abuse behaviors that network members engaged in, the less affection participants felt towards them.

In the second set of hierarchical linear models, network members' (grand mean centered) use of anti-abuse behaviors over the preceding three months was used to predict the quality of participants' relationships with their network members. Again, the 343 network members were considered the level-one variable, nested within the 99 participants. In an intercepts-only model, the ICC for network member's anti-abuse behaviors was 0.62 , indicating that $62 \%$ of the variance in network members' use of anti-abuse behaviors was due to the participant who nominated them. Accounting for the nesting structure of the data, network members' use of anti-abuse behaviors was not significantly predictive of participants' feelings of affection towards their network members, $\beta=.01, t(317)=0.85, p=$ .394. Two exploratory models were also tested here, one in which participants' grand mean 


\section{SOCIAL NETWORKS OF INTIMATE PARTNER VIOLENCE PERPETRATORS}

centered attendance was allowed to interact with network members' use of anti-abuse behaviors, and one in which participants' enrollment in a group for criminally oriented men was allowed to interact with network members' use of anti-abuse behaviors. Neither of these interactions were significant, $\beta_{\text {centered attendance* anti-abuse behaviors }}=.0007, t(317)=1.25, p=.213$; $\beta_{\text {criminally oriented group } * \text { anti-abuse behaviors }}=.03, t(180)=0.89, p=.378$. Thus, network members' use of anti-abuse behaviors during the three months prior to data collection did not significantly predict participants' feelings of affection towards their network members.

$H$ 2. A set of hierarchical linear regressions was conducted to determine whether there is a relationship between network members' expressed support for IPV and the total number of behaviors in which participants engage with them, during the prior three months. It was hypothesized that there would be a positive relationship between network members' support for IPV and the total number of behaviors in which participants engage them. Again, the 343 network members were considered the level-one variable, nested within the 99 participants. In an intercepts-only model, the ICC for the sum total of participants' use of behaviors with each network member was .6247 , indicating that $62.47 \%$ of the variance in participant's total use of behaviors with each of their network members is due to the participant (var[Intecepts] $=84.707$, Wald $Z=4.841, \mathrm{p}<.001)$. Network members' grand mean centered use of pro-abuse behaviors was used to predict the total number of behaviors in which participants had engaged with that network member. Controlling for the nesting structure of the data, network members' use of pro-abuse behaviors was significantly predictive of participants' use of any behaviors, $\beta=.54, t(323)=5.20, p<.001$. Thus, at the 


\section{SOCIAL NETWORKS OF INTIMATE PARTNER VIOLENCE PERPETRATORS}

mean of network members' use of pro-abuse behaviors, participants engage in one additional behavior for every two additional pro-abuse behaviors that their network members use. Two variants of this model were tested: one in which participants' grand mean centered attendance was allowed to interact with network members' grand mean centered use of proabuse behaviors, and one in which participants' enrollment in a group for criminally oriented men was allowed to interact with network members' grand mean centered use of pro-abuse behaviors. The interaction of grand mean centered attendance and network members' proabuse behaviors during the prior three months was not significant $\beta=.01, t(286)=0.21, p=$ .84. However, the interaction of participants' enrollment in a group for criminally oriented men and network members' pro-abuse behaviors was negatively and significantly related to participants' use of behaviors with their network members, $\beta=-.71, t(321)=-1.98, p=.048$. Controlling for the nesting structure of the data, and at the mean of network members' use of pro-abuse behaviors, participants in groups for criminally oriented men engaged in an average of .7 fewer behaviors for every additional pro-abuse behavior that their network member utilized; as opposed to balancing network members' pro-abuse behaviors with their own behaviors, men in groups for criminally oriented participants engaged in fewer behaviors with network members who expressed more pro-abuse attitudes.

Finally, an additional set of hierarchical linear regressions was conducted to determine whether there is a relationship between network members' use of anti-abuse behaviors and the total number of behaviors in which participants engage with them. No hypothesis was drawn about this relationship, as network members' use of anti-abuse 


\section{SOCIAL NETWORKS OF INTIMATE PARTNER VIOLENCE PERPETRATORS}

behaviors was not expected when the study was first proposed. Again, the 343 network members were considered the level-one variable, nested within the 99 participants. In an intercepts-only model, the ICC was .4702, indicating that the nesting of network members within participants accounted for $47.02 \%$ of the variance in scores of network members' use of anti-abuse behaviors [var(Intercepts) $=52.375$, Wald Z $=4.417, p<.001]$. Network members' grand mean centered use of anti-abuse behaviors was used to predict the total number of behaviors in which participants had engaged with that network member during the three months prior to data collection. Controlling for the nesting structure of the data, network members' use of anti-abuse behaviors was significantly and positively predictive of participants' use of any behaviors, $\beta=1.63, t(327)=14.50, p<.001$. Accounting for the nesting structure of the data, and at the mean of network members' use of anti-abuse behaviors, participants engaged in over three abuse-relevant behaviors for every two additional anti-abuse behaviors that their network member engaged in. Here again, two additional exploratory models were tested, one in which participants' grand mean centered attendance was allowed to interact with network members' grand mean centered use of antiabuse behaviors, and one in which participants' enrollment in a group for criminally oriented men was allowed to interact with network members' grand mean centered use of anti-abuse behaviors. Neither the interaction of participants' grand mean centered attendance and network members' anti-abuse behaviors, $\beta=.005, t(316)=0.72, p=.47$, nor the interaction of participants' enrollment in a group for criminally oriented men and network members' anti-abuse behaviors, $\beta=-.35, t(173)=-.87, p=.38$, were significant. Thus, a positive 


\section{SOCIAL NETWORKS OF INTIMATE PARTNER VIOLENCE PERPETRATORS}

association was found between participants' and their network members' use of anti-abuse behaviors, and this was not effected by either their BIP attendance or their enrollment in a criminally-oriented group.

\section{Summary of Findings}

Items from pre-existing measures were compiled to create two inventories of IPVrelevant behaviors: those that BIP participants' network members may engage in, and those that BIP participants may engage in. A series of focus groups with BIP facilitators and participants were conducted to iteratively refine and pilot test the inventories. Surveys were then distributed in 22 BIP groups at Allies in Change. The quantitative findings from the survey instrument are summarized below. Following the completion of quantitative data analysis, preliminary results were presented to a final focus group of BIP participants, to solicit their interpretations and reactions, which were used to inform the discussion that follows the summary of quantitative findings. The research questions, hypotheses, and their associated findings are summarized in table 20, below. 


\section{SOCIAL NETWORKS OF INTIMATE PARTNER VIOLENCE PERPETRATORS}

Table 20.

Summary of Research Questions, Hypotheses and Associated Findings.

\begin{tabular}{|c|c|}
\hline Research Question & Finding \\
\hline \multicolumn{2}{|c|}{ 1. What are the characteristics of BIP participants' social networks? } \\
\hline $\begin{array}{l}\text { 1.a. How many social network members do BIP } \\
\text { participants report? }\end{array}$ & $M$ network members $=3.5$ \\
\hline $\begin{array}{l}\text { 1.b. What are the genders of participants' reported } \\
\text { network members? }\end{array}$ & $\begin{array}{l}\text { Approximately equal numbers of male and } \\
\text { female network members: } M \text { male network } \\
\text { members }=1.8, M \text { female network members }= \\
1.7\end{array}$ \\
\hline $\begin{array}{l}\text { 1.c. What are the relational ties that connect } \\
\text { participants to their network members? }\end{array}$ & $\begin{array}{l}\text { Friends/roommates }(M=1.0) \text {, family of } \\
\text { origin }(M=.8) \text {, current/former partners }(M \\
=.5), \text { bosses/coworkers }(M=.4) \text {, children }(M \\
=.3) \text {, in-laws }(M=.1) \text {, and "other" }(M=.1)\end{array}$ \\
\hline
\end{tabular}

2. How do BIP participants perceive the quality of their relations with their social network members?

Participants were most often "somewhat"

2.a. What is the quality of participants' relationships

satisfied or "very much" satisfied with

with their network members overall?

relationships with network members $(M=2.4$

on a scale of -4 to 4 )

\section{No significant differences were found in} participants' satisfaction with male and

2.b. What is the quality of participants' relationships with their male and female network members?

female network members: $M$ satisfaction with relationships with male network members = 2.5, $M$ satisfaction with relationships with female network members $=2.3$ (on a scale of -4 to 4)

Participants were most satisfied with

2.c. What is the quality of participants' relationships with network members to whom they have various relational ties?

relationships with friends/roommates $(M=$ 2.8) and least satisfied with relationships with current/former partners $(M=1.8)$ and in-laws $(M=1.8)$

3. How do BIP participants' network members communicate about abuse with BIP participants?

Network members used:

3.a. How do BIP participants' network members communicate about abuse?

- anti-abuse behaviors ( $M=2.6$ uses of each)

- pro-abuse behaviors ( $M=1.0$ use of each)

$M=22.1$ behaviors, overall

Are network members' abuse-relevant behaviors related to participants' attendance?
- Network members' use of anti-abuse behavior was positively related to participants' attendance.

- Network members' use of pro-abuse 


\section{SOCIAL NETWORKS OF INTIMATE PARTNER VIOLENCE PERPETRATORS}

\section{behavior was negatively related to participants' attendance.}

Are network members' abuse-relevant behaviors related to participants' enrollment in a criminally oriented group?

Network members of participants in criminally oriented groups used more behaviors (both anti-abuse and pro-abuse) than network members of men in other groups.

3.b. Is the type of relational tie that participants have to
their network members related to the number of times
that the network members use abuse-relevant
behaviors?

Is this relationship moderated by participants' attendance?

Current/former partners $(M=32.4$ times $)$ and family of origin $(M=25.5)$ used abuserelevant behaviors most often.

Is this relationship moderated by participants'
attendance?

Participants' children's use of behavior was negatively related to participants' attendance.

- Participants' family of origin used more behaviors when participants were enrolled in criminally oriented groups $(M=54.2)$, Is this relationship moderated by enrollment in a criminally oriented group? than when they were not $(M=24.0)$.

- Participants' children used more behaviors when participants were enrolled in criminally oriented groups $(M=47.2)$ than when they were not $(M=11.4)$.

Participants' friends/roommates, bosses/coworkers, family of origin, partners/former partners, and "other"

3.c. Do network members to whom participants have different relational ties use different abuse-relevant behaviors? relational ties all used each anti-abuse behavior significantly more frequently than they used each pro-abuse behavior. This was not the case for participants' in-laws and children.

4. How do BIP participants communicate about abuse with their network members?

Participants used:

- $\quad$ self disclosures $(M=3.0$ uses of each component behavior with each network member)

- theoretical discussions about abuse $(M=$

4.a. How do BIP participants communicate about abuse? 2.9 uses of each component behavior with each network member)

- intervening in network members' abusive talk or behavior $(M=1.4$ uses of each component behavior with each network member)

- $\quad$ sharing information about abuse $(M=1.3$ uses of each component behavior with each 


\section{SOCIAL NETWORKS OF INTIMATE PARTNER VIOLENCE PERPETRATORS}

\begin{tabular}{|c|c|}
\hline & $\begin{array}{l}\quad \text { network member }) \\
\boldsymbol{M}=\mathbf{3 1 . 8} \text { behaviors with each network } \\
\text { member overall }\end{array}$ \\
\hline $\begin{array}{l}\text { Are participants' abuse-relevant behaviors } \\
\text { related to their attendance? }\end{array}$ & $\begin{array}{l}\text { Participants' use of intervening behaviors was } \\
\text { negatively related to their attendance. } \\
\text { Participants' use of self-disclosures was } \\
\text { positively related to their attendance. }\end{array}$ \\
\hline $\begin{array}{l}\text { Are participants' abuse-relevant behaviors } \\
\text { related to their enrollment in a criminally } \\
\text { oriented group? }\end{array}$ & $\begin{array}{l}\text { Participants in criminally oriented groups } \\
\text { used more behaviors than participants in non- } \\
\text { criminally oriented groups. }\end{array}$ \\
\hline $\begin{array}{l}\text { 4.b. Is the type of relational tie that participants have } \\
\text { to their network members related to the number of } \\
\text { times that BIP participants use abuse-relevant } \\
\text { behaviors? }\end{array}$ & $\begin{array}{l}\text { Participants used abuse-relevant behaviors } \\
\text { most often with their current/former partners } \\
(M=53.6)\end{array}$ \\
\hline $\begin{array}{l}\text { Is this relationship moderated by participants' } \\
\text { attendance? }\end{array}$ & $\begin{array}{l}\text { Participants' use of behaviors with their } \\
\text { current/former partners was positively } \\
\text { related to their attendance. }\end{array}$ \\
\hline $\begin{array}{l}\text { Is this relationship moderated by enrollment in } \\
\text { a criminally oriented group? }\end{array}$ & No. \\
\hline $\begin{array}{l}\text { 4.c. Do participants use different abuse-relevant } \\
\text { behaviors with network members to whom they have } \\
\text { different relational ties? }\end{array}$ & $\begin{array}{l}\text { Participants used self-disclosures, theoretical } \\
\text { discussions about abuse, and information } \\
\text { sharing significantly more often with their } \\
\text { current/former partners than other relational } \\
\text { ties. }\end{array}$ \\
\hline \multicolumn{2}{|c|}{$\begin{array}{l}\text { Hypothesis } 1 \text {. There is a negative relationship between network members' use of abuse-relevant behaviors } \\
\text { and the quality of participants' relationships with their network members. }\end{array}$} \\
\hline
\end{tabular}

Hypothesis 1a: There is a negative relationship

between network members' use of anti-abuse behaviors

and the quality of participants' relationships with their

Not supported.

network members.

\begin{tabular}{ll}
\hline $\begin{array}{l}\text { Is this relationship moderated by participants' } \\
\text { attendance? }\end{array}$ & No. \\
\hline $\begin{array}{l}\text { Is this relationship moderated by enrollment in } \\
\text { a criminally oriented group? }\end{array}$ & No. \\
\hline $\begin{array}{l}\text { Hypothesis 1b: There is a negative relationship } \\
\text { between network members' use of pro-abuse } \\
\text { behaviors and the quality of participants' relationships } \\
\text { with their network members. }\end{array}$ & Supported. \\
\hline $\begin{array}{l}\text { Is this relationship moderated by participants' } \\
\text { attendance? }\end{array}$ & No. \\
\hline $\begin{array}{l}\text { Is this relationship moderated by enrollment in } \\
\text { a criminally oriented group? }\end{array}$ & No. \\
\hline $\begin{array}{l}\text { Hypothesis 2. There is a positive relationship between network members' use of abuse-relevant behaviors } \\
\text { and the number of times that participants use abuse-relevant behaviors with those network members. }\end{array}$ \\
\hline
\end{tabular}




\section{SOCIAL NETWORKS OF INTIMATE PARTNER VIOLENCE PERPETRATORS}

Hypothesis 2a: There is a positive relationship between network members' use of anti-abuse behaviors and participants' use of abuse-relevant behaviors with those Supported. network members.

\begin{tabular}{cl}
\hline $\begin{array}{l}\text { Is this relationship moderated by participants' } \\
\text { attendance? }\end{array}$ & No. \\
\hline $\begin{array}{l}\text { Is this relationship moderated by enrollment in } \\
\text { a criminally oriented group? }\end{array}$ & No. \\
\hline $\begin{array}{l}\text { Hypothesis } 2 \text { b: There is a positive relationship } \\
\text { between network members' pro-abuse communication } \\
\text { and the participants' use of abuse-relevant behaviors } \\
\text { with those network members. }\end{array}$ & Supported. \\
\hline $\begin{array}{l}\text { Is this relationship moderated by participants' } \\
\text { attendance? }\end{array}$ & No. \\
\hline $\begin{array}{ll}\text { Is this relationship moderated by enrollment in } \\
\text { a criminally oriented group? }\end{array}$ & $\begin{array}{l}\text { For participants in criminally oriented } \\
\text { groups, there was a negative relationship } \\
\text { betwen network members' use of pro-abuse } \\
\text { behaviors and participants' use of abuse- } \\
\text { relevant behaviors. }\end{array}$ \\
\hline
\end{tabular}


The one hundred and two participants who provided usable data nominated a total of 360 network members, or an average of approximately 3.5 network members each. Participants nominated roughly equal numbers of men and women. Their social networks were comprised of the following relational ties, listed in order from most to least frequently nominated: friends/roommates, members of their family of origin, partners/former partners, bosses/coworkers, children, in laws, and "other" relational ties. Participants had daily or almost daily contact with nearly two thirds of their network members (between 2 and 3 individual network members). Participants were most commonly "satisfied" or "very satisfied" with their relationships with their network members, regardless of a network member's gender. Participants were most satisfied with their relationships with their friends/roommates, and least satisfied with their relationships with their current/former partners and their in-laws.

Network members tended to use each anti-abuse behavior more often than each pro-abuse behavior, and this pattern was more pronounced among participants who had been attending Allies in Change for longer. Participants' friends/roommates, bosses/coworkers, family of origin, partners/former partners, and "other" relational ties all used the anti-abuse behaviors significantly more often than the pro-abuse behaviors. Participants' current/former partners used the most abuse-relevant behaviors (both proand anti-), and their in-laws used abuse-relevant behaviors the least of all of the types of relational ties. Participants' children used approximately one fewer behavior for every two weeks that participants had been attending Allies in Change; no other relational ties' 


\section{SOCIAL NETWORKS OF INTIMATE PARTNER VIOLENCE PERPETRATORS}

use of abuse-relevant behaviors were significantly related to the amount of time that participants had been attending the program.

As hypothesized, a negative relationship was found between network members' use of pro-abuse behaviors and participants' rating of the quality of their relationship with that network member. Network members' use of anti-abuse behaviors was not significantly related to participants' rating of the quality of their relationship with that network member. Network members' use of both pro-abuse and anti- abuse behaviors were significantly predictive of participants' use of abuse-relevant behaviors, as predicted by the second hypothesis.

In communicating anti-abuse messages to their network members, participants most often used self-disclosures. Their attendance at Allies in Change was positively related to their use of self-disclosures and information sharing, and negatively related to their use of intervening behaviors. Participants used the most abuse-relevant behaviors with their current and former partners, across the four categories of behaviors that were identified. Those who had been attending Allies in Change for longer engaged in more behaviors with their partners than those who were newer to the program.

Several differences were identified between participants in groups for criminally oriented men and participants in other groups. Network members of participants in groups for criminally oriented men were generally more communicative about IPV than the network members of participants in groups that are not specialized for criminally oriented men. Participants in groups for criminally oriented men also communicated 


\section{SOCIAL NETWORKS OF INTIMATE PARTNER VIOLENCE PERPETRATORS}

about abuse with their network members more often than participants in other groups.

Opposite to participants in non-criminally oriented groups, there was a negative

relationship between criminally oriented participants' and their network members' use of

abuse-relevant behaviors. As opposed to balancing network members' pro-abuse

behaviors with their own behaviors, men in groups for criminally oriented participants

engaged in fewer behaviors with network members who expressed more pro-abuse attitudes. 


\section{SOCIAL NETWORKS OF INTIMATE PARTNER VIOLENCE PERPETRATORS}

\section{Chapter 3. Discussion, Implications, and Limitations}

The section that follows discusses the findings of the current study and draws implications for existing theories and prior research on the relationship between social networks and IPV. The current findings can be best understood by returning to the rationale and significance of the study, placing the findings in the context of previously reviewed literature and the gaps therein, before addressing the implications of a subset of these findings. Three primary implications are highlighted throughout the sections addressing implications for practice, theory, and research, respectively. The implications of primary importance pertain to (1) the conceptualization of BIP participants as active bystanders, intervening in the norms that allow abuse to continue within their communities; (2) the description of how and from whom BIP participants receive support for the perpetration of IPV; and (3) the development of novel data collection tools to enabled further research on BIP participants' use of, and exposure to, abuse-relevant communication with other individuals. Note that the only analysis of differences between participants in criminally oriented groups and participants in non-criminally oriented groups is located in the section that addresses criminally oriented groups, specifically. The next section includes an overview of some of the study's basic findings, couched within a brief review of the literature that motivated the research. These findings are compiled and simplified in table 21 , below. The ramifications of these central findings, as well as descriptions of more nuanced findings, and their relevance for BIP practice, relevant theory, and future research, are discussed in the following section. 


\section{SOCIAL NETWORKS OF INTIMATE PARTNER VIOLENCE PERPETRATORS}

Table 21.

\section{Summary of Substantive Findings}

\begin{tabular}{|c|c|c|c|c|c|c|}
\hline 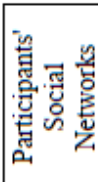 & \multicolumn{6}{|c|}{ 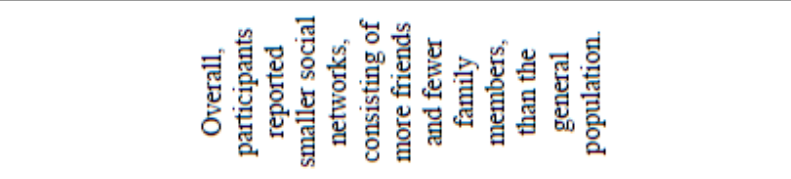 } \\
\hline \multirow{2}{*}{ 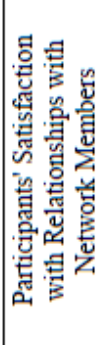 } & \multicolumn{6}{|c|}{ 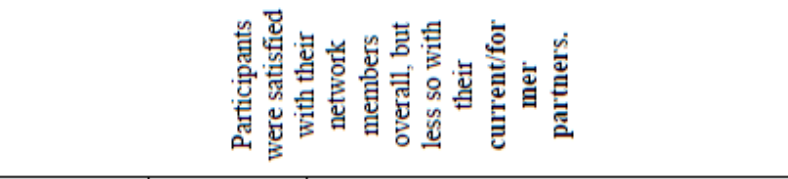 } \\
\hline & $\tilde{z}$ & 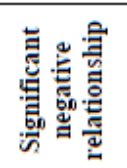 & \multicolumn{4}{|c|}{ 孚 } \\
\hline 资䓈 & $\tilde{z}$ & 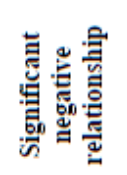 & $\tilde{z}$ & 行 & 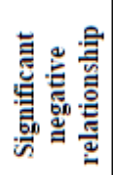 & $\tilde{z}^{2}$ \\
\hline 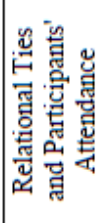 & \multicolumn{2}{|c|}{ 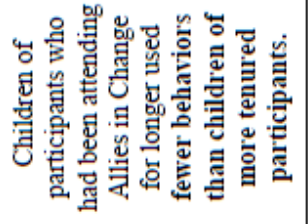 } & \multicolumn{4}{|c|}{ 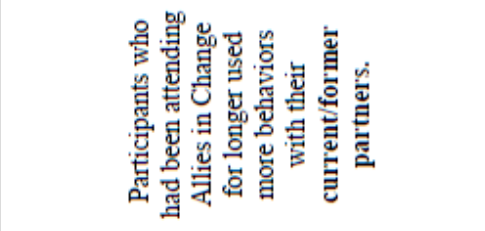 } \\
\hline \multirow[t]{4}{*}{ 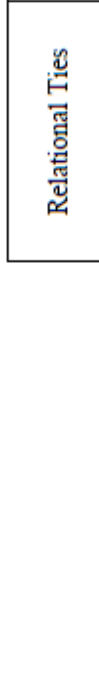 } & \multicolumn{2}{|c|}{ 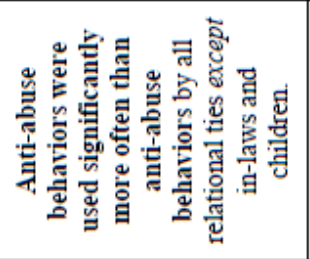 } & \multicolumn{4}{|c|}{ 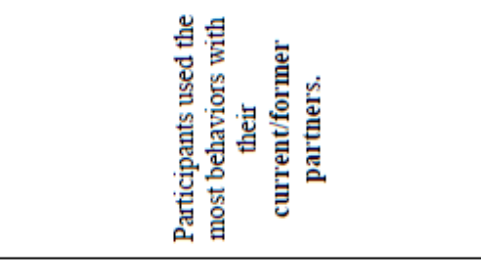 } \\
\hline & \multicolumn{6}{|c|}{ 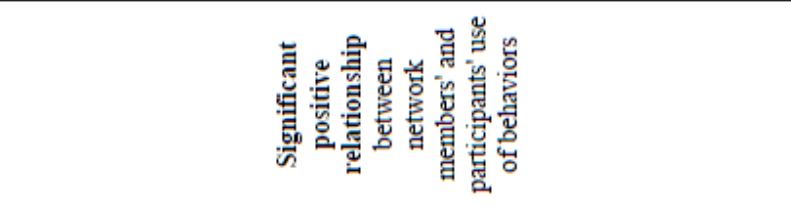 } \\
\hline & 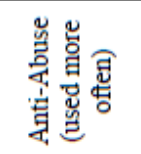 & 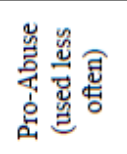 & 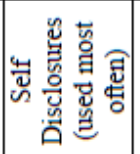 & 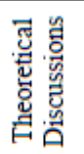 & 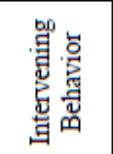 & 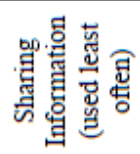 \\
\hline & \multicolumn{2}{|c|}{ 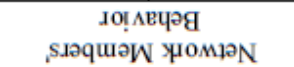 } & \multicolumn{4}{|c|}{ 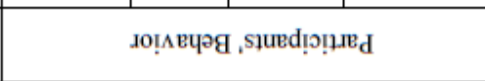 } \\
\hline
\end{tabular}

Note. NS $=$ Non-significant relationship. 


\section{SOCIAL NETWORKS OF INTIMATE PARTNER VIOLENCE PERPETRATORS}

\section{Addressing Gaps in Prior Literature}

The first aim of the current study was to describe the social networks of BIP participants, to gain a deeper understanding of the social environments in which they are most immediately embedded (Borgatti, Mehra, Brass \& Labianca, 2009; Juras et al., 1997; Luke, 2005; Shinn \& Rapkin, 2000), in terms of their structure and content. Prior studies of networks' influence on the perpetration of violence against women have defined social networks as either those people who provide social support to participants (Raghavan et al., 2009) or as participants' friends (Abbey et al., 2001; DeKeseredy, 1988; DeKeseredy, 1990b; Gidycz, Orchowski \& Berkowitz, 2011), excluding other relational ties that may be present in social networks. In the current study, participants nominated any network members who were important to them, and described their relational ties to each network member. Thus, this is the first study to the researcher's knowledge that allows for a more detailed assessment of the size and membership of BIP participants' social networks.

Participants in the current study had smaller social networks than the general population. Based on samples of adult participants in two cohorts of the North American Framingham Heart Study, estimates of average social network sizes were seven and a half (Christakis \& Fowler, 2007), ten and a half (Fowler \& Christakis, 2008) and eleven (McDermott, Fowler \& Christakis, 2013). These estimates of social network size among members of the general population were based on Framingham Heart Study participants' nominations of their relatives, “close friends," places of residence, and places of work 


\section{SOCIAL NETWORKS OF INTIMATE PARTNER VIOLENCE PERPETRATORS}

between 1971 and 2003 (Fowler \& Christakis, 2008; McDermott, Fowler \& Christakis, 2013). Network members were limited to five mutually exclusive relational ties: spouses, siblings, friends, coworkers, and neighbors (Fowler \& Christakis, 2008; McDermott, Fowler \& Christakis, 2013). Thus, there were more restraints on Framingham Heart Study participants' nominations of social network members than on the nomination of network members among participants in the current study. Given the broad prompt that was used to elicit participants' nominations of network members ("the people you have spent the most time with") and the absence of any restrictions on participants' relational ties to their network members, participants in the current study still nominated notably fewer social network members than participants in the population-based Framingham Heart Study (Christakis \& Fowler, 2007; Fowler \& Christakis, 2008; McDermott, Fowler \& Christakis, 2013). Research regarding outpatient treatment for alcoholism, which utilized the same prompt as the current study to solicit participants' nominations of network members, also produced reports of larger social networks than were found in the current study (Beattie \& Longabaugh, 1999): two samples of alcohol treatment program participants in the Northeastern United States between 1984 and 1986 reported 10.1 and 9.9 people, respectively, with whom they had spent the most time during the months prior to the study (Beattie \& Longabaugh, 1999). Thus, the current sample of BIP participants also nominated fewer social network members than samples of alcohol treatment program participants, when social network members were defined in the same way. 


\section{SOCIAL NETWORKS OF INTIMATE PARTNER VIOLENCE PERPETRATORS}

The markedly smaller social network size ${ }^{8}$ among participants in the current study is consistent with prior research about social networks and relationship dissolution. Among a community sample of adults, people who were less popular (i.e., identified as friends by smaller numbers of others) early in the study were more likely to have been divorced at later measurement points (McDermott, Fowler \& Christakis, 2013), and people who are divorced also tend to report smaller social networks (McDermott, Fowler \& Christakis, 2013). Current findings are also consistent with prior research indicating that, at least during their adolescence, men who perpetrate IPV may have smaller social networks than those who do not perpetrate IPV (Casey \& Beadnell, 2010). It should be noted, however, that additional research has found evidence of the opposite, that having violent friends during adolescence is related to adult perpetration of IPV only for those with large social networks (Ramirez, Paik, Sanchagrin, \& Heimer, 2012). The current findings corroborate the prior finding, that men who perpetrate IPV may have smaller social networks than the general population. Additionally, the criminal justice system may encourage smaller social networks among offenders, to reduce the number of relationships that they maintain with anti-social peers (Bonta \& Andrews, 2007). As a focus group participant in the current study described, BIP participants may also experience sharp drops in the size of their social networks following an arrest for the perpetration of IPV. Friends and family members who were previously unaware of their

${ }^{8}$ Among the one hundred and two participants, the average social network consisted of three and a half individuals. 


\section{SOCIAL NETWORKS OF INTIMATE PARTNER VIOLENCE PERPETRATORS}

perpetration of abuse or the severity of their perpetration tend to withdraw from BIP participants once an arrest brings their perpetration to others' attention.

Current findings also indicate that, at least among the current sample of BIP participants from Allies in Change, BIP participants' social networks consist of more friends and fewer family members than the general population. ${ }^{9}$ In two community samples of adults in Connecticut, participants nominated averages of 0.70 and 0.24 friends in their social networks (Christakis \& Fowler, 2007; McDermott, Fowler \& Christakis, 2013), and 2.42 family members (McDermott, Fowler \& Christakis, 2013). These findings regarding the membership of BIP participants' social networks are also consistent with prior findings regarding social networks and relationship dissolution. The occurrence of divorce among individuals' siblings, neighbors, and coworkers has no effect on their own likelihood of divorce, while a friend's divorce is related to a $270 \%$ increase in the chances that they will get divorced (McDermott, Fowler \& Christakis, 2013). It is noteworthy, then, that participants in the current sample nominated more friends than members of the general population, indicating that they may have more opportunities than the general public to experience social network influences that may increase their propensity for divorce.

Findings of the current study also indicate that BIP participants, at least those attending Allies in Change during the fall of 2013, do not consider other group members and facilitators important members of their social networks. Prior research has indicated

\footnotetext{
${ }^{9}$ Participants in the current sample nominated an average of .98 friends and 0.81
} members of their family of origin. 


\section{SOCIAL NETWORKS OF INTIMATE PARTNER VIOLENCE PERPETRATORS}

that men who are considered most successful in their BIPs often form relationships with BIP facilitators and participants throughout their program involvement (Sheehan, Thakor \& Stewart, 2012). No participants in the current study listed other BIP participants or facilitators among the members of their social networks. While findings of the current study do have implications for BIPs' efficacy, these implications do not appear to be related to current participants' relationships with other people involved with their BIP. Instead, network members' IPV- relevant interactions with BIP participants may have a greater impact on their program success than their relational tie to participants.

A related aim of the current study was to identify the mechanisms and extent to which social network members discuss the perpetration of IPV in their interactions with BIP participants at all. Prior research with children, adolescents, and adults indicates that the anti-social messages conveyed within one's social network has implications for their own behavior. Specifically, among children and adolescents, interactions within their social networks reinforce their talk of, and engagement in, antisocial behavior (Dishion, Andrews \& Crosby, 1995; Dishion, Capaldi, Spracklen \& Li, 1995; Dishion, Patterson \& Griesler, 1994; Patterson, Dishion \& Yoerger, 2000; Warr, 2006). IPV among one's parents (Arriaga \& Foshee, 2004; Doumas, Margolin \& John, 1994; Silverman \& Williamson, 1997), peer groups that express hostility towards women (Capaldi et al., 2001; Reed et al., 2008), and perceptions of social norms that condone violence against women (Abbey et al., 2001; Brown \& Messman-Moore, 2010; Raghavan et al., 2009; Silverman \& Williamson, 1997) are all related to the perpetration of sexual assault and 


\section{SOCIAL NETWORKS OF INTIMATE PARTNER VIOLENCE PERPETRATORS}

IPV. As a result, some studies have suggested attending to BIP participants' social networks as a means of improving programs' efficacy (Almeida \& Bograd, 1991; Maxwell, Davis \& Taylor, 2010; Neighbors et al., 2008). However, prior literature has not addressed the extent to which BIP participants perceive that their social network members support the perpetration of IPV, specifically, a focal point of the current study.

Findings of the current study indicate that BIP participants do not believe that their social network members discuss IPV directly with them. BIP participants do report that their network members engage in behaviors that contribute to social norms that may allow abuse to continue. Eight of the sixteen behaviors that participants' network members may use contained the phrase "abuse" or more explicit language (i.e., "harass or monitor"), while the other half of the behaviors did not. Many of the behaviors in the inventory involve demonizing participants' partners or network members' own partners, taking the participants' side over participants' partners', and supporting behaviors that are peripheral to abuse (i.e., legal action against one's partner, allowing one's partner to "call the shots," attending Allies in Change). The only behavior that includes tangible support for abuse is contacting the participants' current or former partner to harass or monitor them. Of the six behaviors that occurred significantly more often than any others ${ }^{10}$, none

\footnotetext{
${ }^{10}$ The six behaviors that network members used significantly more than any other behaviors were: (1) told you that your current/former partner was taking advantage of you or disrespecting you, (2) accused your current/former partner of trying to harm your relationship with your kids, (3) told you that they wouldn't let their own partner get away with the things that your current/former partner does to you, (4) supported you in being more accountable, (5) blamed their partner for their own problems, and (6) did or said something that supported your participation at Allies in Change.
} 


\section{SOCIAL NETWORKS OF INTIMATE PARTNER VIOLENCE PERPETRATORS}

include direct references to abuse. Participants in the current study nominated behavioral items that represent their network members' (1) modeling their own abusive behavior, (2) reinforcing participants' negative characterizations of their partners and descriptions of their partners' malicious intents to potentially validate the use of abuse, and (3) supporting participants' engagement in behaviors that theoretically prevent the perpetration of abuse ${ }^{11}$. These findings are consistent with prior research documenting peer groups' modeling of abusive behavior (Abbey et al., 2001; Raghavan et al., 2009; Silverman \& Williamson, 1997), implicit validation of others' use of abuse (Brown \& Messman-Moore, 2010; Lewis, 2004), and informal sanctioning of abusive behavior (Maxwell, Davis \& Taylor, 2010) in creating social norms around the perpetration of IPV. Through the use of these behaviors, network members subtly convey messages

${ }^{11}$ Network members modeled abusive behavior by telling participants that they wouldn't let their own partner get away with the things that participants' current/former partner does; blaming their partner for their own problems; being abusive to their partner in front of participants; and contacting participants' partners to harass or monitor them. On average, network members engaged in these four behaviors a total of 5.69 times during the three months prior to data collection.

Network members reinforced negative characterizations of participants' partners by telling them that their (the participants') current/former partner was taking advantage of them or disrespecting them; accusing participants' current/former partner of trying to harm their relationship with their kids; supporting participants in taking legal action against their current/former partners; and telling participants that their current/former partner deserved their abusive behavior. On average, network members engaged in these four behaviors a total of 7.93 times during the three months prior to data collection.

Network members also used the following support behaviors that may discourage the perpetration of abuse: supporting participants in being more accountable; doing or saying things that support participation at Allies in Change; pointing out the effects of abuse on children or other people; and trying to make amends with participants for their own abusive behavior. On average, network members engaged in these four behaviors a total of 11.5 times during the three months prior to data collection. 


\section{SOCIAL NETWORKS OF INTIMATE PARTNER VIOLENCE PERPETRATORS}

about abuse (Brown \& Messman-Moore, 2010; Lewis, 2004; Silverman \& Williamson, 1997) and establish network-wide social norms against which BIP participants may compare their own behavior (Berkowitz, 2011; Flood, 2008; Gidycz, Orchowski, \& Neighbors et al., 2010).

Participants reported that their social network members validated their negative characterizations of their partners and supported behaviors peripheral to IPV. These characterizations implicitly validate their use of abuse, without discussing abuse explicitly. An unexpected finding of the current study was that participants' network members also supported their participation in the BIP and their efforts to be accountable, though they did so without addressing the issue of abuse directly. Thus, findings in this domain are consistent with prior research suggesting that social networks may avoid explicit dialogue about abuse as a result of the secrecy that often surrounds partner violence (Cooney, 1998), feelings of guilt and remorse about the use of violence (Holtzworth-Munroe \& Stuart, 1994), and North American social norms that support familial privacy (Lehrer \& Allen, 2008). Participants report that their network members do communicate about abuse, unexpectedly both in favor of, and in opposition to, and do so in indirect ways. Differentiating between network members' pro-abuse and anti-abuse behaviors enabled comparisons of how these two distinct types of behaviors were used by network members of participants with different attendance histories, and by network members with whom participants have different relational ties. 


\section{SOCIAL NETWORKS OF INTIMATE PARTNER VIOLENCE PERPETRATORS}

Examining participants' relationships with each of their network members, independently, enabled the identification of participants' friends and roommates and families of origin as those network members whose indirect behaviors may have the greatest influence on BIP participants. Social networks' characteristic norms and values (Wassertman \& Faust, 1994; Wellman, 1982) shape their members' attitudes and behaviors (Borgatti, Mehra, Brass \& Labianca, 2009; Erickson, 1988) through processes of social influence. Network members with whom individuals have higher quality relationships are more influential in shaping their attitudes and behaviors (Ajzen \& Fishbein, 1970; Priester \& Petty, 2001; Terry \& Hogg, 1996). Findings of the current study indicate that participants are most satisfied with their relationships with their friends and roommates and family of origin. Thus, participants may be especially susceptible to these network members' abuse-relevant behaviors.

The current study examined not only the IPV-relevant messages that BIP participants receive, but also those that they convey to their social network members. Just as social networks shape the attitudes and behaviors of their members, individuals also influence the social networks that they comprise (Cartwright, 1965; Kandel, 1978; Marsden \& Friedkin, 1993). While it is unclear whether BIP participants had an impact on their network members' abuse-relevant attitudes and behaviors, findings indicate that BIP participants convey anti-abuse messages to the members of their social networks, primarily by making self-disclosures about their own histories of abuse and sharing information and resources about abuse with the members of their social networks. 


\section{SOCIAL NETWORKS OF INTIMATE PARTNER VIOLENCE PERPETRATORS}

Research in the area of substance abuse recovery has noted that changing the attitudes of pre-existing network members may support program participants' successful behavior change (Beatttie \& Longabaugh, 1999; Kelly et al., 2011; Humphreys et al., 1999; Mohr et al., 2001). Participants in the current study indicated that they engage in a range of IPV-relevant behaviors with the members of their social networks. All sixteen items in the inventory of BIP participants' abuse-relevant behaviors may be considered anti-abuse.

It is unlikely that BIP participants convey exclusively anti-IPV messages to their social network members. However, it is understandable that BIP participants did not offer up descriptions of ways that they contribute to their network members' perpetration of abuse, perhaps as a way to maintain more positive images of themselves. It is also possible that participants were more willing to participate in the current research as a result of the behavioral inventory's strengths-based focus. Participants may have been more reactive to the study if the survey instrument implied that they engaged in antisocial behaviors with their network members, as was exemplified during the pilot-testing focus group. During the focus group that was convened to pilot test the original survey instrument, participants indicated that they were offended by the measure of their stage of change (the results of which are not discussed currently), which they felt implied that they had perpetrated abuse against their current partner. This discourse during the early stages of the study highlighted the importance of emphasizing participants' pro-social contributions, in order to earn their buy-in and trust. It is also in keeping with the core 


\section{SOCIAL NETWORKS OF INTIMATE PARTNER VIOLENCE PERPETRATORS}

values of community psychology to emphasize individuals' strengths above their

pathology (Kloos, Hill, Thomas, Wandersman, Elias, \& Dalton, 2012).

It was important to consider participants' use of IPV relevant behaviors with their network members for two reasons. First, changing the characteristic norms of participants' social networks may have implications for their own behavior change, as in the case of participants in substance abuse treatment programs (Beatttie \& Longabaugh, 1999; Kelly et al., 2011; Humphreys et al., 1999; Mohr et al., 2001). Second, addressing IPV within their social networks may also have repercussions for BIP participants' social network members and their experiences of abuse. By conveying anti-abuse messages, which reflect their engagement in the BIP program, BIP participants may change the norms of their social networks such that IPV becomes less commonplace. This is the first study to address whether and how BIP participants address the issue of IPV with the members of their social networks, reflecting the extent to which the messages of BIPs are communicated to the community beyond their immediate participants. While the crosssectional nature of the current study does not lend itself to conclusions about participants' ability to change their social networks, findings indicate that participants do communicate about IPV with their social network members.

\section{Criminally Oriented Participants' Social Networks}




\section{SOCIAL NETWORKS OF INTIMATE PARTNER VIOLENCE PERPETRATORS}

While there are indeed differences in the results provided by participants in groups specifically for criminally oriented men and groups for others, the implications of these differences for BIP practice and relevant theory are unclear. Participants are assigned to groups for criminally oriented men on the basis of their criminal and abuse histories and program staff's observations of their disruptive or otherwise difficult behavior in group. What characterizes these participants as criminally oriented is not sufficiently defined to merit speculation about the causes of the differences in their social networks and the IPV-relevant communication therein. However, participants in criminally oriented groups may represent the generally violent/antisocial subtype of IPV perpetrators, who tend to engage in violence and criminal behavior outside of their families to a greater extent than other subtypes of perpetrators (Holtzworth-Munroe \& Stuart, 1994). Additionally, current findings are consistent with prior research has indicated that antisocial behavior, participation in deviant peer groups, and the perpetration of IPV are closely inter-related (Capaldi et al., 2001).

Current findings indicate significant differences in the number of IPV-relevant behaviors used by participants in criminally oriented groups and participants in other, non-criminally oriented, BIP groups. Participants in groups for criminally oriented men reported that they and their network members communicate about IPV more often than participants in other groups. Additionally, a negative relationship was found between participants' anti-abuse behaviors and their network members' pro-abuse behaviors for men in criminally oriented groups: the more these participants' network members engage 


\section{SOCIAL NETWORKS OF INTIMATE PARTNER VIOLENCE PERPETRATORS}

in pro-abuse behaviors, the less often participants engage in anti-abuse behaviors. This pattern aligns with those specified by certain theories of deviancy training, which describe mechanisms whereby criminal behavior is taught and reinforced in individuals (Dishion, Andrews, \& Crosby, 1995; Dishion, Patterson, \& Griesler, 1994). Participants in criminally oriented groups may be less likely to disagree with network members' proabuse communication and to receive reinforcement for their anti-abuse communication. This indicates that they may be involved in deviancy training (Dishion, Andrews, \& Crosby, 1995; Dishion, Patterson, \& Griesler, 1994) to a greater extent than participants in other groups, who experience a different pattern of IPV-relevant communication with their network members. Participants in groups for criminally oriented men appear to have peers who are less vocal about their pro-social attitudes, and who may reinforce their anti-sociality. This points to the heightened necessity of addressing this particular criminogenic need (Bonta \& Andrews, 2007; Andrews \& Bonta, 2010) within criminally oriented groups.

\section{Implications for Practice}

Current findings have implications for BIP practice. Specifically, findings suggest that participants are active bystanders within their communities. Participants appear to spread ideas about abuse from their BIP to their social networks. BIPs may support participants in doing so, thereby increasing the likelihood that their anti-abuse messages have an impact that extends beyond program participants. There are also implications of 


\section{SOCIAL NETWORKS OF INTIMATE PARTNER VIOLENCE PERPETRATORS}

the current findings for BIPs' general efficacy. However, the current study was not intended as a program evaluation, and was not designed to effectively serve as such. Thus, the implications for BIPs' efficacy are secondary to those regarding BIP participants' roles as bystanders within their communities.

BIP Participants as Bystanders

Individuals with greater knowledge of sexual violence are more likely to intervene in potentially dangerous situations (Banyard, 2008). As little as a single session of bystander intervention training has been shown to decrease rape myth acceptance and increase knowledge of sexual violence, pro-social bystander attitudes, bystander efficacy, and self-reported bystander behaviors (Banyard, Moynihan \& Plante, 2007). Therefore, only minimal exposure to bystander intervention programming may result in safer communities. As members of their communities who have some knowledge of sexual assault and IPV, BIP participants may be both well positioned and feel a sense of responsibility (Banyard, Plante \& Moynihan, 2004) to intervene in abuse in their communities. Findings of the current study extend this prior research to BIP participants, specifically, and indicate that BIP participants have preferred, indirect, means of intervening in norms that allow abuse to persist. These findings may lead to a reconceptualization of BIP participants as potential agents of pro-social change within their communities. 


\section{SOCIAL NETWORKS OF INTIMATE PARTNER VIOLENCE PERPETRATORS}

BIP participants may be considered active, yet indirect, bystanders in the norms surrounding the perpetration of IPV. Study participants were exposed to network members' indirect communication both in opposition to, and in support of, the perpetration of IPV. However, participants reported being subject to nuanced social norms that allow for the use of behaviors that support abuse, but prohibit the actual perpetration of abuse, the naming of abuse, or the acknowledgement that other norms contribute to abusive behavior. Thus, participants in the current study rarely intervened in their network members' abusive interactions with their partners, or explicitly confronted others about the implications of their behavior for the perpetration of abuse. Therefore, participants were not very active bystanders in the traditional sense (Banyard, Plante \& Moynihan, 2004). However, participants indicated, through their quantitative survey responses and their focus group discussions, that they do sometimes feel obligated to address IPV within their social networks and wider communities. While they are unlikely to directly intervene in instances of abuse in their environments, BIP participants indicated that they do communicate anti-abuse messages, if indirectly, within their social networks.

The BIP participants in the current study have found ways to chip away at the norms that contribute to the perpetration of abuse within their communities, in ways that feel appropriate and nonthreatening to them. Participants address IPV within their communities in subtle ways, often through sharing their own experiences regarding abuse. By modeling anti-abuse behaviors, participants also provide examples of pro- 


\section{SOCIAL NETWORKS OF INTIMATE PARTNER VIOLENCE PERPETRATORS}

social ways that their community members may interact with their partners. Through their self-disclosures about their prior abusive behavior, participants increase their communities' awareness of abuse as a very relevant reality, edging the community closer to open and more frequent conversations about IPV and, potentially, its underlying norms and belief systems. Therefore, BIP participants may be active, yet indirect, bystanders in their communities (Banyard, Plante \& Moynihan, 2004), potentially addressing norms that enable the continued perpetration of IPV, as opposed to symptomatic incidents of abuse.

The perpetration of IPV is considered symptomatic of subscribing to a belief system that (1) a person is entitled to control their partner's activities, feelings, or thoughts, and that (2) they are justified in using violence to do so (Pence \& Paymar, 1993). These beliefs are likely manifested in abuse-relevant social norms of BIP participants' networks. Current findings indicate that BIP participants make comments and engage in behaviors that might prompt their network members to reflect on these beliefs and subsequent social norms. Thus, while participants did not report intervening in discrete instances of abuse among the members of their social networks, they may draw their network members' attention to network-wide norms and constituent beliefs that theoretically allow abuse to persist within their communities.

In addition to the gentler and more socially acceptable forms of communication about IPV, participants may also lead their social network members to reflect on their own abuse-relevant behaviors and related norms by strategically using the phrase 


\section{SOCIAL NETWORKS OF INTIMATE PARTNER VIOLENCE PERPETRATORS}

"abuse." Participants explained that they often avoid labeling their own behavior as abusive while communicating with their social networks because they believe that their network members will react so strongly to the phrase. Thus, if participants do label their own behavior, or a network member's behavior, as abusive or enabling of abuse, it is likely to have a profound effect on that network member's understanding of the behavior and its implications. While it may create tension between the participant and network member, it may also be a very effective means of influencing network members' behaviors and perspectives on pertinent norms.

Supporting BIP participants as bystanders. Acknowledging and emphasizing BIP participants' role as bystanders in program curricula may further facilitate participants' use of anti-abuse behaviors with their network members, and lead to safer communities (Banyard, Moynihan \& Plante, 2007). BIPs may discuss the idea of bystander intervention with participants, and help them hone their skills for intervening in both norms and discrete incidents of abuse in their communities. For example, participants in the current study described incidents of speaking positively about their partners, pointing out their own fault in conflicts with their partners, and recounting ways that they have non-abusively resolved conflicts with their partners as ways of shifting the norms within their social networks. Additionally, as discussed in greater detail in following sections, BIP participants indicated that they tend to receive validation for many abuse-related messages that they share with their social network members, increasing the likelihood that they will continue to do so (Dishion, Patterson \& Griesler, 1994). By communicating 


\section{SOCIAL NETWORKS OF INTIMATE PARTNER VIOLENCE PERPETRATORS}

anti-abuse attitudes and soliciting their network members' support for those attitudes, BIP participants also appear to be engaged in shaping the contents of the messages that others express within their social networks. BIPs may explore this social dynamic with their participants, to highlight another process that participants may use to alter the norms of their social networks. BIPs may also incorporate discussions of the phrase "abuse" and its implications, and how the phrase may be used strategically to provoke network members to reconsider normative behaviors within their networks.

BIPs may also encourage participants to be more explicit in their anti-abuse communication. Men who perpetrate IPV tend to overestimate the prevalence of IPV within their communities (Neighbors et al., 2010), highlighting the importance of addressing both IPV-relevant norms and misperceptions of IPV-relevant norms with this population. Correcting misperceptions of social norms regarding violence against women is the central focus of social norms campaigns on college campuses (Berkowitz et al., 2004; Flood, 2008) and BIPs frequently discuss social norms regarding abuse within the broader culture (Viola \& Huffine, 2014). However, individuals are more susceptible to the social norms established and maintained by network members with whom they have high-quality relationships than to social norms established and maintained by people to whom they are socially distant or with whom they have lower-quality relationships (Festinger, 1954; Terry \& Hogg, 1996). It would be advisable for BIPs to explore this nuance with participants, as opposed to merely presenting statistics about the prevalence of IPV nation-wide, as would be more characteristic of a university-based social norms 


\section{SOCIAL NETWORKS OF INTIMATE PARTNER VIOLENCE PERPETRATORS}

campaign (Berkowitz et al., 2004; Flood, 2008). Discussion of more proximal social

norms may enable participants to limit their susceptibility to them, and even counteract

them. Similarly, programs may highlight BIP participants' ability to alter their network members' normative misperceptions by openly engaging in anti-abuse behaviors. If BIP participants openly challenge abuse, its underlying belief systems, and the social norms in which they are manifested, their network members may be less prone to overestimate the perpetration of abuse and implicit support for abuse in their community.

It appears that BIP participants intervene in the social norms that allow abuse to persist in their communities, and, in this way, the influence of BIPs may be touching community members who never come in direct contact with the programs. To intensify this effect, programs may consider adding the anti-abuse behaviors discussed above to the pro-social skills that they attempt to build with participants. In doing so, BIP participants may heighten their networks' awareness of IPV (Larson, 1997; Roffman et al., 2008; Valente, 1996), or shape their networks' definitional belief system (FosterFishman, Nowell \& Yang, 2007). Through these processes, participants may exert influence over some of the abuse-relevant messages communicated within their social networks, and potentially be more impactful in modifying network wide social norms that allow abuse to persist. 


\section{SOCIAL NETWORKS OF INTIMATE PARTNER VIOLENCE PERPETRATORS}

\section{General Efficacy of BIPs}

While the purpose of the current study was not to evaluate the efficacy of BIPs, the findings do have implications for their potential effectiveness. The current study design is cross-sectional and cannot be used to draw conclusions about change over time, though it does suggest that BIPs may be effective in increasing participants' engagement with ideas surrounding abuse and accountability. An important caveat is that BIP participants who have been attending the program for longer may be qualitatively different than participants who drop out BIPs after a few weeks or months (Coulter \& Vande Weerd, 2009; Feder \& Wilson, 2005; Gondolf, 1997). The differences that were observed between BIP participants who have been attending the program for more or less time may be a reflection of these differences. However, as elaborated in the following sections, findings suggest that BIP participants with greater program attendance engage in more anti-abuse behaviors and receive more support for anti-abuse behaviors than less tenured program participants.

Abuse-relevant communication and satisfaction. As hypothesized, participants reported lower relationship quality with network members who used more behaviors to indicate that they condone abuse. BIP participants' lower ratings of relationship quality with individuals who use more pro-abuse behaviors may indicate that they are less content being exposed to pro-abuse messages, and may be inclined to limit their contact with network members who espouse pro-abuse messages. This would be consistent with research addressing participation in education programs regarding sexual assault. 


\section{SOCIAL NETWORKS OF INTIMATE PARTNER VIOLENCE PERPETRATORS}

Participation in sexual assault education programs predicts decreased exposure to sexually aggressive peers and sexually explicit material (Gidycz, Orchowski \& Berkowitz, 2011). While the size of network members' social networks was not significantly related to their BIP attendance, focus group participants indicated that they have reduced their contact with network members who engage in pro-abuse behaviors. Current findings suggest that a repeated measures study may reveal that, at its most extreme, very low satisfaction with a network member who frequently uses pro-abuse behaviors might lead to discontinued contact with them, through the process of selection (or de-selection).

Selection refers to the process by which an individual chooses social network members who are already similar to them (Kandel, 1978). Changing one's social network through selection can facilitate behavior change (Buss, 1987; Marsden \& Friedkin, 1993; Cohen, 1977; Festinger, 1954; Humphreys, Mankowski, Moos \& Finney, 1999; Humphreys \& Noke , 1997; Borgatti, Mehra, Brass \& Labianca, 2009; Gidycz, Orchowski \& Berkowitz, 2011). Presumably, if individuals become exceedingly dissatisfied with a network member, they may choose to de-select them from their social network by limiting their contact with them. BIP participants' lower quality relationships with network members who engage in more pro-abuse behaviors may indicate a greater likelihood to eventually de-select these network members. The final focus group with BIP participants revealed that, while they may be skeptical of the theoretical idea that they would disengage from relationships with network members as a result of network 


\section{SOCIAL NETWORKS OF INTIMATE PARTNER VIOLENCE PERPETRATORS}

members' pro-abuse behaviors, they have in fact done so. For example, one participant described how he has cut himself off from a group of former friends who continued to send him jokes and pictures that he felt were inappropriate and damaging to his relationship with his wife. Thus, the lower quality of participants' relationships with network members who use more pro-abuse behaviors might eventually lead to the removal of those individuals from participants' social networks. It should be noted that network members' use of anti-IPV behaviors were not significantly related to relationship quality, indicating that participants are perhaps more sensitive to behaviors that might derail their behavior change than behaviors that might support it.

While participants retained network members who engage in pro-abuse behaviors, having lower quality relationships with them may protect participants from the influence of those pro-abuse behaviors. Individuals may be less motivated to comply with social norms that are established or maintained within low quality relationships. Individuals' motivation to comply with social norms regarding certain behaviors and their attitudes towards those behaviors are highly correlated (Ajzen \& Fishbein, 1971), and together determine individuals' intentions to engage in those behaviors (Ajzen \& Fishbein, 1970; Ajzen \& Fishbein, 1971; Ajzen \& Fishbein, 1972). If BIP participants have lower quality relationships with network members who maintain norms of abusive behavior, participants may be less inclined to comply with those norms, as is the case for participants in alcohol treatment programs (Beattie \& Longabaugh, 1997). 


\section{SOCIAL NETWORKS OF INTIMATE PARTNER VIOLENCE PERPETRATORS}

Participants' use of anti-abuse communication. Findings of the current study suggest that participants who have been attending a BIP for a longer amount of time discuss abuse and accountability to a greater extent than participants who are newer to the program. Participants' use of several anti-abuse behaviors was positively associated with their BIP attendance ${ }^{12}$. Participants in the member-checking focus group explained that, as they attended the program, they became increasingly aware of abuse occurring around them. Though they do not respond to every, or even most, instances of abuse that they notice, qualitative data produced during the member checking focus group lends itself to the speculation that more tenured participants' greater awareness of abuse increases the number of opportunities that they see to engage in a pertinent abuse-relevant behavior. Additionally, the longer that participants attend Allies in Change, the more opportunities they have to mention the program to others, and the more IPV-relevant resources they may know of and are able to share with others. The greater frequency of self-disclosures among men who have been attending the program for more time may reflect a greater tendency towards accountability among those with more experience in the program.

Reciprocity of anti-abuse communication. Findings of the current study suggest that participants who have been attending the BIP for more time are subject to more prosocial influences within their social networks. Participants who had been attending the BIP for longer reported that their social network members conveyed anti-abuse messages to a greater extent, and pro-abuse messages to a lesser extent, than participants who had

${ }^{12}$ Participants' attendance was positively related to sharing information about abuse and making self-disclosures. 


\section{SOCIAL NETWORKS OF INTIMATE PARTNER VIOLENCE PERPETRATORS}

not been attending the program as long. While these findings are promising on their own, they are also synergistic with the finding that participants who have been attending the program for longer also express more anti-abuse messages themselves. The memberchecking focus group of BIP participants described how non-partner network members tend to validate and reinforce each other's characterizations of their partners, whether those characterizations are positive or negative. If participants paint their partners as irrational villains, their network members may tend to support this characterization, and if participants speak more positively about their partners, their network members will agree with those characterizations. This explanation is consistent with the content of the inventory of network members' behaviors. Much of the behavioral inventory reflects communications that are likely used to reinforce participants' negative talk about their partners and positive talk about the BIP and accountability.

It is promising that the two behaviors that network members used most often appear to be reactions to participants' disclosures about trying to be accountable and attending Allies in Change, indicating that participants may be engaging in the behaviors that solicit this validation from their network members ${ }^{13}$. Alternatively, it is possible that participants who have been attending the program for longer interpret their network members' behaviors as more supportive, in general, than participants who are newer to the program. Viewing important network members' behaviors as supportive, as opposed

\footnotetext{
${ }^{13}$ The two behaviors that network members used most often were supporting participants in being more accountable and doing or saying things that support participants' participation at Allies in Change.
} 


\section{SOCIAL NETWORKS OF INTIMATE PARTNER VIOLENCE PERPETRATORS}

to antagonistic, may represent a positive shift in BIP participants' thinking, in general.

While this phenomenon should be further explored in a repeated-measures study, it seems that BIP participants may solicit their network members' use of anti-abuse behaviors, and that they do so more often if they have been attending the program for longer.

Participants' interactions with specific network members. Participants' abuserelevant interactions with specific network members, namely their partners and their children, also point to their engagement with concepts from the BIP. While prior studies have collected information about participants' network members in the aggregate (Abbey et al., 2001; Raghavan et al., 2009), the current study was the first to examine the abuserelevant behaviors of specific network members individually. Isolating participants' interactions with their partners and their children provides further information that suggests participants' reflection on abuse and accountability.

Participants reported that they engaged in the most communication about abuse with their current and former partners. Participants also reported that their current and former partners were also more communicative about abuse than any other relational tie. This may be interpreted in a number of ways: participants' abuse-relevant interactions with their partners may be indicative of continued abusive interactions between them. For example, participants indicated that they "called this person out if you saw them ignoring or being rude to their partner" with their own partners, indicating that they were engaged in conflict. However, participants' abuse-relevant communication with their partners, particularly their theoretical discussions about abuse and self-disclosures, may also 


\section{SOCIAL NETWORKS OF INTIMATE PARTNER VIOLENCE PERPETRATORS}

indicate that participants are processing their thoughts about abuse with their partners. Focus group participants indicated that they turn to their partners as sounding boards and conversation partners to work through their new understandings of abuse. In this scenario, abuse-relevant interactions between participants and their partners may indicate participants' knowledge of abuse, desire to continue reflecting on abuse, and intellectual and emotional connections to their partners.

Future research in this area should analyze participants' interactions with their partners separate from their interactions with other relational ties to explore whether participants engage in similar patterns of interactions with their partners and their other relational ties, and whether their interactions with their partners have different impacts for their abuse-relevant attitudes and behaviors. However, current findings of participants' use of IPV-relevant behaviors with their partners may imply that BIP participants are continuing to process and reflect on information about abuse and accountability outside of the BIP.

Participants' children were the only network members to use significantly fewer IPV-relevant behaviors with participants who had been in the program for more time. The nature of parent-child relationships may make participants' children more prone to their influence than any other network member, suggesting that this statistical trend is a result of participants' successful influence over their children. Influence is the impact of individuals' attitudes or behavior on the attitude or behavior of others (Lippitt, Polansky \& Rosen, 1952), which may occur through direct communication about those attitudes or 


\section{SOCIAL NETWORKS OF INTIMATE PARTNER VIOLENCE PERPETRATORS}

behaviors, or through the implications of social norms within networks (Lippitt, Polansky

\& Rosen, 1952; Marsden \& Friedkin, 1993). As a longitudinal study could confirm, more tenured participants' reports of their children's less frequent use of abuse-relevant behavior may indicate that their own anti-IPV behavior may be influencing their children, hopefully profoundly enough, and while the children are young enough, to prevent their children from subsequently perpetrating IPV themselves. Thus, BIP participants' use of IPV-relevant communication in their social networks may have implications that span generations, pointing to their potential impact on the wider community.

Overall, findings of the current study indicate that BIP participants engage in antiabuse behaviors and prefer their social network members to do the same, potentially reflecting positively on their engagement with BIPs. Participants' lower satisfaction with social network members who use more abuse-relevant behaviors may indicate that they are somewhat averse to receiving pro-abuse messages, and also less susceptible to the influence of network members who frequently engage in pro-abuse behaviors. The patterns of communication between BIP participants and their social network members suggest that BIP participants may solicit reinforcement for anti-abuse behaviors from their social network members. Participants' relatively frequent communication about abuse with their current and former partners may indicate that they process abuserelevant information with their partners. The association between their program attendance and their children's use of abuse-relevant behavior suggests their exertion of anti-abuse influence. 


\section{SOCIAL NETWORKS OF INTIMATE PARTNER VIOLENCE PERPETRATORS}

In summary, the primary implication for BIP practice is that these programs may have an influence that extends beyond their participants to the members of their participants' communities. BIPs may improve their ability to reach the wider community by increasing their attention to network-wide social norms, ways that participants may intervene therein, and participants' abilities to be active bystanders in their social networks. While it was not the purpose of the current study to address BIP effectiveness, findings do inform this area of inquiry. Differences were identified in the behaviors of more and less tenured BIP participants and their social network members. Participants' lower satisfaction with network members who use more pro-abuse behaviors, more tenured participants' possible solicitation of anti-abuse messages from the members of their social networks, the potential that participants process program-relevant material with their partners, and the possibility that they exert anti-abuse influence over their children, all indicate anti-abuse tendencies among BIP participants. The findings of the current study also have implications for the theories that informed its development (DeKeseredy \& Schwartz, 1993; DeKseredy, 1990b; DeKeseredy, 1988; Dishion, Andrews, \& Crosby, 1995; Dishion, Patterson, \& Griesler, 1994; Schwartz \& DeKeseredy, 1997; Silverman \& Williamson, 1997). Specifically, findings speak to two areas of theory that contributed to the current study: broadening the construct of deviancy training and modifying DeKeseredy's model of peer support for violence against women for a community population. Implications for both of these theories involve acknowledging the role of female network members in expressing support for, and 


\section{SOCIAL NETWORKS OF INTIMATE PARTNER VIOLENCE PERPETRATORS}

contributing to the norms that enable, the perpetration of abuse. These theoretical implications are discussed next.

\section{Implications for Theory}

This study was not intended to as an evaluation of existing theories' relevance for BIP participants' communication with their network members. However, as this is first study to systematically assess specific patterns of abuse-relevant communication within BIP participants' social networks, it is uniquely positioned to speak to existing theories' relevance to this population. Two theoretical underpinnings of the current study were deviancy training (Dishion, Andrews, \& Crosby, 1995; Dishion, Patterson, \& Griesler, 1994) and DeKeseredy's model of male peer support for violence against women (DeKeseredy \& Schwartz, 1993; DeKeseredy, 1990b; DeKeseredy, 1988; Schwartz \& DeKeseredy, 1997; Silverman \& Williamson, 1997). Both processes theoretically involve male peer groups' expressions of support for violence against women, a phenomenon that current findings challenge. Neither deviancy training nor DeKeseredy and colleagues' model were developed with adult community members' perpetration of IPV in mind, and current findings suggest differences between the content of these models and processes of abuse-relevant communication among this population. Thus, a second primary contribution of the current study is a more precise representation of how adult BIP participants in the community receive support for the perpetration of IPV within their immediate social contexts. Specifically, current findings suggest that both male and 


\section{SOCIAL NETWORKS OF INTIMATE PARTNER VIOLENCE PERPETRATORS}

female network members express support for violence against women to BIP participants, and do so in less direct ways than those suggested by the idea of deviancy training and DeKeseredy and colleagues' model. Potential modifications to the ideas of both deviancy training and DeKeseredy and colleagues' model, which would make them more applicable to community-based men who perpetrate IPV, are discussed.

\section{Deviancy Training}

Findings of the current study indicate that both male and female members of BIP participants' families of origin may engage in deviancy training with BIP participants. When network members reinforce negative characterizations of participants' partners, it may be considered deviancy training (Dishion, Andrews, \& Crosby, 1995; Dishion, Patterson, \& Griesler, 1994), which has been directly linked to the perpetration of IPV (Capaldi et al., 2001). Traditionally, deviancy training has been understood as a process that occurs between male peers (Dishion, Andrews, \& Crosby, 1995; Dishion, Patterson, \& Griesler, 1994). Parents' perpetration of abuse has been linked to the selection of peer group members who implicitly and explicitly support abuse (Silverman \& Williamson, 1997), via deviancy training. While BIP participants' families of origin may have an impact on the formation of their social networks in childhood and adolescence, members of participants' families of origin used the second highest numbers of pro-abuse behaviors, behind participants' current and former partners, in the current study. Thus, participants' family of origin, including their mothers, fathers, brothers, and sisters, may 


\section{SOCIAL NETWORKS OF INTIMATE PARTNER VIOLENCE PERPETRATORS}

also be directly engaged in deviancy training with BIP participants. This finding indicates that the concept of deviancy training should be expanded from a process that occurs between male peers, to a process that may also occur between adults, potentially, adults of different generations and genders. As opposed to youth, who reinforce each other's talk of participation in anti-social behavior via laughter (Dishion, Adrews \& Crosby, 1995; Dishion, Patterson \& Griesler, 1994), current findings indicate that adults may reinforce each other's use of abuse by validating their reasons for engaging in abusive behavior, specifically, their negative characterizations of their partners. Expressing support for abuse primarily through indirect means also has implications for DeKeseredy's model of male peers support for violence against women.

\section{DeKeseredy's Model of Male Peer Support for Violence Against Women}

DeKeseredy's model of peer influences on the perpetration of violence against women indicates that social norms regarding the perpetration of abuse, in addition to explicit discussions, contribute to its prevalence (Schwartz \& DeKeseredy, 1997). The findings of the current study suggest that, within the social networks of adult men in the community (as opposed to college campuses) who have perpetrated abuse against an intimate partner, behaviors that contribute to social norms regarding abuse are more common than behaviors that directly address the behavior. DeKeseredy's model indicates that social norms that contribute to violence against women are most likely to emerge when social networks consist entirely of heterosexual men with patriarchal belief systems 


\section{SOCIAL NETWORKS OF INTIMATE PARTNER VIOLENCE PERPETRATORS}

(Schwartz \& DeKeseredy, 1997). In the current community sample, however, participants nominated approximately equal numbers of male and female network members, both of whom engaged in approximately equal numbers of behaviors that contribute to networkwide social norms.

The assertion that young men provide each other with direct, explicit advice about the perpetration of violence against women is at the center of DeKeseredy's model of male peer support and sexual violence (DeKeseredy \& Schwartz, 1993; DeKseredy, 1990b; DeKeseredy, 1988; Schwartz \& DeKeseredy, 1997; Silverman \& Williamson, 1997). The model proposes that, among adult men on college campuses, social networks may influence the perpetration of IPV through direct communication and informational support that condones or actively encourages the use of violence against women, in the context of intimate relationships and more casual dating relationships (DeKeseredy, 1988; DeKeseredy, 1990b, DeKeseredy, 1997). The model indicates that norms within social networks may also encourage the perpetration of violence against women (Berkowitz, 2004; DeKeseredy, 1990a; Gidycz, Orchowski \& Berkowitz, 2011; Kilmartin et al., 2008; Lewis, 2004; Neighbors et al., 2010; Schwartz \& DeKeseredy, 1997; Silverman \& Williamson, 1997).

The focus groups that were conducted to construct the inventory of network members' behaviors, and quantitative results of the subsequent surveys, did not indicate that BIP participants' network members often use direct communication about IPV. Instead, BIP participants' network members use more indirect forms of communication 


\section{SOCIAL NETWORKS OF INTIMATE PARTNER VIOLENCE PERPETRATORS}

about IPV to convey both pro-abuse and anti-abuse attitudes. Findings indicate that BIP participants' social network members communicate about abuse largely through social norms, and that the social norms within BIP participants' social networks are nuanced. The one item that most closely resembles those that DeKeseredy's model suggests is "told you ways to avoid the consequences of abuse." However, this item is unclear, in that it could refer either to strategies to avoid the detection of abuse, or to cease perpetrating abuse in order to avoid its consequences. Many of the network members' pro-abuse behaviors involve "talking up" participants by instigating or encouraging participants' anger towards their partners by agreeing with participants' negative portrayals of their partners. This study did not find evidence that BIP participants' network members tell participants to perpetrate abuse or how to do so. However, participants in the current study reported that their network members validated their hostility towards their partners, which may enable their perpetration of abuse.

The contents of the behavioral inventory of network members' behaviors is more consistent with prior research involving men who had perpetrated IPV, specifically, as opposed to general violence against women. Among adult men who have perpetrated IPV, social network members tend to discuss behaviors that are peripheral to the perpetration of abuse, but very rarely discuss abuse directly (Lewis, 2004). Indeed, participants in the member-checking focus group indicated that they try to avoid conversations about abuse with their network members. According to the focus group, the only network members who do discuss abuse explicitly, other than participants' partners, 


\section{SOCIAL NETWORKS OF INTIMATE PARTNER VIOLENCE PERPETRATORS}

are network members who knew about prior abuse in the relationship and are interested in learning whether it has stopped. However, considering that this caveat was only mentioned in the fourth and final focus group, it likely occurs only rarely.

The member checking focus group of BIP participants elaborated on the contents of the social norms that they are exposed to within their social networks, indicating that these norms are complex and nuanced. BIP participants' social networks maintain social norms that both contribute to the perpetration of abuse, and simultaneously sanction the explicit discussion of abuse, or acknowledgment of participants' use of abuse. Focus group participants explained that they adhere to social norms that prohibit them from addressing the presence or implications of social norms regarding IPV. Participants indicated that they felt they would be ostracized for acknowledging that they had engaged in abusive behavior, pointing to some of the nuance in how social networks communicate about IPV. While social networks convey norms that both reinforce and sanction the perpetration of abuse, participants believed that acknowledging that these norms have implications for the perpetration of abuse would lead to judgment. Focus group participants indicated that they are sometimes inclined to address abuse-relevant norms within their social networks. However, they decidedly do not use the phrase "abuse" in doing so, unless they intend to make a point aggressively, as discussed above, for fear of eliciting strong negative responses.

Fear that their network members will judge them for engaging in the very behaviors that those network members' norms influence prevents BIP participants from 


\section{SOCIAL NETWORKS OF INTIMATE PARTNER VIOLENCE PERPETRATORS}

discussing their efforts to end their abuse, and from confronting their network members' pro-abuse norms. This is exemplified by the three behaviors that BIP participants use least often, ${ }^{14}$ all of which involve directly acknowledging abuse, or the implications of their network members' behaviors on abuse. This finding is indicative of a contradiction within BIP participants' social networks. Network members may implicitly condone, and even engage in, behaviors that contribute to the perpetration of IPV, as discussed above, but also may be highly reactive to the insinuation that their behavior contributes to abuse. This complexity in the social norms within BIP participants' social networks explains why BIP participants and their network members do not communicate about abuse directly, and indicates a marked difference between the current findings and those predicted by DeKeseredy's model (Schwartz \& DeKeseredy, 1997) of male peer support for violence against women.

Current findings support another aspect of DeKeseredy's model (Schwartz \& DeKeseredy, 1997), that which suggests opportunities for members of participants' social networks to have a pro-social influence on BIP participants though the social norms that they maintain. Despite this caveat in DeKeseredy's model of male peer support for violence against women, nearly all of the literature regarding social network influences on IPV reviewed in the first chapters of current study addressed factors that increase participants' likelihood of perpetration. As a result, only IPV-relevant behaviors that

\footnotetext{
${ }^{14}$ The three behaviors that participants used least often were recommending Allies in Change or a similar program, speaking up against sexist jokes or jokes about abuse, and asking network members not to talk about abuse or act abusively.
} 


\section{SOCIAL NETWORKS OF INTIMATE PARTNER VIOLENCE PERPETRATORS}

would increase participants' likelihood of perpetrating abuse were expected at the outset of the study; the anti-IPV behaviors that BIP participants' network members utilize were unexpected. However, four anti-abuse behaviors that participants' network members may use were identified over the course of the measure development focus groups, and participants' social network members did indeed use these anti-abuse behaviors ${ }^{15}$.

Network members' support for participants' behavior change is also consistent with findings regarding social network influences on individuals in treatment for substance abuse. Friends' explicit support for abstinence significantly mediates the relationship between mutual help group participation and program participants' abstinence, in combination with relationship quality, and is considered a major determinant of successfully modifying one's drinking behavior (Beattie \& Longabaugh, 1999; Humphreys et al., 1999; Humphreys \& Noke, 1997; Kelly et al., 2011). Thus, at least some network members of participants in alcohol treatment programs are actively supportive of their behavior change, and have a significant impact on participants' abstinence. Though the social dynamics surrounding IPV differ from those of drinking behavior (Cooney, 1998), findings indicate that, similar to those seeking substance abuse treatment, as well as young men in all-male peer groups on college campuses, individuals in BIPs are subject to both anti-social and pro-social influences within their social networks.

\footnotetext{
${ }^{15}$ Network members used the four anti-abuse behaviors an average of 2.61 times each during the prior three months, while they used each of the ten pro-abuse behaviors an average of 0.98 times each during that same window.
} 


\section{SOCIAL NETWORKS OF INTIMATE PARTNER VIOLENCE PERPETRATORS}

In summary, the current findings have implications for our understanding of how BIP participants receive messages about IPV within their social networks, distinct from the processes suggested by literature on deviancy training among youth and processes of support for violence against women among men on college campuses. Findings indicate that, in order to apply to adult BIP participants, the notion of deviancy training must be expanded to account for intergenerational and cross-gender support for BIP participants' negative characterizations of their partners. An expanded conceptualization of deviancy training might also include verbal validation, in addition to laughter, as a mechanism of reinforcing behavior. Findings of the current study also suggest modifications that would make DeKeseredy's model of male peer support for violence against women more applicable to BIP participants in the community, specifically, increasing the centrality of both social norms and anti-abuse influence within the model. In addition to these implications for the theories that informed the current study, findings also point to future directions for relevant research.

\section{Implications for Research}

Measure Development

A third major contribution of the current study is the development of two new behavioral inventories: one assessing BIP participants' social network members' abuserelevant behavior, and one assessing BIP participants' abuse-relevant behavior. DeKeseredy and colleagues (DeKeseredy \& Schwartz, 1993; Schwartz \& DeKeseredy, 


\section{SOCIAL NETWORKS OF INTIMATE PARTNER VIOLENCE PERPETRATORS}

1997) designed a measure to assess the behaviors that young men's social network members engage in, with the effect of influencing their perpetration of sexual assault. However, the measure is designed to assess behaviors specific to influencing others' perpetration of sexual assault and is not valid for the assessment of network influences on the perpetration of IPV more broadly. Additionally, the behavioral indicators included in DeKeseredy and colleagues' (DeKeseredy \& Schwartz, 1993; Schwartz \& DeKeseredy, 1997) measure are largely specific to university culture, and do not seem relevant to a community population. The primary strength of the inventories developed in this research is their specificity to BIP participants. The content and phrasing of the items are relevant to participants and therefore are more likely to be endorsed by BIP participants in the community. Thus, the current measures are a contribution to the set of tools available to investigate social influences on IPV.

Several studies have assessed social networks' support for violence against women by asking participants to report on their perceptions of others' attitudes or behaviors, or speculations about their social network members' perpetration of IPV or sexual assault. Neighbors and colleagues (2010) assessed IPV perpetrators' perceptions of others' perpetration in IPV, using a tool that reflects participants' perceptions of social norms. Similarly, Brown and Messman-Moore (2010) measured individuals’ peer groups' attitudes towards sexual assault by asking participants to report their perceptions of their social network members' attitudes. Abbey and colleagues (2001) also asked participants to speculate about their friends' reactions to sexual assault, and how much 


\section{SOCIAL NETWORKS OF INTIMATE PARTNER VIOLENCE PERPETRATORS}

pressure they had felt from their friends to perpetrate sexual assault. Raghavan and colleagues (2009) asked participants whether any men who provide them with social support had engaged in IPV in the six months prior to the survey. Network members' actual perpetration of sexual assault and IPV, perceptions of network members' perpetration of these behaviors, and speculations about network members' reactions to these behaviors, may reflect participants' perceptions of network-wide social norms. However, this metric does not capture the specific behaviors that occur between social network members that may generate participants' perceptions of social norms.

Furthermore, responses to such measures may be more indicative of participants' normative misperceptions, which Neighbors and colleagues (2010) have established are substantial, rather than network members' use of discrete behaviors.

Additionally, the inventories developed in this study are the first to measure the behaviors that BIP participants may use to potentially influence their social network members regarding IPV. Thus, an additional contribution of this study is the development of these two inventories of the behaviors that BIP participants and their social network members may use to convey their attitudes about, or participation in, IPV, which may be used in future research. Specifically, administering the current measures to BIP participants on a daily or weekly basis over the course of several weeks or months is suggested as a next step for research in this domain. Details regarding how the current inventories should be used are elaborated next, before a discussion of the additional research questions that the inventories may be used to pursue. 


\section{SOCIAL NETWORKS OF INTIMATE PARTNER VIOLENCE PERPETRATORS}

Currently, the most compelling evidence of the inventories' validity is the participation of BIP facilitators and participants in their development. The original versions of the two inventories were amalgamations of relevant pre-existing measures, which were iteratively revised on the basis of guided conversations and pointed feedback provided by one group of BIP facilitators and two groups of BIP participants. Thus, the inventories are inherently pertinent to BIP participants, or, at minimum, those BIP participants attending Allies in Change in 2013. The two inventories were constructed to describe and quantify the abuse-relevant messages conveyed between BIP participants and their network members, and subscales were created within each inventory based on similarities in the items' content. At the present time, the factor structures of the two inventories remain unknown and future measure development work is needed to assess the inventories' construct validity.

In the interim, the suggested scoring of the inventories is as follows, based on the suggested scoring of the Conflict Tactics Scale 2 (CTS2) and the Conflict Tactics ScaleParent Child (Straus, 2004). As discussed in prior sections, the CTS2 is a commonly used inventory for assessing individuals' involvement in specific abusive behaviors (Straus et al., 1996), and was considered in the development of the current inventories. As a first step, participants' responses for each behavior ( 0 times, $1-5$ times, 6 - 10 times, 11 times or more, or not applicable) should be recoded to the median of the interval corresponding to each response option: $0,2.5,8,12$, or missing, accordingly. Missing values should not be estimated or replaced with any other value, because of the variety of 


\section{SOCIAL NETWORKS OF INTIMATE PARTNER VIOLENCE PERPETRATORS}

reasons that participants may skip particular items. For example, participants may fail to indicate a response or choose the "not applicable" response option as an alternative to the " 0 times" response option; participants may have engaged in the behavior but, due to social desirability bias, may choose not to report it; or because the item is simply not applicable to a participant's situation (i.e., "stuck up for this person's partner if they were talking badly about them" would only be applicable to participants' interactions with network members who have partners, and who speak badly about them).

Recoded scores on individual items from the inventory of network members' behaviors and the inventory of participants' behaviors may be combined in a number of ways. Items from each inventory may be examined individually, and their average usage across participants and network members may be compared to each other, to gain a descriptive understanding of which abuse relevant behaviors are used more and less often within a given sample. It may be informative to consider this information as an initial step in examining abuse relevant communication among new samples of participants.

Each network member's score on each item from the inventory of network members' behaviors may also be summed to represent their total use of abuse relevant behavior during the prior three months; the same may be done with participants' scores on each item from their respective inventory, representing their total use of abuse relevant behavior with each individual network member during the prior three months. These total scores quantify the extent of participants' and their network members' communication about abuse, regardless of its content. 


\section{SOCIAL NETWORKS OF INTIMATE PARTNER VIOLENCE PERPETRATORS}

Scores on specific items from each inventory may also be combined to represent network members' and participants' communication of theoretically distinct abuserelevant content. The inventory of network members' behavior may be parsed into two subscales, one representing network members' pro-abuse behaviors (items 17, 18, 19, 21, $22,23,24,26,27$, and 28), and one representing network members' anti-abuse behaviors (items 20, 29, 30, and 31). The inventory of participants' behaviors may similarly be segmented into four subscales: intervention into others' abuse relevant behavior (items 1, $3,5,7,9$ and 10), theoretical discussion of abuse (items 4 and 11), making selfdisclosures about abuse (items 12, 13, 14, and 15), and sharing information and resources pertinent to abuse (items 2,6 , and 8 ). The items that comprise each subscale should be averaged, to account for the different numbers of items that comprise each subscale. If participants are missing data on specific items, averages for each subscale should be computed using only the items for which participants provided data.

The six subscales described above were derived theoretically, on the basis of the items' intuitive meaning and content, and the factor structures of the two inventories have not been empirically verified. While exploratory factor analyses are suggested as a future step in this program of research, the results of an empirical approach to data reduction should be interpreted with caution. The theoretically derived subscales may have minimal internal consistency, and from a purely statistical perspective, the items that compose each subscale may not cluster together, due, in part, to the varied relevance of each item to different participants and network members. For example, the self-disclosure subscale 


\section{SOCIAL NETWORKS OF INTIMATE PARTNER VIOLENCE PERPETRATORS}

includes the following four items: "shared your story about abuse with this person," "told this person that you go to Allies in Change," "made amends with this person for your abusive behavior," and "apologized to this person for demonstrating abusive behavior in the past." On their face, all of these items involve sharing aspects of one's experience with abuse. However, these behaviors may be more or less applicable in different contexts and relationships: participants may rarely perpetrate abuse against, or in the presence of, friends/roommates or bosses/coworkers, and therefore would not make amends with them or apologize to them for abusive behavior, while they may still tell them that they attend Allies in Change or share their story about abuse with them. Network members of participants who have children may use abuse-relevant behaviors that involve children relatively frequently, while network members of participants who are not parents would not accuse those participants' partners of trying to harm their children. Thus, factor analyses may reveal subscales that correspond to participants' contexts, or the nature of their relationships with their network members, as opposed to the content of their communication. The primary purpose of creating the two inventories within the current study was to understand and describe the content of BIP participants' and their network members' abuse relevant communication, and creating subscales that theoretically correspond to this content is a direct means of doing so.

Future research should attempt to refine the current inventories, through the addition of specific, discrete abuse relevant behaviors that may be more prevalent among BIP participants in other programs in other locales. Additionally, factor analysis may 


\section{SOCIAL NETWORKS OF INTIMATE PARTNER VIOLENCE PERPETRATORS}

reveal items that do not contribute substantial unique variance to either inventory, and which may be collapsed with other items or removed from either inventory to reduce the burden on participants. The results of exploratory factor analyses may also suggest patterns in participants' interpretations of the items, enabling the rephrasing of items as necessary. While both inventories may be developed further, their initial formulation is a step towards the pursuit of additional research questions, specifically, those pertaining to changes in the content of BIP participants' and their network members' discourse about abuse over their time in a BIP.

Next Steps: Exploring Processes of Change over Time

Findings suggest that BIP participants may undergo some degree of change in their interactions with their social network members as they progress through a BIP. While the current study did not assess change over time, differences in participants' and their network members' use of behaviors depending upon the length of time that they had been attending the program were identified. Participants' attendance in the BIP was negatively related to their use of several anti-IPV behaviors, ${ }^{16}$ and the longer that participants had been attending the BIP, the less often their network members engaged in abuse-supportive behaviors. There are at least four potential causes of the negative association between this set of participants' behaviors and their BIP attendance,

\footnotetext{
${ }^{16}$ The behaviors that more tenured participants used less often were recommending a BIP to their network members, speaking up against sexist jokes or jokes about abuse, and asking others to limit their abusive behavior.
} 


\section{SOCIAL NETWORKS OF INTIMATE PARTNER VIOLENCE PERPETRATORS}

particularly in the context of the negative association between network members' use of

pro-abuse behaviors and participants' BIP attendance. The four potential explanations for this pattern of results all suggest that the nature of participants' abuse-relevant communication may be different at the beginning and the end of their time in the BIP. Repeated measures studies are needed to identify which, if any, of these four potential processes most closely resemble participants' changing social interactions over the course of their BIP participation.

One potential explanation for the negative relationship between BIP attendance and IPV-relevant behaviors is that, upon beginning the BIP, participants are excited about the program, learn quite a bit about abuse very quickly, and have a desire to show off their new knowledge to others. Both the participants and facilitators in the memberchecking focus group agreed that newer participants are eager to share their new knowledge and thoughts about abuse with the members of their social networks, and as the information becomes less novel to them, they are less motivated to share it with others. Similarly, participants who are just beginning the BIP may use their new knowledge in coercive or abusive ways. For example, they may share information about abuse, make self-disclosures, and initiate theoretical conversations about abuse with their partners to demonstrate that they have changed through their BIP participation, to accuse their partners of perpetrating abuse, or to excuse their prior abusive behavior. This pattern would be consistent with participants' use of information sharing, self-disclosures, and theoretical conversations with their current and former partners significantly more often 


\section{SOCIAL NETWORKS OF INTIMATE PARTNER VIOLENCE PERPETRATORS}

than with other network members. Participants with more BIP attendance may be more accountable than those just beginning the program, and may use anti-IPV behaviors more judiciously and less manipulatively. More tenured participants may also recognize, as BIPs tend to emphasize, that they cannot control others' behavior. Participants with greater attendance may therefore be less preoccupied with modifying the behaviors of other people than with being accountable for their own behavior, and use fewer antiabuse behaviors with the members of their social networks, accordingly.

A second possible explanation for the negative association between participants' BIP attendance and their IPV-relevant behaviors is that they have successfully exerted influence over their network members. In addition to their use of IPV-relevant behaviors from the inventory, the mere fact of participants' BIP attendance may have impacted their social network members (Hawe, Shiell \& Riley, 2009; Larson, 1997; Roffman et al., 2008). Participants' intentional anti-abuse behaviors at the beginning of their time in the BIP may have produced declines in their network members' pro-abuse behaviors, resulting in fewer occasions or reasons for participants to convey anti-abuse messages to those network members. For example, participants' children's use of IPV-relevant behaviors was negatively associated with participants' program attendance. Participants likely have more influence over their children than other network members, and declines in their children's IPV-relevant behaviors may be indicative that participants successfully communicated anti-IPV messages to them early in their program participation, reducing the necessity of engaging in further anti-IPV behaviors. 


\section{SOCIAL NETWORKS OF INTIMATE PARTNER VIOLENCE PERPETRATORS}

Focus group participants described ways that they believe they have influenced their network members' IPV-relevant behavior, specifically, network members' disparaging comments about their partners. Focus group participants believed that they have influenced their network members' behaviors in these situations by (1) sharing stories about productively addressing conflict in their own relationships, (2) setting an example of describing their own fault in conflicts with their partners, and (3) making selfdisclosures, sharing information about abusive behavior, and describing their own behavior as abusive (focus group participants indicated that the third of these strategies was the least common). These strategies align with making self-disclosures and engaging in theoretical discussions of abuse, the two categories of behaviors that BIP participants used most often. The negative association between participants' BIP attendance and their network members' use of pro-abuse behaviors also points to participants' successful influence on their network members.

A third explanation for the negative relationship between participants' BIP attendance and their use of anti-IPV behaviors is that, after a number of attempts to modify their network members' IPV-relevant behaviors, they give up trying to do so. Individuals repeatedly express attitudes and behaviors that their network members reinforce, and limit their expression of attitudes and behaviors that their peers, particularly peers with whom they have high-quality relationships (Terry \& Hogg, 1996), punish or ignore (Dishion, Patterson \& Griesler, 1994). If participants' attempts to discuss abuse with their network elicit negative reactions or fail to generate any change in 


\section{SOCIAL NETWORKS OF INTIMATE PARTNER VIOLENCE PERPETRATORS}

their network members' behaviors, participants are unlikely to continue trying to communicate IPV-relevant messages to those network members. Focus group participants provided anecdotes exemplifying this course of events. As a result of these interactions, in addition to social norms that prevent direct conversations about abuse, BIP participants prefer limiting their exposure to their network members' pro-abuse behavior instead of trying to modify it.

Participants may be more likely to direct conversations away from abuse, instead of attempting to exert IPV-relevant influence over network members who have been unresponsive to such influence in the past. Focus group participants indicated that this has been true of their experiences, and quantitative findings demonstrate that BIP participants engage in only one additional anti-IPV behavior for every two additional proabuse behaviors that their network members use. While the sequencing of participants' anti-IPV behaviors and their network members' pro-IPV behaviors is unclear, this pattern might indicate that participants choose to respond to only half of their network members' pro-IPV behaviors, and opt to avoid engaging their network members about abuse the other half of the time. This would be consistent with the focus group participants' preference to limit their discussions of abuse with network members who have previously responded poorly to anti-IPV communication. There was a positive relationship between participants' and their network members' use of anti-abuse behaviors, indicating that participants are more likely to communicate about abuse with network members who reinforce or support their anti-abuse behaviors. 


\section{SOCIAL NETWORKS OF INTIMATE PARTNER VIOLENCE PERPETRATORS}

A fourth explanation for more experienced BIP participants' less frequent use of anti-IPV behavior is that they have stopped spending time with network members with whom they felt it was necessary to use anti-IPV behavior. BIP participants may distance themselves from network members who convey more pro-abuse attitudes and are unresponsive to participants' anti-IPV behavior; this would also explain the negative relationship between network members' use of pro-abuse behaviors and participants' BIP attendance. As participants attend the BIP over many weeks and months, they may pare down their social networks to members with whom participants do not need to engage in anti-IPV behavior, through selection. This pattern would support and extend prior findings that participating in intervention programs can alter the structure of individuals' social networks, at least among participants in alcohol treatment programs (Humphreys \& Noke, 1997; Humphreys et al., 1999). Thus, participants who are further along in their BIP attendance may have network members who do not necessitate as frequent use of anti-IPV behaviors.

In summary, the inventories that resulted from the current study are a step towards future research examining how abuse-relevant influence is spread within BIP participants' immediate social contexts. These are the first measurement tools that may be used to quantify interpersonal interactions regarding abuse and related norms and behaviors. Future research may utilize these measures to build upon current findings of differences in the abuse-relevant communication within the social networks of more and less tenured BIP participants. A next step should involve investigating how and why 


\section{SOCIAL NETWORKS OF INTIMATE PARTNER VIOLENCE PERPETRATORS}

participants' abuse-relevant interactions with their network members change over the course of their BIP participation, and hopefully link these findings to changes in BIP participants' perpetration of abuse. Future research may also overcome some of the limitations of the current study, which are addressed next.

\section{Limitations}

\section{Study Design}

Many of the current study's implications for future research point to the necessity of establishing causality, or examining transactional processes between BIP participants and their network members, as next steps. This study did not assess the extent to which participants' communication about IPV actually changed their network members' attitudes towards IPV, nor the extent to which network members' IPV-specific behaviors impacted the IPV-relevant attitudes of BIP participants. While the study identified the social network members who may be more influential on BIP participants and vice versa, future repeated-measures studies, engaging both BIP participants and their network members as participants, is needed to assess actual changes in BIP participants' and their network members' perspectives on abuse. Additionally, the current study did not attempt to establish a relationship between social network members' IPV-supportive behaviors and BIP participants' perpetration of IPV, an important next step in establishing the impact of social network influences on the efficacy of BIPs. While this study provides the descriptive foundation and possible measures for doing so, future research should explore 


\section{SOCIAL NETWORKS OF INTIMATE PARTNER VIOLENCE PERPETRATORS}

whether and how BIP participants' and their network members' expressed support and sanctioning of IPV actually resonate with each other, and whether they ultimately impact each other's perpetration of abuse. Future research may address these issues by assessing changes in both participants' and their network members' abuse-relevant attitudes, behaviors and interactions across several measurement points.

The current findings do not establish whether BIP participants or their network members initiate conversations about abuse more often, or how BIP participants and their network members' respond to each other's' abuse-relevant communication. This information may indicate whether BIP participants tend to take the initiative to share their information and experiences about abuse with others, or whether they address abuse primarily through responding to others' abuse-relevant behavior. Understanding the circumstances surrounding BIP participants' abuse-relevant behavior may enable programs to better support them in creating proximal social environments that facilitate being accountable. While the current study identified specific abuse-relevant behaviors that BIP participants and their network members use, participants were asked to report on these behaviors both retrospectively, and in the aggregate. The resulting data did not reveal the sequencing or transactional patterns of BIP participants' and network members' use of abuse-relevant behaviors. Future research should attempt to examine these interaction patterns more precisely, via daily-diary techniques, in-depth interviews or focus groups about social interactions about abuse, or observations of interactions between BIP participants and their network members. 


\section{SOCIAL NETWORKS OF INTIMATE PARTNER VIOLENCE PERPETRATORS}

Neither did the current study explore why BIP participants address IPV with some network members over others. Banyard (2011) recommends examining the actual and perceived attitudes of network members with whom individuals do and do not address IPV, to determine how individuals' perceptions of their peers shapes their willingness to attempt to influence those peers. Depending on their perceptions of network members' receptivity to influence, participants who strongly object to network members' attitudes and behaviors may choose to distance themselves from peers instead of trying to influence those attitudes and behaviors. The situations in which participants might attempt to influence their network members may also shape impact their likelihood of doing so. Specifically, the size of the social situation in which the influence attempt would occur, and the relationship and physical setting in which the objectionable attitude or behavior was manifested may all determine individuals' willingness to attempt to influence others (Banyard, 2011). Qualitative methods should be used to solicit participants' in-depth reflections on why they engage in abuse-relevant behaviors with some network members and not others.

\section{Data Collection, Processing and Analysis}

A number of this study's limitations arise from data collection and data processing methods. BIP participants in the current study were recruited from a single program, potentially limiting the findings' generalizability to participants enrolled in other BIPs. Across the United States, BIPs vary greatly in their use of the Duluth 


\section{SOCIAL NETWORKS OF INTIMATE PARTNER VIOLENCE PERPETRATORS}

curriculum, program length, facilitators' education and training, contact with victims, referral sources, drop-out rate, and funding streams (Price \& Rosenbaum, 2009), all of which may have implications for the quality and extent of their impact on participants. As discussed in greater detail in the Participants section, Allies in Change has a relatively unique orientation towards working with BIP participants, offers a range of highly specialized BIP groups, is exposed to a perhaps exceptional amount of relevant training and education, and, through their involvement in this project, have been cognizant of participants' interactions with their social networks. Allies in Change is also the only program in Oregon known to separates BIP participants by their level of risk or criminal orientation (Viola \& Huffine, May 13, 2014). This may create unique dynamics within the agency's non-criminally oriented groups. The absence of disruptive, difficult, or outwardly anti-social participants may enable the Allies in Change's non-specialized groups to function differently than they might at other agencies, and may limit the amount of deviancy training that occurs within their intervention groups. Similarly, findings regarding participants in criminally oriented groups may not apply to criminally oriented participants in other agencies, who attend BIP groups that are not specialized for criminally oriented offenders. Other programs that may begin to separate criminally oriented participants from other clients may use different procedures for doing so, resulting in slightly different populations of criminally-oriented participants, to whom the current findings may not apply. Additionally, Allies in Change is located in the Portlandmetro area, and caters to a largely urban population; geographical and lifestyle 


\section{SOCIAL NETWORKS OF INTIMATE PARTNER VIOLENCE PERPETRATORS}

differences between urban and suburban or rural areas may create differences in the structure of BIP participants' social networks, and the frequency of contact among individuals therein. Thus, generalizability of the current findings to BIP participants enrolled in other programs and based in different locations may be limited.

The prompt used to solicit participants' nominations of their network members asked them to consider the people with whom they had spent the most time over the prior three months. This prompt may have discouraged participants from listing network members who they consider highly influential, but who they see relatively rarely. For example, participants only see their BIP facilitators weekly, at most, but may spend considerable time between their weekly meetings reflecting on their interactions. Conversely, despite the researcher's reiteration that participants should only complete the survey for as many network members as made sense for them, it is also possible that participants felt pressure to nominate more network members than they regularly spend time with. Thus, participants may have described social networks that do not accurately represent the people with whom they have the most interactions, or the most salient interactions.

The lack of distinction between participants' current and former partners may have been problematic. Participants' current partners and former partners were collapsed into one category for analyses in the current study, painting a convoluted picture of participants' relationships with these network members. Members of the general population likely engage with their current partners in different ways than their former 


\section{SOCIAL NETWORKS OF INTIMATE PARTNER VIOLENCE PERPETRATORS}

partners. However, some BIP participants may engage with their current partners to the same extent and via the same forms of communication and IPV-relevant behaviors that other BIP participants use to communicate with their former partners, given the unique dynamics of BIP participants' romantic relationships and the involvement of the legal system therein. In the current study, participants' current and former network members were combined because of the somewhat blurry distinction between them: many BIP participants are technically separated from their partners, but still have regular contact with them, while others still consider themselves in relationships with their partners, but have very limited contact with them as a result of court orders. Future research should gather information about the status of participants' relationships with each of these network members to draw greater distinctions between them and facilitate separate analyses of these two relational ties. It would be worth comparing participants' satisfaction and communication with their current and former partners to identify the extent of their differences.

The phrasing of a number of survey items also posed limitations. Returning to the contents of the behavioral inventories with relatively fresh eyes, several months after finalizing them and incorporating them into the surveys, the interpretations of two items appeared ambiguous. Specifically, one of the behaviors that participants may have used with their network members, "asked this person not to talk about abuse or act abusively around you," may not have been very clear. The item was intended to assess participants' efforts to limit their exposure to network members' expressions of pro-abuse attitudes. 


\section{SOCIAL NETWORKS OF INTIMATE PARTNER VIOLENCE PERPETRATORS}

However, participants may have interpreted this item as referring to any instances in which they ended any conversation about abuse with a given network member, including conversations that conveyed anti-abuse sentiments. However, the coupling of "talk about abuse" and "act abusively" hopefully clarified the item's intention, and none of the participants, in either the focus groups or survey completion, posed questions about this item.

Similarly, the valence of one item used to assess network members' IPV-relevant behavior, "told you ways to avoid consequences of abusive behavior," was ambiguous. This item may reflect network members' provision of advice about ways to perpetrate abuse to avoid being detected, which was the item's intended interpretation. However, considering network members' use of other anti-abuse behaviors, this behavior might also reflect network members' advice to stop perpetrating abuse as a way to avoid its consequences. Recognizing the potential pro-social interpretation of this item later in the research process points to another limitation of the study. The researcher was not attuned to network members' use of anti-abuse behaviors at the outset of the study, and as a result, did not incorporate them in the current project as much as might be possible. Future research might address network members' anti-abuse behaviors more thoroughly, directing focus groups' attention towards their network members' anti-IPV communication and including more equal numbers of pro-abuse and anti-abuse items in behavioral inventories. 


\section{SOCIAL NETWORKS OF INTIMATE PARTNER VIOLENCE PERPETRATORS}

Another methodological limitation of the current study is that asking participants to reflect on events and behaviors from the prior three months may have resulted in less accuracy and less variation was ideal, from a statistical perspective, on the behavioral inventories. While survey instructions indicated that participants were to consider their own behavior and their network members' behavior from the three months prior, participants' comments during the pilot-testing focus group and survey administrations indicated that this was not always the case. The three-month window was initially selected for the sake of consistency with studies in the area of substance abuse, which often use retrospective reports of 90 days prior to the survey (e.g. Mohr et al., 2001). Participants appeared to occasionally forget the three-month time frame, and instead reported on the use of IPV-relevant behaviors since beginning at Allies in Change. Daily or weekly diary studies may produce very low base-rates of IPV-relevant behaviors, but more accurately capture the variation in participants' and network members' use of these behaviors over time. This would also enable temporal precedence, moving closer to the ability to draw conclusions about the effects of participants' and network members' behaviors on each other.

Regarding data analysis, the low base rates of associated with the behaviors from both behavioral inventories resulted in skewed distributions. The presence of a "not applicable" option resulted in a high level of missing data. While an ANOVA framework might have been better suited to handle the skewed distributions, multi-level mixed models were used more readily to analyze the current data, to enable the inclusion of the 


\section{SOCIAL NETWORKS OF INTIMATE PARTNER VIOLENCE PERPETRATORS}

greatest amount of data. The violation of distributional assumptions underlying multilevel mixed modeling is another limitation of this study. Additionally, the majority of the mixed models would not converge with the inclusion of a third level of analysis. Many of the models include behaviors' nesting within network members, but not network members' nesting within participants. It is likely that network members' nesting within participants explains a great deal of variation in the data, and future analyses should include this additional layer of nesting as best as possible.

Limitations of Research on Male Peer Support for Violence Against Women DeKeseredy (1990a, p. 132) identifies five major limitations of existing sociological research on male peer support and woman abuse, one of which the current study addressed directly, and four of which this study addressed to different extents. DeKeseredy (1990a) calls for researchers to examine the variety of ways that male social networks influence men to victimize women, which is at the crux of the current study. DeKeseredy (1990a) also indicates the need for his model of peer support for IPV to be tested, which the current study did not intend to do. However, DeKeseredy also notes that survey methodology may be insufficient for measuring the extent and nature of perpetrators' peers' support for IPV, due to social desirability biases in participants' reporting; that a limitation of most IPV research is the exclusion of women's perspectives; that qualitative research is needed to complement the largely quantitative 


\section{SOCIAL NETWORKS OF INTIMATE PARTNER VIOLENCE PERPETRATORS}

body of research that currently exists regarding IPV. These three limitations are discussed next.

Participants may not be expected to be completely accurate or honest about the abuse-relevant behaviors in which they or their social network members have engaged. Participants in this self-report study may have intentionally reported that they engage in more anti-abuse behaviors than they actually have, to create more socially desirable images of themselves. Participants may have intentionally portrayed their social networks as less supportive of abuse than they are, to paint a positive picture of their friends and family. They may have also indicated that their social networks are more supportive of abuse than they actually are, to justify their own attitudes and behaviors. Inaccuracies in participants' reporting of their network members' use of abuse-relevant behaviors may have also resulted from misinterpretations of their network members' behaviors as abuse supportive; participants may be especially prone to interpret their network members' behaviors as validations of their use of abuse, given their tendency to overestimate the prevalence of IPV within their community (Neighbors et al., 2010). An ideal research design to examine the interactions between BIP participants and their social network members would involve observing interactions between BIP participants and their social network members. However, base rates of interactions about IPV may be so low that they may not appear in a meaningful way during brief observation periods. Additionally, the biases resulting from self-report data may be comparable to those introduced by the 


\section{SOCIAL NETWORKS OF INTIMATE PARTNER VIOLENCE PERPETRATORS}

presence of an observer during interactions between BIP participants and their network members.

Though the failure to ask women for their perspective on a problem that so directly impacts their physical safety is indeed a limitation of research in this area, it is not the focus of this particular study. Additionally, IPV is not always perpetrated by men against women, and the experiences of male victims and female perpetrators may also be foci of other programs of research. However, future research could integrate BIP participants' partners' reports of abuse and perceived safety with BIP participants' and their network members' communication about IPV to tie IPV-relevant communication within BIP participants' social networks directly to their implications for BIP participants' partners.

The current study's research questions and hypotheses were addressed with both quantitative and qualitative data. Conducting focus groups with program facilitators and participants to assist with survey development and with the interpretation of the quantitative results ensured that the findings do not rest solely on quantitative survey data, partially addressing the limitation of using exclusive quantitative data that DeKeseredy (1990a) identifies. Incorporating qualitative data into the current study provided a more nuanced understanding and critical analysis of the phenomena under study, and enabled the consideration and reporting of participants' own understandings of their experiences (Kidder \& Fine, 1997). Further qualitative research may be helpful in elucidating BIP participants' motivations for, and considerations in, engage their network 


\section{SOCIAL NETWORKS OF INTIMATE PARTNER VIOLENCE PERPETRATORS}

members around IPV. Interviews or focus groups with participants' network members would also shed light on their reactions to participants' IPV-relevant behavior, and how they have influenced or been influenced by BIP participants. 


\section{SOCIAL NETWORKS OF INTIMATE PARTNER VIOLENCE PERPETRATORS}

\section{Conclusion}

The current study is the first, to the researcher's knowledge, to explore discrete behaviors by which messages about IPV are communicated between individuals, including those who have perpetrated IPV. While prior research has established that individuals' attitudes and behaviors regarding violence against women are related to their perceptions of the prevalence of abuse within their communities (Abbey et al., 2001;

Brown \& Messman-Moore, 2010; Neighbors et al., 2010; Raghavan et al., 2009) and on their college campuses (Berkowitz et al., 2004; Flood, 2008), this is the first study to examine the specific interpersonal behaviors that may contribute to, and potentially interrupt, those perceptions. The three primary implications that resulted from the current study are (1) the understanding of BIP participants as bystanders who actively intervene in abuse-relevant social norms in their social networks; (2) a detailed picture of how and from whom BIP participants receive support for the perpetration of IPV; and (3) the creation of two new behavioral inventories that may be used to explore patterns and effects of abuse-relevant communication in greater depth. These three implications represent steps towards a deeper understanding of the interpersonal transmission of messages that allow the perpetration of abuse to continue within our communities.

Additional noteworthy and unexpected findings are that BIP participants' network members support their accountability, and that BIP attendance is related to the extent to which social networks support accountability. These findings were unanticipated, as prior theories have emphasized the ways in which social influence contributes to the 


\section{SOCIAL NETWORKS OF INTIMATE PARTNER VIOLENCE PERPETRATORS}

perpetration of violence against women, as opposed to its prevention. Further meaningful findings include participants' lower satisfaction with network members who use more pro-abuse behaviors, more tenured participants' possible solicitation of anti-abuse messages from the members of their social networks, and different patterns of communication between more and less tenured BIP participants and specific network members, all of which indicate greater anti-abuse tendencies among BIP participants with greater attendance. Thus, current findings also appear suggestive of BIPs' efficacy. The identification of differences between the social networks of criminally oriented and noncriminally oriented BIP participants also suggests the distinctiveness of these populations, and the potential effectiveness of working with them separately. While these findings are secondary for the purposes of the current study, they are potentially significant, and worth further attention in future projects. However, perhaps the most basic and important contribution of the current study is the finding that BIP participants regularly engage in abuse-relevant behaviors with their social network members, and therefore contribute to the discourse about abuse within their communities and beyond.

The social structures that serve as channels for communicating high-level constructs, such as norms that condone violence against women, are potentially more influential in enabling the continued perpetration of IPV than those high-level constructs themselves (Michalski, 2004). Though identifying the specific social structures that facilitate IPV may be key to understanding and effectively intervening in abusive behavior (Michalski, 2004), individuals often come in contact with these structural 


\section{SOCIAL NETWORKS OF INTIMATE PARTNER VIOLENCE PERPETRATORS}

features that encourage or discourage violent confrontation with intimate others within more proximal contexts, specifically, their social networks. Patterns of abusive behavior may be transmitted through familial (Capaldi \& Clark, 1998; Simons, Wu, Johnson \& Conger, 1995) or peer (Brown \& Messman-Moore, 2010; Browning, 2002; Dishion, Patterson \& Griesler, 1994; Erickson, 1988; Schwartz \& DeKeseredy, 1997) influences; according to Michalski's (2004) logic, should these members of individuals' social networks stop perpetuating the social structures that facilitate IPV, those social structures would become less relevant, as they would reach fewer individuals. Anyone, including BIP participants, may choose which social structures they do or do not convey to their social network members, thereby shaping the social structures that their social network members may continue to transmit to others, potentially modifying the ways and extent to which social structures that facilitate IPV are perpetuated within network members' communities. Findings indicate that BIP participants are active bystanders in abuserelevant social norms, transmitting anti-abuse sentiments to the members of their social networks. Whether BIP participants' intention is to shape the norms within their social networks or to solicit encouragement for their own accountability, it appears that they are active in shaping the social structures manifested within their networks.

Just as it may be possible for BIP participants' abuse-relevant behaviors to shift their social network members' perceptions of network norms (Berkowitz, 2004; Brown \& Messman-Moore, 2010; Flood, 2008), any changes in network members' attitudes and behaviors resulting from their contact with BIP participants may radiate outwards, 


\section{SOCIAL NETWORKS OF INTIMATE PARTNER VIOLENCE PERPETRATORS}

shifting their broader community members' perceptions of the norms within that community. Reducing the perpetration of IPV has been conceptualized as a communitylevel task (Almeida \& Bograd, 1991), largely contingent upon engaging webs of social networks in attitudinal and behavioral change (Banyard, Plante \& Moynihan, 2004). While BIP participants have themselves been perpetrators of abuse, current findings indicate that they may also be agents of social change in their communities, communicating anti-abuse messages to the members of their social networks. Intentional or not, BIP participants' contributions to shifting community-wide norms around IPV and intervention therein may have profound consequences for the 1.3 million women affected by IPV in the United States each year (Tjaden \& Thoennes, 2000). 


\section{SOCIAL NETWORKS OF INTIMATE PARTNER VIOLENCE PERPETRATORS}

\section{References}

Abbey, A., McAuslan, P., Zawacki, T., Clinton, A. M., \& Buck, P. O. (2001). Attitudinal, experiential and situational predictors of sexual assault perpetration. Journal of Interpersonal Violence, 16(8), 784-807.

Ajrouch, K. J., Antonucci, T. C., \& Janevich, M. R. (2000). Social networks among blacks and whites: The interaction between race and age. The Journals of Gerontology, Series B., 56 (2), $112-118$.

Ajzen, I. (1971). Attitudinal vs. normative messages: An investigation of the differential effects of persuasive communications on behavior. Sociometry, 34(2), 263-280.

Ajzen, I. \& Fishbein, M. (1970). The prediction of behavior from attitudinal and normative variables. Journal of Experimental Social Psychology, 6, 466-487.

Ajzen, I. \& Fishbein, M. (1972). Attitudes and normative beliefs as factors influencing behavioral intentions. Journal of Personality and Social Psychology, 21 (1), 1 9.

Ajzen, I. \& Fishbein, M. (1974). Factors influencing intentions and the intentionbehavioral relation. Human Relations, 27 (1), $1-15$.

Allies in Change Counseling Center (2012). Retrieved October 26, 2012, from http://www.alliesinchange.org/index.html.

Almeida, R. \& Bograd, M. (1991). Sponsorship: Men holding men accountable for domestic violence. Journal of Feminist Family Therapy, 2, 243-256.

Altman, I., \& Rogoff, B. (1987). World views in psychology: Trait, interactional, organismic, and transactional perspectives. In D. Stokols I. Altman (Eds.), 


\section{SOCIAL NETWORKS OF INTIMATE PARTNER VIOLENCE PERPETRATORS}

Handbook of Environmental Psychology. Volume 1 (pp. 7-40). New York:

Wiley.

Alvazzi del Frate, A. (2012, September 6). Small Arms Survey 2012. Monitoring

trends in small arms proliferation and armed violence. Lecture conducted from

Vera Institute of Justice, New York, NY.

Andrews, D. A. \& Bonta, J. (2010). Rehabilitating criminal justice policy and practice. Psychology, Public Policy, and Law, 16 (1), 39 - 55.

Arriaga, X. B., \& Foshee, V. A. (2004). Adolescent dating violence: Do adolescents follow in their friends' or their parents' footsteps? Journal of Interpersonal Violence, 19, 162-184.

Babcock, J. C., Green, C. E., \& Robie, C. (2004). Does batterers' treatment work? A meta-analytic review of domestic violence treatment. Clinical Psychology Review, 23, $1023-1053$.

Banyard, V. L. (2008). Measurement and correlates of prosocial bystander behavior: The case of interpersonal violence. Violence and Victims, 23, 83-97.

Banyard, V. L., Moynihan, M. M., \& Plante, E. G. (2007). Sexual violence prevention through bystander education: An experimental evaluation. Journal of Community Psychology, 35, $463-481$.

Banyard, V. L., Plante, E. G., Moynihan, M. M. (2004). Bystander education: Bringing a broader community perspective to sexual violence prevention. Journal of Community Psychology, 32, $61-79$. 


\section{SOCIAL NETWORKS OF INTIMATE PARTNER VIOLENCE PERPETRATORS}

Beattie M.C. \& Longabaugh R. (1997). Interpersonal factors and post-treatment drinking and subjective well-being. Addiction, 92, 1507-1521.

Beattie, M. C. \& Longabaugh, R. (1999). General and alcohol-specific social support following treatment. Addictive Behaviors, 24, $593-606$.

Berkowitz, A. D. (2004). The social norms approach, research and annotated bibliography. Retrieved July 17, 2012 from http://www.alanberkowitz.com/articles/social_norms.pdf.

Berndt, T. J. (2002). Friendship quality and social development. Current Directions in Psychological Science, 11, 7-10.

Bonta, J., \& Andrews, D. A. (2007). Risk-need-responsivity model for offender assessment and rehabilitation (User Report 2007-06). Ottawa, Ontario: Public Safety Canada.

Bonta, J., Rugge, T., Scott, T. L., Bourgon, G., \& Annie, K. Y. (2008). Exploring the black box of community supervision. Journal of Offender Rehabilitation, 47(3), 248-270.

Borgatti, S. P., Mehra, A., Brass, D. J. \& Labianca, G. (2009). Network analysis in the social sciences. Science, 323, $892-895$.

Borsari, B. \& Carey, K. B. (2001). Peer influences on college drinking: A review of the research. Journal of Substance Abuse, 13, $391-424$. 


\section{SOCIAL NETWORKS OF INTIMATE PARTNER VIOLENCE PERPETRATORS}

Broadbent, J. (2003). Movement in context: Thick networks and Japanese

Environmental Protest. In M. Diani \& D. McAdam (Eds.), Social Movements and Networks: Relational Approaches to Collective Action (204-229). New York, NY: Oxford University Press.

Brown, A. K. \& Messman-Moore, T. L. (2009). Personal and perceived peer attitudes supporting sexual aggression as predictors of male college students' willingness to intervene against sexual aggression. Journal of Interpersonal Violence, 25, $503-517$

Browning, C. R. (2002). The span of collective efficacy: Extending social disorganization theory to partner violence. Journal of Marriage and Family, 64, $833-850$

Buss, D. M. (1987). Selection, evocation, and manipulation. Journal of Personality and Social Psychology, 53, $1214-1221$.

Capaldi, D. M., \& Clark, S. (1998). Prospective family predictors of aggression toward female partners for at-risk young men. Developmental Psychology, 34, 11751188.

Capaldi, D. M., \& Crosby, L. (1997). Observed and reported psychological and physical aggression in young, at-risk couples. Social Development, 6, 184-206.

Capaldi, D. M., Dishion, T. J., Stoolmiller, M., \& Yoerger, K. (2001). Aggression toward female partners by at-risk young men: The contribution of male adolescent friendships. Developmental Psychology, 37, 61-73. 


\section{SOCIAL NETWORKS OF INTIMATE PARTNER VIOLENCE PERPETRATORS}

Carlson, J., Casey, E., Edleson, J., Tolman, R. M., Neugut, T. B., \& Kimball, E. (In press). Strategies to engage men and boys in violence prevention: A global organizational perspective. Violence Against Women. Retrieved October 26, 2012 from:

http://www.tacoma.uw.edu/sites/default/files/global/documents/social/mmvp_car 1son_et_al_strategies_2012.pdf

Cartwright, D. (1965). Influence, Leadership, Control. In J. G. March (Ed.), Handbook of Organizations (1 - 47). Chicago: Rand McNally.

Casey, E. A. \& Smith T. (2010). “How Can I Not?”: Men’s Pathways to Involvement in Anti-Violence Against Women Work. Violence Against Women, 16, 953-973.

Casey, E.A. (2010) Strategies for engaging men as anti-violence allies: Implications for ally movements. Advances in Social Work, 11, 267-282.

Casey, E.A. \& Beadnell, B. (2010). The structure of male adolescent peer networks and risk for intimate partner violence perpetration: Findings from a national sample. Journal of Youth and Adolescence, 39, 620-633.

Casey, E.A. \& Ohler, K. (2012) Being a positive bystander: Male anti-violence allies' experiences of 'stepping up.' Journal of Interpersonal Violence, 27, 62 - 83.

Catalano, S. (2007). Intimate partner violence in the United States. U.S. Department of Justice: Bureau of Justice Statistics. Retrieved September 8, 2012, from: http://bjs.ojp.usdoj.gov/content/pub/pdf/ipvus.pdf 


\section{SOCIAL NETWORKS OF INTIMATE PARTNER VIOLENCE PERPETRATORS}

Cazenave, N. A. \& Straus, M. A. (1995). Race, class, network embeddedness, and family violence: A search for potent support systems. Journal of Comparative Family Studies, 10, 280 - 299.

Centers for Disease Control and Prevention. (2006). Costs of intimate partner violence against women in the United States. Atlanta, GA. CDC, National Center for Injury Prevention and Control.

Centers for Disease Control and Prevention. (2008). Adverse health conditions and health risk behaviors associated with intimate partner violence - United States, 2005. Morbidity and Mortality Weekly Report, 57, 113-140.

Cherry, E. (2006). Veganism as a cultural movement: A relational approach. Social Movement Studies, 5, 155-170.

Christens, B. (2012). Toward Relational Empowerment. American Journal of Community Psychology, 50, 114 - 128.

Christakis, N.A. \& Fowler, J. H. (2007). The spread of obesity in a large social network over 32 years. The New England Journal of Medicine, 357, 370-379.

Clifford, P. R \& Longabaugh, R. (1991). Manual for the Administration of the Important People and Activities Instrument. Providence, RI: Center for Alcohol and Addiction Studies, Brown University.

Coker, D. (2002) Transformative justice: Anti-subordination processes in cases of domestic violence. In H. Strang and J. Braithwaite (Eds.), Restorative Justice 


\section{SOCIAL NETWORKS OF INTIMATE PARTNER VIOLENCE PERPETRATORS}

and Family Violence (pp. 128 - 152). New York, NY: Cambridge University Press.

Coker, A. L., Smith, P. H., McKeown, R. E., \& King, M. R. (2000). Frequency and correlates of intimate partner violence by type: Physical, sexual, and psychological battering. American Journal of Public Health, 90, 553-559.

Collins, W. A., Maccoby, E. E., Steinberg, L., Hetherington, E. M., \& Bornstein, M. H. (2000). Contemporary research on parenting: A case for nature and nurture. American Psychologist, 55, 218-232.

Contrino, K. M., Derman, K. H., Nochajski, T. H., Wieczorek, W. F., \& Navratil, P. K. (2007). Compliance and learning in an intervention program for partner-violent men. Journal of Interpersonal Violence, 22, $1555-1566$.

Cooney, M. (1998). Warriors and peacemakers: How third parties shape violence. New York: New York University Press.

Coulter, M. \& VandeWeerd, C. (2009). Reducing domestic violence and other criminal recidivism: Effectiveness of a multilevel batterers intervention program. Violence and Victims, 24, $139-152$.

Davies, A. \& Dale, A. (1996). Locating the stranger rapist. Medical Science Law, 36, $146-156$.

Davis, R. C., \& Taylor, B. G. (1999). Does batterer treatment reduce violence? A synthesis of the literature. Women and Criminal Justice, 10, 69-93. 


\section{SOCIAL NETWORKS OF INTIMATE PARTNER VIOLENCE PERPETRATORS}

DeKeseredy, W. S. (1988). Premarital woman abuse: The multidimensional influence of male peer support. Sociological Viewpoints, 4, 44-60.

DeKeseredy, W. S. (1990a). Male peer support and woman abuse: The current state of knowledge. Sociological Focus, 23, 129-139.

DeKeseredy, W. S. (1990b). Woman abuse in dating relationships: The contribution of male peer support. Sociological Inquiry, 60, $236-243$.

DeKeseredy, W. S., \& Schwartz, M. D. (1993). Male peer support and woman abuse: An expansion of DeKeseredy's model. Sociological Spectrum, 13, 393-413.

Dishion, T. J., Andrews, D. W., \& Crosby, L. (1995). Antisocial boys and their friends in early adolescence: Relationship characteristics, quality, and interactional process. Child Development, 66(1), 139-151.

Dishion, T. J., Capaldi, D. M., Spracklen, K. M., \& Li, F. (1995). Peer ecology of male adolescent drug use. Development and Psychopathology, 7, 803-824.

Dishion, T. J., Eddy, J. M., Haas, E., Li, F., \& Spracklen, K. (1997). Friendships and violent behavior during adolescence. Social Development, 6, 207-225.

Dishion, T. J., Patterson, G. R., \& Griesler, P. C. (1994). Peer adaptation in the development of antisocial behavior: A confluence model. In L. R. Huesmann (Ed.), Aggressive behavior: Current perspectives (pp. 61-95). New York: Plenum Press. 


\section{SOCIAL NETWORKS OF INTIMATE PARTNER VIOLENCE PERPETRATORS}

Dominguez, S. \& Maya-Jariego, I. (2008). Acculturation of host individuals: Immigrants and personal networks. American Journal of Community Psychology, 42, 309-327.

Doumas, D., Margolin, G., \& John, R. S. (1994). The intergenerational transmission of aggression across three generations. Journal of Family Violence, 9, 157-175.

Dowden, C., \& Andrews, D. A. (1999). What works in young offender treatment: A meta-analysis. Forum on Corrections Research, 11, 21-24.

Dowden, C., \& Andrews, D. A. (2000). Effective correctional treatment and violent reoffending: A meta-analysis. Canadian Journal of Criminology, 42, 449 - 467.

Dutton, D. G. (2011). The case against the role of gender in intimate partner violence. Aggression and Violent Behavior, 17, $99-104$.

Edleson, J. (2012). Groupwork with men who batter: What research literature indicates. National Online Resource Center on Violence Against Women. Retrieved September 8, 2012, from: http://vawnet.org/Assoc_Files_VAWnet/AR_GroupworkMenWhoBatter.pdf. Emerge (2012). Emerge Counseling and Education to Stop Domestic Violence. Retrieved September 9, 2012, from: http://www.emergedv.com/. Emirbayer, M. \& Goodwin, J. (1994). Network analysis, culture, and the problem of agency. The American Journal of Sociology, 99, 1411 - 1454. 


\section{SOCIAL NETWORKS OF INTIMATE PARTNER VIOLENCE PERPETRATORS}

Erickson, B. H. (1982). Networks, ideologies, and belief systems. In P. V. Marsden \& N. Lin (Eds.), Social structure and network analysis (pp. 159-172). Beverly Hills: Sage.

Erickson, B. H. (1988). The relational basis of attitudes. In B. Wellman \& S. D. Berkowitz (Eds.), Social Structures: A network approach (pp. 99-121). Cambridge, UK: Cambridge University Press.

Fabiano, P., Perkins, H. W., Berkowitz, A. B., Linkenbach, J. \& Stark, C. (2004). Engaging men as social justice allies in ending violence against women: Evidence for a social norms approach. Journal of American College Health, 52(3), 105-112.

Falkin G.P. \& Strauss, S.M. (2003). Social supporters and drug use enablers: A dilemma for women in recovery. Addictive Behaviors, 28, 141-155.

Feder, L., \& Wilson, D.B. (2005). A meta-analytic review of court-mandated batterer intervention programs: Can courts affect abusers' behavior? Journal of Experimental Criminology, 1, 239-262.

Festinger, L. (1954). A Theory of Social Comparison Processes. Human Relations, 7 , $117-140$.

Fiori, K. L., Antonucci, T. C. \& Cortina, K. S. (2006). Social Network Typologies and Mental Health Among Older Adults. Journal of Gerontology, 61B, 25 - 32. 


\section{SOCIAL NETWORKS OF INTIMATE PARTNER VIOLENCE PERPETRATORS}

Fingerman, K. L., Hay, E. L. \& Birditt, K. S. (2004). The best of ties the worst of ties: Close, problematic, and ambivalent social relationships. Journal of Marriage and Family, 66 (3), $792-808$.

Flood, M. (2008). Involving men in efforts to end violence against women. Domestic Violence Network Forum (Eastern Suburbs Domestic Violence Network), March 18, 2008, Sydney Australia.

Foster-Fishman, P. G., Nowell, B., \& Yang, H. (2007). Putting the system back into systems change: A framework for understanding and changing organizational and community systems. American Journal of Community Psychology, 39, 197 $-215$.

Fowler, J. H. \& Christakis, N.A. (2008). Dynamic spread of happiness in a large social network: Longitudinal analysis over 20 years in the Framingham Heart Study. BMJ, 337, $2338-2347$.

Frye, V. (2007). The informal social control of intimate partner violence against women: Exploring personal attitudes and perceived neighborhood cohesion. Journal of Community Psychology, 35, 1001 - 1018.

Funk, R. (2008). Men's Work: Men's Voices and Actions against Sexism and Violence. Journal of Prevention \& Intervention in the Community, 36, 155-171.

Galvez, G., Mankowski, E.S., McGlade, M.S., Ruiz, M., \& Glass, N. (2011). Workrelated intimate partner violence among employed immigrants from Mexico. Psychology of Men \& Masculinity, 12(3), 230 - 246. 


\section{SOCIAL NETWORKS OF INTIMATE PARTNER VIOLENCE PERPETRATORS}

Gidycz, C. A., Orchowski, L. M. \& Berkowitz, A. D. (2011). College men: An evaluation of a social norms and bystander intervention program. Violence Against Women, 16, $720-742$.

Gondolf, E. (1997). Patterns of reassault in batterer programs. Violence and Victims, 12 (4), $373-387$.

Gondolf, E. (2000). How batterer program participants avoid reassualt. Violence Against Women, 11 (6), $1204-1222$.

Gondolf, E.W. (2002). Batterer Intervention Systems: Issues, outcomes, and recommendations. Thousand Oaks, CA: Sage Publications.

Goodrum, Umberson \& Anderson (2001). The Batterer's View of the Self and Others in Domestic Violence. Sociological Inquiry, 71, 221-240.

Goodwin, J., Jasper, J. M., \& Polletta, F. (2001). Introduction: Why Emotions Matter. In J. Goodwin, J. M. Jasper, and F. Polletta (eds.) Passionate Politics: Emotions and Social Movements. Chicago, IL: The University of Chicago Press, $1-26$.

Gordon, A. J. \& Zrull, M. (1991). Social networks and recovery: One year after inpatient treatment. Journal of Substance Abuse Treatment, 8, 143 - 152.

Graduate Institute of International and Development Studies (2012). Small Arms Survey 2012: Moving Targets. Geneva, Switzerland.

Granovetter, M. (1982). The strength of weak ties: A network theory revisited. In P. V. Marsden \& N. Lin (Eds.), Social structure and network analysis (105-130). Beverly Hills: Sage. 


\section{SOCIAL NETWORKS OF INTIMATE PARTNER VIOLENCE PERPETRATORS}

Hanson, R. K \& Wallace-Capretta, S. (2000). Predicting Recidivism Among Male Batterers, 2000-06. Public Works and Government Services of Canada.

Harris, G. T., Hilton, N. Z. \& Rice, M. E. (2011). Explaining the frequency of intimate partner violence by male perpetrators: Do attitude, relationship, and neighborhood variables add to antisociality? Criminal Justice and Behavior, 38, $309-331$.

Hartup, W. W., \& Stevens, N. (1997). Friendships and adaptation in the life course. Psychological Bulletin, 121, 355-370.

Hawe, P., Shiell, A. \& Riley, T. (2009). Theorising interventions as events in systems. American Journal of Community Psychology, 43, 267 - 276.

Hawkley, L. C., Hughes, M. E., Waite, L. J., MAsi, C. M., Thisted, R. A. \& Cacioppo, J. T. (2008). From social structural factors to perceptions of relationship quality and loneliness: The Chicago Health, Aging, and Social Relations Study. Journals of Gerontology, Series B, 63 (6), 375-384.

Haynie, D. L. (2002). Friendship networks and delinquency: The relative nature of peer delinquency. Journal of Quantitative Criminology, 18(2), 99-134.

Hearn, J. \& Whitehead, A. (2006). Collateral damage: Men's 'domestic' violence to women seen through relations with men. Probation Journal, 53, $38-56$.

Hegarty, K., Sheehan, M., \& Schonfeld, C. (1999). A multidimensional definition of partner abuse: Development and preliminary validation of the Composite Abuse Scale. Journal of family violence, 14(4), 399-415. 


\section{SOCIAL NETWORKS OF INTIMATE PARTNER VIOLENCE PERPETRATORS}

Hilton, N. Z. \& Harris, G. T. (2005). Predicting wife assault: A critical review and implications for policy and practice. Trauma and Violence Abuse, 6, 3-23.

Hogg, M. A. (2010). Influence and leadership. In S. T. Fiske, D. T. Gilbert, \& G. Lindzey (Eds.), The handbook of social psychology (5th ed., Vol. 2, pp. 11661206). New York: Wiley.

Holtzworth-Munroe, A., \& Stuart, G. L. (1994). Typologies of male batterers: Three subtypes and the differences among them. Psychological Bulletin, 116, 476-497.

Howell, D. C. (2007). Statistical Methods for Psychology (6 $6^{\text {th }}$ ed.). Belmont, CA: Thomson Wadsworth.

Humphreys, K., Mavis, B. E., \& Stoffelmayr, B. E. (1994). Are twelve-step programs appropriate for disenfranchised groups? Evidence from a study of posttreatment mutual help group involvement. Prevention in Human Services, 11, 165-180.

Humphreys K. \& Noke J, M. (1997). The influence of posttreatment mutual help group participation on the friendship networks of substance abuse patients. American Journal of Community Psychology, 25, 1-16.

Humphreys, K., Mankowski, E. S., Moos, R. H. \& Finney, J. W. (1999). Do enhanced friendship networks and active coping mediate the effect of self-help groups on substance abuse? Annals of Behavioral Medicine, 21, $54-60$. 


\section{SOCIAL NETWORKS OF INTIMATE PARTNER VIOLENCE PERPETRATORS}

Jewell, L. M. \& Wormith, J. S. (2010). Variables associated with attrition from domestic violence treatment programs targeting male batterers: A meta-analysis. Criminal Justice and Behavior, 37, 1086 - 1113.

Jewkes, R. (2002). Intimate partner violence: causes and prevention. The Lancet, 359, $1423-1429$.

Juras, J. L., Mackin, J. R., Curtis, S. E. \& Foster-Fishman, P. G. (1997). Key concepts of community psychology: Implications for consulting in educational and human service settings. Journal of Educational and Psychological Consultation, 8, 111 $-133$.

Kandel, D. B. (1978). Homophily, selection, and socialization in adolescent friendships. American Journal of Sociology, 84, $427-436$.

Kelly, J. F., Stout, R. L., Magill, M., \& Tonigan, J. S. (2011). The role of Alcoholics Anonymous in mobilizing adaptive social network changes: A prospective lagged mediational analysis. Drug and Alcohol Dependence, 114, 119-126.

Kidder, L.H., \& Fine, M. (1997). Qualitative inquiry in psychology: A radical tradition. In D. Fox and I. Prilleltensky (Eds.) Critical Psychology: An introduction (pp. 34-50). Thousand Oaks, CA: Sage.

Kilmartin, C.T., Smith, T., Green, A., Heinzen, H., Kuchler, M., \& Kolar, D. (2008). A real-time social norms intervention to reduce college mens' sexism. Sex Roles, $59,264-273$. 


\section{SOCIAL NETWORKS OF INTIMATE PARTNER VIOLENCE PERPETRATORS}

Krug, E.G., Dahlberg, L. L., Mercy, J. A., Zwi, A. B. \& Lozano, R. (2002). World report on violence and health: First world report on violence and health. Geneva, Switzerland: World Health Organization.

Larson, J. R. (1997). Modeling the entry of shared and unshared information into group discussion: A review and BASIC language computer program. Small Group Research, 28, $454-479$.

Lehrer, A. \& Allen, N. E. (2008). Social change movements and the struggle over meaning-making: A case study of domestic violence narratives. American Journal of Community Psychology, 42, 220 - 234.

Lewis, R. (2004). Making justice work. British Journal of Criminology, 44, 204 - 224.

Lincoln, Y. S. \& Guba, E.G. (1985). Naturalistic inquiry. Newbury Park, CA: Sage.

Lippitt, R., Polansky, N. \& Rosen, S. (1952). The dynamics of power. Human Relations, 5, $37-64$.

Luke, D. A. (2005). Getting the big picture in community science: Methods that capture context. American Journal of Community Psychology, 35, 185 - 200.

Kloos, B., Hill, J., Thomas, E., Wandersman, A., Elias, M. J., \& Dalton, J. H. (2012). Community Psychology: Linking Individuals and Communities (3rd ed.). Belmont, CA: Wadsworth/Cengage Learning.

Magdol, L., Moffitt, T. E., Caspi, A., Newman, D. L., Fagan, J. \& Silva, P. A. (1997). Gender differences in partner violence in a birth cohort of 21-year-olds: Bridging 


\section{SOCIAL NETWORKS OF INTIMATE PARTNER VIOLENCE PERPETRATORS}

the gap between clinical and epidemiological approaches. Journal of Consulting and Clinical Psychology, 65, $68-78$.

Marsden, P. V. \& Friedkin, N. E. (1993). Network studies of social influence. Sociological Methods and Research, 22, 125 - 149.

Maxwell, C. D., Davis, R. C. \& Taylor, B. G. (2010). The impact of length of domestic violence treatment on the patterns of subsequent intimate partner violence. Journal of Experimental Criminology, 6, 475 - 497.

McAdam, D. (1995). “'Initiator” and "spin-off” movements: Diffusion processes in protest cycles. In M. Traugott (Ed.), Repertoires and Cycles of Collective Action (217 - 240). Durham, NC: Duke.

McAdam, D., \& Paulsen, R. (1993). Specifying the relationship between social ties and activism. American Journal of Sociology, 99, 640-667.

McDermott, R., Fowler, J. H., \& Christakis, N. A. (2013). Breaking up is hard to do, unless everyone else is doing it too: Social network effects on divorce in a longitudinal sample. Social Forces, 92(2), 491-519.

Mendelson, M. J. \& Aboud, F. E. (1999). Measuring friendship quality in late adolescents and young adults: McGill Friendship Questionnaires. Canadian Journal of Behavioural Science, 31 (2), 130 - 132.

Michalski, J. H. (2004). Making sociological sense out of trends in intimate partner violence: The social structure of violence against women. Violence Against Women, 10, $652-675$. 


\section{SOCIAL NETWORKS OF INTIMATE PARTNER VIOLENCE PERPETRATORS}

Mohr C.D., Averna S., Kenny, D.A., \& Del Boca, F.K. (2001). Getting by (or getting high) with a little help from my friends: an examination of adult alcoholics' friendships. Journal of Studies on Alcohol and Drugs, 62, 637-645.

Morgan, D. (1992). Designing focus group research. In M. Stewart, F. Tudiver, M.J. Bass, E.V. Dunn, \& P.G. Norton (Eds.), Tools for Primary Care Research, (177 - 93). Newbury Park, CA: Sage.

Morgan, D. L. (1998). Practical strategies for combining qualitative and quantitative methods: Applications to health research. Qualitative Health Research, 8(3), $362-376$.

Neighbors, C., Walker, D. D., Roffman, R. A., Mbilinyi, L. F., \& Edleson, J. L. (2008). Self determination theory and motivational interviewing: Complementary models to elicit voluntary engagement by partner-abusive men. American Journal of Family Therapy, 36, 126-136.

Neighbors, C., Walker, D., Mbilinyi, L., O'Rourke, A., Edleson, J. L., Zegree, J, \& Roffman, R. A. (2010). Normative misperceptions of abuse among perpetrators of intimate partner violence. Violence Against Women, 16, 370-386.

O'Brien, K. (1993). Using focus groups to develop health surveys: An example from research on social relationships and AIDS-preventive behavior. Health Education \& Behavior, 20(3), 361-372. 


\section{SOCIAL NETWORKS OF INTIMATE PARTNER VIOLENCE PERPETRATORS}

Passy, F. (2003). Social networks matter. But how? In M. Diani and D. McAdam (Eds.), Social Movements and Networks: Relational Approaches to Collective Action $(21$ - 48). New York, NY: Oxford University Press.

Patterson, G. R., Dishion, T. J., \& Yoerger, K. (2000). Adolescent growth in new forms of problem behavior: Macro-and micro-peer dynamics. Prevention Science, 1(1), 3-13.

Paymar, M., \& Barnes, G. (2006). Countering confusion about the Duluth Model. Retrieved April 19, 2014 from http://www.theduluthmodel.org/about/research.html.

Pence, E., \& Paymar, M. (1993). Education groups for men who batter: The Duluth model. New York: Springer.

Pilger, D. \& Watts, C. (2013). Global estimates of homicide risk related to intimate partner violence. The Lancet, 382, 1625 - 1626.

Price, B. J., \& Rosenbaum, A. (2009). Batterer intervention programs: A report from the field. Violence and victims, 24(6), 757-770.

Priester, J. R. \& Petty, R. E. (2001). Extending the bases of subjective attitudinal ambivalence: Interpersonal and intrapersonal antecedents of evaluative tension. American Psychological Association, 80 (1), 19 - 34.

Raghavan, C., Rajah, V., Gentile, K., Collado, L. \& Kavanagh, A. M. (2009). Community violence, social support networks, ethnic group differences, and 


\section{SOCIAL NETWORKS OF INTIMATE PARTNER VIOLENCE PERPETRATORS}

male perpetration of intimate partner violence. Journal of Interpersonal Violence, 24, $1615-1632$.

Ramirez, M., Paik, A., Sanchagrin, K., \& Heimer, K. (2012). Violent peers, network centrality, and intimate partner violence perpetration by young men. Journal of Adolescent Health, 51(5), 503-509.

Reed E., Silverman J.G., Raj A., Rothman E.F., Decker M.R., Gottlieb B.R., Molnar, B.E. \& Miller, E. (2008). Social and environmental contexts of adolescent and young adult male perpetrators of intimate partner violence: A qualitative study. American Journal of Men's Health, 2(3), 260-271.

Roffman, R. A., Edleson, J. L., Neighbors, C., Mbilinyi, L \& Walker, D. (2008). The men's domestic abuse check-up: A protocol for reaching the nonadjudicated and untreated man who batters and who abuses substances. Violence Against Women, 14, $589-605$.

Rosenbaum, A., \& Leisring, P. A. (2001). Group intervention programs for batterers. In R. A. Geffner \& A. Rosenbaum (Eds.), Domestic violence offenders: Current interventions, research, and implications for policies and standards (pp. 57-71). New York: Haworth.

Ruiz-Perez, I., Plazaola-Castano, J. \& del Rio-Lozano, M. (2007). Physical health consequences of intimate partner violence in Spanish women. European Journal of Public Health, 17 (5), 437 - 443. 


\section{SOCIAL NETWORKS OF INTIMATE PARTNER VIOLENCE PERPETRATORS}

Ryan, M. (1982). Behavioral intention formation: The interdependency of attitudinal and social influence variables. Journal of Consumer Research, 9, (3), 263 - 278.

Rynes, K. N. \& Scott, T. J. (2012). Do social networks explain 12-step sponsorship effects? A prospective lagged mediation analysis. Psychology of Addictive Behaviors, 26 (3), $432-439$.

Rynes, K. N \& Tonigan, J. S. (2012). Do social networks explain 12-step sponsorship effects? A prospective lagged mediation analysis. Psychology of Addictive Behaviors, 26 (3), $432-439$.

Salazar, L. F., Baker, C. K., Price, A. W. \& Carlin, K. (2003). Moving beyond the individual: Examining the effects of domestic violence policies on social norms. American Journal of Community Psychology, 32, 253 - 264.

Salmivalli, C. (2010). Bullying and the peer group: A review. Aggression and Violent Behavior, 15, $112-120$.

Saunders, D. G. (2008). Group interventions for men who batter: A summary of program descriptions and research. Violence and Victims, 23(2), 156-172.

Schwartz, M. D. \& DeKeseredy, W. S. (1997). Sexual Assault on the College Campus: The Role of Male Peer Support. Thousand Oaks, CA: Sage Publications.

Schwartz, M. D. \& Nogrady, C. A. (1996). Fraternity membership, rape myths, and sexual aggression on a college campus. Violence Against Women, 2, 148 - 162.

Sheehan, K. A., Thakor, S. \& Stewart, D. E. (2012). Turning points for perpetrators of intimate partner violence. Trauma, Violence \& Abuse, 13, 30-40. 


\section{SOCIAL NETWORKS OF INTIMATE PARTNER VIOLENCE PERPETRATORS}

Shinn, M., \& Rapkin, B. (2000). Cross-level research without cross-ups in community psychology. In J. Rappaport \& E. Seidman (Eds). Handbook of Community Psychology (669-695). New York: Plenum/Kluwer.

Silverman, J. G., \& Williamson, G. M. (1997). Social ecology and entitlements involved in battering by heterosexual college males: Contributions of family and peers. Violence \& Victims, 12, 147-164.

Simons, R. L., Wu, C, Johnson, C, \& Conger, R. D. (1995). A test of various perspectives on the intergenerational transmission of domestic violence. Criminology, 33, 141-172.

Straus, M.A. (2004). Scoring the CTS2 and the CTSCP. Retrieved June 12, 2014 from: http://gauss.unh.edu/ mas2/CTS28a3.pdf.

Straus, M. A., Hamby, S. L., Boney-McCoy, S., \& Sugarman, D. B. (1996). The Revised Conflict Tactics Scales (CTS2) development and preliminary psychometric data. Journal of Family Issues, 17(3), 283-316.

Tabachnick, B. L., \& Fidell, L. S. (2007). Using multivariate statistics. (5th ed.). Boston, MA: Pearson Education, Inc.

Taylor, B. G., Davis, R. C. \& Maxwell, C. D. (2001). The effects of a group batterer treatment program: A randomized experiment in Brooklyn. Justice Quarterly, $18,171-201$. 


\section{SOCIAL NETWORKS OF INTIMATE PARTNER VIOLENCE PERPETRATORS}

Terry, D. J. \& Hogg, M. A. (1996). Group norms and the attitude-behavior relationships: A role for group identification. Personality and Social Psychology Bulletin, 22, $776-793$.

Thompson, R. S., Bonomi, A.E., Anderson, M., Reid, R.J., Dimer, J.A., Carrell, D. \& Rivara, F.P. (2006). Intimate partner violence: Prevalence, types, and chronicity in adult women. American Journal of Preventive Medicine, 30(6), 447-457.

Thornberry, T. P., Lizotte, A. J., Krohn, M. D., Farnworth, M., \& Jang, S. J. (1994). Delinquent peers, beliefs and delinquent behavior: A longitudinal test of interactional theory. Criminology, 32, 47-83.

Tindall, D. B. (2008). Networks, social influence, and concern about climate change: The effects of personal network ties to environmentalists on the general public in Canada. 2008 Berlin Conference on the Human Dimensions of Global Environmental Change International Conference of the Social-Ecological Research Programme, Feb 22-23, 2008. Retrieved May 26, 2012 from: http://userpage.fuberlin.de/ffu/akumwelt/bc2008/papers/bc2008_245_Tindall.pdf

Tjaden, P., \& Thoennes, N. (2000). Prevalence and causes of male-to-female and female-to-male intimate partner violence as measured by the National Violence Against Women Survey. Washington, DC: U.S. Department of Justice, Office of Justice Programs. 


\section{SOCIAL NETWORKS OF INTIMATE PARTNER VIOLENCE PERPETRATORS}

Tolman, R. M. (1989). The development of a measure of psychological maltreatment of women by their male partners. Violence and Victims, 4,159-177.

Viola, W. E \& Huffine, C. (2012, January 10). Meeting of the Tri County Batterer Intervention Providers Network: Negative Peer Affiliations.

Viola, W.E. \& Huffine, C. (2014, January 14). Meeting of the Tri County Batterer Intervention Providers Network: Why doesn't batterer intervention get more respect?.

Viola, W. E \& Huffine, C. (2014, February 11). Meeting of the Tri County Batterer Intervention Providers Network: Pro-Social Sexual Attitudes.

Viola, W.E. \& Huffine, C. (2014, March 11). Meeting of the Tri County Batterer Intervention Providers Network: Trauma Informed Care.

Viola, W. E. \& Huffine, C. (2014, May 13). Meeting of the Tri County Batterer Intervention Providers Network: Working with high-risk and/or psychopathic abusers.

Valente, T. (1996). Social network thresholds in the diffusion of innovations. Social Networks, 18, $69-89$.

Warr, M. (2006). Life course transitions and desistance from crime. Criminology, 36(2), 183-216.

Wasserman, S., \& Faust, K. (1994). Social network analysis: Methods and applications. New York: Cambridge University Press. 


\section{SOCIAL NETWORKS OF INTIMATE PARTNER VIOLENCE PERPETRATORS}

Wellman, B. (1982). Studying personal communities. In P. V. Marsden \& N. Lin (Eds.), Social structure and network analysis $(61-80)$. Beverly Hills: Sage.

Zywiak, W. H., Longabaugh, R., \& Wirtz, P. W. (2002). Decomposing the relationships between pretreatment social network characteristics and alcohol treatment outcome. Journal of Studies on Alcohol and Drugs, 63(1), 114 - 121. 
SOCIAL NETWORKS OF INTIMATE PARTNER VIOLENCE PERPETRATORS

Appendix A: BIP Facilitator Focus Group Recruitment Flier

Social Networks and Abusive Relationships Study

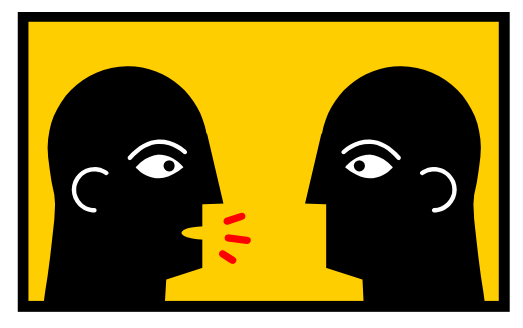

Join me for a conversation about your clients' friends, family members, coworkers, and other community members who are important in their lives, and how they communicate about abuse.

I'm developing a survey about the ways that batterer intervention program participants talk to other people about their attitudes and behavior towards their own romantic relationships, and I need your help writing the survey! The group discussion will help me figure out what the survey should ask about.

Tuesday, July $23^{\text {rd }}$, from 10:00 AM to 12:00PM 307 Cramer Hall, Portland State University A light breakfast will be provided

RSVP to Wendy Viola, M.S. at violaw@pdx.edu or

(503) $725-3955$ 


\section{SOCIAL NETWORKS OF INTIMATE PARTNER VIOLENCE PERPETRATORS}

Appendix B: BIP Facilitator Focus Group Recruitment Email

Hello All, My name is Wendy Viola, I'm a doctoral student working with Eric Mankowski at Portland State University. I've been involved with the community of batterer intervention providers in the Multnomah, Washington, and Clackamas County area over the last several years.

I will be hosting a conversation with batterer intervention program facilitators in the area about your perceptions of your clients' non-romantic relationships, and the ways that they engage with other family members, friends, and members of their communities. This focus group will be held over breakfast at the Portland State University campus on the morning of Tuesday, July 23rd, from 10:00 AM to 12:00 PM. A flier with some additional information is attached here.

This work is part of my dissertation project, which will describe the non-romantic relationships of batterer intervention program participants, and the extent to which participants' perpetration of abuse does, or does not, factor in those relationships. A better understanding of the people with whom your clients spend time, and whether and how they communicate about IPV within these relationships, may help you identify potential risks and safeguards in your clients' social lives. I'll be distributing my findings in the community, with the hope that you'll find them useful and pertinent to working with your clients.

I'd be very appreciative of the chance to learn your perspectives on this topic. I hope that you'll take advantage of this opportunity to come together with other providers to share your thoughts and opinions. I'd also encourage you to distribute this information within your organization. Please RSVP to me via email, or at (503) 725-3955, and do not hesitate to contact me if you have any questions.

Many thanks,

Wendy Viola, M.S., A.B.D.

Applied Social and Community Psychology

Portland State University 


\section{SOCIAL NETWORKS OF INTIMATE PARTNER VIOLENCE PERPETRATORS}

Appendix C: Consent Form for BIP Providers' Focus Group

\section{蛋 Portland State}

Social Networks and Abusive Relationships Study

You are invited to participate in a focus group conducted by Wendy Viola, M.S., from Portland State University. The researcher hopes to learn about the friends, family members, coworkers, or other community members who are important in the lives of men who participate in your batterer intervention program (BIP) groups, and how BIP clients interact with these people in regard to attitudes and behavior. You were selected as a possible participant because you are a BIP provider in the state of Oregon and attend, and your organization is listed in the Oregon Batterer Intervention Providers Directory.

If you decide to participate, you will take part in a small group conversation about the people that your BIP clients interact with, their attitudes and behavior, and how your BIP clients interact with their community members around attitudes and behavior towards women. Other group members will also be local BIP providers. No BIP clients will attend the focus group. At the start of the focus group, the researcher will provide some ground rules for the conversation and introduce the topic. The researcher will pose five or six main questions to the group, and you will be asked to share your experiences and opinions on them.

The focus group will be recorded with a digital recorder so that the researcher can concentrate on what is being said and guide the conversation. The recording will only be heard by the research team, and kept in a locked laboratory on the Portland State University campus.

If you choose to participate, your identity as a participant will not be revealed to anyone who is not present at the time of the focus group. Your identity will not be attached to any information that the focus group produces. However, the researcher cannot guarantee that other group members will keep information that you share during the focus group confidential.

The discussion is expected to last for about an hour and a half. It is possible that sharing information about your clients or your organization's practices may make you uncomfortable. However, you may choose to cease your participation at any time, or to abstain from addressing any questions that you would rather not answer. Participating in this focus group may be beneficial to you in that you will have the 


\section{SOCIAL NETWORKS OF INTIMATE PARTNER VIOLENCE PERPETRATORS}

opportunity to discuss your experiences regarding your clients' interactions with others in their lives, and hear from your colleagues about their experiences doing so. It is also possible that you may not receive any direct benefit from taking part in this conversation, but in the information that you share will be used to develop a questionnaire that will be included in a survey about the same topic, which will be distributed to BIP clients. The results of the survey may contribute to understanding how men's communities contribute to the work that they do in group, and possibly help providers make groups more effective in the future.

Your participation is voluntary. You do not have to take part in this focus group, and whether or not you choose to participate will not affect your standing or relationship with the Tri County Batterer Intervention Provider Network or your listing in the Oregon Batterer Intervention Providers Directory. You may also withdraw from this focus group at any time without affecting your status with the Tri County Batterer Intervention Provider Network or your listing in the Oregon Batterer Intervention Program Directory.

If you have concerns or problems with your participation in this focus group or your rights as a research subject, please contact the Portland State University Human Subjects Research Review Committee, PO Box 751, Portland, OR 97207, (503) 7254288 / 1-877-480-4400. If you have questions about the study itself, contact Eric Mankowski at mankowskie@pdx.edu or (503) 725 -3901, or Wendy Viola at violaw@pdx.edu or (503) 725-3955.

Your signature indicates that you have read and understand the above information and agree to take part in this focus group. Please understand that you may withdraw your consent at any time without penalty, and that, by signing, you are not waiving any legal claims, rights, or remedies. The researcher will provide you with a copy of this form for your own records.

Name (Please print):

Signature:

Date: 


\section{SOCIAL NETWORKS OF INTIMATE PARTNER VIOLENCE PERPETRATORS}

Appendix D: Script for BIP Providers' Focus Group

Introduce self, Rachel (taking notes, handling logistics)

Today I would like to hear your thoughts about the friends and family members of the men in your groups. I am interested in the ways that they may influence your clients' abusive behavior and their motivation to change.

\section{\#1: consent forms}

Before we begin, let's go around and introduce ourselves. Please share your name, the organization where you provide groups, and tell us how long you've been leading groups.

\section{How the conversation will go:}

- A conversation between you. I'll step in to guide the conversation, but about dialogue between you.

- Wide participation would be great-l'd like to hear from everyone!

- I'd also like to ask that we speak one at a time.

- While it's likely that we have a diversity of opinions represented in this group, and we welcome disagreement, l'd like to ask that you disagree with each other respectfully - the goal is not to reach consensus

- While you're welcome to debrief the information that we discuss today with other members of your organization, l'd like to ask that you please refrain from sharing the identities and affiliations of group members who have made specific comments.

Does this sound alright? Anything to add? If not, l'll go ahead and turn on the recorder...

My hope for this conversation is for us to ultimately brainstorm a list of the ways that the people in your male clients' lives influence their use of abuse and motivation to change, and a list of the ways that your clients try to influence those other people in their lives regarding abuse.

I have a few questions to get us started.

1. Who are the people, other than your clients' partners, that are important in your clients' lives?

2. When, do these people tend to come up in conversation? Are there any topics that tend to elicit references to these people more than others? 


\section{SOCIAL NETWORKS OF INTIMATE PARTNER VIOLENCE PERPETRATORS}

3. What are some of the ways that your clients receive support or reinforcement for abuse from others in their lives?

a. How do clients respond to these actions and behaviors when their friends or family members engage in them?

b. What do your clients do to indicate that they object to these actions and behaviors?

4. What are some of the things that clients' friends and family members say or do which you think may interfere with the work that you do with them in group?

a. How do clients respond to these actions and behaviors when their friends and family members engage in them?

b. What do your clients do to indicate that they object to these actions and behaviors?

5. What are some of the things that clients say or do with their friends and family that express things that they've learned in group?

6. I'd like to get your input on a number of survey items that describe ways that your clients and other people in their lives express their attitudes and behaviors about abuse to each other. I'm going to pass around copies of some of these items. Take your time to read over them, and please circle the number next to the ones that you think that your clients might engage in with some regularity. If you think that any of the items could be modified to make them more meaningful or more common among your clients, please write in those modifications right on the form in the space provided next to each item. I'll collect them from you at the end, so please don't put your names on them.

a. Which items did you think your clients would realistically say that they've done in the last month? In the last three months?

b. Which items could be tweaked so that your clients would realistically say that they've done them in the last month to three months? How would you adjust these items?

c. For this set of items, do you think that participants are likely to have engaged in them in the last month? Or do you think it would be more appropriate/realistic to ask about the last 3 months? 


\section{SOCIAL NETWORKS OF INTIMATE PARTNER VIOLENCE PERPETRATORS}

\section{Appendix E: Initial Item Pool used in Survey Development}

Below are a series of behaviors that BIP participants' social network members may engage in, and behaviors that BIP participants themselves may engage in, with members of their social networks. Please circle the numbers next to all of the items that you believe that BIP participants will report that they or their social network members have engaged in during the prior month. If you think that phrasing the items differently would be more appropriate, please rewrite the item in the space provided.

\section{Behaviors which participants' social network members may have engaged in:}

\begin{tabular}{|c|c|c|c|c|c|c|}
\hline & In the last month, how often did this person... & $\begin{array}{l}0 \\
\text { times }\end{array}$ & $\begin{array}{l}1-5 \\
\text { times }\end{array}$ & $\begin{array}{l}6-10 \\
\text { times }\end{array}$ & $\begin{array}{l}11- \\
20 \\
\text { times }\end{array}$ & $\begin{array}{l}\text { Over } \\
20 \\
\text { times }\end{array}$ \\
\hline 1 & $\begin{array}{l}\text { Tell you that you should respond to your partners' } \\
\text { challenges to your authority by using physical force } \\
\text { (e.g., holding her down, twisting her arm, etc.)? }\end{array}$ & & & & & \\
\hline 2 & $\begin{array}{l}\text { Tell you that you should respond to your partners' } \\
\text { challenges to your authority by insulting them? }\end{array}$ & & & & & \\
\hline 3 & Tell you that it is alright for you to hit your partner? & & & & & \\
\hline 4 & $\begin{array}{l}\text { Tell you that if you spend money on your partner, } \\
\text { you should receive sexual favors in return? }\end{array}$ & & & & & \\
\hline 5 & $\begin{array}{l}\text { Tell you that your partner should have sex with you } \\
\text { when you want? }\end{array}$ & & & & & \\
\hline 6 & $\begin{array}{l}\text { Tell you to respond to your partners' sexual } \\
\text { rejections by using force (e.g., twisting her arm, } \\
\text { holding her down, etc.) to get sex? }\end{array}$ & & & & & \\
\hline 7 & $\begin{array}{l}\text { Tell you that it is alright for you to physically force } \\
\text { (e.g., twisting her arm, holding her down, etc.) your } \\
\text { partner to provide sexual favors under certain } \\
\text { conditions? }\end{array}$ & & & & & \\
\hline 8 & $\begin{array}{l}\text { Buy you a drink after you had a violent fight with } \\
\text { your partner? }\end{array}$ & & & & & \\
\hline 9 & $\begin{array}{l}\text { Allow you into his home if you needed somewhere } \\
\text { to go because of fear of police, friends, or family } \\
\text { coming to help your partner? }\end{array}$ & & & & & \\
\hline 10 & $\begin{array}{l}\text { Tell you that your partner was to blame during a } \\
\text { fight }\end{array}$ & & & & & \\
\hline 11 & $\begin{array}{l}\text { Tell you that you did the right thing by being } \\
\text { abusive to your partner }\end{array}$ & & & & & \\
\hline 12 & $\begin{array}{l}\text { Call your partner names while they were talking to } \\
\text { you }\end{array}$ & & & & & \\
\hline 13 & $\begin{array}{l}\text { Give you advice about how to be abusive to your } \\
\text { partner }\end{array}$ & & & & & \\
\hline 14 & $\begin{array}{l}\text { Tell you examples of ways that they've been } \\
\text { abusive to their partner }\end{array}$ & & & & & \\
\hline 15 & Tell you that it was ok that you were abusive to & & & & & \\
\hline
\end{tabular}




\section{SOCIAL NETWORKS OF INTIMATE PARTNER VIOLENCE PERPETRATORS}

\begin{tabular}{|l|l|l|}
\hline & your partner & \\
\hline 16 & $\begin{array}{l}\text { Give you advice about how to keep the abuse in } \\
\text { your relationship secret }\end{array}$ & \\
\hline 17 & Encourage you to control your partner's behavior & \\
\hline 18 & Make jokes about abuse to you & \\
\hline 19 & Tell you that your partner needed to be controlled & \\
\hline
\end{tabular}

\begin{tabular}{|c|c|c|c|c|c|c|}
\hline & $\begin{array}{l}\text { In the last month, how often did you see this } \\
\text { person... }\end{array}$ & $\begin{array}{l}0 \\
\text { times }\end{array}$ & $\begin{array}{l}1-5 \\
\text { times }\end{array}$ & $\begin{array}{l}6-10 \\
\text { times }\end{array}$ & $\begin{array}{l}11- \\
20 \\
\text { times }\end{array}$ & $\begin{array}{l}\text { Over } \\
20 \\
\text { times }\end{array}$ \\
\hline 20 & Call their partner names & & & & & \\
\hline 21 & Swear at their partner & & & & & \\
\hline 22 & Yell and scream at their partner & & & & & \\
\hline 23 & Treat their partner like an inferior & & & & & \\
\hline 24 & $\begin{array}{l}\text { Monitor their partner's time and make them } \\
\text { account for their whereabouts }\end{array}$ & & & & & \\
\hline 25 & $\begin{array}{l}\text { Use their money or made important financial } \\
\text { decisions without consulting their partner }\end{array}$ & & & & & \\
\hline 26 & $\begin{array}{l}\text { Accuse their partner of having an affair with } \\
\text { someone else }\end{array}$ & & & & & \\
\hline 27 & $\begin{array}{l}\text { Interfere in their partner's relationships with other } \\
\text { family members }\end{array}$ & & & & & \\
\hline 28 & Talk about being jealous of their partners' friends & & & & & \\
\hline 29 & $\begin{array}{l}\text { Try to keep their partner from doing things to help } \\
\text { themselves }\end{array}$ & & & & & \\
\hline 30 & Restrict their partner's use of the telephone & & & & & \\
\hline 31 & $\begin{array}{l}\text { Tell their partner that their feelings were irrational } \\
\text { or crazy }\end{array}$ & & & & & \\
\hline 32 & Blame their partner for their problems & & & & & \\
\hline 33 & Try to make their partner feel crazy & & & & & \\
\hline
\end{tabular}

\section{Behaviors that participants may have engaged in}

\begin{tabular}{|c|l|l|l|l|l|l|}
\hline & In the last month, how often did you... & $\begin{array}{l}0 \\
\text { times }\end{array}$ & $\begin{array}{l}1-5 \\
\text { times }\end{array}$ & $\begin{array}{l}6-10 \\
\text { times }\end{array}$ & $\begin{array}{l}11- \\
20 \\
\text { times }\end{array}$ & $\begin{array}{l}\text { Over } \\
20 \\
\text { times }\end{array}$ \\
\hline 34 & $\begin{array}{l}\text { Intervene or call } 911 \text { if you saw this person yelling } \\
\text { and fighting with their partner. }\end{array}$ & & & \\
\hline 35 & $\begin{array}{l}\text { Intervene or call } 911 \text { you heard other people yelling } \\
\text { and fighting while you were with this person }\end{array}$ & & \\
\hline 36 & $\begin{array}{l}\text { Question this person further if they say that they } \\
\text { had an unwanted sexual experience but they don't } \\
\text { call it "rape." }\end{array}$ & & \\
\hline 37 & $\begin{array}{l}\text { Ask this person's partner if they need help if they're } \\
\text { being shoved or yelled at by this person. }\end{array}$ &
\end{tabular}




\section{SOCIAL NETWORKS OF INTIMATE PARTNER VIOLENCE PERPETRATORS}

\begin{tabular}{|c|c|c|}
\hline 38 & $\begin{array}{l}\text { Confront this person if you saw them grabbing, } \\
\text { pushing, or insulting their partner. }\end{array}$ & \\
\hline 39 & $\begin{array}{l}\text { Intervene or call } 911 \text { if I saw this person grabbing, } \\
\text { pushing, or insulting their partner. }\end{array}$ & \\
\hline 40 & $\begin{array}{l}\text { Speak up against it and express concern if you } \\
\text { heard this person talking about forcing someone to } \\
\text { have sex with them }\end{array}$ & \\
\hline 41 & $\begin{array}{l}\text { Ask this person's partner if they are okay or need } \\
\text { help if they seem upset. }\end{array}$ & \\
\hline 42 & $\begin{array}{l}\text { Approach this person and let them know that } \\
\text { you're here to help if you thought they were in an } \\
\text { abusive relationship. }\end{array}$ & \\
\hline 43 & Share information about abuse with this person. & \\
\hline 44 & $\begin{array}{l}\text { Confront this person for making excuses for others' } \\
\text { abusive behavior. }\end{array}$ & \\
\hline 45 & Speak up against sexist jokes in front of this person. & \\
\hline 46 & $\begin{array}{l}\text { Speak up against jokes about abuse in front of this } \\
\text { person. }\end{array}$ & \\
\hline 47 & $\begin{array}{l}\text { Speak up against commercials that depict violence } \\
\text { against women in front of this person. }\end{array}$ & \\
\hline 48 & $\begin{array}{l}\text { Confront this person if they explain that women like } \\
\text { to be raped. }\end{array}$ & \\
\hline 49 & $\begin{array}{l}\text { Confront this person if they imply that "she } \\
\text { deserved to be raped." }\end{array}$ & \\
\hline 50 & $\begin{array}{l}\text { Indicate my displeasure to this person when they } \\
\text { make sexist comments. }\end{array}$ & \\
\hline 51 & $\begin{array}{l}\text { Talk to this person about the importance of } \\
\text { obtaining verbal consent before engaging in sexual } \\
\text { behavior. }\end{array}$ & \\
\hline 52 & $\begin{array}{l}\text { Keep any information that you have to yourself if } \\
\text { you hear that this person has been accused of } \\
\text { sexual violence. }\end{array}$ & \\
\hline 53 & $\begin{array}{l}\text { Educate this person about abuse and what they can } \\
\text { do about it. }\end{array}$ & \\
\hline 54 & $\begin{array}{l}\text { Encourage this person to keep quiet about } \\
\text { unwanted sexual experiences so they don't get } \\
\text { others in trouble. }\end{array}$ & \\
\hline 55 & $\begin{array}{l}\text { Criticize this person if they told you that they were } \\
\text { abusive towards their partner. }\end{array}$ & \\
\hline 56 & $\begin{array}{l}\text { Refer this person to help if they tell you that they're } \\
\text { in an abusive relationship }\end{array}$ & \\
\hline 57 & $\begin{array}{l}\text { Express your discomfort if this person makes a joke } \\
\text { about abuse. }\end{array}$ & \\
\hline 58 & $\begin{array}{l}\text { Express your discomfort if this person says that } \\
\text { rape victims are to blame for being raped. }\end{array}$ & \\
\hline 59 & $\begin{array}{l}\text { Talk to this person about abuse if you suspect } \\
\text { they're in an abusive relationship. }\end{array}$ & \\
\hline
\end{tabular}




\section{SOCIAL NETWORKS OF INTIMATE PARTNER VIOLENCE PERPETRATORS}

\begin{tabular}{|l|l|l|}
\hline 60 & $\begin{array}{l}\text { Ask this person's partner if they're ok after hearing } \\
\text { about a fight between them. }\end{array}$ & \\
\hline 61 & $\begin{array}{l}\text { Speak up in front of this person if someone is } \\
\text { providing misinformation about abuse. }\end{array}$ & \\
\hline 62 & $\begin{array}{l}\text { Criticize this person if they tell you that they had } \\
\text { sex with someone who was passed out or who } \\
\text { didn't give consent. }\end{array}$ & \\
\hline 63 & Tell this person that you go to Allies in Change. & \\
\hline 64 & $\begin{array}{l}\text { Object if this person tells you that their partner } \\
\text { "had it coming." }\end{array}$ & \\
\hline 65 & $\begin{array}{l}\text { Try to talk this person out of it if they tell you that } \\
\text { they're going to be abusive to their partner. }\end{array}$ & \\
\hline 66 & $\begin{array}{l}\text { Tell this person about the consequences of being } \\
\text { abusive. }\end{array}$ \\
\hline 67 & $\begin{array}{l}\text { Explain the importance of being accountable to this } \\
\text { person. }\end{array}$ & \\
\hline 68 & $\begin{array}{l}\text { Stick up for this person's partner if they talk badly } \\
\text { about them. }\end{array}$ & \\
\hline
\end{tabular}




\title{
SOCIAL NETWORKS OF INTIMATE PARTNER VIOLENCE PERPETRATORS
}

\author{
Appendix F: Points from BIP Providers' Focus Group
}

Add an option for "Not applicable: I have not had a partner in the last 3 months" Instead of "calling 911": notice/point out abuse, comment on abusive behavior and that it is wrong

Network members' behavior

- Accuse your partner of having an affair.

- Tell you that your partner is taking advantage of you.

- Accuse your partner of trying to harm your relationship with your kids.

- Tell you that your partner needed to be controlled.

- Tell you that your partner is not to be trusted.

- Tell you that they wouldn't let their own partner talk to them the way that your partner talks to you.

- Tell you that they wouldn't let their partner get away with the things that your partner does.

- Tell you that you have to do something about your partner's behavior.

- Tell you that your partner is disrespecting you.

- Make fun of you for trying to change your relationship.

- Support you trying to become more accountable.

- Tell you that you have to retaliate against something your partner did to you.

- Tell you that your partner's behavior justified your abuse.

- Support you in taking legal action against your partner.

- Contact your partner to harass or monitor them.

- Tell you that you are to blame for the abuse in your relationship.

- Point out effects of abuse on your children.

- Hold you accountable for abusive behavior.

- Encourage you keep attending Allies in Change.

- Try to make amends with you for their abusive behavior.

Your own behavior

- Tell this person that they should think about going to Allies in Change or a similar program.

- Provide this person with resources for victims of abuse.

- Share your story about abuse with this person.

- Tell this person that it makes you uncomfortable to hear them talk about abuse or act abusively in front of you.

- Talk with this person about abuse that you witnessed as a child.

- Share books or other materials from Allies in Change with this person.

- Make amends with this person for your abusive behavior.

- Talk with this person about the effects of abuse on children. 


\section{SOCIAL NETWORKS OF INTIMATE PARTNER VIOLENCE PERPETRATORS}

Appendix G: Item Pool Resulting from BIP Providers' Focus Group

Below are a series of behaviors that other people in your life may engage in, and behaviors that you may engage in with these people. Please circle the numbers next to all of the items that you believe that you or other people in your life have engaged in during the last $\mathbf{3}$ months. If you think that phrasing the items differently would be more appropriate, please rewrite the item in the space provided.

Think about a friend or family member, other than your partner, who is important to you.

\begin{tabular}{|c|c|c|c|c|c|c|c|}
\hline & $\begin{array}{l}\text { In the last } 3 \text { months, how often } \\
\text { did this person... }\end{array}$ & $\begin{array}{l}\text { Not } \\
\text { applicable }\end{array}$ & $\begin{array}{l}0 \\
\text { times }\end{array}$ & $\begin{array}{l}1-5 \\
\text { times }\end{array}$ & $\begin{array}{l}6-10 \\
\text { times }\end{array}$ & $\begin{array}{l}11-20 \\
\text { times }\end{array}$ & $\begin{array}{l}\text { Over } \\
20 \\
\text { times }\end{array}$ \\
\hline 1. & $\begin{array}{l}\text { Tell you that you should not } \\
\text { accept your partner's } \\
\text { challenges to your authority? }\end{array}$ & & & & & & \\
\hline 2. & $\begin{array}{l}\text { Accuse your partner of having } \\
\text { an affair? }\end{array}$ & & & & & & \\
\hline 3. & $\begin{array}{l}\text { Tell you that if you spend } \\
\text { money on your partner, you } \\
\text { should receive sexual favors in } \\
\text { return? }\end{array}$ & & & & & & \\
\hline 4. & $\begin{array}{l}\text { Tell you that your partner } \\
\text { should have sex with you } \\
\text { when you want? }\end{array}$ & & & & & & \\
\hline 5. & $\begin{array}{l}\text { Tell you that your partner is } \\
\text { taking advantage of you? }\end{array}$ & & & & & & \\
\hline 6. & $\begin{array}{l}\text { Accuse your partner of trying } \\
\text { to harm your relationship with } \\
\text { your kids? }\end{array}$ & & & & & & \\
\hline 7. & $\begin{array}{l}\text { Buy you a drink after you had } \\
\text { a violent fight with your } \\
\text { partner? }\end{array}$ & & & & & & \\
\hline 8. & $\begin{array}{l}\text { Allow you into their home if } \\
\text { you needed somewhere to go } \\
\text { because police, friends, or } \\
\text { family coming to help your } \\
\text { partner? }\end{array}$ & & & & & & \\
\hline 9. & $\begin{array}{l}\text { Tell you that your partner was } \\
\text { to blame for a fight? }\end{array}$ & & & & & & \\
\hline 10. & $\begin{array}{l}\text { Call your partner names while } \\
\text { they were talking to you? }\end{array}$ & & & & & & \\
\hline
\end{tabular}




\section{SOCIAL NETWORKS OF INTIMATE PARTNER VIOLENCE PERPETRATORS}

\begin{tabular}{|c|c|}
\hline 11. & $\begin{array}{l}\text { Give you advice about ways to } \\
\text { control your partner? }\end{array}$ \\
\hline 12. & $\begin{array}{l}\text { Tell you examples of ways that } \\
\text { they've been abusive to their } \\
\text { partner? }\end{array}$ \\
\hline 13. & $\begin{array}{l}\text { Tell you that your partner } \\
\text { needed to be controlled? }\end{array}$ \\
\hline 14. & $\begin{array}{l}\text { Make jokes about abuse to } \\
\text { you? }\end{array}$ \\
\hline 15. & $\begin{array}{l}\text { Tell you that you should not } \\
\text { trust your partner? }\end{array}$ \\
\hline 16. & $\begin{array}{l}\text { Tell you that they wouldn't let } \\
\text { their own partner talk to them } \\
\text { the way that your partner } \\
\text { talks to you? }\end{array}$ \\
\hline 17. & $\begin{array}{l}\text { Tell you that they wouldn't let } \\
\text { their partner get away with } \\
\text { the things that your partner } \\
\text { does? }\end{array}$ \\
\hline 18. & $\begin{array}{l}\text { Tell you that you have to do } \\
\text { something about your } \\
\text { partner's behavior? }\end{array}$ \\
\hline 19. & $\begin{array}{l}\text { Tell you that your partner is } \\
\text { disrespecting you? }\end{array}$ \\
\hline 20. & $\begin{array}{l}\text { Make fun of you for trying to } \\
\text { change your relationship with } \\
\text { your partner? }\end{array}$ \\
\hline 21. & $\begin{array}{l}\text { Support your attempts to be } \\
\text { more accountable? }\end{array}$ \\
\hline 22. & $\begin{array}{l}\text { Tell you that you have to } \\
\text { retaliate against something } \\
\text { your partner did to you? }\end{array}$ \\
\hline 23. & $\begin{array}{l}\text { Tell you that your partner's } \\
\text { behavior justified your abuse? }\end{array}$ \\
\hline 24. & $\begin{array}{l}\text { Support you in taking legal } \\
\text { action against your partner? }\end{array}$ \\
\hline 25. & $\begin{array}{l}\text { Contact your partner to harass } \\
\text { or monitor them? }\end{array}$ \\
\hline 26. & $\begin{array}{l}\text { Tell you that you are to blame } \\
\text { for the abuse in your } \\
\text { relationship? }\end{array}$ \\
\hline 27. & $\begin{array}{l}\text { Point out effects of abuse on } \\
\text { your children? }\end{array}$ \\
\hline
\end{tabular}




\section{SOCIAL NETWORKS OF INTIMATE PARTNER VIOLENCE PERPETRATORS}

\begin{tabular}{|l|l|l|}
\hline 28. & $\begin{array}{l}\text { Hold you accountable for } \\
\text { abusive behavior? }\end{array}$ & \\
\hline 29. & $\begin{array}{l}\text { Encourage you to keep } \\
\text { attending Allies in Change? }\end{array}$ & \\
\hline 30. & $\begin{array}{l}\text { Try to make amends with you } \\
\text { for their abusive behavior? }\end{array}$ & \\
\hline
\end{tabular}

\begin{tabular}{|c|c|c|c|c|c|c|c|}
\hline & $\begin{array}{l}\text { In the last } 3 \text { months, how often } \\
\text { did you see this person... }\end{array}$ & $\begin{array}{l}\text { Not } \\
\text { applicable }\end{array}$ & $\begin{array}{l}0 \\
\text { times }\end{array}$ & $\begin{array}{l}1-5 \\
\text { times }\end{array}$ & $\begin{array}{l}6-10 \\
\text { times }\end{array}$ & $\begin{array}{l}11-20 \\
\text { times }\end{array}$ & $\begin{array}{l}\text { Over } \\
20 \\
\text { times }\end{array}$ \\
\hline 31. & Call their partner names? & & & & & & \\
\hline 32. & Swear at their partner? & & & & & & \\
\hline 33. & $\begin{array}{l}\text { Yell and scream at their } \\
\text { partner? }\end{array}$ & & & & & & \\
\hline 34. & $\begin{array}{l}\text { Treat their partner like an } \\
\text { inferior? }\end{array}$ & & & & & & \\
\hline 35. & $\begin{array}{l}\text { Monitor their partner's time } \\
\text { and make them account for } \\
\text { their whereabouts? }\end{array}$ & & & & & & \\
\hline 36. & $\begin{array}{l}\text { Spend a lot of money or make } \\
\text { important financial decisions } \\
\text { without consulting their } \\
\text { partner? }\end{array}$ & & & & & & \\
\hline 37. & $\begin{array}{l}\text { Accuse their partner of having } \\
\text { an affair? }\end{array}$ & & & & & & \\
\hline 38. & $\begin{array}{l}\text { Interfere in their partner's } \\
\text { relationships with other family } \\
\text { members? }\end{array}$ & & & & & & \\
\hline 39. & $\begin{array}{l}\text { Talk about being jealous of } \\
\text { their partners' friends? }\end{array}$ & & & & & & \\
\hline 40. & $\begin{array}{l}\text { Try to keep their partner from } \\
\text { doing things to help themself? }\end{array}$ & & & & & & \\
\hline 41. & $\begin{array}{l}\text { Restrict their partner's use of } \\
\text { the telephone? }\end{array}$ & & & & & & \\
\hline 42. & $\begin{array}{l}\text { Tell their partner that their } \\
\text { feelings were irrational or } \\
\text { crazy? }\end{array}$ & & & & & & \\
\hline 43. & $\begin{array}{l}\text { Blame their partner for their } \\
\text { problems? }\end{array}$ & & & & & & \\
\hline 44. & $\begin{array}{l}\text { Try to make their partner feel } \\
\text { crazy? }\end{array}$ & & & & & & \\
\hline
\end{tabular}




\section{SOCIAL NETWORKS OF INTIMATE PARTNER VIOLENCE PERPETRATORS}

Think about your interactions with this friend or family member.

\begin{tabular}{|c|c|c|c|c|c|c|c|}
\hline & $\begin{array}{l}\text { In the last } 3 \text { months, how often } \\
\text { did you... }\end{array}$ & $\begin{array}{l}\text { Not } \\
\text { applicable }\end{array}$ & $\begin{array}{l}0 \\
\text { times }\end{array}$ & $\begin{array}{l}1-5 \\
\text { times }\end{array}$ & $\begin{array}{l}6-10 \\
\text { times }\end{array}$ & \begin{tabular}{|l|}
$11-$ \\
20 \\
times
\end{tabular} & $\begin{array}{l}\text { Over } 20 \\
\text { times }\end{array}$ \\
\hline 45. & $\begin{array}{l}\text { Intervene if you heard another } \\
\text { couple fighting, while you were } \\
\text { with this person? }\end{array}$ & & & & & & \\
\hline 46. & $\begin{array}{l}\text { Ask this person's partner if they } \\
\text { needed help if they were being } \\
\text { shoved or yelled at by this } \\
\text { person? }\end{array}$ & & & & & & \\
\hline 47. & $\begin{array}{l}\text { Confront this person if you saw } \\
\text { them insulting or using } \\
\text { controlling behavior with their } \\
\text { partner? }\end{array}$ & & & & & & \\
\hline 48. & $\begin{array}{l}\text { Intervene if you saw this } \\
\text { person grabbing or pushing } \\
\text { their partner? }\end{array}$ & & & & & & \\
\hline 49. & $\begin{array}{l}\text { Speak up if you heard this } \\
\text { person talking about forcing } \\
\text { someone to have sex with } \\
\text { them? }\end{array}$ & & & & & & \\
\hline 50. & $\begin{array}{l}\text { Let this person know that you } \\
\text { were there to help if you } \\
\text { thought they were in an } \\
\text { abusive relationship? }\end{array}$ & & & & & & \\
\hline 51. & $\begin{array}{l}\text { Share information about abuse } \\
\text { with this person? }\end{array}$ & & & & & & \\
\hline 52. & $\begin{array}{l}\text { Confront this person for } \\
\text { making excuses for others' } \\
\text { abusive behavior? }\end{array}$ & & & & & & \\
\hline 53. & $\begin{array}{l}\text { Speak up against sexist jokes in } \\
\text { front of this person? }\end{array}$ & & & & & & \\
\hline 54. & $\begin{array}{l}\text { Speak up against jokes about } \\
\text { abuse in front of this person? }\end{array}$ & & & & & & \\
\hline 55. & $\begin{array}{l}\text { Speak up against commercials, } \\
\text { TV shows, movies, or music } \\
\text { that support violence against } \\
\text { women in front of this person? }\end{array}$ & & & & & & \\
\hline 56. & $\begin{array}{l}\text { Confront this person if they } \\
\text { explain that women like or } \\
\text { deserve to be raped? }\end{array}$ & & & & & & \\
\hline
\end{tabular}




\section{SOCIAL NETWORKS OF INTIMATE PARTNER VIOLENCE PERPETRATORS}

\begin{tabular}{|c|c|}
\hline 57. & $\begin{array}{l}\text { Indicate your displeasure to } \\
\text { this person if they made sexist } \\
\text { comments? }\end{array}$ \\
\hline 58. & $\begin{array}{l}\text { Provide this person with } \\
\text { resources for victims of abuse? }\end{array}$ \\
\hline 59. & $\begin{array}{l}\text { Tell this person that they } \\
\text { should think about going to } \\
\text { Allies in Change or a similar } \\
\text { program? }\end{array}$ \\
\hline 60. & $\begin{array}{l}\text { Express concern if this person if } \\
\text { they told you that they were } \\
\text { abusive towards their partner? }\end{array}$ \\
\hline 61. & $\begin{array}{l}\text { Refer this person to help if they } \\
\text { told you that they were in an } \\
\text { abusive relationship? }\end{array}$ \\
\hline 62. & $\begin{array}{l}\text { Share your story about abuse } \\
\text { with this person? }\end{array}$ \\
\hline 63. & $\begin{array}{l}\text { Tell this person that it makes } \\
\text { you uncomfortable to hear } \\
\text { them talk about abuse or act } \\
\text { abusively in front of you? }\end{array}$ \\
\hline 64. & $\begin{array}{l}\text { Talk with this person about } \\
\text { abuse that you witnessed as a } \\
\text { child? }\end{array}$ \\
\hline 65. & $\begin{array}{l}\text { Speak up in front of this person } \\
\text { if someone was providing } \\
\text { misinformation about abuse? }\end{array}$ \\
\hline 66. & $\begin{array}{l}\text { Tell this person that you go to } \\
\text { Allies in Change? }\end{array}$ \\
\hline 67. & $\begin{array}{l}\text { Object if this person was not } \\
\text { being accountable for their } \\
\text { own abusive behavior? }\end{array}$ \\
\hline 68. & $\begin{array}{l}\text { Try to talk this person out of it } \\
\text { if they told you that they were } \\
\text { going to be abusive to their } \\
\text { partner? }\end{array}$ \\
\hline 69. & $\begin{array}{l}\text { Talk with this person about } \\
\text { consequences of being } \\
\text { abusive? }\end{array}$ \\
\hline 70. & $\begin{array}{l}\text { Talk with this person about the } \\
\text { importance of being } \\
\text { accountable? }\end{array}$ \\
\hline 71. & Stick up for this person's \\
\hline
\end{tabular}


SOCIAL NETWORKS OF INTIMATE PARTNER VIOLENCE PERPETRATORS

\begin{tabular}{|c|c|c|}
\hline & $\begin{array}{l}\text { partner if they were talking } \\
\text { badly about them? }\end{array}$ & \\
\hline 72. & $\begin{array}{l}\text { Share books or other materials } \\
\text { from Allies in Change with this } \\
\text { person? }\end{array}$ & \\
\hline 73. & $\begin{array}{l}\text { Make amends with this person } \\
\text { for your abusive behavior? }\end{array}$ & \\
\hline 74. & $\begin{array}{l}\text { Talk with this person about the } \\
\text { effects of abuse on children? }\end{array}$ & \\
\hline
\end{tabular}




\title{
SOCIAL NETWORKS OF INTIMATE PARTNER VIOLENCE PERPETRATORS
}

\author{
Appendix H: Consent Form for BIP Participant Focus Group
}

\section{P Portland $\underset{\text { Universitr }}{\text { State }}$}

\section{Social Networks and Relationships Study}

You are invited to participate in a focus group conducted by Wendy Viola, M.S., from Portland State University. The researcher hopes to learn about the friends, family members, coworkers, or other community members who are important in your life, and how you interact with them about attitudes and behavior towards women. You were selected as a possible participant because you are currently enrolled in a group at Allies in Change.

If you decide to participate, you will take part in a small group conversation about the people in your life, and how you talk about attitudes and behavior towards women. Other group members will be the men with whom you usually attend groups at Allies in Change, and the group will be much like the groups that you usually attend. The researcher will cofacilitate the group, along with your usual group facilitator. At the start of the focus group, the researcher will provide some ground rules for the conversation and introduce the topic. The researcher will pose five or six main questions to the group, and you will be asked to share your experiences and opinions about them.

The focus group will be recorded with a digital recorder so that the researcher can concentrate on what is being said and guide the conversation. The recording will only be heard by the research team, and kept in a locked laboratory on the Portland State University campus.

If you choose to participate, your identity as a participant will not be revealed to anyone who is not present at the time of the focus group. Your identity will not be attached to any information that the focus group produces. However, the researcher cannot guarantee that other group members will keep information that you share during the focus group confidential. Additionally, if you report any behavior that suggests that you are at an immediate risk of harming yourself or another person, this information will be reported to the police. Additionally, your Allies in Change facilitator will be present during the focus group and will hear what you say during the group. Allies in Change's policies about responding to disclosures of illegal activity will apply as they usually do.

The discussion will be held during your regularly scheduled group meetings at Allies in Change on Thursday, August $8^{\text {th }}, 2013$. The discussion is expected to last for about an hour and a half. It is possible that participating in the discussion will make you remember events that were upsetting, or realize new things about the people in your life that may be uncomfortable. Your Allies in Change group facilitator will be available to talk about any discomfort that you may experience as a result, and your group may provide a space for talking about many of these issues. Participating in this focus group may be beneficial to 


\section{SOCIAL NETWORKS OF INTIMATE PARTNER VIOLENCE PERPETRATORS}

you in that you will have the opportunity to talk about and reflect on your interactions with other people in your community, in a group of other men who also attend Allies in Change. It is also possible that you may not receive any direct benefit from taking part in this conversation, but in the information that you share will be used to develop questions that will be included in a survey about the same topic. The results of the survey may contribute to understanding how men's communities contribute to the work that they (you) do in group, and possibly help Allies in Change make their groups more effective.

Your participation is voluntary. You do not have to take part in this focus group, and whether or not you choose to participate will not affect your standing or relationship with Allies in Change. You may also withdraw from this focus group at any time without affecting your status with Allies in Change. If you choose not to attend your Allies in Change group on the day that the focus group is conducted (August $8^{\text {th }}, 2013$ ), you will receive an excused absence for that day. However, if you are not present at that group meeting, you will not receive credit for attending that group meeting, and it will not count towards your minimum required number of sessions. You have the option of attending your Allies in Change on the evening of August $8^{\text {th }}, 2013$, and not participating in the focus group. As long as you are present at Allies in Change for the meeting on the evening of August $8^{\text {th }}, 2013$, you will be marked as present, and your attendance will count towards your minimum number of required sessions.

If you have concerns or problems with your participation in this focus group or your rights as a research participant, please contact the Portland State University Human Subjects Research Review Committee, PO Box 751, Portland, OR 97207, (503) 725-4288 / 1-877-4804400. If you have questions about the study itself, contact Eric Mankowski at mankowskie@pdx.edu or (503) 725 -3901, or Wendy Viola at violaw@pdx.edu or (503) 725-3955.

Your signature indicates that you have read and understand the above information and agree to take part in this focus group. Please understand that you may withdraw your consent at any time without penalty, and that, by signing, you are not waiving any legal claims, rights, or remedies. The researcher will provide you with a copy of this form for your own records.

Name (Please print):

Signature:

Date: 


\section{SOCIAL NETWORKS OF INTIMATE PARTNER VIOLENCE PERPETRATORS}

Appendix I: Script for BIP Participants' Focus Group

Script for BIP participant focus group for developing inventories

Today I would like to hear your thoughts about your friends and family members, other than your partners, and how they influence your relationships with your partners. I am interested in the ways that they may influence you and make you think about what you learn in your group at Allies in Change.

\section{\#1: consent forms}

Before we begin, let's go around and introduce ourselves. Please share your name, and tell us how long you've been going to groups at Allies in Change.

My hope for this conversation that we'll brainstorm a list of the ways that the people in your life influence you and motivate you to change, and a list of the ways that you try to influence other people in your life regarding the work that you've been doing at Allies in Change.

How the conversation will go:

- A conversation between you. I'll step in to guide the conversation, as will Sherry, but about dialogue between you.

- Wide participation would be great-l'd like to hear from everyone!

- l'd also like to ask that we speak one at a time.

- While it's likely that we have a diversity of opinions represented in this group, and we welcome disagreement, l'd like to ask that you disagree with each other respectfully - the goal is not to reach consensus

- Finally, just like in every other group you attend at Allies in Change, what people say in the group should stay in the group. You're welcome to debrief today's conversation with your partner, but remember not to discuss any information that would reveal the identities of other people who are here today.

- One more note before we get started: you'll notice that your facilitator is here, and she'll be participating in this conversation too. She'll also hear whatever you say and have the responsibility to react the way that she normally would. Allies in Change's policies about the limits of confidentiality apply here as well. This means that if there's anything that you would usually avoid saying in front of your facilitator, this meeting is no different. As researchers, we also have a responsibility to report to the police if you say anything about immediate plans to harm yourself or someone else.

Does this sound alright? Anything to add? If not, I'll go ahead and turn on the recorder... 


\section{SOCIAL NETWORKS OF INTIMATE PARTNER VIOLENCE PERPETRATORS}

I have a few questions to get us started.

1. Who are the people, other than your partner, who are important in your life?

2. What topics that you talk about in group make you think about other people in your life?

3. What are some of the things that your friends and family members say or do which interfere or conflict with the work that you do in group at Allies in Change?

a. How do you respond to these actions and behaviors when your friends and family members engage in them?

b. What do you do to indicate that you object to these actions and behaviors?

4. What are some of the things that your friends and family members say or do that reinforce or support that work that you do in group at Allies in Change?

5. What are some of the things that you say or do with your friends and family members that reflect what you've been doing in group at Allies in Change?

6. I'd like to get your input on a number of survey items that describe ways that you and others in your lives may express your attitudes and behaviors about abuse to each other. I'm going to pass around copies of some of these items. Take your time to read over them, and mark the ones that you think that you, or other the participants in your Allies in Change groups, might do with some regularity. If you think that any of the items could be modified to make them more meaningful or more like things that you or others in your life do more often, please write in those modifications right on the form. I'll collect them from you at the end, so please don't put your names on them.

a. Which items did you think you or other men at Allies in Change would realistically say that they've done in the last 3 months?

b. Which items could be tweaked so that you or other men at Allies in Change would realistically say that they've done them in the last 3 months? 


\section{SOCIAL NETWORKS OF INTIMATE PARTNER VIOLENCE PERPETRATORS}

Appendix J: Points from BIP Participants' Focus Group

Expectations from others that conflict with work at Allies

- Friends and family want to say "you don't have a problem, that's not like you, that's not the _ we know" not wanting to talk about it - prevents them from being honest and accountable because other people just don't want to hear it.

- Synchronicity between work in group and outside relationships: changing own behavior elicits different responses from other people (better friends, people opening up to him more) - implicit reinforcement for changes that result from work in group

- Less often chauvinistic, but more about "I need to have my way," "I should be able to overrule my wife." Counter these with "maybe it's important to her, what's it to you?," other more gentle ways of intervening

Responses to anti-Allies pressure

- Gently calling others out on their controlling behavior

- Can't as easily withdraw from family, in which case agree to disagree-don't push conversations too far so that they don't escalate-avoid topics of abuse

- Sometimes will purposefully and knowingly make comments that they know aren't "right," in order to keep the peace-looking for a way to get around doing so. If you ignore the comment, you clearly disagree, but if you say something in support, you're going against your principles. Feel pressure to say things in support because it's a good-old-boys business and it's out of necessity for maintaining business relationships.

- Socially: can make comments that indicate that you don't think the same thing ("Ouch, that hurts") - it's easier to approach friends in this way than business relationships

Reinforcement that you've received, examples of ways that others have expressed their support for changes

- Feedback about interpersonal skills at work "you're a pleasure to work with now and you weren't before," people are better able and less afraid to approach them now

- Friends who they've talked about the group with have all been very supportive, appreciative: "I wish I had a group like that to talk with," "not everybody's capable or willing to do that," feel a general sense of support and encouragement when talking about the group

Specific things you talk about with other people that reflect the topics that you talk about in group: 


\section{SOCIAL NETWORKS OF INTIMATE PARTNER VIOLENCE PERPETRATORS}

- Try to define abusive behavior: "getting what you want from somebody else at their expense," push-back comes from other people's misperceptions of abuse (that abuse is only physical, and it's harder to imagine someone that you're close to as someone who's physically abusive, which translates into a lack of understanding and support).

- "maybe that's not what's bothering you" - helping people zero in on their specific feelings, instead of trying to address abuse more broadly

First page: no friends have ever said any of these things, except for 21 and 12

- \#12 (Tell you examples of ways that they've been abusive to their partner?): applies to group members, but probably wouldn't apply to anyone outside of the group

- Expand Not Applicable to "Not applicable, I never had the opportunity"

Other items that would be relevant:

- When kids get emotionally intense or engage in behaviors that you recognize were problems for yourself, give them tools for dealing with it (i.e. stop and breath)

- It seems like all of the items would be applicable to participants in the mandatory groups

- Most of the items are verbal interactions, don't include witnessing other people involved in other events, which could still impact your own behavior

- A lot of the abusive behaviors they talk about are grouchiness, volatility, making your spouse second-guess themselves-this is the real start of the abuse, and those behaviors are way more common and could be represented on the survey

- If you're the victim of a friend's grumpiness, shortness, or withdrawal, it's easier to say something because you have a role there. But it's harder when you witness them doing this with someone else

- "Really, are you really going to fight about that?" "what's going on with you?" to confront others' controlling behaviors - these are ways that they try to influence people outside of the group, by nonconfrontationally appealing to others' sense of fair-play and what's right and what's wrong. The fact that they're there means that they're working the program

- Defining male privilege for a friend

- If you witness behavior that you've done in the past, you can either withdraw, because you're not one to judge, or you can use that as an entry, to say that you've done that yourself 


\section{SOCIAL NETWORKS OF INTIMATE PARTNER VIOLENCE PERPETRATORS}

- "I see something in you that you probably learned from me, and I wish that you hadn't"

- Have to start interpreting others' behaviors as not an attack on you - we all have the ability to be relational

- Easier to approach things relationally, from an empathetic stance or with information to avoid being perceived as judgmental 


\section{SOCIAL NETWORKS OF INTIMATE PARTNER VIOLENCE PERPETRATORS}

\section{Appendix K: Behavioral Inventories Resulting from BIP Participants' Focus Group}

Below are a series of behaviors that other people in your life may engage in, and behaviors that you may engage in with these people. Please circle the numbers next to all of the items that you believe that you or other people in your life have engaged in during the last $\mathbf{3}$ months. If you think that phrasing the items differently would be more appropriate, please rewrite the item in the space provided.

Think about a friend or family member, other than your partner, who is important to you.

\begin{tabular}{|c|c|c|c|c|c|c|c|}
\hline & $\begin{array}{l}\text { In the last } 3 \text { months, how often did } \\
\text { this person... }\end{array}$ & $\begin{array}{l}\text { Not } \\
\text { applicable }\end{array}$ & $\begin{array}{l}0 \\
\text { times }\end{array}$ & $\begin{array}{l}1-5 \\
\text { times }\end{array}$ & $\begin{array}{l}6-10 \\
\text { times }\end{array}$ & $\begin{array}{l}11- \\
20 \\
\text { times }\end{array}$ & $\begin{array}{l}\text { Over } \\
20 \\
\text { times }\end{array}$ \\
\hline 1. & $\begin{array}{l}\text { Tell you that you should not accept } \\
\text { your partner's challenges to your } \\
\text { authority? }\end{array}$ & & & & & & \\
\hline 2. & $\begin{array}{l}\text { Accuse your partner of having an } \\
\text { affair? }\end{array}$ & & & & & & \\
\hline 3. & $\begin{array}{l}\text { Tell you that your partner is taking } \\
\text { advantage of you? }\end{array}$ & & & & & & \\
\hline 4. & $\begin{array}{l}\text { Accuse your partner of trying to harm } \\
\text { your relationship with your kids? }\end{array}$ & & & & & & \\
\hline 5. & $\begin{array}{l}\text { Tell you that your partner was to } \\
\text { blame for a fight? }\end{array}$ & & & & & & \\
\hline 6. & $\begin{array}{l}\text { Call your partner names while they } \\
\text { were talking to you? }\end{array}$ & & & & & & \\
\hline 7. & $\begin{array}{l}\text { Give you advice about ways to control } \\
\text { your partner? }\end{array}$ & & & & & & \\
\hline 8. & $\begin{array}{l}\text { Suggest ways to be abusive towards } \\
\text { your partner? }\end{array}$ & & & & & & \\
\hline 9. & $\begin{array}{l}\text { Tell you that your partner needed to } \\
\text { be controlled? }\end{array}$ & & & & & & \\
\hline 10. & Make jokes about abuse to you? & & & & & & \\
\hline 11. & $\begin{array}{l}\text { Tell you that you should not trust } \\
\text { your partner? }\end{array}$ & & & & & & \\
\hline 12. & $\begin{array}{l}\text { Tell you that they wouldn't let their } \\
\text { partner get away with the things that } \\
\text { your partner does? }\end{array}$ & & & & & & \\
\hline 13. & $\begin{array}{l}\text { Tell you that you have to do } \\
\text { something about your partner's } \\
\text { behavior? }\end{array}$ & & & & & & \\
\hline 14. & $\begin{array}{l}\text { Tell you that your partner is } \\
\text { disrespecting you? }\end{array}$ & & & & & & \\
\hline 15. & $\begin{array}{l}\text { Make fun of you for trying to change } \\
\text { your relationship with your partner? }\end{array}$ & & & & & & \\
\hline 16. & $\begin{array}{l}\text { Support your attempts to be more } \\
\text { accountable? }\end{array}$ & & & & & & \\
\hline
\end{tabular}




\section{SOCIAL NETWORKS OF INTIMATE PARTNER VIOLENCE PERPETRATORS}

\begin{tabular}{|c|c|c|c|c|c|c|c|}
\hline 17. & $\begin{array}{l}\text { Tell you that your partner's behavior } \\
\text { justified your abuse? }\end{array}$ & & & & & & \\
\hline 18. & $\begin{array}{l}\text { Support you in taking legal action } \\
\text { against your partner? }\end{array}$ & & & & & & \\
\hline 19. & $\begin{array}{l}\text { Contact your partner to harass or } \\
\text { monitor them? }\end{array}$ & & & & & & \\
\hline 20. & $\begin{array}{l}\text { Tell you that you are to blame for the } \\
\text { abuse in your relationship? }\end{array}$ & & & & & & \\
\hline 21. & $\begin{array}{l}\text { Point out effects of abuse on your } \\
\text { children? }\end{array}$ & & & & & & \\
\hline 22. & $\begin{array}{l}\text { Hold you accountable for abusive } \\
\text { behavior? }\end{array}$ & & & & & & \\
\hline 23. & $\begin{array}{l}\text { Support your participation at Allies in } \\
\text { Change? }\end{array}$ & & & & & & \\
\hline 24. & $\begin{array}{l}\text { Try to make amends with you for } \\
\text { their abusive behavior? }\end{array}$ & & & & & & \\
\hline 25. & $\begin{array}{l}\text { Tell you that you don't have a } \\
\text { problem with abuse? }\end{array}$ & & & & & & \\
\hline \multirow[t]{2}{*}{26.} & $\begin{array}{l}\text { Respond favorably when you used } \\
\text { something that you learned in group } \\
\text { while you were interacting with } \\
\text { them? }\end{array}$ & & & & & & \\
\hline & $\begin{array}{l}\text { In the last } 3 \text { months, how often did } \\
\text { you see this person... }\end{array}$ & $\begin{array}{l}\text { Not } \\
\text { applicable }\end{array}$ & $\begin{array}{l}0 \\
\text { times }\end{array}$ & $\begin{array}{l}1-5 \\
\text { times }\end{array}$ & $\begin{array}{l}6-10 \\
\text { times }\end{array}$ & $\begin{array}{l}11- \\
20 \\
\text { times } \\
\end{array}$ & $\begin{array}{l}\text { Over } \\
20 \\
\text { times } \\
\end{array}$ \\
\hline 27. & Call their partner names? & & & & & & \\
\hline 28. & Swear at their partner? & & & & & & \\
\hline 29. & Yell and scream at their partner? & & & & & & \\
\hline 30. & Treat their partner like an inferior? & & & & & & \\
\hline 31. & $\begin{array}{l}\text { Accuse their partner of having an } \\
\text { affair? }\end{array}$ & & & & & & \\
\hline 32. & $\begin{array}{l}\text { Interfere in their partner's } \\
\text { relationships with other family } \\
\text { members? }\end{array}$ & & & & & & \\
\hline 33. & $\begin{array}{l}\text { Make their partner believe that their } \\
\text { feelings were irrational or crazy? }\end{array}$ & & & & & & \\
\hline 34. & $\begin{array}{l}\text { Blame their partner for their } \\
\text { problems? }\end{array}$ & & & & & & \\
\hline
\end{tabular}




\section{SOCIAL NETWORKS OF INTIMATE PARTNER VIOLENCE PERPETRATORS}

Think about your interactions with this friend or family member.

\begin{tabular}{|c|c|c|c|c|c|c|c|}
\hline & $\begin{array}{l}\text { In the last } 3 \text { months, how often did } \\
\text { you... }\end{array}$ & $\begin{array}{l}\text { Not } \\
\text { applicable }\end{array}$ & $\begin{array}{l}0 \\
\text { times }\end{array}$ & $\begin{array}{l}1-5 \\
\text { times }\end{array}$ & $\begin{array}{l}6-10 \\
\text { times }\end{array}$ & $\begin{array}{l}11- \\
20 \\
\text { times }\end{array}$ & $\begin{array}{l}\text { Over } \\
20 \\
\text { times }\end{array}$ \\
\hline 1. & $\begin{array}{l}\text { Intervene if you heard another couple } \\
\text { fighting, while you were with this } \\
\text { person? }\end{array}$ & & & & & & \\
\hline 2. & $\begin{array}{l}\text { Ask this person's partner if they } \\
\text { needed help if they were being } \\
\text { shoved or yelled at by this person? }\end{array}$ & & & & & & \\
\hline 3. & $\begin{array}{l}\text { Confront this person if you saw them } \\
\text { insulting or using controlling behavior } \\
\text { with their partner? }\end{array}$ & & & & & & \\
\hline 4. & $\begin{array}{l}\text { Confront this person if you saw them } \\
\text { being grouchy, snapping, or ignoring } \\
\text { their partner? }\end{array}$ & & & & & & \\
\hline 5. & $\begin{array}{l}\text { Intervene if you saw this person } \\
\text { grabbing or pushing their partner? }\end{array}$ & & & & & & \\
\hline 6. & $\begin{array}{l}\text { Let this person know that you were } \\
\text { there to help if you thought they } \\
\text { were in an abusive relationship? }\end{array}$ & & & & & & \\
\hline 7. & $\begin{array}{l}\text { Share information about abuse with } \\
\text { this person? }\end{array}$ & & & & & & \\
\hline 8. & $\begin{array}{l}\text { Confront this person for making } \\
\text { excuses for others' abusive behavior? }\end{array}$ & & & & & & \\
\hline 9. & $\begin{array}{l}\text { Speak up against sexist jokes in front } \\
\text { of this person? }\end{array}$ & & & & & & \\
\hline 10. & $\begin{array}{l}\text { Speak up against jokes about abuse in } \\
\text { front of this person? }\end{array}$ & & & & & & \\
\hline 11. & $\begin{array}{l}\text { Speak up against commercials, TV } \\
\text { shows, movies, or music that support } \\
\text { violence against women in front of } \\
\text { this person? }\end{array}$ & & & & & & \\
\hline 12. & $\begin{array}{l}\text { Indicate your displeasure to this } \\
\text { person if they made sexist } \\
\text { comments? }\end{array}$ & & & & & & \\
\hline 13. & $\begin{array}{l}\text { Provide this person with resources for } \\
\text { victims of abuse? }\end{array}$ & & & & & & \\
\hline 14. & $\begin{array}{l}\text { Tell this person that they should think } \\
\text { about going to Allies in Change or a } \\
\text { similar program? }\end{array}$ & & & & & & \\
\hline 15. & $\begin{array}{l}\text { Express concern if this person if they } \\
\text { told you that they were abusive } \\
\text { towards their partner? }\end{array}$ & & & & & & \\
\hline 16. & $\begin{array}{l}\text { Refer this person to help if they told } \\
\text { you that they were in an abusive }\end{array}$ & & & & & & \\
\hline
\end{tabular}




\section{SOCIAL NETWORKS OF INTIMATE PARTNER VIOLENCE PERPETRATORS}

\begin{tabular}{|c|c|c|}
\hline & relationship? & \\
\hline 17. & $\begin{array}{l}\text { Share your story about abuse with } \\
\text { this person? }\end{array}$ & \\
\hline 18. & $\begin{array}{l}\text { Tell this person that it makes you } \\
\text { uncomfortable to hear them talk } \\
\text { about abuse or act abusively in front } \\
\text { of you? }\end{array}$ & \\
\hline 19. & $\begin{array}{l}\text { Talk with this person about abuse } \\
\text { that you witnessed as a child? }\end{array}$ & \\
\hline 20. & $\begin{array}{l}\text { Speak up in front of this person if } \\
\text { someone was providing } \\
\text { misinformation about abuse? }\end{array}$ & \\
\hline 21. & $\begin{array}{l}\text { Tell this person that you go to Allies in } \\
\text { Change? }\end{array}$ & \\
\hline 22. & $\begin{array}{l}\text { Object if this person was not being } \\
\text { accountable for their own abusive } \\
\text { behavior? }\end{array}$ & \\
\hline 23. & $\begin{array}{l}\text { Try to talk this person out of it if they } \\
\text { told you that they were going to be } \\
\text { abusive to their partner? }\end{array}$ & \\
\hline 24. & $\begin{array}{l}\text { Talk with this person about } \\
\text { consequences of being abusive? }\end{array}$ & \\
\hline 25. & $\begin{array}{l}\text { Talk with this person about the } \\
\text { importance of being accountable? }\end{array}$ & \\
\hline 26. & $\begin{array}{l}\text { Stick up for this person's partner if } \\
\text { they were talking badly about them? }\end{array}$ & \\
\hline 27. & $\begin{array}{l}\text { Share books or other materials from } \\
\text { Allies in Change with this person? }\end{array}$ & \\
\hline 28. & $\begin{array}{l}\text { Make amends with this person for } \\
\text { your abusive behavior? }\end{array}$ & \\
\hline 29. & $\begin{array}{l}\text { Talk with this person about the } \\
\text { effects of abuse on children? }\end{array}$ & \\
\hline 30. & $\begin{array}{l}\text { Ask this person why it's important to } \\
\text { them to control some aspect of their } \\
\text { partner's behavior? }\end{array}$ & \\
\hline 31. & $\begin{array}{l}\text { Teach this person a tool for } \\
\text { controlling their own behavior? }\end{array}$ & \\
\hline 32. & $\begin{array}{l}\text { Apologize to this person for modeling } \\
\text { abusive behavior in the past? }\end{array}$ & \\
\hline 33. & $\begin{array}{l}\text { Encourage this person to consider } \\
\text { that maybe somebody else's behavior } \\
\text { wasn't an attack on them? }\end{array}$ & \\
\hline
\end{tabular}




\title{
SOCIAL NETWORKS OF INTIMATE PARTNER VIOLENCE PERPETRATORS
}

\author{
Appendix L: Survey Instrument used for Pilot Testing
}

This survey will ask you some questions about the people you have spent the most time with in the past three months. Thinking about these people one at a time, please answer the following questions about each of those people that you have spent the most time with in the last three months.

\section{Contact \#1}

What is this person's gender? $\square$ Male $\square$ Female

What is your relationship to this person? (For example, are they your parent? Your boss or coworker? A friend from high school?)

How often do you usually spend time with this person, either in person, on the phone, or over the internet?

$\square$ Less than once a year $\square$ A few times a year $\quad \square$ Twice -3 times a month $\square$ Almost every day

$\square$ About once a year $\square$ About every month $\square$ About once a week $\square$ More than once a day

\begin{tabular}{|c|c|c|c|c|c|c|c|c|c|}
\hline $\begin{array}{l}\text { The items below concern your feelings for the person that you identified at the top } \\
\text { of this page. With him or her in mind, decide how much you agree or disagree with } \\
\text { each item. On the scale directly to the right of each item, circle the number that } \\
\text { indicates how much you agree that the statement describes your feelings. There } \\
\text { are no right or wrong answers, because adults' feelings for people in their lives } \\
\text { differ from person to person. Just honestly describe your feelings for this person. }\end{array}$ & & & & & & $\frac{1}{0}$ & 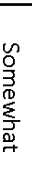 & & \\
\hline 1. I am happy with my relationship with this person & -4 & -3 & -2 & -1 & 0 & 1 & 2 & 3 & 4 \\
\hline 2. I feel my relationship with this person is a great one & -4 & -3 & -2 & -1 & 0 & 1 & 2 & 3 & 4 \\
\hline 3. I am satisfied with my relationship with this person & -4 & -3 & -2 & -1 & 0 & 1 & 2 & 3 & 4 \\
\hline 4. I think that my relationship with this person is strong & -4 & -3 & -2 & -1 & 0 & 1 & 2 & 3 & 4 \\
\hline 5. I feel my relationship with this person is good & -4 & -3 & -2 & -1 & 0 & 1 & 2 & 3 & 4 \\
\hline 6. I am pleased with my relationship with this person & -4 & -3 & -2 & -1 & 0 & 1 & 2 & 3 & 4 \\
\hline 7. I am contented with my relationship with this person & -4 & -3 & -2 & -1 & 0 & 1 & 2 & 3 & 4 \\
\hline
\end{tabular}

\begin{tabular}{|c|c|c|c|c|c|c|}
\hline $\begin{array}{l}\text { The following is a list of behaviors that you may have engaged in with the person you described on the } \\
\text { top of this page. Think back over the last three months, and check the box that corresponds to the } \\
\text { approximate number of times that you have engaged in each of the following behaviors with this } \\
\text { person during the last three months. }\end{array}$ & 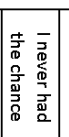 & 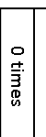 & $\begin{array}{l}\vdash \\
1 \\
v \\
\overrightarrow{5} \\
0 \\
0 \\
0\end{array}$ & $\begin{array}{l}a \\
1 \\
1 \\
\Delta \\
0 \\
\pm \\
5 \\
0 \\
0 \\
0\end{array}$ & 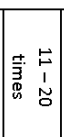 & 穿亮 \\
\hline \multicolumn{7}{|l|}{ 1. Confront this person if you saw them being insulting, grouchy, snapping, or ignoring their partner? } \\
\hline \multicolumn{7}{|l|}{ 2. Share information about abuse, and/or resources for victims of abuse with this person? } \\
\hline \multicolumn{7}{|l|}{ 3. Stick up for this person's partner if they were talking badly about them? } \\
\hline \multicolumn{7}{|l|}{ 4. Talk with this person about the effects of abuse on children? } \\
\hline \multicolumn{7}{|l|}{ 5. Ask this person why it's important to them to control their partner's behavior? } \\
\hline \multicolumn{7}{|l|}{ 6. Tell this person that they should think about going to Allies in Change or a similar program? } \\
\hline \multicolumn{7}{|l|}{ 7. Speak up against sexist jokes or jokes about abuse in front of this person? } \\
\hline \multicolumn{7}{|l|}{ 8. Share books or other materials from Allies in Change with this person? } \\
\hline \multicolumn{7}{|l|}{$\begin{array}{l}\text { 9. Tell this person that it makes you uncomfortable to hear them talk about abuse or act abusively } \\
\text { around you? }\end{array}$} \\
\hline \multicolumn{7}{|l|}{ 10. Object if this person was not being accountable for their abusive behavior? } \\
\hline \multicolumn{7}{|l|}{ 11. Talk with this person about consequences of being abusive? } \\
\hline \multicolumn{7}{|l|}{ 12. Share your story about abuse with this person? } \\
\hline \multicolumn{7}{|l|}{ 13. Tell this person that you go to Allies in Change? } \\
\hline \multicolumn{7}{|l|}{ 14. Make amends with this person for your abusive behavior? } \\
\hline \multicolumn{7}{|l|}{ 15. Apologize to this person for modeling abusive behavior in the past? } \\
\hline $\begin{array}{l}\text { 16. Have you used any other behaviors with this person that might have made them think about abuse? } \\
\text { If so, please describe them here. }\end{array}$ & & & & & & \\
\hline
\end{tabular}




\section{SOCIAL NETWORKS OF INTIMATE PARTNER VIOLENCE PERPETRATORS}

\begin{tabular}{|c|c|c|c|c|c|c|}
\hline $\begin{array}{l}\text { The following is a list of behaviors that the person you described on the other side of this page may } \\
\text { have engaged in during the last three months. Think back over the last three months, and check the } \\
\text { box that corresponds to the approximate number of times that this person has engaged in each } \\
\text { behavior during the last three months. }\end{array}$ & 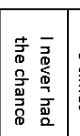 & 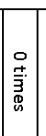 & 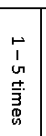 & 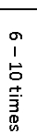 & 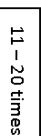 & 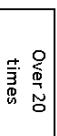 \\
\hline \multicolumn{7}{|l|}{ 17. Tell you that your partner is taking advantage of you or disrespecting you? } \\
\hline \multicolumn{7}{|l|}{ 18. Accuse your partner of trying to harm your relationship with your kids? } \\
\hline \multicolumn{7}{|l|}{ 19. Tell you that they wouldn't let their partner get away with the things that your partner does? } \\
\hline \multicolumn{7}{|l|}{ 20. Support you in being more accountable? } \\
\hline \multicolumn{7}{|l|}{ 21. Tell you that your partner's behavior justified your abuse? } \\
\hline \multicolumn{7}{|l|}{ 22. Refuse to accept that you were abusive in the past? } \\
\hline \multicolumn{7}{|l|}{$\begin{array}{l}\text { 23. Call their partner names; yell, scream or swear at their partner; act grouchy, snappy, or ignore their } \\
\text { partner in front of you? }\end{array}$} \\
\hline \multicolumn{7}{|l|}{ 24. Blame their partner for their problems? } \\
\hline \multicolumn{7}{|l|}{ 25. Give you advice about ways to be controlling or abusive towards your partner? } \\
\hline \multicolumn{7}{|l|}{ 26. Support you in taking legal action against your partner? } \\
\hline \multicolumn{7}{|l|}{ 27. Contact your partner to harass or monitor them? } \\
\hline \multicolumn{7}{|l|}{ 28. Make fun of you for trying to change your relationship with your partner? } \\
\hline \multicolumn{7}{|l|}{ 29. Point out effects of abuse on your children? } \\
\hline \multicolumn{7}{|l|}{ 30. Support your participation at Allies in Change? } \\
\hline \multicolumn{7}{|l|}{ 31. Try to make amends with you for their abusive behavior? } \\
\hline $\begin{array}{l}\text { 32. Has this person used any other behaviors that made you think about changing your abusive } \\
\text { behavior? If so, please describe them here. }\end{array}$ & & & & & & \\
\hline
\end{tabular}




\section{SOCIAL NETWORKS OF INTIMATE PARTNER VIOLENCE PERPETRATORS}

\section{Contact \#2}

What is this person's gender? $\square$ Male $\square$ Female

What is your relationship to this person? (For example, are they your parent? Your boss or coworker? A friend from high school?)

How often do you usually spend time with this person, either in person, on the phone, or over the internet?

$\square$ Less than once a year $\square$ A few times a year $\square$ Twice -3 times a month $\square$ Almost every day

About once a year $\square$ About every month $\quad \square$ About once a week $\quad \square$ More than once a day

\begin{tabular}{|c|c|c|c|c|c|c|c|c|c|}
\hline $\begin{array}{l}\text { The items below concern your feelings for the person that you identified at the top } \\
\text { of this page. With him or her in mind, decide how much you agree or disagree with } \\
\text { each item. On the scale directly to the right of each item, circle the number that } \\
\text { indicates how much you agree that the statement describes your feelings. There } \\
\text { are no right or wrong answers, because adults' feelings for people in their lives } \\
\text { differ from person to person. Just honestly describe your feelings for this person. }\end{array}$ & 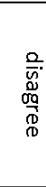 & & & & & & 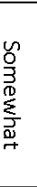 & & \\
\hline 1. I am happy with my relationship with this person & -4 & -3 & -2 & -1 & 0 & 1 & 2 & 3 & 4 \\
\hline 2. I feel my relationship with this person is a great one & -4 & -3 & -2 & -1 & 0 & 1 & 2 & 3 & 4 \\
\hline 3. I am satisfied with my relationship with this person & -4 & -3 & -2 & -1 & 0 & 1 & 2 & 3 & 4 \\
\hline 4. I think that my relationship with this person is strong & -4 & -3 & -2 & -1 & 0 & 1 & 2 & 3 & 4 \\
\hline 5. I feel my relationship with this person is good & -4 & -3 & -2 & -1 & 0 & 1 & 2 & 3 & 4 \\
\hline 6. I am pleased with my relationship with this person & -4 & -3 & -2 & -1 & 0 & 1 & 2 & 3 & 4 \\
\hline 7. I am contented with my relationship with this person & -4 & -3 & -2 & -1 & 0 & 1 & 2 & 3 & 4 \\
\hline
\end{tabular}

The following is a list of behaviors that you may have engaged in with the person you described on the top of this page. Think back over the last three months, and check the box that corresponds to the approximate number of times that you have engaged in each of the following behaviors with this person during the last three months.

33. Confront this person if you saw them being insulting, grouchy, snapping, or ignoring their partner?

34. Share information about abuse, and/or resources for victims of abuse with this person?

35. Stick up for this person's partner if they were talking badly about them?

36. Talk with this person about the effects of abuse on children?

37. Ask this person why it's important to them to control their partner's behavior?

38. Tell this person that they should think about going to Allies in Change or a similar program?

39. Speak up against sexist jokes or jokes about abuse in front of this person?

40. Share books or other materials from Allies in Change with this person?

41. Tell this person that it makes you uncomfortable to hear them talk about abuse or act abusively around you?

42. Object if this person was not being accountable for their abusive behavior?

43. Talk with this person about consequences of being abusive?

44. Share your story about abuse with this person?

45. Tell this person that you go to Allies in Change?

46. Make amends with this person for your abusive behavior?

47. Apologize to this person for modeling abusive behavior in the past?

48. Have you used any other behaviors with this person that might have made them think about abuse? If so, please describe them here. 


\section{SOCIAL NETWORKS OF INTIMATE PARTNER VIOLENCE PERPETRATORS}

\begin{tabular}{|c|c|c|c|c|c|c|}
\hline $\begin{array}{l}\text { The following is a list of behaviors that the person you described on the other side of this page may } \\
\text { have engaged in during the last three months. Think back over the last three months, and check the } \\
\text { box that corresponds to the approximate number of times that this person has engaged in each } \\
\text { behavior during the last three months. }\end{array}$ & 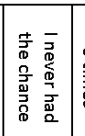 & 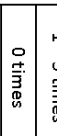 & 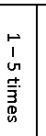 & 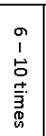 & 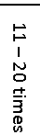 & 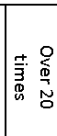 \\
\hline \multicolumn{7}{|l|}{ 49. Tell you that your partner is taking advantage of you or disrespecting you? } \\
\hline \multicolumn{7}{|l|}{ 50. Accuse your partner of trying to harm your relationship with your kids? } \\
\hline \multicolumn{7}{|l|}{ 51. Tell you that they wouldn't let their partner get away with the things that your partner does? } \\
\hline \multicolumn{7}{|l|}{ 52. Support you in being more accountable? } \\
\hline \multicolumn{7}{|l|}{ 53. Tell you that your partner's behavior justified your abuse? } \\
\hline \multicolumn{7}{|l|}{ 54. Refuse to accept that you were abusive in the past? } \\
\hline \multicolumn{7}{|l|}{$\begin{array}{l}\text { 55. Call their partner names; yell, scream or swear at their partner; act grouchy, snappy, or ignore their } \\
\text { partner in front of you? }\end{array}$} \\
\hline \multicolumn{7}{|l|}{ 56. Blame their partner for their problems? } \\
\hline \multicolumn{7}{|l|}{ 57. Give you advice about ways to be controlling or abusive towards your partner? } \\
\hline \multicolumn{7}{|l|}{ 58. Support you in taking legal action against your partner? } \\
\hline \multicolumn{7}{|l|}{ 59. Contact your partner to harass or monitor them? } \\
\hline \multicolumn{7}{|l|}{ 60. Make fun of you for trying to change your relationship with your partner? } \\
\hline \multicolumn{7}{|l|}{ 61. Point out effects of abuse on your children? } \\
\hline \multicolumn{7}{|l|}{ 62. Support your participation at Allies in Change? } \\
\hline \multicolumn{7}{|l|}{ 63. Try to make amends with you for their abusive behavior? } \\
\hline $\begin{array}{l}\text { 64. Has this person used any other behaviors that made you think about changing your abusive } \\
\text { behavior? If so, please describe them here. }\end{array}$ & & & & & & \\
\hline
\end{tabular}




\section{SOCIAL NETWORKS OF INTIMATE PARTNER VIOLENCE PERPETRATORS}

\section{Contact \#3}

What is this person's gender? $\square$ Male $\square$ Female

What is your relationship to this person? (For example, are they your parent? Your boss or coworker? A friend from high school?)

How of ten do you usually spend time with this person, either in person, on the phone, or over the internet?

$\square$ Less than once a year $\square$ A few times a year $\square$ Twice - 3 times a month $\square$ Almost every day

$\square$ About once a year $\square$ About every month $\quad \square$ About once a week $\quad \square$ More than once a day

\begin{tabular}{|c|c|c|c|c|c|c|c|c|c|}
\hline $\begin{array}{l}\text { The items below concern your feelings for the person that you identified at the top } \\
\text { of this page. With him or her in mind, decide how much you agree or disagree with } \\
\text { each item. On the scale directly to the right of each item, circle the number that } \\
\text { indicates how much you agree that the statement describes your feelings. There } \\
\text { are no right or wrong answers, because adults' feelings for people in their lives } \\
\text { differ from person to person. Just honestly describe your feelings for this person. }\end{array}$ & & & & & & $\begin{array}{l}\mathscr{a} \\
\frac{0}{D} \\
\mathbb{D}\end{array}$ & $\begin{array}{l}\mathscr{0} \\
\frac{0}{3} \\
\sum_{0}^{\infty} \\
\frac{1}{2}\end{array}$ & & \\
\hline 1. I am happy with my relationship with this person & -4 & -3 & -2 & -1 & 0 & 1 & 2 & 3 & 4 \\
\hline 2. I feel my relationship with this person is a great one & -4 & -3 & -2 & -1 & 0 & 1 & 2 & 3 & 4 \\
\hline 3. I am satisfied with my relationship with this person & -4 & -3 & -2 & -1 & 0 & 1 & 2 & 3 & 4 \\
\hline 4. I think that my relationship with this person is strong & -4 & -3 & -2 & -1 & 0 & 1 & 2 & 3 & 4 \\
\hline 5. I feel my relationship with this person is good & -4 & -3 & -2 & -1 & 0 & 1 & 2 & 3 & 4 \\
\hline 6. I am pleased with my relationship with this person & -4 & -3 & -2 & -1 & 0 & 1 & 2 & 3 & 4 \\
\hline 7. I am contented with my relationship with this person & -4 & -3 & -2 & -1 & 0 & 1 & 2 & 3 & 4 \\
\hline
\end{tabular}

\begin{tabular}{|c|c|c|c|c|c|c|}
\hline $\begin{array}{l}\text { The following is a list of behaviors that you may have engaged in with the person you described on the } \\
\text { top of this page. Think back over the last three months, and check the box that corresponds to the } \\
\text { approximate number of times that you have engaged in each of the following behaviors with this } \\
\text { person during the last three months. }\end{array}$ & 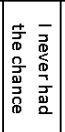 & $\begin{array}{l}0 \\
\text { 泀 } \\
0 \\
0\end{array}$ & 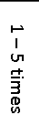 & 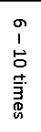 & 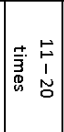 & 声㿣 \\
\hline \multicolumn{7}{|l|}{ 1. Confront this person if you saw them being insulting, grouchy, snapping, or ignoring their partner? } \\
\hline \multicolumn{7}{|l|}{ 2. Share information about abuse, and/or resources for victims of abuse with this person? } \\
\hline \multicolumn{7}{|l|}{ 3. Stick up for this person's partner if they were talking badly about them? } \\
\hline \multicolumn{7}{|l|}{ 4. Talk with this person about the effects of abuse on children? } \\
\hline \multicolumn{7}{|l|}{ 5. Ask this person why it's important to them to control their partner's behavior? } \\
\hline \multicolumn{7}{|l|}{ 6. Tell this person that they should think about going to Allies in Change or a similar program? } \\
\hline \multicolumn{7}{|l|}{ 7. Speak up against sexist jokes or jokes about abuse in front of this person? } \\
\hline \multicolumn{7}{|l|}{ 8. Share books or other materials from Allies in Change with this person? } \\
\hline \multicolumn{7}{|l|}{$\begin{array}{l}\text { 9. Tell this person that it makes you uncomfortable to hear them talk about abuse or act abusively } \\
\text { around you? }\end{array}$} \\
\hline \multicolumn{7}{|l|}{ 10. Object if this person was not being accountable for their abusive behavior? } \\
\hline \multicolumn{7}{|l|}{ 11. Talk with this person about consequences of being abusive? } \\
\hline \multicolumn{7}{|l|}{ 12. Share your story about abuse with this person? } \\
\hline \multicolumn{7}{|l|}{ 13. Tell this person that you go to Allies in Change? } \\
\hline \multicolumn{7}{|l|}{ 14. Make amends with this person for your abusive behavior? } \\
\hline \multicolumn{7}{|l|}{ 15. Apologize to this person for modeling abusive behavior in the past? } \\
\hline $\begin{array}{l}\text { 16. Have you used any other behaviors with this person that might have made them think about abuse? } \\
\text { If so, please describe them here. }\end{array}$ & & & & & & \\
\hline
\end{tabular}




\section{SOCIAL NETWORKS OF INTIMATE PARTNER VIOLENCE PERPETRATORS}

\begin{tabular}{|c|c|c|c|c|c|}
\hline $\begin{array}{l}\text { The following is a list of behaviors that the person you described on the other side of this page may } \\
\text { have engaged in during the last three months. Think back over the last three months, and check the } \\
\text { box that corresponds to the approximate number of times that this person has engaged in each } \\
\text { behavior during the last three months. }\end{array}$ & 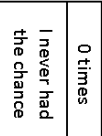 & 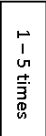 & 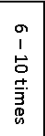 & 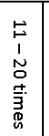 & 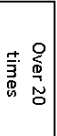 \\
\hline \multicolumn{6}{|l|}{ 17. Tell you that your partner is taking advantage of you or disrespecting you? } \\
\hline \multicolumn{6}{|l|}{ 18. Accuse your partner of trying to harm your relationship with your kids? } \\
\hline \multicolumn{6}{|l|}{ 19. Tell you that they wouldn't let their partner get away with the things that your partner does? } \\
\hline \multicolumn{6}{|l|}{ 20. Support you in being more accountable? } \\
\hline \multicolumn{6}{|l|}{ 21. Tell you that your partner's behavior justified your abuse? } \\
\hline \multicolumn{6}{|l|}{ 22. Refuse to accept that you were abusive in the past? } \\
\hline \multicolumn{6}{|l|}{$\begin{array}{l}\text { 23. Call their partner names; yell, scream or swear at their partner; act grouchy, snappy, or ignore their } \\
\text { partner in front of you? }\end{array}$} \\
\hline \multicolumn{6}{|l|}{ 24. Blame their partner for their problems? } \\
\hline \multicolumn{6}{|l|}{ 25. Give you advice about ways to be controlling or abusive towards your partner? } \\
\hline \multicolumn{6}{|l|}{ 26. Support you in taking legal action against your partner? } \\
\hline \multicolumn{6}{|l|}{ 27. Contact your partner to harass or monitor them? } \\
\hline \multicolumn{6}{|l|}{ 28. Make fun of you for trying to change your relationship with your partner? } \\
\hline \multicolumn{6}{|l|}{ 29. Point out effects of abuse on your children? } \\
\hline \multicolumn{6}{|l|}{ 30. Support your participation at Allies in Change? } \\
\hline \multicolumn{6}{|l|}{ 31. Try to make amends with you for their abusive behavior? } \\
\hline $\begin{array}{l}\text { 32. Has this person used any other behaviors that made you think about changing your abusive } \\
\text { behavior? If so, please describe them here. }\end{array}$ & & & & & \\
\hline
\end{tabular}




\section{SOCIAL NETWORKS OF INTIMATE PARTNER VIOLENCE PERPETRATORS}

\section{Contact \#4}

What is this person's gender? $\square$ Male $\square$ Female

What is your relationship to this person? (For example, are they your parent? Your boss or coworker? A friend from high school?)

How often do you usually spend time with this person, either in person, on the phone, or over the internet?

$\square$ Less than once a year $\square$ A few times a vear $\square$ Twice -3 times a month $\square$ Almost every day

About once a year $\square$ About every month $\square$ About once a week $\square$ More than once a day

\begin{tabular}{|c|c|c|c|c|c|c|c|c|c|}
\hline $\begin{array}{l}\text { The items below concern your feelings for the person that you identified at the top } \\
\text { of this page. With him or her in mind, decide how much you agree or disagree with } \\
\text { each item. On the scale directly to the right of each item, circle the number that } \\
\text { indicates how much you agree that the statement describes your feelings. There } \\
\text { are no right or wrong answers, because adults' feelings for people in their lives } \\
\text { differ from person to person. Just honestly describe your feelings for this person. }\end{array}$ & & & & & & & 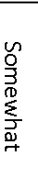 & & \\
\hline 1. I am happy with my relationship with this person & -4 & -3 & -2 & -1 & 0 & 1 & 2 & 3 & 4 \\
\hline 2. I feel my relationship with this person is a great one & -4 & -3 & -2 & -1 & 0 & 1 & 2 & 3 & 4 \\
\hline 3. I am satisfied with my relationship with this person & -4 & -3 & -2 & -1 & 0 & 1 & 2 & 3 & 4 \\
\hline 4. I think that my relationship with this person is strong & -4 & -3 & -2 & -1 & 0 & 1 & 2 & 3 & 4 \\
\hline 5. I feel my relationship with this person is good & -4 & -3 & -2 & -1 & 0 & 1 & 2 & 3 & 4 \\
\hline 6. I am pleased with my relationship with this person & -4 & -3 & -2 & -1 & 0 & 1 & 2 & 3 & 4 \\
\hline 7. I am contented with my relationship with this person & -4 & -3 & -2 & -1 & 0 & 1 & 2 & 3 & 4 \\
\hline
\end{tabular}

\begin{tabular}{|c|c|c|c|c|c|c|}
\hline $\begin{array}{l}\text { The following is a list of behaviors that you may have engaged in with the person you described on the } \\
\text { top of this page. Think back over the last three months, and check the box that corresponds to the } \\
\text { approximate number of times that you have engaged in each of the following behaviors with this } \\
\text { person during the last three months. }\end{array}$ & 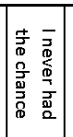 & 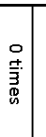 & $\begin{array}{l}\omega \\
1 \\
v \\
w \\
5 \\
\mathbb{5} \\
0\end{array}$ & $\begin{array}{l}0 \\
1 \\
1 \\
0 \\
0 \\
\pm \\
\overline{3} \\
0 \\
0\end{array}$ & 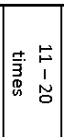 & 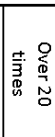 \\
\hline \multicolumn{7}{|l|}{ 1. Confront this person if you saw them being insulting, grouchy, snapping, or ignoring their partner? } \\
\hline \multicolumn{7}{|l|}{ 2. Share information about abuse, and/or resources for victims of abuse with this person? } \\
\hline \multicolumn{7}{|l|}{ 3. Stick up for this person's partner if they were talking badly about them? } \\
\hline \multicolumn{7}{|l|}{ 4. Talk with this person about the effects of abuse on children? } \\
\hline \multicolumn{7}{|l|}{ 5. Ask this person why it's important to them to control their partner's behavior? } \\
\hline \multicolumn{7}{|l|}{ 6. Tell this person that they should think about going to Allies in Change or a similar program? } \\
\hline \multicolumn{7}{|l|}{ 7. Speak up against sexist jokes or jokes about abuse in front of this person? } \\
\hline \multicolumn{7}{|l|}{ 8. Share books or other materials from Allies in Change with this person? } \\
\hline \multicolumn{7}{|l|}{$\begin{array}{l}\text { 9. Tell this person that it makes you uncomfortable to hear them talk about abuse or act abusively } \\
\text { around you? }\end{array}$} \\
\hline \multicolumn{7}{|l|}{ 10. Object if this person was not being accountable for their abusive behavior? } \\
\hline \multicolumn{7}{|l|}{ 11. Talk with this person about consequences of being abusive? } \\
\hline \multicolumn{7}{|l|}{ 12. Share your story about abuse with this person? } \\
\hline \multicolumn{7}{|l|}{ 13. Tell this person that you go to Allies in Change? } \\
\hline \multicolumn{7}{|l|}{ 14. Make amends with this person for your abusive behavior? } \\
\hline \multicolumn{7}{|l|}{ 15. Apologize to this person for modeling abusive behavior in the past? } \\
\hline $\begin{array}{l}\text { 16. Have you used any other behaviors with this person that might have made them think about abuse? } \\
\text { If so, please describe them here. }\end{array}$ & & & & & & \\
\hline
\end{tabular}




\section{SOCIAL NETWORKS OF INTIMATE PARTNER VIOLENCE PERPETRATORS}

\begin{tabular}{|c|c|c|c|c|c|c|}
\hline $\begin{array}{l}\text { The following is a list of behaviors that the person you described on the other side of this page may } \\
\text { have engaged in during the last three months. Think back over the last three months, and check the } \\
\text { box that corresponds to the approximate number of times that this person has engaged in each } \\
\text { behavior during the last three months. }\end{array}$ & 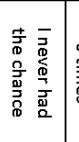 & 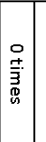 & 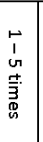 & 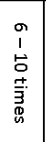 & 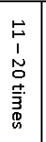 & 急: \\
\hline \multicolumn{7}{|l|}{ 17. Tell you that your partner is taking advantage of you or disrespecting you? } \\
\hline \multicolumn{7}{|l|}{ 18. Accuse your partner of trying to harm your relationship with your kids? } \\
\hline \multicolumn{7}{|l|}{ 19. Tell you that they wouldn't let their partner get away with the things that your partner does? } \\
\hline \multicolumn{7}{|l|}{ 20. Support you in being more accountable? } \\
\hline \multicolumn{7}{|l|}{ 21. Tell you that your partner's behavior justified your abuse? } \\
\hline \multicolumn{7}{|l|}{ 22. Refuse to accept that you were abusive in the past? } \\
\hline \multicolumn{7}{|l|}{$\begin{array}{l}\text { 23. Call their partner names; yell, scream or swear at their partner; act grouchy, snappy, or ignore their } \\
\text { partner in front of you? }\end{array}$} \\
\hline \multicolumn{7}{|l|}{ 24. Blame their partner for their problems? } \\
\hline \multicolumn{7}{|l|}{ 25. Give you advice about ways to be controlling or abusive towards your partner? } \\
\hline \multicolumn{7}{|l|}{ 26. Support you in taking legal action against your partner? } \\
\hline \multicolumn{7}{|l|}{ 27. Contact your partner to harass or monitor them? } \\
\hline \multicolumn{7}{|l|}{ 28. Make fun of you for trying to change your relationship with your partner? } \\
\hline \multicolumn{7}{|l|}{ 29. Point out effects of abuse on your children? } \\
\hline \multicolumn{7}{|l|}{ 30. Support your participation at Allies in Change? } \\
\hline \multicolumn{7}{|l|}{ 31. Try to make amends with you for their abusive behavior? } \\
\hline $\begin{array}{l}\text { 32. Has this person used any other behaviors that made you think about changing your abusive } \\
\text { behavior? If so, please describe them here. }\end{array}$ & & & & & & \\
\hline
\end{tabular}




\section{SOCIAL NETWORKS OF INTIMATE PARTNER VIOLENCE PERPETRATORS}

\section{Contact \#5}

What is this person's gender? $\square$ Male $\square$ Female

What is your relationship to this person? (For example, are they your parent? Your boss or coworker? A friend from high school?)

How often do you usually spend time with this person, either in person, on the phone, or over the internet?

$\square$ Less than once a year $\square$ A few times a year $\square$ Twice - 3 times a month $\square$ Almost every day

$\square$ About once a year $\square$ About every month $\square$ About once a week $\square$ More than once a day

\begin{tabular}{|c|c|c|c|c|c|c|c|c|c|}
\hline $\begin{array}{l}\text { The items below concern your feelings for the person that you identified at the top } \\
\text { of this page. With him or her in mind, decide how much you agree or disagree with } \\
\text { each item. On the scale directly to the right of each item, circle the number that } \\
\text { indicates how much you agree that the statement describes your feelings. There } \\
\text { are no right or wrong answers, because adults' feelings for people in their lives } \\
\text { differ from person to person. Just honestly describe your feelings for this person. }\end{array}$ & & & & & & & & & \\
\hline 1. I am happy with my relationship with this person & -4 & -3 & -2 & -1 & 0 & 1 & 2 & 3 & 4 \\
\hline 2. I feel my relationship with this person is a great one & -4 & -3 & -2 & -1 & 0 & 1 & 2 & 3 & 4 \\
\hline 3. I am satisfied with my relationship with this person & -4 & -3 & -2 & -1 & 0 & 1 & 2 & 3 & 4 \\
\hline 4. I think that my relationship with this person is strong & -4 & -3 & -2 & -1 & 0 & 1 & 2 & 3 & 4 \\
\hline 5. I feel my relationship with this person is good & -4 & -3 & -2 & -1 & 0 & 1 & 2 & 3 & 4 \\
\hline 6. I am pleased with my relationship with this person & -4 & -3 & -2 & -1 & 0 & 1 & 2 & 3 & 4 \\
\hline 7. I am contented with my relationship with this person & -4 & -3 & -2 & -1 & 0 & 1 & 2 & 3 & 4 \\
\hline
\end{tabular}

The following is a list of behaviors that you may have engaged in with the person you described on the top of this page. Think back over the last three months, and check the box that corresponds to the approximate number of times that you have engaged in each of the following behaviors with this person during the last three months.

1. Confront this person if you saw them being insulting, grouchy, snapping, or ignoring their partner?

2. Share information about abuse, and/or resources for victims of abuse with this person?

3. Stick up for this person's partner if they were talking badly about them?

4. Talk with this person about the effects of abuse on children?

5. Ask this person why it's important to them to control their partner's behavior?

6. Tell this person that they should think about going to Allies in Change or a similar program?

7. Speak up against sexist jokes or jokes about abuse in front of this person?

8. Share books or other materials from Allies in Change with this person?

9. Tell this person that it makes you uncomfortable to hear them talk about abuse or act abusively around you?

10. Object if this person was not being accountable for their abusive behavior?

11. Talk with this person about consequences of being abusive?

12. Share your story about abuse with this person?

13. Tell this person that you go to Allies in Change?

14. Make amends with this person for your abusive behavior?

15. Apologize to this person for modeling abusive behavior in the past?

16. Have you used any other behaviors with this person that might have made them think about abuse? If so, please describe them here. 


\section{SOCIAL NETWORKS OF INTIMATE PARTNER VIOLENCE PERPETRATORS}

\begin{tabular}{|c|c|c|c|c|c|c|}
\hline $\begin{array}{l}\text { The following is a list of behaviors that the person you described on the other side of this page may } \\
\text { have engaged in during the last three months. Think back over the last three months, and check the } \\
\text { box that corresponds to the approximate number of times that this person has engaged in each } \\
\text { behavior during the last three months. }\end{array}$ & 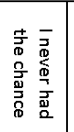 & 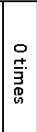 & 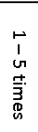 & 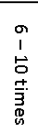 & 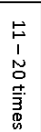 & 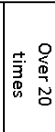 \\
\hline \multicolumn{7}{|l|}{ 17. Tell you that your partner is taking advantage of you or disrespecting you? } \\
\hline \multicolumn{7}{|l|}{ 18. Accuse your partner of trying to harm your relationship with your kids? } \\
\hline \multicolumn{7}{|l|}{ 19. Tell you that they wouldn't let their partner get away with the things that your partner does? } \\
\hline \multicolumn{7}{|l|}{ 20. Support you in being more accountable? } \\
\hline \multicolumn{7}{|l|}{ 21. Tell you that your partner's behavior justified your abuse? } \\
\hline \multicolumn{7}{|l|}{ 22. Refuse to accept that you were abusive in the past? } \\
\hline \multicolumn{7}{|l|}{$\begin{array}{l}\text { 23. Call their partner names; yell, scream or swear at their partner; act grouchy, snappy, or ignore their } \\
\text { partner in front of you? }\end{array}$} \\
\hline \multicolumn{7}{|l|}{ 24. Blame their partner for their problems? } \\
\hline \multicolumn{7}{|l|}{ 25. Give you advice about ways to be controlling or abusive towards your partner? } \\
\hline \multicolumn{7}{|l|}{ 26. Support you in taking legal action against your partner? } \\
\hline \multicolumn{7}{|l|}{ 27. Contact your partner to harass or monitor them? } \\
\hline \multicolumn{7}{|l|}{ 28. Make fun of you for trying to change your relationship with your partner? } \\
\hline \multicolumn{7}{|l|}{ 29. Point out effects of abuse on your children? } \\
\hline \multicolumn{7}{|l|}{ 30. Support your participation at Allies in Change? } \\
\hline \multicolumn{7}{|l|}{ 31. Try to make amends with you for their abusive behavior? } \\
\hline $\begin{array}{l}\text { 32. Has this person used any other behaviors that made you think about changing your abusive } \\
\text { behavior? If so, please describe them here. }\end{array}$ & & & & & & \\
\hline
\end{tabular}




\section{SOCIAL NETWORKS OF INTIMATE PARTNER VIOLENCE PERPETRATORS}

\section{Contact \#6}

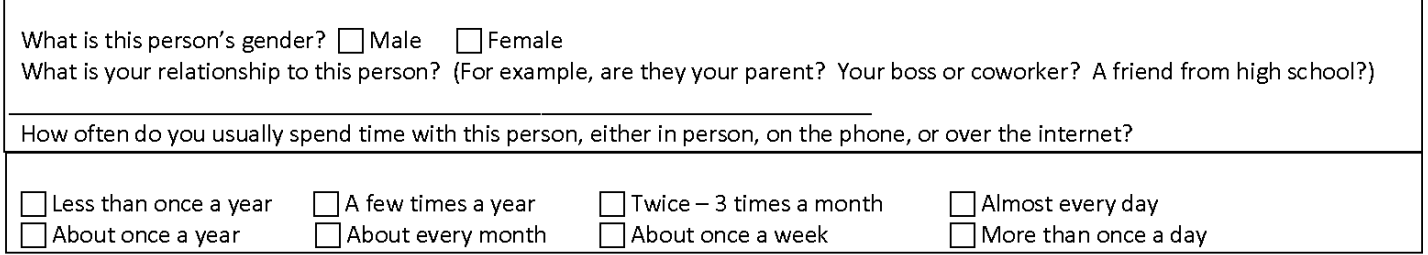

\begin{tabular}{|c|c|c|c|c|c|c|c|c|c|}
\hline $\begin{array}{l}\text { The items below concern your feelings for the person that you identified at the top } \\
\text { of this page. With him or her in mind, decide how much you agree or disagree with } \\
\text { each item. On the scale directly to the right of each item, circle the number that } \\
\text { indicates how much you agree that the statement describes your feelings. There } \\
\text { are no right or wrong answers, because adults' feelings for people in their lives } \\
\text { differ from person to person. Just honestly describe your feelings for this person. }\end{array}$ & & & & & & 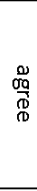 & & & \\
\hline 1. I am happy with my relationship with this person & -4 & -3 & -2 & -1 & 0 & 1 & 2 & 3 & 4 \\
\hline 2. I feel my relationship with this person is a great one & -4 & -3 & -2 & -1 & 0 & 1 & 2 & 3 & 4 \\
\hline 3. I am satisfied with my relationship with this person & -4 & -3 & -2 & -1 & 0 & 1 & 2 & 3 & 4 \\
\hline 4. I think that my relationship with this person is strong & -4 & -3 & -2 & -1 & 0 & 1 & 2 & 3 & 4 \\
\hline 5. I feel my relationship with this person is good & -4 & -3 & -2 & -1 & 0 & 1 & 2 & 3 & 4 \\
\hline 6. I am pleased with my relationship with this person & -4 & -3 & -2 & -1 & 0 & 1 & 2 & 3 & 4 \\
\hline 7. I am contented with my relationship with this person & -4 & -3 & -2 & -1 & 0 & 1 & 2 & 3 & 4 \\
\hline
\end{tabular}

\begin{tabular}{|c|c|c|c|c|c|c|}
\hline $\begin{array}{l}\text { The following is a list of behaviors that you may have engaged in with the person you described on the } \\
\text { top of this page. Think back over the last three months, and check the box that corresponds to the } \\
\text { approximate number of times that you have engaged in each of the following behaviors with this } \\
\text { person during the last three months. }\end{array}$ & 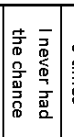 & $\begin{array}{l}\circ \\
\stackrel{ \pm}{3} \\
\stackrel{3}{0} \\
0\end{array}$ & $\begin{array}{l}\mapsto \\
1 \\
v \\
\overrightarrow{3} \\
0 \\
0\end{array}$ & $\begin{array}{l}0 \\
1 \\
1 \\
5 \\
0 \\
\overline{3} \\
0 \\
0\end{array}$ & 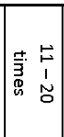 & 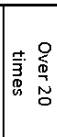 \\
\hline \multicolumn{7}{|l|}{ 1. Confront this person if you saw them being insulting, grouchy, snapping, or ignoring their partner? } \\
\hline \multicolumn{7}{|l|}{ 2. Share information about abuse, and/or resources for victims of abuse with this person? } \\
\hline \multicolumn{7}{|l|}{ 3. Stick up for this person's partner if they were talking badly about them? } \\
\hline \multicolumn{7}{|l|}{ 4. Talk with this person about the effects of abuse on children? } \\
\hline \multicolumn{7}{|l|}{ 5. Ask this person why it's important to them to control their partner's behavior? } \\
\hline \multicolumn{7}{|l|}{ 6. Tell this person that they should think about going to Allies in Change or a similar program? } \\
\hline \multicolumn{7}{|l|}{ 7. Speak up against sexist jokes or jokes about abuse in front of this person? } \\
\hline \multicolumn{7}{|l|}{ 8. Share books or other materials from Allies in Change with this person? } \\
\hline \multicolumn{7}{|l|}{$\begin{array}{l}\text { 9. Tell this person that it makes you uncomfortable to hear them talk about abuse or act abusively } \\
\text { around you? }\end{array}$} \\
\hline \multicolumn{7}{|l|}{ 10. Object if this person was not being accountable for their abusive behavior? } \\
\hline \multicolumn{7}{|l|}{ 11. Talk with this person about consequences of being abusive? } \\
\hline \multicolumn{7}{|l|}{ 12. Share your story about abuse with this person? } \\
\hline \multicolumn{7}{|l|}{ 13. Tell this person that you go to Allies in Change? } \\
\hline \multicolumn{7}{|l|}{ 14. Make amends with this person for your abusive behavior? } \\
\hline \multicolumn{7}{|l|}{ 15. Apologize to this person for modeling abusive behavior in the past? } \\
\hline $\begin{array}{l}\text { 16. Have you used any other behaviors with this person that might have made them think about abuse? } \\
\text { If so, please describe them here. }\end{array}$ & & & & & & \\
\hline
\end{tabular}




\section{SOCIAL NETWORKS OF INTIMATE PARTNER VIOLENCE PERPETRATORS}

\begin{tabular}{|c|c|c|c|c|c|}
\hline $\begin{array}{l}\text { The following is a list of behaviors that the person you described on the other side of this page may } \\
\text { have engaged in during the last three months. Think back over the last three months, and check the } \\
\text { box that corresponds to the approximate number of times that this person has engaged in each } \\
\text { behavior during the last three months. }\end{array}$ & 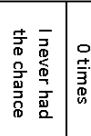 & 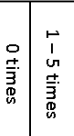 & 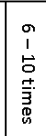 & 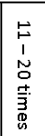 & 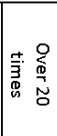 \\
\hline \multicolumn{6}{|l|}{ 17. Tell you that your partner is taking advantage of you or disrespecting you? } \\
\hline \multicolumn{6}{|l|}{ 18. Accuse your partner of trying to harm your relationship with your kids? } \\
\hline \multicolumn{6}{|l|}{ 19. Tell you that they wouldn't let their partner get away with the things that your partner does? } \\
\hline \multicolumn{6}{|l|}{ 20. Support you in being more accountable? } \\
\hline \multicolumn{6}{|l|}{ 21. Tell you that your partner's behavior justified your abuse? } \\
\hline \multicolumn{6}{|l|}{ 22. Refuse to accept that you were abusive in the past? } \\
\hline \multicolumn{6}{|l|}{$\begin{array}{l}\text { 23. Call their partner names; yell, scream or swear at their partner; act grouchy, snappy, or ignore their } \\
\text { partner in front of you? }\end{array}$} \\
\hline \multicolumn{6}{|l|}{ 24. Blame their partner for their problems? } \\
\hline \multicolumn{6}{|l|}{ 25. Give you advice about ways to be controlling or abusive towards your partner? } \\
\hline \multicolumn{6}{|l|}{ 26. Support you in taking legal action against your partner? } \\
\hline \multicolumn{6}{|l|}{ 27. Contact your partner to harass or monitor them? } \\
\hline \multicolumn{6}{|l|}{ 28. Make fun of you for trying to change your relationship with your partner? } \\
\hline \multicolumn{6}{|l|}{ 29. Point out effects of abuse on your children? } \\
\hline \multicolumn{6}{|l|}{ 30. Support your participation at Allies in Change? } \\
\hline \multicolumn{6}{|l|}{ 31. Try to make amends with you for their abusive behavior? } \\
\hline $\begin{array}{l}\text { 32. Has this person used any other behaviors that made you think about changing your abusive } \\
\text { behavior? If so, please describe them here. }\end{array}$ & & & & & \\
\hline
\end{tabular}




\section{SOCIAL NETWORKS OF INTIMATE PARTNER VIOLENCE PERPETRATORS}

\begin{tabular}{|c|c|c|c|c|c|c|c|c|c|}
\hline \multicolumn{10}{|c|}{$\begin{array}{l}\text { What is this person's gender? } \square \text { Male } \square \text { Female } \\
\text { What is your relationship to this person? (For example, are they your parent? Your boss or coworker? A friend from high school?) }\end{array}$} \\
\hline \multicolumn{10}{|c|}{ How often do you usually spend time with this person, either in person, on the phone, or over the internet? } \\
\hline 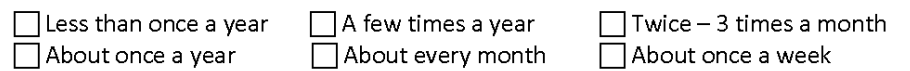 & \multicolumn{9}{|c|}{$\begin{array}{l}\square \text { Almost every day } \\
\square \text { More than once a day }\end{array}$} \\
\hline $\begin{array}{l}\text { The items below concern your feelings for the person that you identified at the top } \\
\text { of this page. With him or her in mind, decide how much you agree or disagree with } \\
\text { each item. On the scale directly to the right of each item, circle the number that } \\
\text { indicates how much you agree that the statement describes your feelings. There } \\
\text { are no right or wrong answers, because adults' feelings for people in their lives } \\
\text { differ from person to person. Just honestly describe your feelings for this person. }\end{array}$ & \multicolumn{2}{|c|}{ 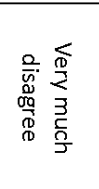 } & \multicolumn{2}{|c|}{ 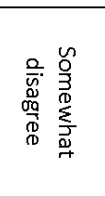 } & \multicolumn{3}{|c|}{ 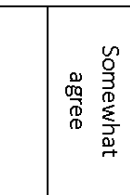 } & \multicolumn{2}{|c|}{ 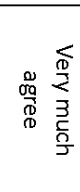 } \\
\hline 1. I am happy with my relationship with this person & -4 & -3 & -2 & -1 & 0 & 1 & 2 & 3 & 4 \\
\hline 2. I feel my relationship with this person is a great one & -4 & -3 & -2 & -1 & 0 & 1 & 2 & 3 & 4 \\
\hline 3. I am satisfied with my relationship with this person & -4 & -3 & -2 & -1 & 0 & 1 & 2 & 3 & 4 \\
\hline 4. I think that my relationship with this person is strong & -4 & -3 & -2 & -1 & 0 & 1 & 2 & 3 & 4 \\
\hline 5. I feel my relationship with this person is good & -4 & -3 & -2 & -1 & 0 & 1 & 2 & 3 & 4 \\
\hline 6. I am pleased with my relationship with this person & -4 & -3 & -2 & -1 & 0 & 1 & 2 & 3 & 4 \\
\hline 7. I am contented with my relationship with this person & -4 & -3 & -2 & -1 & 0 & 1 & 2 & 3 & 4 \\
\hline
\end{tabular}

\begin{tabular}{|c|c|c|c|c|c|}
\hline $\begin{array}{l}\text { The following is a list of behaviors that you may have engaged in with the person you described on the } \\
\text { top of this page. Think back over the last three months, and check the box that corresponds to the } \\
\text { approximate number of times that you have engaged in each of the following behaviors with this } \\
\text { person during the last three months. }\end{array}$ & 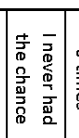 & & 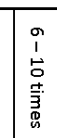 & 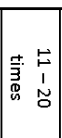 & 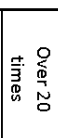 \\
\hline \multicolumn{6}{|l|}{ 1. Confront this person if you saw them being insulting, grouchy, snapping, or ignoring their partner? } \\
\hline \multicolumn{6}{|l|}{ 2. Share information about abuse, and/or resources for victims of abuse with this person? } \\
\hline \multicolumn{6}{|l|}{ 3. Stick up for this person's partner if they were talking badly about them? } \\
\hline \multicolumn{6}{|l|}{ 4. Talk with this person about the effects of abuse on children? } \\
\hline \multicolumn{6}{|l|}{ 5. Ask this person why it's important to them to control their partner's behavior? } \\
\hline \multicolumn{6}{|l|}{ 6. Tell this person that they should think about going to Allies in Change or a similar program? } \\
\hline \multicolumn{6}{|l|}{ 7. Speak up against sexist jokes or jokes about abuse in front of this person? } \\
\hline \multicolumn{6}{|l|}{ 8. Share books or other materials from Allies in Change with this person? } \\
\hline \multicolumn{6}{|l|}{$\begin{array}{l}\text { 9. Tell this person that it makes you uncomfortable to hear them talk about abuse or act abusively } \\
\text { around you? }\end{array}$} \\
\hline \multicolumn{6}{|l|}{ 10. Object if this person was not being accountable for their abusive behavior? } \\
\hline \multicolumn{6}{|l|}{ 11. Talk with this person about consequences of being abusive? } \\
\hline \multicolumn{6}{|l|}{ 12. Share your story about abuse with this person? } \\
\hline \multicolumn{6}{|l|}{ 13. Tell this person that you go to Allies in Change? } \\
\hline \multicolumn{6}{|l|}{ 14. Make amends with this person for your abusive behavior? } \\
\hline \multicolumn{6}{|l|}{ 15. Apologize to this person for modeling abusive behavior in the past? } \\
\hline $\begin{array}{l}\text { 16. Have you used any other behaviors with this person that might have made them think about abuse? } \\
\text { If so, please describe them here. }\end{array}$ & & & & & \\
\hline
\end{tabular}




\section{SOCIAL NETWORKS OF INTIMATE PARTNER VIOLENCE PERPETRATORS}

\begin{tabular}{|c|c|c|c|c|c|c|}
\hline $\begin{array}{l}\text { The following is a list of behaviors that the person you described on the other side of this page may } \\
\text { have engaged in during the last three months. Think back over the last three months, and check the } \\
\text { box that corresponds to the approximate number of times that this person has engaged in each } \\
\text { behavior during the last three months. }\end{array}$ & 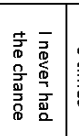 & 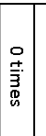 & 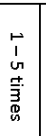 & 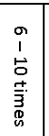 & 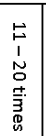 & ). \\
\hline \multicolumn{7}{|l|}{ 17. Tell you that your partner is taking advantage of you or disrespecting you? } \\
\hline \multicolumn{7}{|l|}{ 18. Accuse your partner of trying to harm your relationship with your kids? } \\
\hline \multicolumn{7}{|l|}{ 19. Tell you that they wouldn't let their partner get away with the things that your partner does? } \\
\hline \multicolumn{7}{|l|}{ 20. Support you in being more accountable? } \\
\hline \multicolumn{7}{|l|}{ 21. Tell you that your partner's behavior justified your abuse? } \\
\hline \multicolumn{7}{|l|}{ 22. Refuse to accept that you were abusive in the past? } \\
\hline \multicolumn{7}{|l|}{$\begin{array}{l}\text { 23. Call their partner names; yell, scream or swear at their partner; act grouchy, snappy, or ignore their } \\
\text { partner in front of you? }\end{array}$} \\
\hline \multicolumn{7}{|l|}{ 24. Blame their partner for their problems? } \\
\hline \multicolumn{7}{|l|}{ 25. Give you advice about ways to be controlling or abusive towards your partner? } \\
\hline \multicolumn{7}{|l|}{ 26. Support you in taking legal action against your partner? } \\
\hline \multicolumn{7}{|l|}{ 27. Contact your partner to harass or monitor them? } \\
\hline \multicolumn{7}{|l|}{ 28. Make fun of you for trying to change your relationship with your partner? } \\
\hline \multicolumn{7}{|l|}{ 29. Point out effects of abuse on your children? } \\
\hline \multicolumn{7}{|l|}{ 30. Support your participation at All ies in Change? } \\
\hline \multicolumn{7}{|l|}{ 31. Try to make amends with you for their abusive behavior? } \\
\hline $\begin{array}{l}\text { 32. Has this person used any other behaviors that made you think about changing your abusive } \\
\text { behavior? If so, please describe them here. }\end{array}$ & & & & & & \\
\hline
\end{tabular}




\section{SOCIAL NETWORKS OF INTIMATE PARTNER VIOLENCE PERPETRATORS}

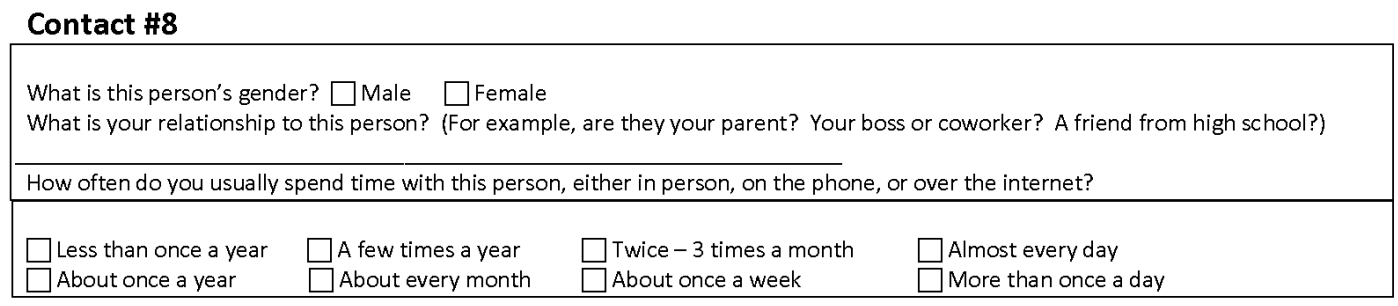

\begin{tabular}{|c|c|c|c|c|c|c|c|c|c|}
\hline $\begin{array}{l}\text { The items below concern your feelings for the person that you identified at the top } \\
\text { of this page. With him or her in mind, decide how much you agree or disagree with } \\
\text { each item. On the scale directly to the right of each item, circle the number that } \\
\text { indicates how much you agree that the statement describes your feelings. There } \\
\text { are no right or wrong answers, because adults' feelings for people in their lives } \\
\text { differ from person to person. Just honestly describe your feelings for this person. }\end{array}$ & & & & & & & 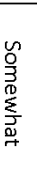 & & \\
\hline 1. I am happy with my relationship with this person & -4 & -3 & -2 & -1 & 0 & 1 & 2 & 3 & 4 \\
\hline 2. I feel my relationship with this person is a great one & -4 & -3 & -2 & -1 & 0 & 1 & 2 & 3 & 4 \\
\hline 3. I am satisfied with my relationship with this person & -4 & -3 & -2 & -1 & 0 & 1 & 2 & 3 & 4 \\
\hline 4. I think that my relationship with this person is strong & -4 & -3 & -2 & -1 & 0 & 1 & 2 & 3 & 4 \\
\hline 5. I feel my relationship with this person is good & -4 & -3 & -2 & -1 & 0 & 1 & 2 & 3 & 4 \\
\hline 6. I am pleased with my relationship with this person & -4 & -3 & -2 & -1 & 0 & 1 & 2 & 3 & 4 \\
\hline 7. I am contented with my relationship with this person & -4 & -3 & -2 & -1 & 0 & 1 & 2 & 3 & 4 \\
\hline
\end{tabular}

\begin{tabular}{|c|c|c|c|c|c|}
\hline $\begin{array}{l}\text { The following is a list of behaviors that you may have engaged in with the person you described on the } \\
\text { top of this page. Think back over the last three months, and check the box that corresponds to the } \\
\text { approximate number of times that you have engaged in each of the following behaviors with this } \\
\text { person during the last three months. }\end{array}$ & 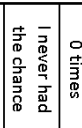 & 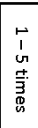 & 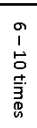 & 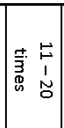 & 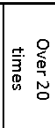 \\
\hline \multicolumn{6}{|l|}{ 1. Confront this person if you saw them being insulting, grouchy, snapping, or ignoring their partner? } \\
\hline \multicolumn{6}{|l|}{ 2. Share information about abuse, and/or resources for victims of abuse with this person? } \\
\hline \multicolumn{6}{|l|}{ 3. Stick up for this person's partner if they were talking badly about them? } \\
\hline \multicolumn{6}{|l|}{ 4. Talk with this person about the effects of abuse on children? } \\
\hline \multicolumn{6}{|l|}{ 5. Ask this person why it's important to them to control their partner's behavior? } \\
\hline \multicolumn{6}{|l|}{ 6. Tell this person that they should think about going to Allies in Change or a similar program? } \\
\hline \multicolumn{6}{|l|}{ 7. Speak up against sexist jokes or jokes about abuse in front of this person? } \\
\hline \multicolumn{6}{|l|}{ 8. Share books or other materials from Allies in Change with this person? } \\
\hline \multicolumn{6}{|l|}{$\begin{array}{l}\text { 9. Tell this person that it makes you uncomfortable to hear them talk about abuse or act abusively } \\
\text { around you? }\end{array}$} \\
\hline \multicolumn{6}{|l|}{ 10. Object if this person was not being accountable for their abusive behavior? } \\
\hline \multicolumn{6}{|l|}{ 11. Talk with this person about consequences of being abusive? } \\
\hline \multicolumn{6}{|l|}{ 12. Share your story about abuse with this person? } \\
\hline \multicolumn{6}{|l|}{ 13. Tell this person that you go to Allies in Change? } \\
\hline \multicolumn{6}{|l|}{ 14. Make amends with this person for your abusive behavior? } \\
\hline \multicolumn{6}{|l|}{ 15. Apologize to this person for modeling abusive behavior in the past? } \\
\hline $\begin{array}{l}\text { 16. Have you used any other behaviors with this person that might have made them think about abuse? } \\
\text { If so, please describe them here. }\end{array}$ & & & & & \\
\hline
\end{tabular}




\section{SOCIAL NETWORKS OF INTIMATE PARTNER VIOLENCE PERPETRATORS}

\begin{tabular}{|c|c|c|c|c|c|}
\hline $\begin{array}{l}\text { The following is a list of behaviors that the person you described on the other side of this page may } \\
\text { have engaged in during the last three months. Think back over the last three months, and check the } \\
\text { box that corresponds to the approximate number of times that this person has engaged in each } \\
\text { behavior during the last three months. }\end{array}$ & 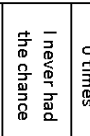 & 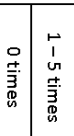 & 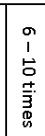 & 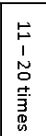 & 声: \\
\hline \multicolumn{6}{|l|}{ 17. Tell you that your partner is taking advantage of you or disrespecting you? } \\
\hline \multicolumn{6}{|l|}{ 18. Accuse your partner of trying to harm your relationship with your kids? } \\
\hline \multicolumn{6}{|l|}{ 19. Tell you that they wouldn't let their partner get away with the things that your partner does? } \\
\hline \multicolumn{6}{|l|}{ 20. Support you in being more accountable? } \\
\hline \multicolumn{6}{|l|}{ 21. Tell you that your partner's behavior justified your abuse? } \\
\hline \multicolumn{6}{|l|}{ 22. Refuse to accept that you were abusive in the past? } \\
\hline \multicolumn{6}{|l|}{$\begin{array}{l}\text { 23. Call their partner names; yell, scream or swear at their partner; act grouchy, snappy, or ignore their } \\
\text { partner in front of you? }\end{array}$} \\
\hline \multicolumn{6}{|l|}{ 24. Blame their partner for their problems? } \\
\hline \multicolumn{6}{|l|}{ 25. Give you advice about ways to be controlling or abusive towards your partner? } \\
\hline \multicolumn{6}{|l|}{ 26. Support you in taking legal action against your partner? } \\
\hline \multicolumn{6}{|l|}{ 27. Contact your partner to harass or monitor them? } \\
\hline \multicolumn{6}{|l|}{ 28. Make fun of you for trying to change your relationship with your partner? } \\
\hline \multicolumn{6}{|l|}{ 29. Point out effects of abuse on your children? } \\
\hline \multicolumn{6}{|l|}{ 30. Support your participation at Allies in Change? } \\
\hline \multicolumn{6}{|l|}{ 31. Try to make amends with you for their abusive behavior? } \\
\hline $\begin{array}{l}\text { 32. Has this person used any other behaviors that made you think about changing your abusive } \\
\text { behavior? If so, please describe them here. }\end{array}$ & & & & & \\
\hline
\end{tabular}




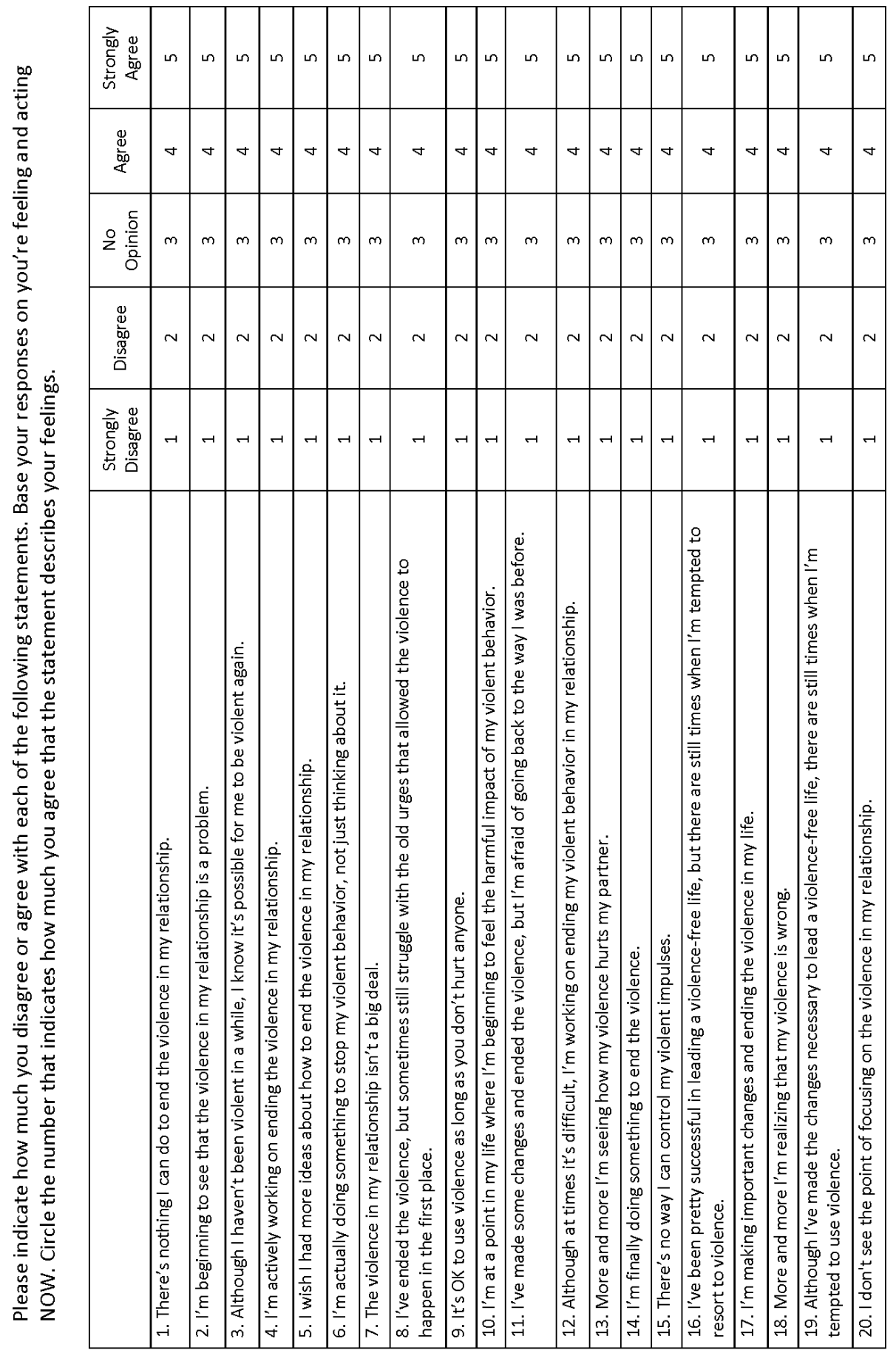




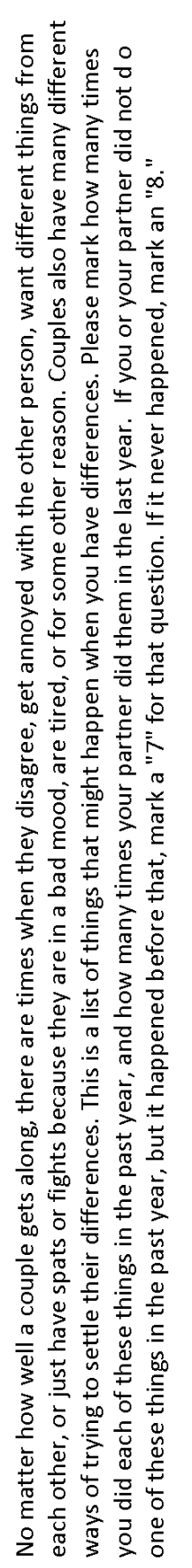

\begin{tabular}{|c|c|c|c|c|c|}
\hline 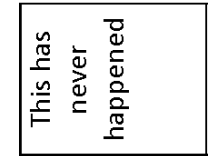 & $\infty$ & $\infty$ & $\infty$ & $\infty$ & $\infty$ \\
\hline 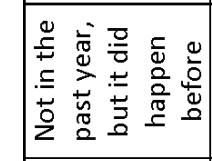 & r & r & r & $\wedge$ & $r$ \\
\hline 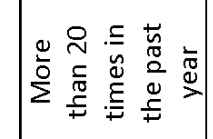 & 0 & 0 & 0 & 0 & 0 \\
\hline 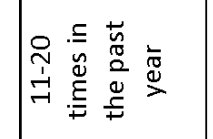 & n & in & in & in & in \\
\hline 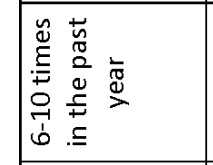 & $\sigma$ & $\sigma$ & $\sigma$ & 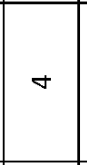 & $\sigma$ \\
\hline 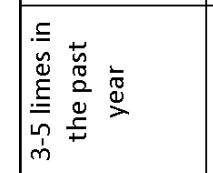 & $m$ & $m$ & $m$ & $m$ & $m$ \\
\hline 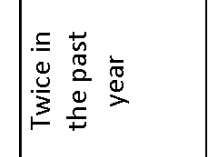 & $\sim$ & $\sim$ & $\sim$ & $\sim$ & $\sim$ \\
\hline \multirow[t]{2}{*}{ 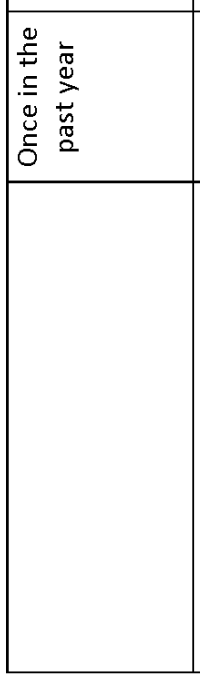 } & $r$ & $r$ & $\rightarrow$ & - & $r$ \\
\hline & 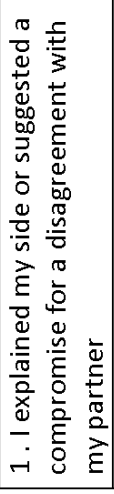 & 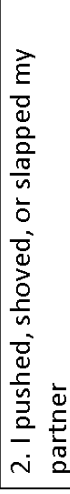 & 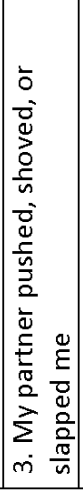 & 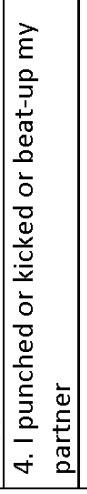 & 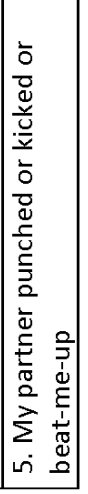 \\
\hline
\end{tabular}




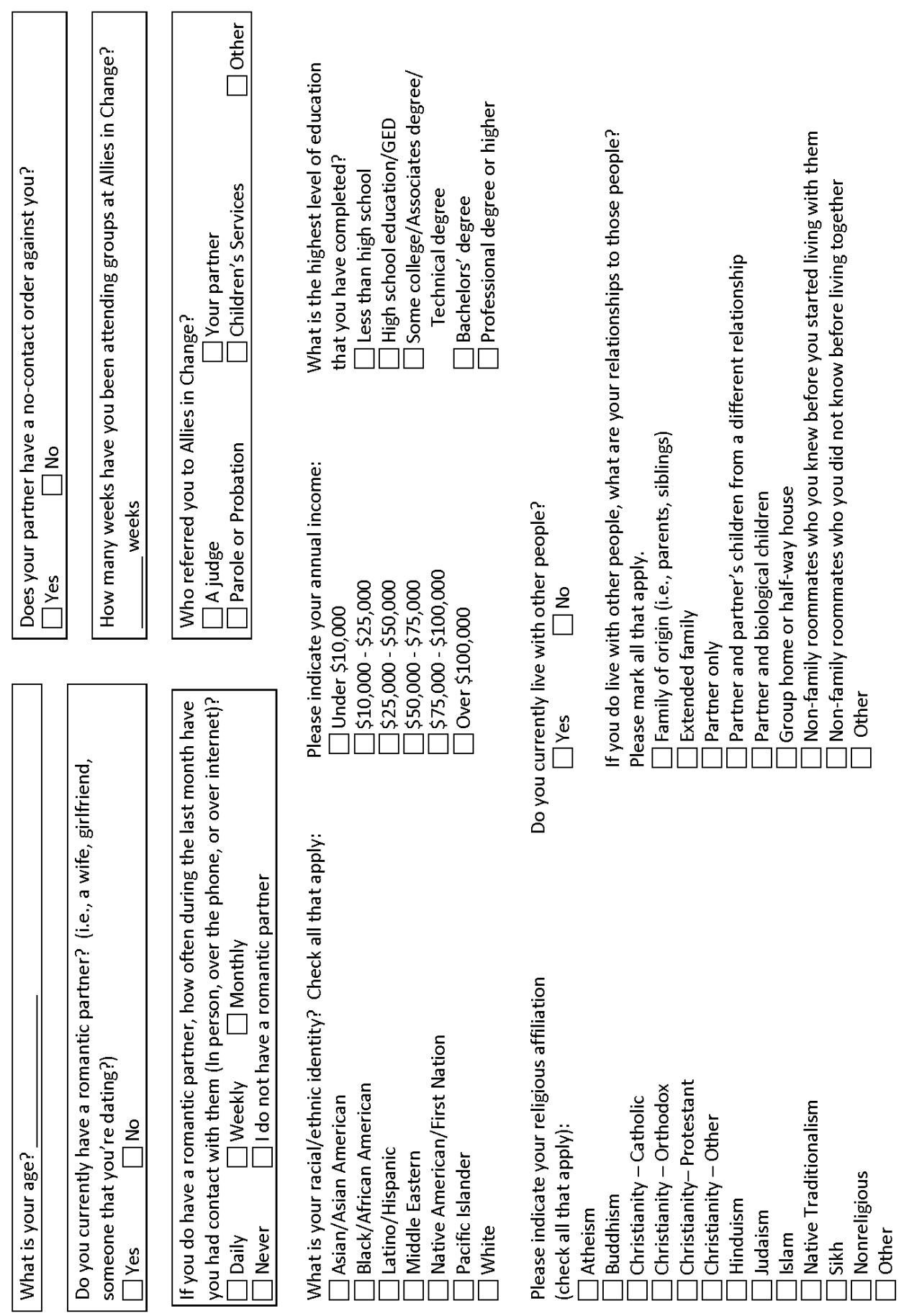


SOCIAL NETWORKS OF INTIMATE PARTNER VIOLENCE PERPETRATORS

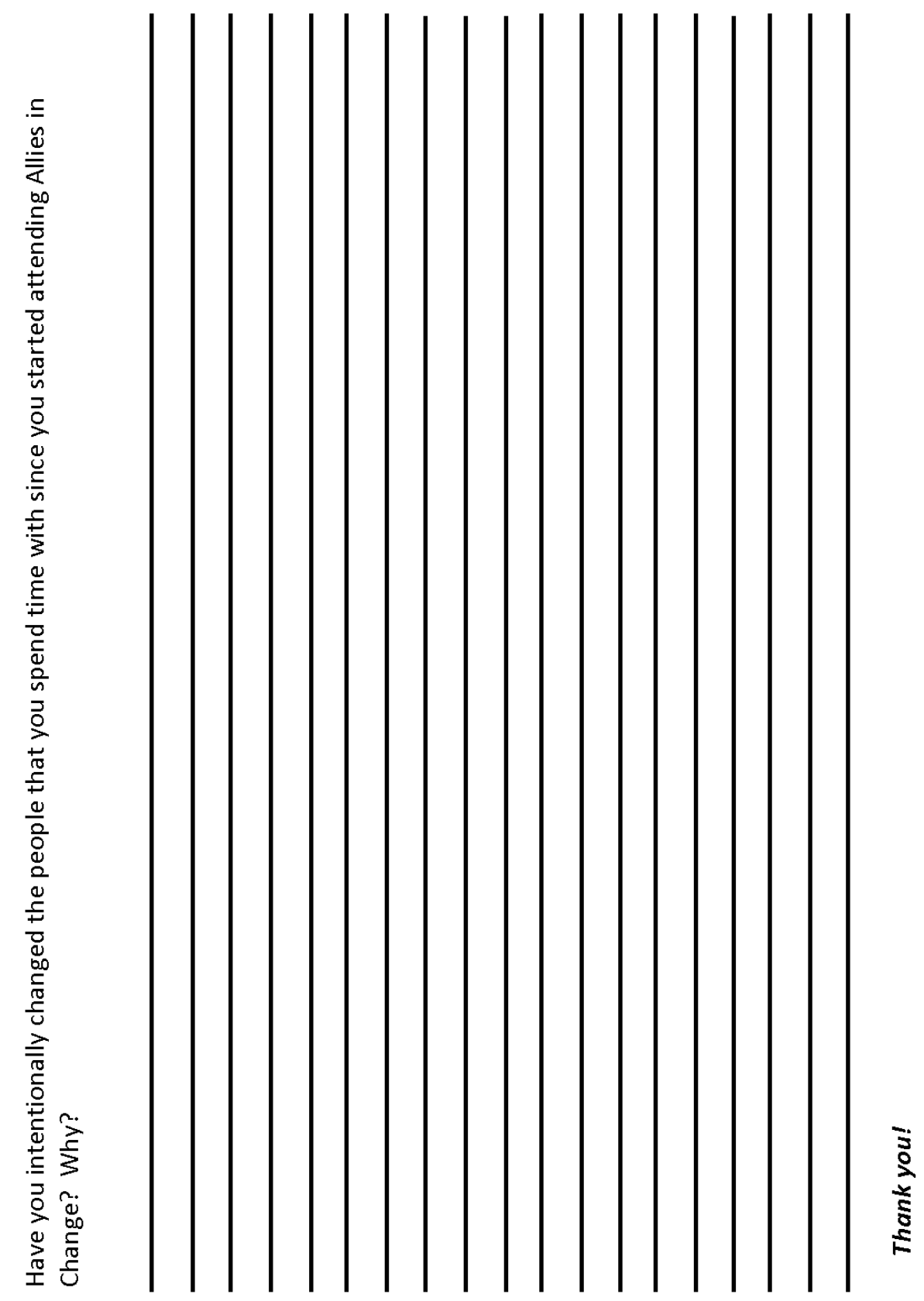




\section{SOCIAL NETWORKS OF INTIMATE PARTNER VIOLENCE PERPETRATORS}

Appendix M: Consent Form for Pilot Testing Focus Group

\section{P Portland $\underset{\text { UNIVESSITY }}{\text { State }}$}

\section{Social Networks and Relationships Study}

You are invited to participate in a focus group conducted by Wendy Viola, M.S., from Portland State University. The researcher hopes to learn your feedback on a survey about the friends, family members, coworkers, or other community members who are important in your life, and how you interact with them about attitudes and behavior towards women. You were selected as a possible participant because you are currently enrolled in a group at Allies in Change.

If you decide to participate, you will complete a survey, and take part in a small group conversation about your experience doing so. Other group members will be the men with whom you usually participate in groups at Allies in Change. The conversation that will take place after you've completed the survey will be much like the groups that you usually attend at Allies in Change. The researcher will cofacilitate the group, along with your usual group facilitators. At the start of the focus group, the researcher will hand out the survey. Once everyone has completed the survey, the researcher will provide some ground rules for the conversation to follow. The researcher will pose five or six main questions to the group, and you will be asked to share your experiences and opinions on them.

The focus group will be recorded with a digital recorder so that the researcher can concentrate on what is being said and guide the conversation. The recording will only be heard by the research team, and kept in a locked laboratory on the Portland State University campus.

If you choose to participate, your identity as a participant will not be revealed to anyone who is not present at the time of the focus group. Your identity will not be attached to any information that the focus group produces. However, the researcher cannot guarantee that other group members will keep information that you share during the focus group confidential. Additionally, if you report any behavior that suggests that you are at an immediate risk of harming yourself or another person, this information will be reported to the police. Additionally, your Allies in Change facilitators will be present during the focus group and will hear what you say during the group. Allies in Change's policies about responding to disclosures of illegal activity will apply as they usually do. 


\section{SOCIAL NETWORKS OF INTIMATE PARTNER VIOLENCE PERPETRATORS}

The focus group will be held during your regularly scheduled group meeting at Allies in Change on August $20^{\text {th }}, 2013$. Completing the survey and the following discussion is expected to take about an hour and a half. It is possible that completing the survey and participating in the discussion will make you remember events that were upsetting, or realize new things about your friends and family members that may be uncomfortable. Your Allies in Change group facilitators will be available to talk about any discomfort that you may experience as a result, and your Allies in Change group may provide a space for talking about many of these issues. Participating in this focus group may be beneficial to you in that you will have the opportunity to talk about and reflect on your interactions with other people in your community, in a group of other men who also attend groups at Allies in Change. It is also possible that you may not receive any direct benefit from taking part in this conversation, but in the information that you share will be used to develop a survey about the same topic. The results of the survey may contribute to understanding how men's communities contribute to the work that they (you) do in group, and possibly help Allies in Change make their groups more effective.

Your participation is voluntary. You do not have to take part in this focus group, and whether or not you choose to participate will not affect your standing or relationship with Allies in Change. You may also withdraw from the survey and the following conversation at any time without affecting your status with Allies in Change. If you choose not to attend your Allies in Change group on the day that the focus group is conducted (August $20^{\text {th }}, 2013$ ), you will receive an excused absence for that day. However, if you are not present on August $20^{\text {th }}, 2013$, you will not receive credit for attending that group meeting, and it will not count towards your minimum required number of sessions. You have the option of attending your Allies in Change group on August $20^{\text {th }}, 2013$, and not participating in the focus group. As long as you are present at Allies in Change for the group meeting on August $20^{\text {th }}, 2013$, you will be marked as present, and your attendance will count towards your minimum number of required sessions.

If you have concerns or problems with your participation in this focus group or your rights as a research subject, please contact the Portland State University Human Subjects Research Review Committee, PO Box 751, Portland, OR 97207, (503) 725-4288 / 1-877-480-4400. If you have questions about the study itself, contact Eric Mankowski at mankowskie@pdx.edu or (503) 725 -3901, or Wendy Viola at violaw@pdx.edu or (503) 725-3955.

Your signature indicates that you have read and understand the above information and agree to take part in this focus group. Please understand that you may withdraw your consent at any time without penalty, and that, by signing, 


\section{SOCIAL NETWORKS OF INTIMATE PARTNER VIOLENCE PERPETRATORS}

you are not waiving any legal claims, rights, or remedies. The researcher will provide you with a copy of this form for your own records.

Name (Please print):

Signature:

Date: 


\section{SOCIAL NETWORKS OF INTIMATE PARTNER VIOLENCE PERPETRATORS}

Appendix N: Script for Pilot Testing Focus Group

Today I would like to get your feedback on a survey about your friends and family members, other than your partners, and how they may influence your behavior in your relationships and make you think about what you learn in your group at Allies in Change. I've developed part of this survey by speaking with other participants at Allies in Change, and in a few weeks, I'll begin distributing these surveys in all of the groups that are held here at Allies. Before I start administering the surveys so widely, l'd like your feedback on the survey itself. I'm going to ask you to complete the survey, and then we'll have a conversation about how it went for you.

\section{\#1: consent forms}

Before we begin, let's go around and introduce ourselves. Please share your name, and tell us how long you've been going to groups at Allies in Change.

So, I'm going to pass out the surveys now. Please don't put your names on them, and take your time filling them out. Part of what l'd like to learn is how much time to budget for participants to complete the survey. Please feel free to ask questions as you move through the survey if anything is unclear. I'm going to turn on a recorder, so we have a record of any questions that came up for you while you were completing the survey.

[After all participants have completed the survey]

Now, I'd like for us to have a conversation about the survey and your reactions to it.

How the conversation will go:

- A conversation between you. I'll step in to guide the conversation, as will Curt and Joan, but about dialogue between you.

- Wide participation would be great-l'd like to hear from everyone!

- l'd also like to ask that we speak one at a time.

- While it's likely that we have a diversity of opinions represented in this group, and we welcome disagreement, l'd like to ask that you disagree with each other respectfully - the goal is not to reach consensus

- Finally, just like in every other group you attend at Allies in Change, what people say in the group should stay in the group. You're welcome to debrief today's conversation with your partner, but remember not to 


\section{SOCIAL NETWORKS OF INTIMATE PARTNER VIOLENCE PERPETRATORS}

discuss any information that would reveal the identities of other people who are here today.

- One more note before we get started: you'll notice that your facilitators are here, and they'll be participating in this conversation too. They'll also hear whatever you say and have the responsibility to react the way that they normally would. Allies in Change's policies about the limits of confidentiality apply here as well. This means that if there's anything that you would usually avoid saying in front of your facilitators, this meeting is no different. As researchers, we also have a responsibility to report to the police if you say anything about immediate plans to harm yourself or someone else.

Does this sound alright? Anything to add?

I have a few questions to get us started.

1. Were there any questions on the survey that didn't make sense to you?

2. Were any of the instructions throughout the survey unclear?

3. The survey included a check-list of behaviors that you might have done. Do these behaviors seem realistic? Do these behaviors seem like things that you might do, might have done in the past, or could imagine doing in the future?

4. The survey also included a check-list of behaviors that other people in your life might do. Do these behaviors seem realistic? Do they seem like things that other people in your life might do, might have done in the past, or could do in the future?

5. The survey provides space for you to provide information about 8 contacts. Does this number seem about right? Would you recommend providing space for fewer contacts? About how many?

6. Do you have any suggestions for making the survey clearer? 


\section{SOCIAL NETWORKS OF INTIMATE PARTNER VIOLENCE PERPETRATORS}

\section{Appendix O: Final Version of Survey Instrument}

This survey will ask you some questions about the people you have spent the most time with in the past three months. Thinking about these people one at a time, please answer the following questions about each of those people that you have spent the most time with in the last three months. Please answer the following questions for as many people as you think would be relevant for you.

\section{Person \#1}

What is this person's gender? $\square$ Male $\square$ Female

What is your relationship to this person? (For example, are they your parent? Your boss or coworker? A friend from high school?)

How often do you usually spend time with this person, either in person, on the phone, or over the internet?

$\square$ Less than once a year $\square$ A few times a year $\square$ Twice - 3 times a month $\square$ Almost every day

$\square$ About once a year $\square$ About every month $\square$ About once a week

The items below ask about your feelings for the person that you identified at the top of this page. With him or her in mind, decide how much you agree or disagree with each item. On the scale below each item, circle the number that indicates how much you agree that the statement describes your feelings. There are no right or wrong answers, because adults' feelings for people in their lives differ from person to person. Just honestly describe your feelings for this person.

1. I am happy with my relationship with this person Very much disagree Somewhat disagree$$
-1
$$

0

Somewhat agree

2

2. I feel my relationship with this person is a great one Very much disagree Somewhat disagree

3. I am satisfied with my relationship with this person Very much disagree Somewhat disagree$$
-1
$$

4. I think that my relationship with this person is strong Very much disagree Somewhat disagree $-4$ $-3$ $-2$ $-1$ 0

5. I feel my relationship with this person is good Very much disagree Somewhat disagree

6. I am pleased with my relationship with this person Very much disagree Somewhat disagree
$-4$

$$
-3
$$
$-2$

$$
-1
$$

Somewhat agre
Somewhat agr

Somewhat agree

1

Very much agree

Very much agree

Very much agree

Somewhat agree Very much agree

12

Somewhat agree $\quad$ Very much agree

$\begin{array}{llll}1 & 2 & 3 & 4\end{array}$

7. I am content with my relationship with this person Very much disagree Somewhat disagree

$-1 \quad 0$

Somewhat agree

Very much agree

2

3 


\section{SOCIAL NETWORKS OF INTIMATE PARTNER VIOLENCE PERPETRATORS}

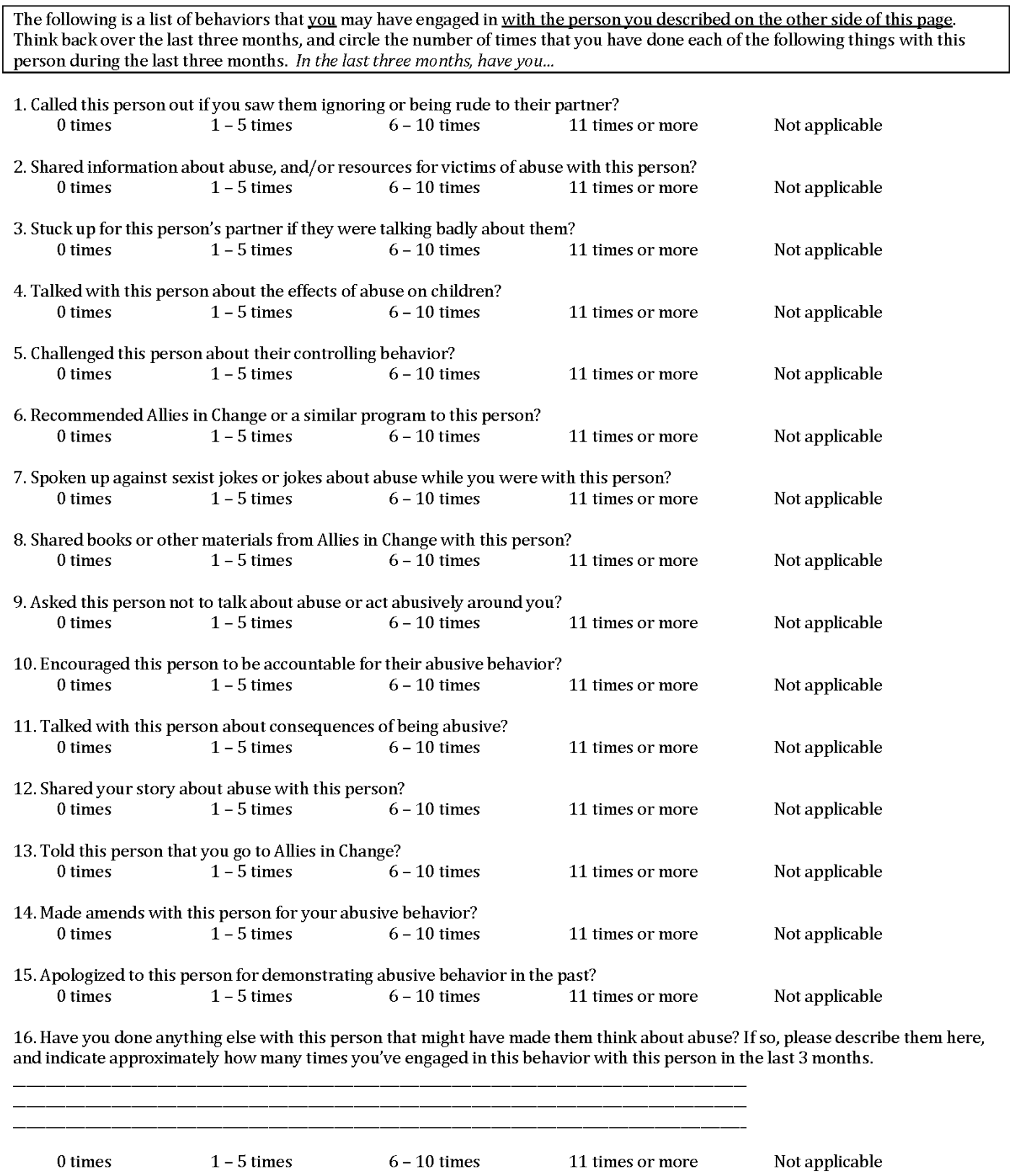




\section{SOCIAL NETWORKS OF INTIMATE PARTNER VIOLENCE PERPETRATORS}

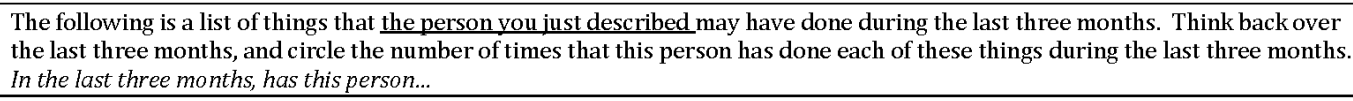

17. Told you that your current/former partner was taking advantage of you or disrespecting you?
0 times
$1-5$ times
6- 10 times
11 times or more
Not applicable

18. Accu sed your current/former partner of trying to harm your relationship with your kids?
0 times
1 - 5 times
6- 10 times
11 times or more
Not applicable

19. Told you that they wouldn't let their own partner get away with the things that your current/former partner does to you?
0 times
1 - 5 times
$6-10$ times
11 times or more
Not applicable

20. Supported you in being more accountable?
0 times
1 - 5 times
$6-10$ times
11 times or more
Not applicable

21. Told you that your current/former partner deserved your abusive behavior?
0 times
$1-5$ times
6 - 10 times
11 times or more
Not applicable

22. Refused to accept that you have been abusive?
0 times
$1-5$ times
$6-10$ times
11 times or more
Not applicable

23. Been abusive towards their partner in front of you?
0 times
$1-5$ times
$6-10$ times
11 times or more
Not applicable

24. Blamed their partner for their own problems?
0 times
1 - 5 times
$6-10$ times
11 times or more
Not applicable

25 . Told you ways to avoid the consequences of abuse?
0 times
1 - 5 times
$6-10$ times
11 times or more
Not applicable

26. Supported you in taking legal action against your current/former partner?
0 times
1 - 5 times
$6-10$ times
11 times or more
Not applicable

27. Contacted your current/former partner to harass or monitor them?
0 times
1 - 5 times
$6-10$ times
11 times or more
Not applicable

28. Made fun of you for letting your current/former partner call the shots in your relationship?
0 times
1 - 5 times
6-10 times
11 times or more
Not applicable

29. Pointed out effects of abuse on children or other people?
0 times
1 - 5 times
6-10 times
11 times or more
Not applicable

30. Did or said something that supported your participation at Allies in Change?
0 times
1 - 5 times
6-10 times
11 times or more
Not applicable

31. Tried to make amends with you for their abusive behavior?
0 times
1 - 5 times
6-10 times
11 times or more
Not applicable

32. Has this person done anything else that made you think about abuse? If so, please describe it here, and indicate approxi mately how many times you've engaged in this behavior with this person in the last 3 months. 


\section{SOCIAL NETWORKS OF INTIMATE PARTNER VIOLENCE PERPETRATORS}

\section{Person \#2}

What is this person's gender? $\square$ Male $\square$ Female

What is your relationship to this person? (For example, are they your parent? Your boss or coworker? A friend from high school?)

How often do you usually spend time with this person, either in person, on the phone, or over the internet?

$\square$ Less than once a year $\square$ A few times a year $\square$ Twice - 3 times a month $\square$ Almost every day

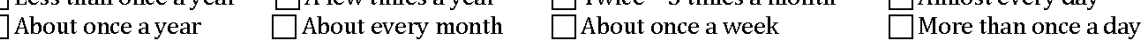

The items below ask about your feelings for the person that you identified at the top of this page. With him or her in mind, decide how much you agree or disagree with each item. On the scale below each item, circle the number that indicates how much you agree that the statement describes your feelings. There are no right or wrong answers, because adults' feelings for people in their lives differ from person to person. Just honestly describe your feelings for this person.

8. I am happy with my relationship with this person Very much disagree Somewhat disagree $\begin{array}{llll}-4 & -3 & -2 & -1\end{array}$ 0 \begin{tabular}{cccc} 
Somewhat agree & \multicolumn{2}{l}{ Very much agree } \\
1 & 2 & 3 & 4
\end{tabular}

9. I feel my relationship with this person is a great one Very much disagree Somewhat disagree $-2$ $-1$

Somewhat agree Very much agree

10. I am satisfied with my relationship with this person Very much disagree Somewhat disagree
$-3$
$-2$
$-1$

$-4$

0

Somewhat agree

12

Very much agree

11. I think that my relationship with this person is strong Very much disagree Somewhat disagree

Somewhat agree Very much agree

$\begin{array}{llll}-4 & -3 & -2 & -1\end{array}$

西 Very much disagree Somewhat disagree $\begin{array}{llll}-4 & -3 & -2 & -1\end{array}$

13. I am pleased with my relationship with this person Very much disagree Somewhat disagree

$\begin{array}{lllll}-4 & -3 & -2 & -1 & 0\end{array}$

Somewhat agree 1

Very much agree

14. I am content with my relationship with this person Very much disagree Somewhat disagree $-4 \quad-3$

$-2 \quad-1$

0

Somewhat agree 


\section{SOCIAL NETWORKS OF INTIMATE PARTNER VIOLENCE PERPETRATORS}

The following is a list of behaviors that you may have engaged in with the person you described on the other side of this page

Think back over the last three months, and circle the number of times that you have done each of the following things with this

person during the last three months. In the last three months, have you..

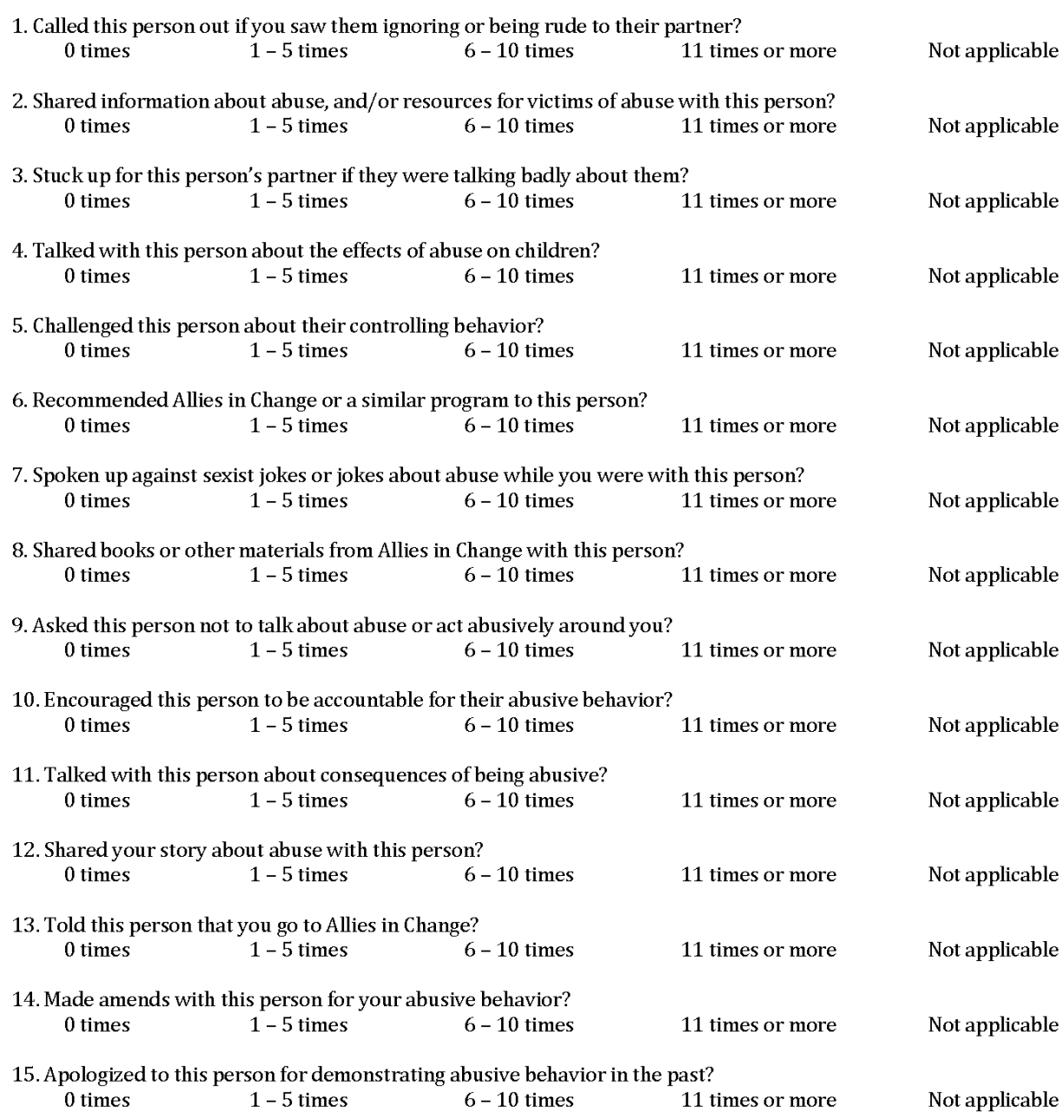

16. Have you done anything else with this person that might have made them think about abuse? If so, please describe them here, and indicate approximately how many times you've engaged in this behavior with this person in the last 3 months.

0 times $1-5$ times $\quad 6-10$ times $\quad 11$ times or more $\quad$ Not applicable




\section{SOCIAL NETWORKS OF INTIMATE PARTNER VIOLENCE PERPETRATORS}

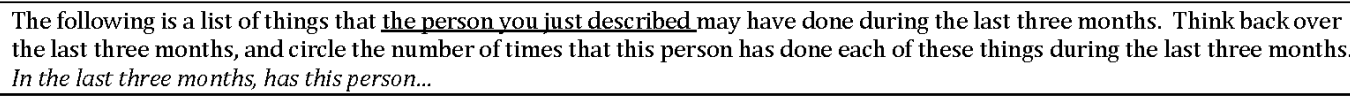

17. Told you that your current/former partner was taking advantage of you or disrespecting you?
0 times
$1-5$ times
6 - 10 times
11 times or more
Not applicable

18. Accused your current/former partner of trying to harm your relationship with your kids?
0 times
$1-5$ times
6-10 times
11 times or more
Not applicable

19. Told you that they wouldn't let their own partner get away with the things that your current/former partner does to you?
0 times
$1-5$ times
6-10 time
11 times or more
Not applicable

20. Supported you in being more accountable?
0 times
1 - 5 times
6-10 times
11 times or more
Not applicable

21. Told you that your current/former partner deserved your abusive behavior?
0 times
1 - 5 times
6-10 times
11 times or more
Not applicable

22. Refused to accept that you have been abusive?
0 times
1 - 5 times
$6-10$ times
11 times or more
Not applicable

23. Been abusive towards their partner in front of you?
0 times
$1-5$ times
6 - 10 times
11 times or more
Not applicable

24. Blamed their partner for their own problems?
0 times
1 - 5 times
6-10 times
11 times or more
Not applicable

25 . Told you ways to avoid the consequences of abuse?
0 times
$1-5$ times
6-10 times
11 times or more
Not applicable

26. Supported you in taking legal action against your current/former partner?
0 times
$1-5$ times
6-10 times
11 times or more
Not applicable

27. Contacted your current/former partner to harass or monitor them?
0 times
$1-5$ times
6-10 times
11 times or more
Not applicable

28. Made fun of you for letting your current/former partner call the shots in your relationship?

0 times $\quad 1-5$ times $\quad 6-10$ times $\quad 11$ times or more

$$
1-5 \text { times } \quad 6-10 \text { times } 11 \text { times or more }
$$

Not applicable

29. Pointed out effects of abuse on children or other people?
0 times
$1-5$ times
$6-10$ times
11 times or more
Not applicable

30. Did or said something that supported your participation at Allies in Change?
0 times
1 - 5 times
$6-10$ times
11 times or more
Not applicable

31. Tried to make amends with you for their abusive behavior?

6 - 10 times

Not applicable

32. Has this person done anything else that made you think about abuse? If so, please describe it here, and indicate approximately how many times you've engaged in this behavior with this person in the last 3 months. 


\section{SOCIAL NETWORKS OF INTIMATE PARTNER VIOLENCE PERPETRATORS}

Person \#3

What is this person's gender? $\square$ Male $\square$ Female

What is your relationship to this person? (For example, are they your parent? Your boss or coworker? A friend from high school?)

How often do you usually spend time with this person, either in person, on the phone, or over the internet?

$\square$ Less than once a year $\square$ A few times a year $\square$ Twice -3 times a month $\square$ Almost every day

\begin{tabular}{|c|c|c|}
\hline About once a year & About every mo & More than once a d \\
\hline
\end{tabular}

The items below ask about your feelings for the person that you identified at the top of this page. With him or her in mind, decide how much you agree or disagree with each item. On the scale below each item, circle the number that indicates how much you agree that the statement describes your feelings. There are no right or wrong answers, because adults' feelings for people in their lives differ from person to person. Just honestly describe your feelings for this person.

15. I am happy with my relationship with this person Very much disagree Somewhat disagree

$\begin{array}{lllll}-4 & -3 & -2 & -1\end{array}$

16. I feel my relationship with this person is a great one Very much disagree Somewhat disagree
$-4$
$-3$
$-2$
$-1$

0

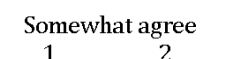

1

Somewhat agree

1
Very much agree

17. I am satisfied with my relationship with this person Very much disagree Somewhat disagree

$$
-2
$$

$-1$ 0

18. I think that my relationship with this person is strong Very much disagree Somewhat disagree $\begin{array}{llll}-4 & -3 & -2 & -1\end{array}$

\begin{tabular}{cccc} 
Somewhat agree & \multicolumn{2}{c}{ Very much agree } \\
1 & 2 & 3 & 4
\end{tabular}

19. I feel my relationship with this person is good Very much disagree Somewhat disagree
$-4$$$
-3
$$$$
-2
$$
$-1$

Somewhat agree

1

2

Very much agree

20. I am pleased with my relationship with this person Very much disagree Somewhat disagree

$-4$

$-3$

$-2$

$-1$

0

Somewhat agree

Very much agree

21. I am content with my relationship with this person

Very much disagree Somewhat disagree

$\begin{array}{lllll}-4 & -3 & -2 & -1 & 0\end{array}$

Somewhat agree

1

2

Very much agree

$3 \quad 4$ 


\section{SOCIAL NETWORKS OF INTIMATE PARTNER VIOLENCE PERPETRATORS}

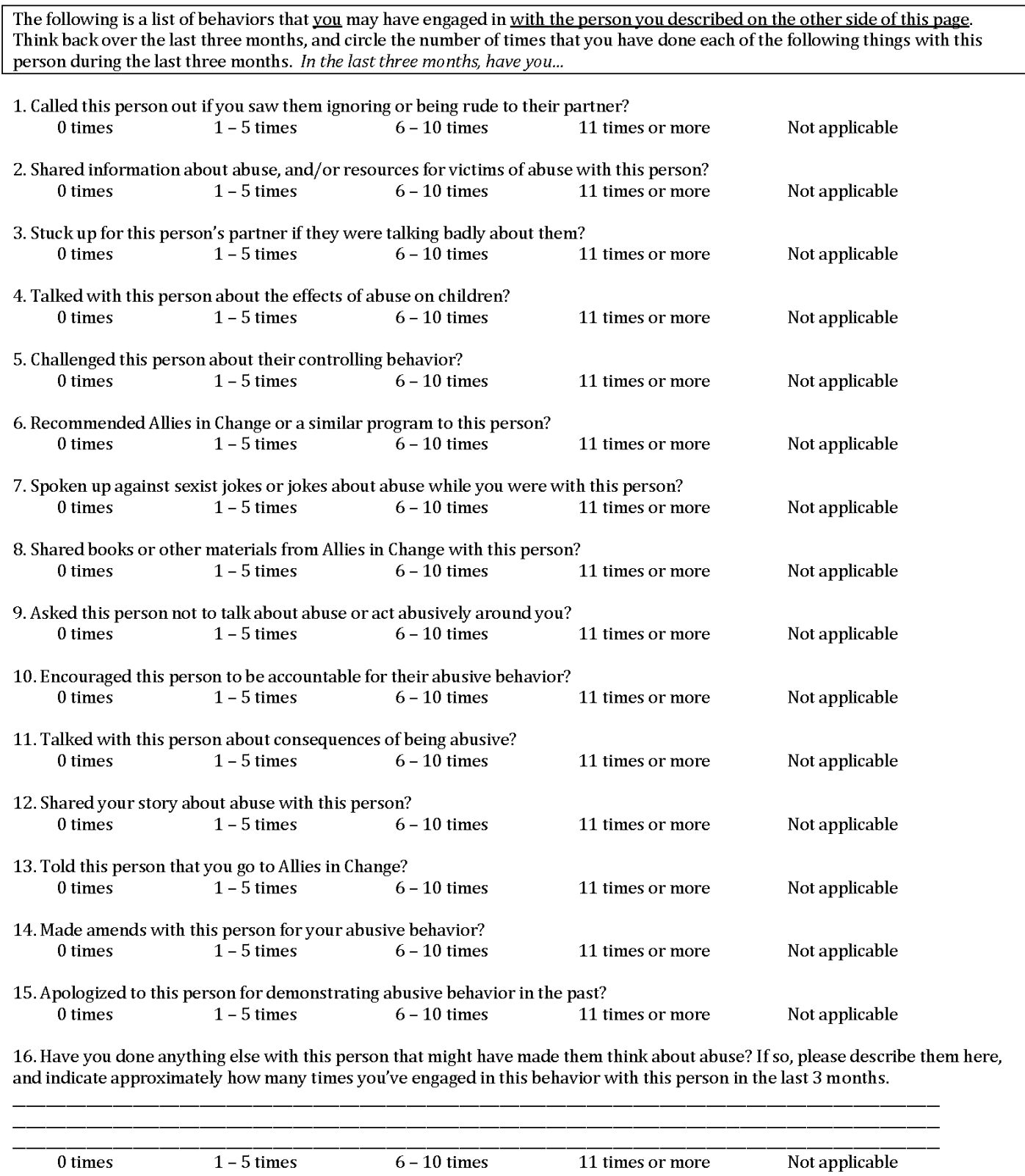




\section{SOCIAL NETWORKS OF INTIMATE PARTNER VIOLENCE PERPETRATORS}

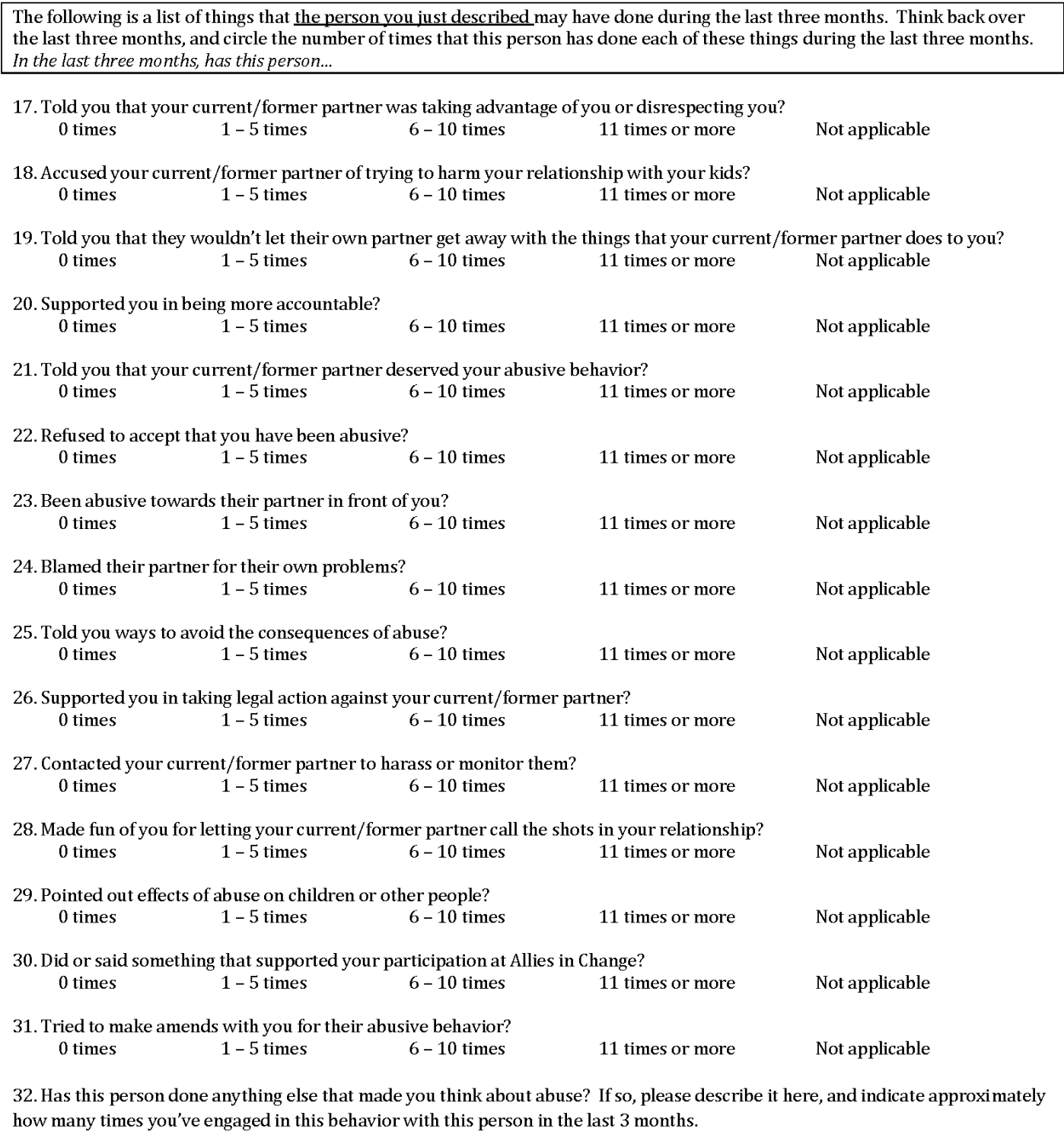

(1)

The following is a list of things that the person you just described may have done during the last three months. Think back over In the last three months, has this person...

Told you that your current/former partner was taking advantage of you or disrespecting you? Accused your current/former partner of trying to harm your relationship with your kids? Told you that they wouldn't let their own partner get away with the things that your current/former partner does Supported you in being more accountable?

Told you that your current/former partner deserved your abusive behavior? Refused to accept that you have been abusive? een abusive towards their partner in front of you? lamed their partner for their own problems? old you ways to avoid the consequences of abuse? Supported you in taking legal action against your current/former partner? Contacted your current/former partner to harass or monitor them? Made fun of you for letting your current/former partner call the shots in your relationship? Pointed out effects of abuse on children or other people? Did or said something that supported your participation at Allies in Change?
0 times with you for their abusive behavior?
11 times or more
Not applicable how many times you've engaged in this behavior with this person in the last 3 months.
0 times
$1-5$ times
$6-10$ times
11 times or more
Not applicable 


\title{
SOCIAL NETWORKS OF INTIMATE PARTNER VIOLENCE PERPETRATORS
}

\section{Person \#4}

\author{
What is this person's gender? $\square$ Male $\square$ Female
}

What is your relationship to this person? (For example, are they your parent? Your boss or coworker? A friend from high sc hool?)

How often do you usually spend time with this person, either in person, on the phone, or over the internet? $\square$ Less than once a year $\square$ A few times a year $\square$ Twice -3 times a month $\square$ Almost every day About once a year $\square$ About every month $\square$ About once a week $\square$ More than once a day

The items below ask about your feelings for the person that you identified at the top of this page. With him or her in mind, decide how much you agree or disagree with each item. On the scale below each item, circle the number that indicates how much you agree that the statement describes your feelings. There are no right or wrong answers, because adults' feelings for people in their lives differ from person to person. Just honestly describe your feelings for this person.

22. I am happy with my relationship with this person Very much disagree Somewhat disagree

Somewhat agree

12

Somewhat agre
Very much agree

23. I feel my relationship with this person is a great one

Very much disagree Somewhat disagree

$$
\begin{array}{lllll}
-4 & -3 & -2 & -1 & 0
\end{array}
$$

24. I am satisfied with my relationship with this person Very much disagree Somewhat disagree$$
-3
$$$$
-2
$$

$$
\text { Somewhat agr }
$$$$
1
$$$$
2
$$

Somewhat agree

1

$-1$

0

$$
-2
$$

\section{ood}

Very much disagree Somewhat disagree

0

Somewhat agree

1

Somewhat agree

Very much disagree Somewhat disagree

$\begin{array}{llll}-4 & -3 & -2 & -1\end{array}$

28. I am content with my relationship with this person Very much disagree Somewhat disagree

\begin{abstract}
$-2$
\end{abstract}
$-1$
Very much agree

Very much agree

Very much agre

3

Very much agree

Very much agree

3

Somewhat agree Very much agree

123




\section{SOCIAL NETWORKS OF INTIMATE PARTNER VIOLENCE PERPETRATORS}

The following is a list of behaviors that you may have engaged in with the person you described on the other side of this page.

Think back over the last three months, and circle the number of times that you have done each of the following things with this

person during the last three months. In the last three months, have you..

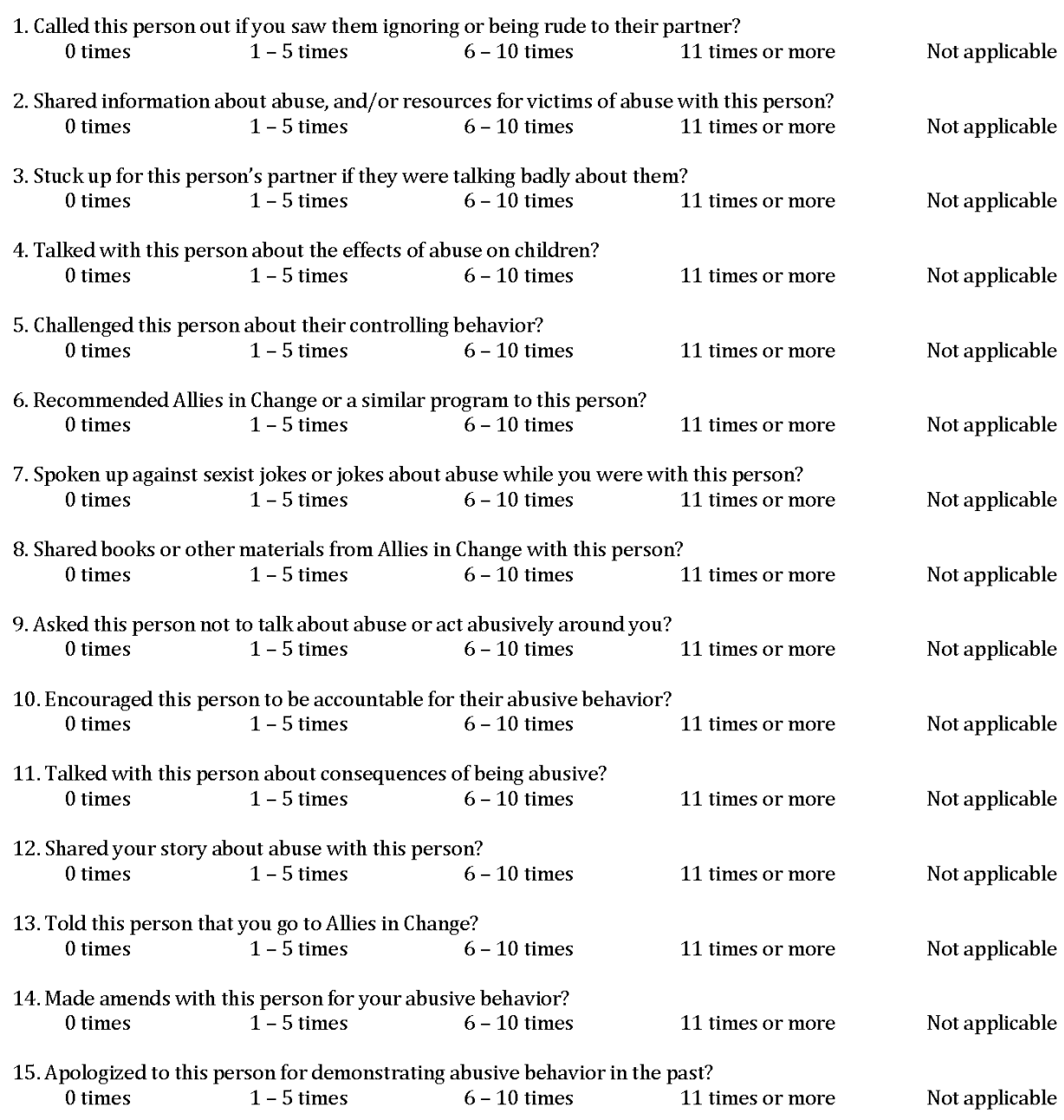

16. Have you done anything else with this person that might have made them think about abuse? If so, please describe them here, and indicate approximately how many times you've engaged in this behavior with this person in the last 3 months.

0 times $\quad 1-5$ times $\quad 6-10$ times $\quad 11$ times or more $\quad$ Not applicable




\section{SOCIAL NETWORKS OF INTIMATE PARTNER VIOLENCE PERPETRATORS}

The following is a list of things that the person you just described may have done during the last three months. Think back over
the last three months, and circle the number of times that this person has done each of these things during the last three months. In the last three months, has this person...

17. Told you that your current/former partner was taking advantage of you or disrespecting you?
0 times
$1-5$ times
6- 10 times
11 times or more
Not applicable

18. Accused your current/former partner of trying to harm your relationship with your kids?
0 times
$1-5$ times
6- 10 times
11 times or more
Not applicable

19. Told you that they wouldn't let their own partner get away with the things that your current/former partner does to you?
0 times
$1-5$ times
$6-10$ times
11 times or more
Not applicable

20. Supported you in being more accountable?
0 times
$1-5$ times
$6-10$ times
11 times or more
Not applicable

21. Told you that your current/former partner deserved your abusive behavior?
0 times
$1-5$ times
6- 10 times
11 times or more
Not applicable

22. Refused to accept that you have been abusive?
0 times
1 - 5 times
$6-10$ times
11 times or more
Not applicable

23. Been abusive towards their partner in front of you?
0 times
1 - 5 times
6-10 times
11 times or more
Not applicable

24 . Blamed their partner for their own problems?
0 times
1- 5 times
6-10 times
11 times or more
Not applicable

25 . Told you ways to avoid the consequences of abuse?
0 times
1 - 5 times
6-10 times
11 times or more
Not applicable

26. Supported you in taking legal action against your current/former partner?
0 times
$1-5$ times
6-10 times
11 times or more
Not applicable

27. Contacted your current/former partner to harass or monitor them?
0 times
1 - 5 times
$6-10$ times
11 times or more
Not applicable

28. Made fun of you for letting your current/former partner call the shots in your relationship?
0 times
$1-5$ times
6-10 times
11 times or more
Not applicable

29. Pointed out effects of abuse on children or other people?
0 times
1 - 5 times
6-10 times
11 times or more
Not applicable

30. Did or said something that supported your participation at Allies in Change?
0 times
1 - 5 times
6-10 times
11 times or more
Not applicable

31. Tried to make amends with you for their abusive behavior?
0 times
1 - 5 times
6-10 times
11 times or more
Not applicable

32. Has this person done anything else that made you think about abuse? If so, please describe it here, and indicate approximately how many times you've engaged in this behavior with this person in the last 3 months.

0 times $\quad 1-5$ times $\quad 6-10$ times $\quad 11$ times or more $\quad$ Not applicable




\section{SOCIAL NETWORKS OF INTIMATE PARTNER VIOLENCE PERPETRATORS}

\section{Person \#5}

What is this person's gender? $\square$ Male $\square$ Female

What is your relationship to this person? (For example, are they your parent? Your boss or coworker? A friend from high school?)

How often do you usually spend time with this person, either in person, on the phone, or over the internet?

$\square$ Less than once a year $\square$ A few times a year $\square$ Twice - 3 times a month $\square$ Almost every day

$\square$ About once a year $\square$ About every month $\square$ About once a week $\square$ More than once a day

The items below ask about your feelings for the person that you identified at the top of this page. With him or her in mind, decide how much you agree or disagree with each item. On the scale below each item, circle the number that indicates how much you agree that the statement describes your feelings. There are no right or wrong answers, because adults' feelings for people in their lives differ from person to person. Just honestly describe your feelings for this person.

29. I am happy with my relationship with this person Very much disagree Somewhat disagree$$
-2
$$

0

Somewhat agree

Somewhat agre

1

ery much disagree Somewhat disagree

$$
\begin{array}{lllll}
-4 & -3 & -2 & -1 & 0
\end{array}
$$

31. I am satisfied with my relationship with this person Very much disagree Somewhat disagree$$
-3
$$$$
-1
$$

0

32. I think that my relationship with this person is strong Very much disagree Somewhat disagree $\begin{array}{llll}-4 & -3 & -2 & -1\end{array}$ $-1$

33. I feel my relationship with this person is good Very much disagree Somewhat disagree$$
-1
$$

34. I am pleased with my relationship with this person Very much disagree Somewhat disagree
$-4$
$-2$
$-1$

35. I am content with my relationship with this person Very much disagree Somewhat disagree
$-4$

$$
-3
$$$$
-2
$$

$-10$

Somewhat agree

Somewhat agree

1

2

Somewhat agree

Somewhat agree

1

2

Very much agree

Somewhat agree

Very much agree
Very much agree

Very much agre

3

Very much agree

3

Very much agree

3

Very much agree

(1)

3 


\section{SOCIAL NETWORKS OF INTIMATE PARTNER VIOLENCE PERPETRATORS}

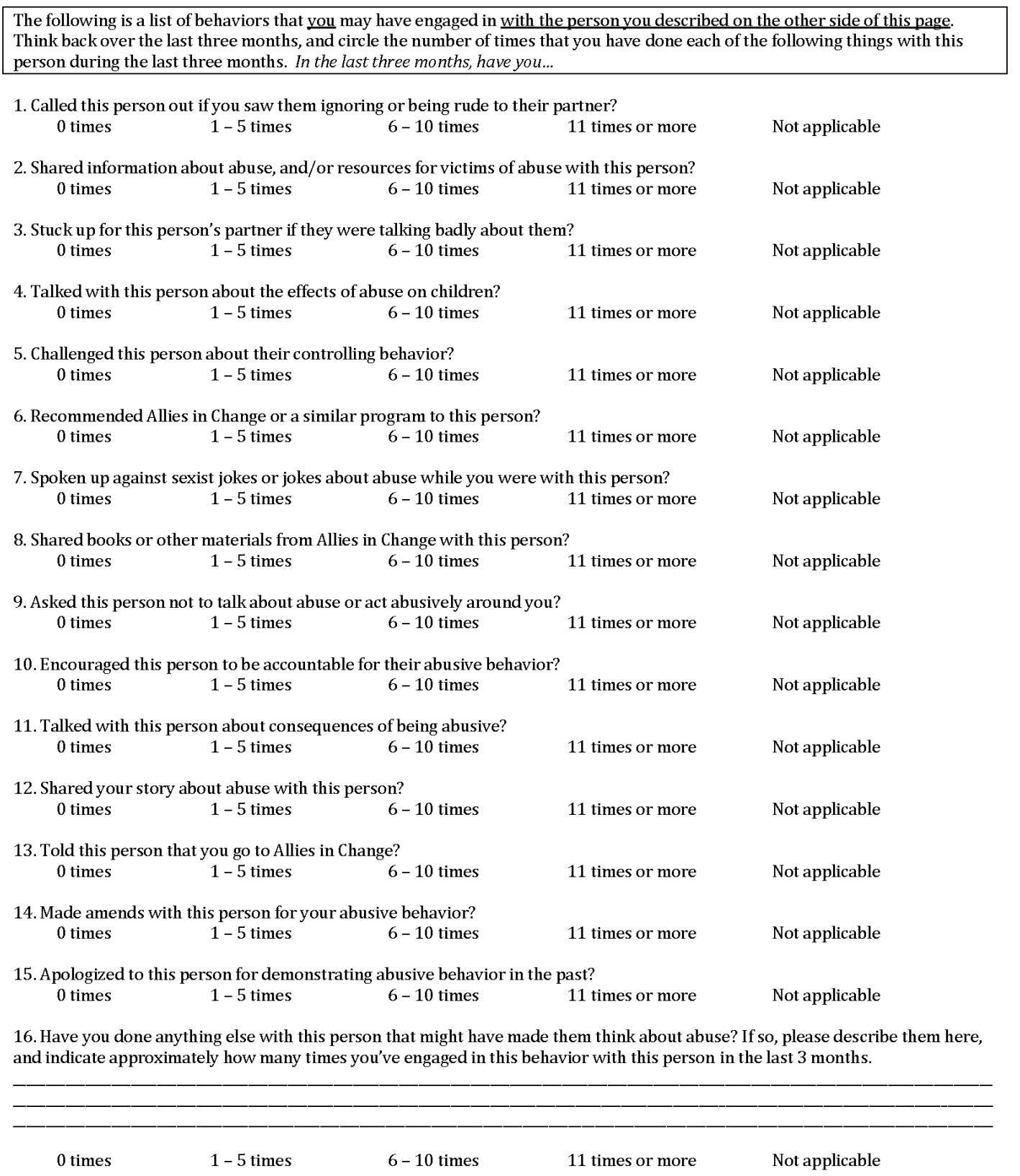




\section{SOCIAL NETWORKS OF INTIMATE PARTNER VIOLENCE PERPETRATORS}

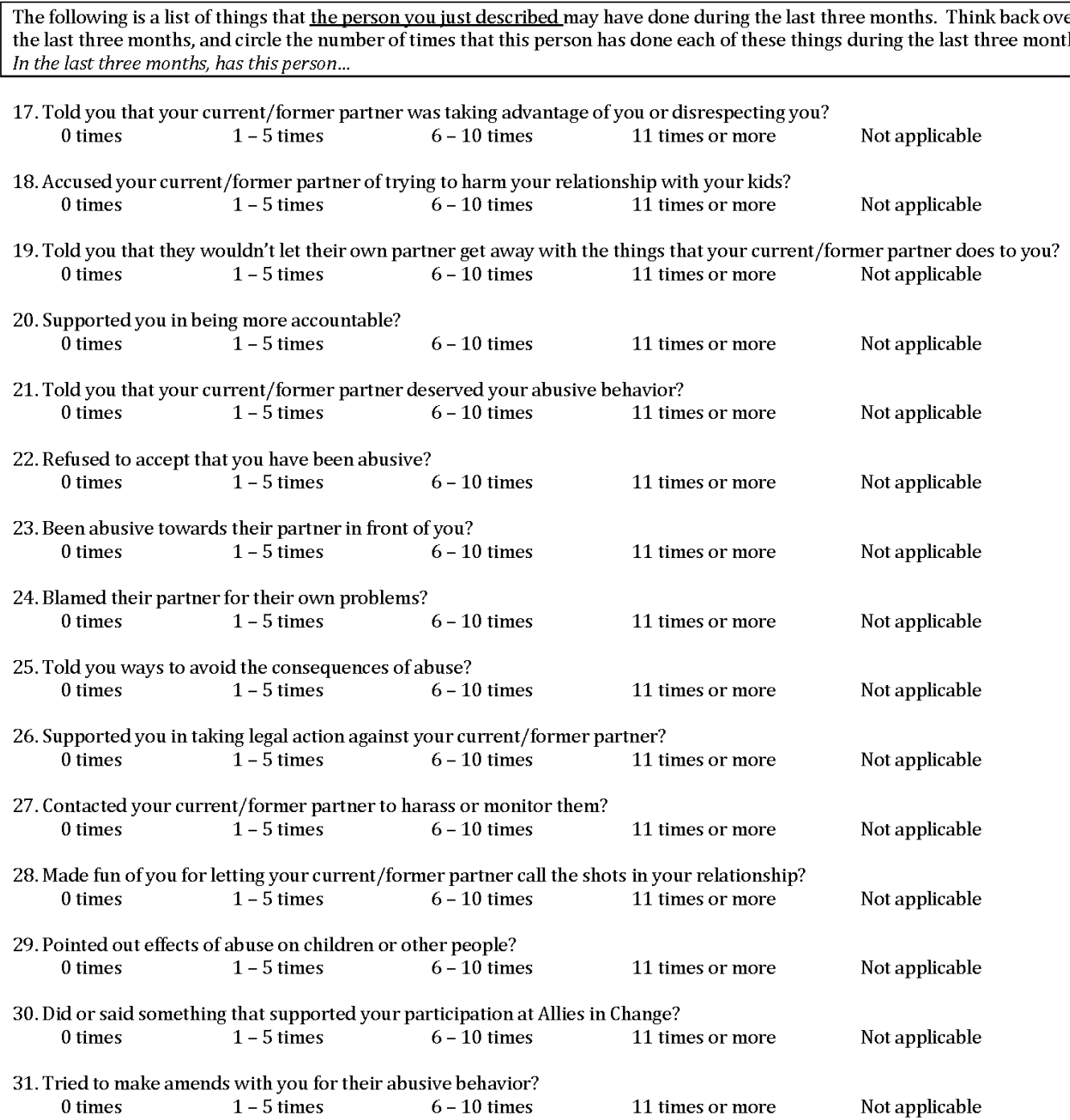

32. Has this person done any thing else that made you think about abuse? If so, please describe it here, and indicate approximately how many times you've engaged in this behavior with this person in the last 3 months.

0 times $1-5$ times $6-10$ times 11 times or more - Not applicable




\section{SOCIAL NETWORKS OF INTIMATE PARTNER VIOLENCE PERPETRATORS}

\section{Person \#6}

What is this person's gender? $\square$ Male $\square$ Female

What is your relationship to this person? (For example, are they your parent? Your boss or coworker? A friend from high school?)

How often do you usually spend time with this person, either in person, on the phone, or over the internet?

$\square$ Less than once a year $\square$ A few times a year $\square$ Twice -3 times a month $\square$ Almost every day

\begin{tabular}{|c|c|c|}
\hline About once a year & About every mo & More than once a d \\
\hline
\end{tabular}

The items below ask about your feelings for the person that you identified at the top of this page. With him or her in mind, decide how much you agree or disagree with each item. On the scale below each item, circle the number that indicates how much you agree that the statement describes your feelings. There are no right or wrong answers, because adults' feelings for people in their lives differ from person to person. Just honestly describe your feelings for this person.

1. I am happy with my relationship with this person Very much disagree Somewhat disagree

$\begin{array}{lllll}-4 & -3 & -2 & -1 & 0\end{array}$

2. I feel my relationship with this person is a great one very much disagree Somewhat disagree
$-4$
$-3$
$-2$
$-1$

0
Somewhat agree
1

Somewhat agree Very much agree

3. I am satisfied with my relationship with this person Very much disagree Somewhat disagree
$-4$$$
-3
$$

$$
-2
$$
$-1$
0

Somewhat agree

2

Very much agree

4. I think that my relationship with this person is strong Very much disagree Somewhat disagree $\begin{array}{llll}-4 & -3 & -2 & -1\end{array}$

\begin{tabular}{cccc} 
Somewhat agree & \multicolumn{2}{c}{ Very much agree } \\
1 & 2 & 3 & 4
\end{tabular}

5. I feel my relationship with this person is good Very much disagree Somewhat disagree
$-4$$$
-3
$$

$$
-2
$$

$$
-1
$$

Somewhat agree

2

Very much agree

6. I am pleased with my relationship with this person Very much disagree Somewhat disagree

$-3$

$-2$

$-1$

7. I am content with my relationship with this person Very much disagree Somewhat disagree $-4$ $-3$ Some
-2

$-1$

\begin{tabular}{cccc}
\multicolumn{2}{l}{ Somewhat agree } & \multicolumn{2}{l}{ Very much agree } \\
1 & 2 & 3 & 4 \\
& & \\
& & \\
\multicolumn{2}{r}{ Somewhat agree } & \multicolumn{2}{c}{ Very much agree } \\
1 & 2 & 3 & 4
\end{tabular}




\section{SOCIAL NETWORKS OF INTIMATE PARTNER VIOLENCE PERPETRATORS}

The following is a list of behaviors that you may have engaged in with the person you described on the other side of this page

Think back over the last three months, and circle the number of times that you have done each of the following things with this

person during the last three months. In the last three months, have you...
1. Called this person out if you saw them ignoring or being rude to their partner?

$$
\begin{array}{llll}
0 \text { times } & 1-5 \text { times } & 6-10 \text { times } & 11 \text { times or more }
\end{array}
$$
2. Shared information about abuse, and/or resources for victims of abuse with this person?

$\begin{array}{ccccc}0 \text { times } & 1-5 \text { times } & 6-10 \text { times } & 11 \text { times or more } & \text { Not applicable }\end{array}$
3. Stuck up for this person's partner if they were talking badly about them?

$$
\begin{array}{ccccc}
0 \text { times } & 1-5 \text { times } & 6-10 \text { times } & 11 \text { times or more } & \text { Not applicable }
\end{array}
$$
4. Talked with this person about the effects of abuse on children?
0 times
$1-5$ times
6-10 times
11 times or more
Not applicable
5. Challenged this person about their controlling behavior?
0 times
$1-5$ times
6-10 times
11 times or more
Not applicable
6. Recommended Allies in Change or a similar program to this person?
0 times
$1-5$ times
6- 10 times
11 times or more
Not applicable
7. Spoken up against sexist jokes or jokes about abuse while you were with this person?
0 times
$1-5$ times
6-10 times
11 times or more
Not applicable
8. Shared books or other materials from Allies in Change with this person?
0 times
$1-5$ times
$6-10$ times
11 times or more
Not applicable
9. Asked this person not to talk about abuse or act abusively around you?
0 times
$1-5$ times
6 - 10 times
11 times or more
Not applicable
10. Encouraged this person to be accountable for their abusive behavior?
0 times
$1-5$ times
6- 10 times
11 times or more
Not applicable
11. Talked with this person about consequences of being abusive?

$\begin{array}{cccc}0 \text { times } & 1-5 \text { times } & 6-10 \text { times } & 11 \text { times or more }\end{array}$

\begin{tabular}{|c|c|c|c|c|}
\hline 0 times & $1-5$ times & $6-10$ times & 11 times or more & Not applicable \\
\hline
\end{tabular}
12. Shared your story about abuse with this person?
13. Told this person that you go to Allies in Change?

$\begin{array}{cccc}0 \text { times } & 1-5 \text { times } & 6-10 \text { times } & 11 \text { times or more } \quad \text { Not applicable }\end{array}$

\begin{tabular}{|c|c|c|}
\hline 0 times & $1-$ & \\
\hline
\end{tabular}
14. Made amends with this person for your abusive behavior?
15. Apologized to this person for demonstrating abusive behavior in the past?
0 times
1 - 5 times
6- 10 times
11 times or more
Not applicable

16. Have you done anything else with this person that might have made them think about abuse? If so, please describe them here, and indicate approximately how many times you've engaged in this behavior with this person in the last 3 months.

0 times $\quad 1-5$ times $\quad 6-10$ times $\quad 11$ times or more $\quad$ Not applicable




\section{SOCIAL NETWORKS OF INTIMATE PARTNER VIOLENCE PERPETRATORS}

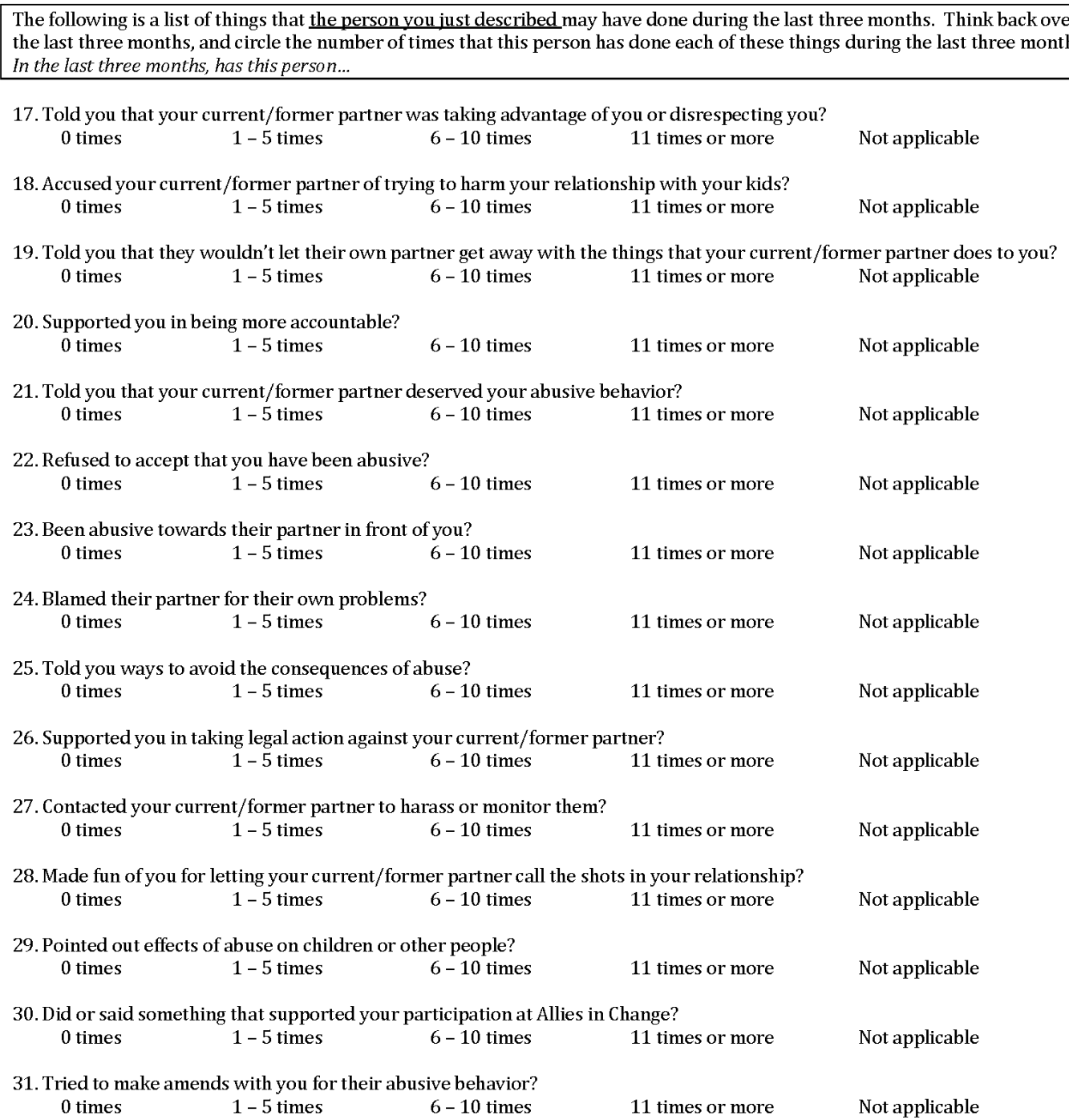

32. Has this person done anything else that made you think about abuse? If so, please describe it here, and indicate approximately how many times you've engaged in this behavior with this person in the last 3 months.

0 times $1-5$ times $6-10$ times 11 times or more $\quad$ Not applicable




\section{SOCIAL NETWORKS OF INTIMATE PARTNER VIOLENCE PERPETRATORS}

\section{Person \#7}

What is this person's gender? $\square$ Male $\square$ Female

What is your relationship to this person? (For example, are they your parent? Your boss or coworker? A friend from high school?)

How often do you usually spend time with this person, either in person, on the phone, or over the internet?

$\square$ Less than once a year $\square$ A few times a year $\square$ Twice - 3 times a month $\square$ Almost every day

$\square$ About once a year $\square$ About every month $\square$ About once a week $\square$ More than once a day

The items below ask about your feelings for the person that you identified at the top of this page. With him or her in mind, decide how much you agree or disagree with each item. On the scale below each item, circle the number that indicates how much you agree that the statement describes your feelings. There are no right or wrong answers, because adults' feelings for people in their lives differ from person to person. Just honestly describe your feelings for this person.

1. I am happy with my relationship with this person

Very much disagree Somewhat disagree

$$
\text { Somewhat agree }
$$$$
12
$$

\section{Somewhat agree}

1

Somewhat disagre

$$
\begin{array}{lllll}
-4 & -3 & -2 & -1 & 0
\end{array}
$$

3. I am satisfied with my relationship with this person

Very much disagree Somewhat disagree$$
-3
$$$$
-1
$$

Somewhat agree

1

Somewhat agree

12

Somewhat agree

Somewhat agree

1

2

Very much agree

Very much disagree Somewhat disagree$$
-4
$$

$-2$

$-1$

7. I am content with my relationship with this person Very much disagree Somewhat disagree

$-2$

$-1 \quad 0$

Somewhat agree

1

2

Very much agree

34




\section{SOCIAL NETWORKS OF INTIMATE PARTNER VIOLENCE PERPETRATORS}

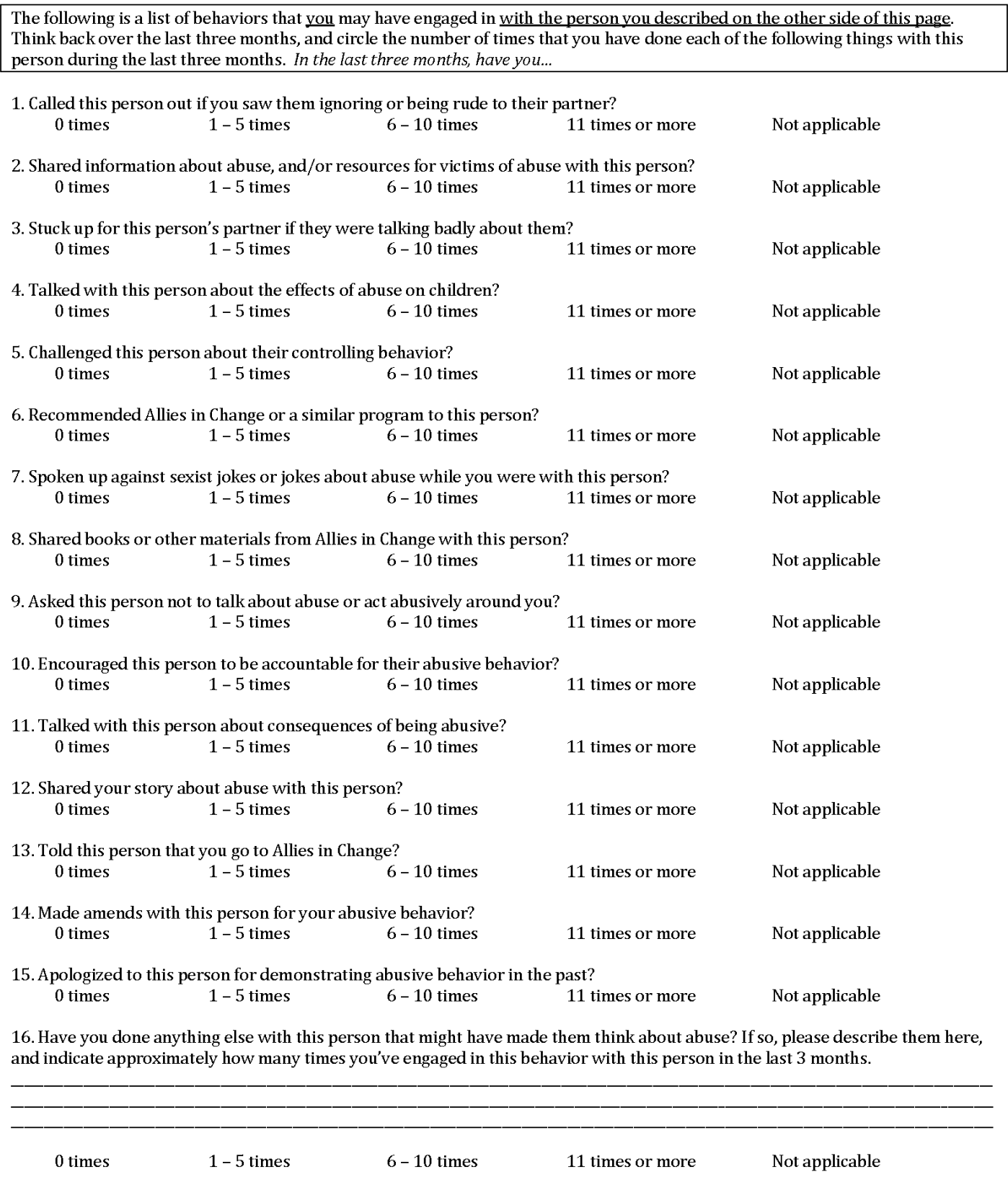




\section{SOCIAL NETWORKS OF INTIMATE PARTNER VIOLENCE PERPETRATORS}

The following is a list of things that the person vou just described may have done during the last three months. Think back over the last three months, and circle the number of times that this person has done each of these things during the last three months. In the last three months, has this person...

17. Told you that your current/former partner was taking advantage of you or disrespecting you?
0 times
$1-5$ times
6 - 10 times
11 times or more
Not applicable

18. Accused your current/former partner of trying to harm your relationship with your kids?
0 times
$1-5$ times
6- 10 times
11 times or more
Not applicable

19. Told you that they wouldn't let their own partner get away with the things that your current/former partner does to you?
0 times
1 - 5 times
6-10 times
11 times or more
Not applicable

20. Supported you in being more accountable?
0 times
1- 5 times
$6-10$ times
11 times or more
Not applicable

21. Told you that your current/former partner deserved your abusive behavior?
0 times
1- 5 times
6-10 times
11 times or more
Not applicable

22. Refused to accept that you have been abusive?
0 times
1 - 5 times
$6-10$ times
11 times or more
Not applicable

23. Been abusive towards their partner in front of you?
0 times
1- 5 times
$6-10$ times
11 times or more
Not applicable

24. Blamed their partner for their own problems?
0 times
1 - 5 times
$6-10$ times
11 times or more
Not applicable

25. Told you ways to avoid the consequences of abuse?
0 times
1 - 5 times
6-10 times
11 times or more
Not applicable

26. Supported you in taking legal action against your current/former partner?
0 times
1- 5 times
6-10 times
11 times or more
Not applicable

27. Contacted your current/former partner to harass or monitor them?
0 times
1 - 5 times
6- 10 times
11 times or more
Not applicable

28. Made fun of you for letting your current/former partner call the shots in your relationship? 0 times $\quad 1-5$ times $\quad 6-10$ times $\quad 11$ times or more Not applicable

29. Pointed out effects of abuse on children or other people? 0 times $\quad 1-5$ times $\quad 6-10$ times $\quad 11$ times or more $\quad$ Not applicable

30. Did or said something that supported your participation at Allies in Change? 0 times $\quad 1-5$ times $\quad 6-10$ times 11 times or more Not applicable

31. Tried to make amends with you for their abusive behavior?

0 times $\quad 1-5$ times $\quad 6-10$ times $\quad 11$ times or more Not applicable

32. Has this person done anything else that made you think about abuse? If so, please describe it here, and indicate approximately how many times you've engaged in this behavior with this person in the last 3 months.

0 times $1-5$ times $6-10$ times 11 times or more $-\overline{\text { Not applicable }}$




\section{SOCIAL NETWORKS OF INTIMATE PARTNER VIOLENCE PERPETRATORS}

\section{Person \#8}

What is this person's gender? $\square$ Male $\square$ Female

What is your relationship to this person? (For example, are they your parent? Your boss or coworker? A friend from high sc hool?)

How often do you usually spend time with this person, either in person, on the phone, or over the internet?

$\square$ Less than once a year $\square$ A few times a year $\square$ Twice -3 times a month $\square$ Almost every day

About once a year $\square$ About every month $\square$ About once a week $\square$ More than once a day

The items below ask about your feelings for the person that you identified at the top of this page. With him or her in mind, decide how much you agree or disagree with each item. On the scale below each item, circle the number that indicates how much you agree that the statement describes your feelings. There are no right or wrong answers, because adults'

feelings for people in their lives differ from person to person. Just honestly describe your feelings for this person.

1. I am happy with my relationship with this person

Very much disagree Somewhat disagree Somewhat agree Very much agree

$\begin{array}{ccccccccc}-4 & -3 & -2 & -1 & 0 & 1 & 2 & 3 & 4\end{array}$

2. I feel my relationship with this person is a great one Very much disagree Somewhat disagree

$\begin{array}{llll}-4 & -3 & -2 & -1\end{array}$

Somewhat agree Very much agree

$\begin{array}{llll}1 & 2 & 3 & 4\end{array}$

3. I am satisfied with my relationship with this person Very much disagree Somewhat disagree Somewhat agree Very much agree

$\begin{array}{lllllllll}-4 & -3 & -2 & -1 & 0 & 1 & 2 & 3 & 4\end{array}$

4. I think that my relationship with this person is strong Very much disagree Somewhat disagree

Somewhat agree Very much agree

$\begin{array}{llll}-4 & -3 & -2 & -1\end{array}$

$\begin{array}{llll}1 & 2 & 3 & 4\end{array}$

5. I feel my relationship with this person is good
Very much disagree Somewhat disagree
Somewhat agree
Very much agree

$\begin{array}{llll}-4 & -3 & -2 & -1\end{array}$

12

6. I am pleased with my relationship with this person

Very much disagree Somewhat disagree

$-3$

$-2$

Somewhat agree

Very much agree

7. I am content with my relationship with this person

Very much disagree Somewhat disagree

$\begin{array}{llll}-4 & -3 & -2 & -1\end{array}$

Somewhat agree

Very much agree

$\begin{array}{llll}1 & 2 & 3 & 4\end{array}$




\section{SOCIAL NETWORKS OF INTIMATE PARTNER VIOLENCE PERPETRATORS}

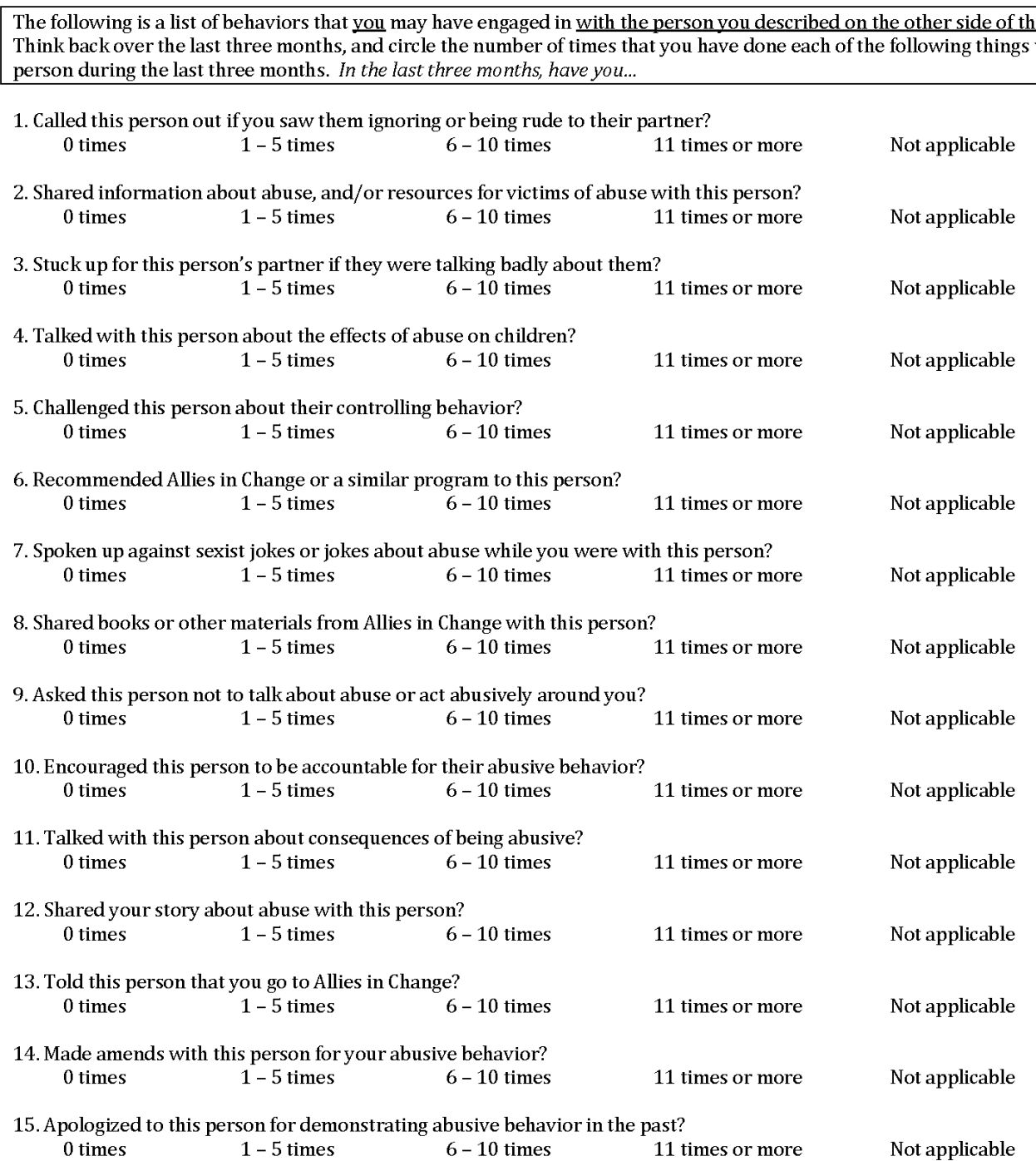

16. Have you done anything else with this person that might have made them think about abuse? If so, please describe them here, and indicate approximately how many times you've engaged in this behavior with this person in the last 3 months.

0 times $\quad 1-5$ times $\quad 6-10$ times $\quad 11$ times or more $\quad$ Not applicable




\section{SOCIAL NETWORKS OF INTIMATE PARTNER VIOLENCE PERPETRATORS}

The following is a list of things that the person you just described may have done during the last three months. Think back over the last three months, and circle the number of times that this person has done each of these things during the last three months. In the last three months, has this person.

17. Told you that your current/former partner was taking advantage of you or disrespecting you?

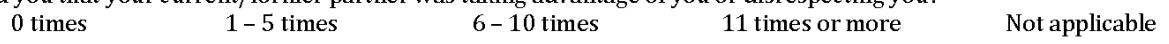

18. Accused your current/former partner of trying to harm your relationship with your kids?
0 times
$1-5$ times
$6-10$ times
11 times or more
Not applicable

19. Told you that they wouldn't let their own partner get away with the things that your current/former partner does to you?
0 times
1 - 5 times
6 - 10 times
11 times or more
Not applicable

20. Supported you in being more accountable?
0 times
1- 5 times
$6-10$ times
11 times or more
Not applicable

21. Told you that your current/former partner deserved your abu sive behavior?

$\begin{array}{ccccc}0 \text { times } & 1-5 \text { times } & 6-10 \text { times } & 11 \text { times or more } & \text { Not applicable }\end{array}$

22. Refused to accept that you have been abusive?
0 times
1- 5 times
$6-10$ times
11 times or more
Not applicable

23. Been abusive towards their partner in front of you?
0 times
1 - 5 times
$6-10$ times
11 times or more
Not applicable

24. Blamed their partner for their own problems?
0 times
$1-5$ times
$6-10$ times
11 times or more
Not applicable

25. Told you ways to avoid the consequences of abuse?
0 times
$1-5$ times
6-10 times
11 times or more
Not applicable

26. Supported you in taking legal action against your current/former partner?
0 times
1 - 5 times
6-10 times
11 times or more
Not applicable

27. Contacted your current/former partner to harass or monitor them?
0 times
1 - 5 times
6-10 times
11 times or more
Not applicable

28. Made fun of you for letting your current/former partner call the shots in your relationship?
0 times
1 - 5 times
6-10 times
11 times or more
Not applicable

29. Pointed out effects of abuse on children or other people?
0 times
1- 5 times
6-10 times
11 times or more
Not applicable

30. Did or said something that supported your participation at Allies in Change?
0 times
1 - 5 times
6-10 times
11 times or more
Not applicable

31. Tried to make amends with you for their abusive behavior?
0 times
1 - 5 times
6-10 times
11 times or more
Not applicable

32. Has this person done anything else that made you think about abuse? If so, please describe it here, and indicate approximately how many times you've engaged in this behavior with this person in the last 3 months.

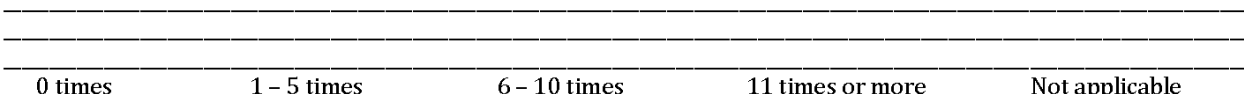




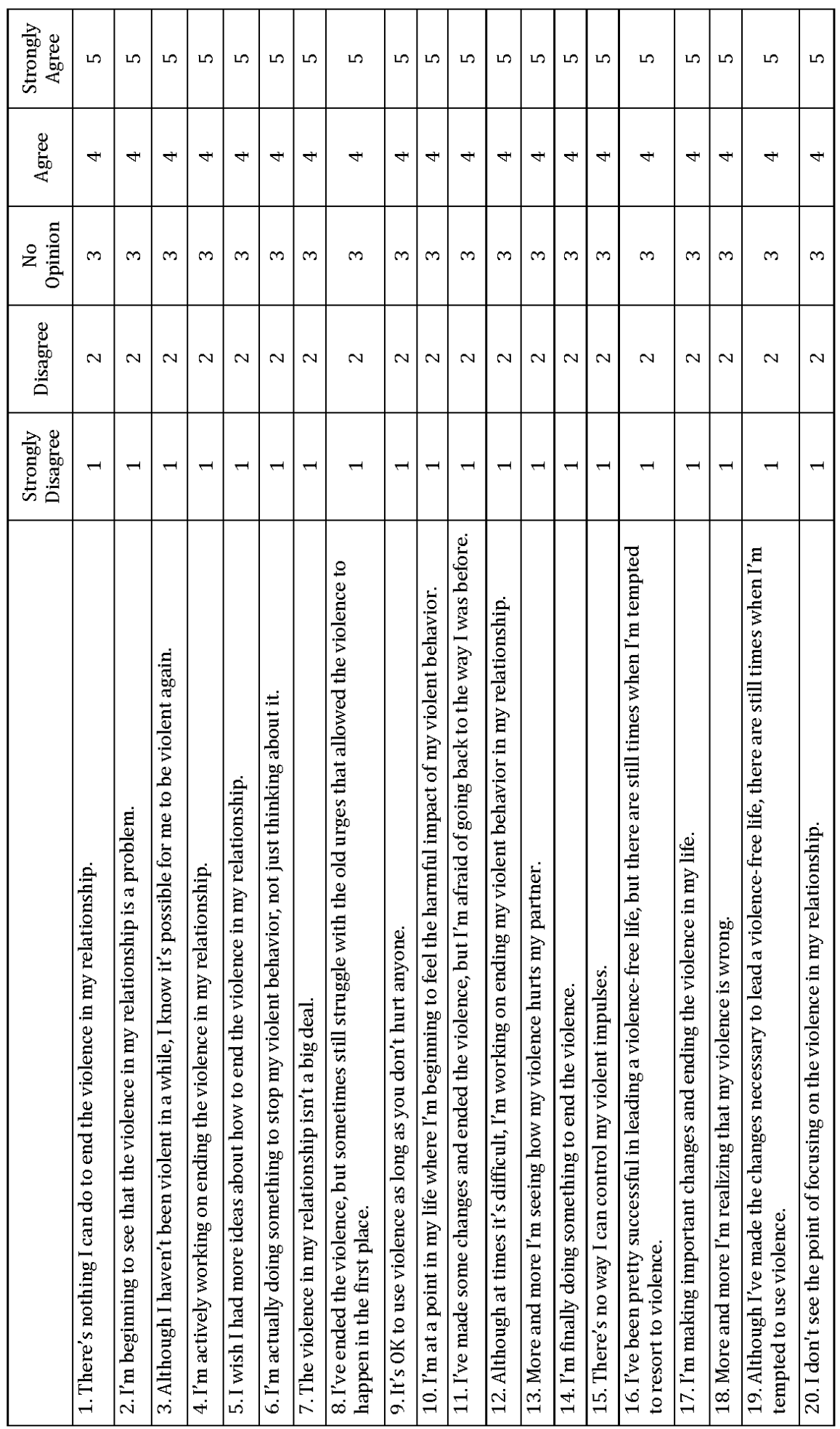


SOCIAL NETWORKS OF INTIMATE PARTNER VIOLENCE PERPETRATORS

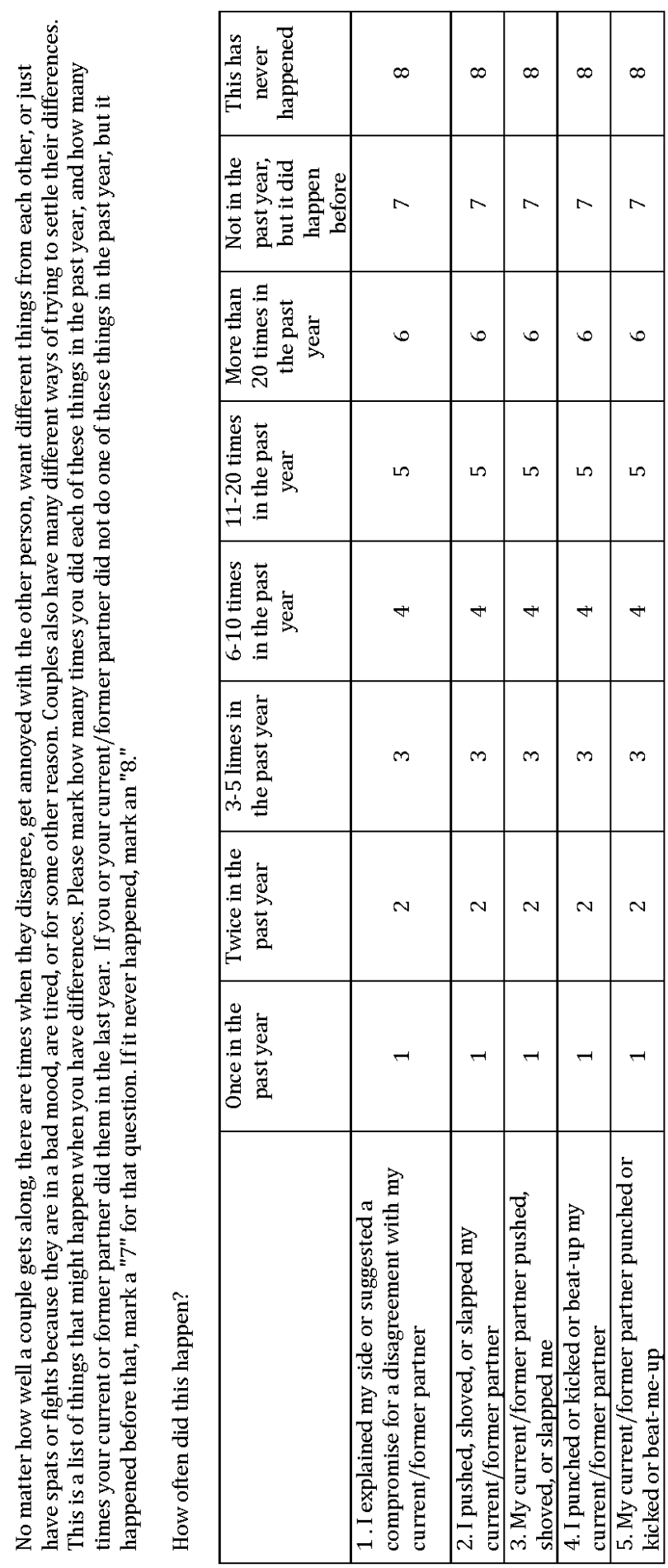




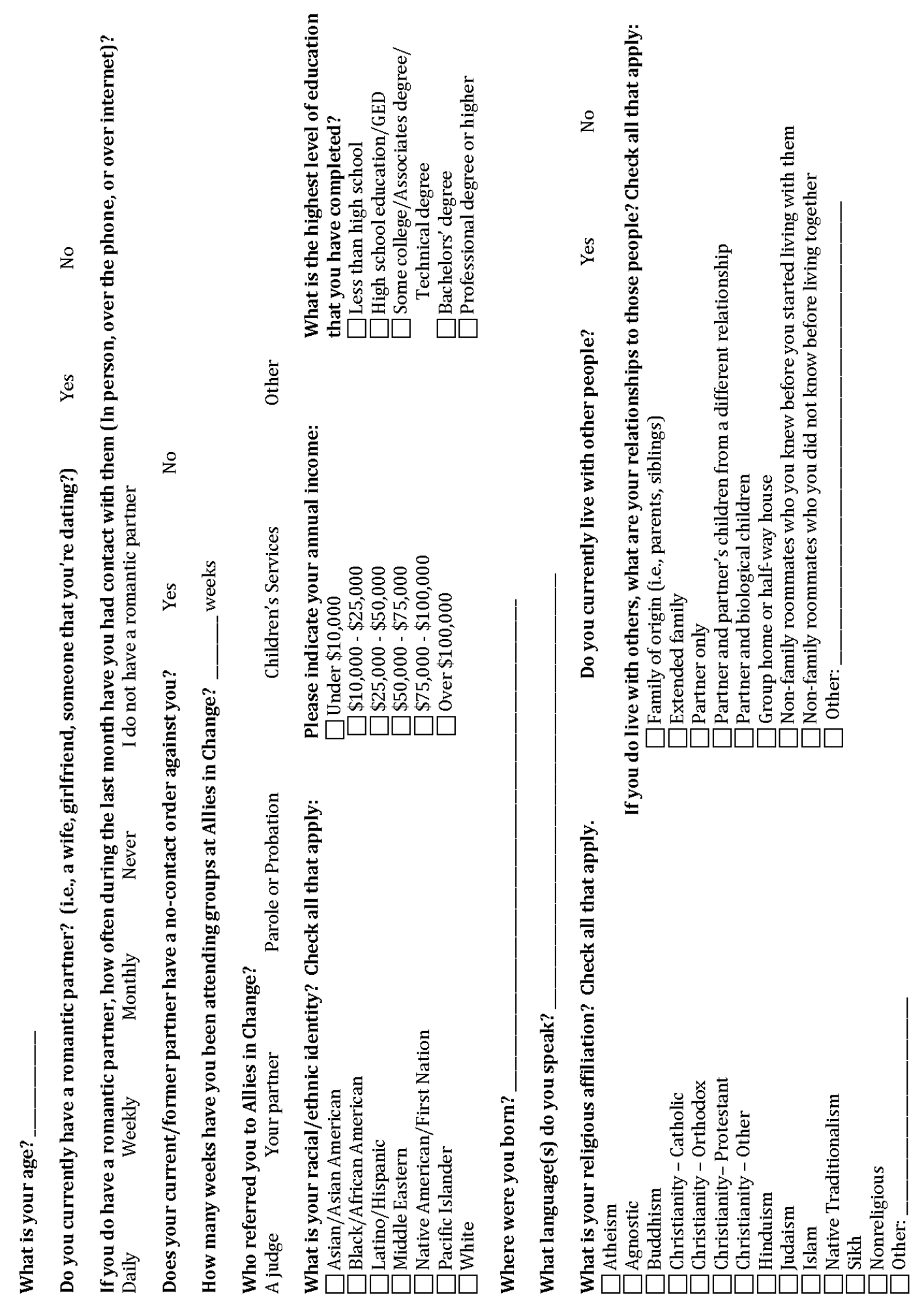


SOCIAL NETWORKS OF INTIMATE PARTNER VIOLENCE PERPETRATORS

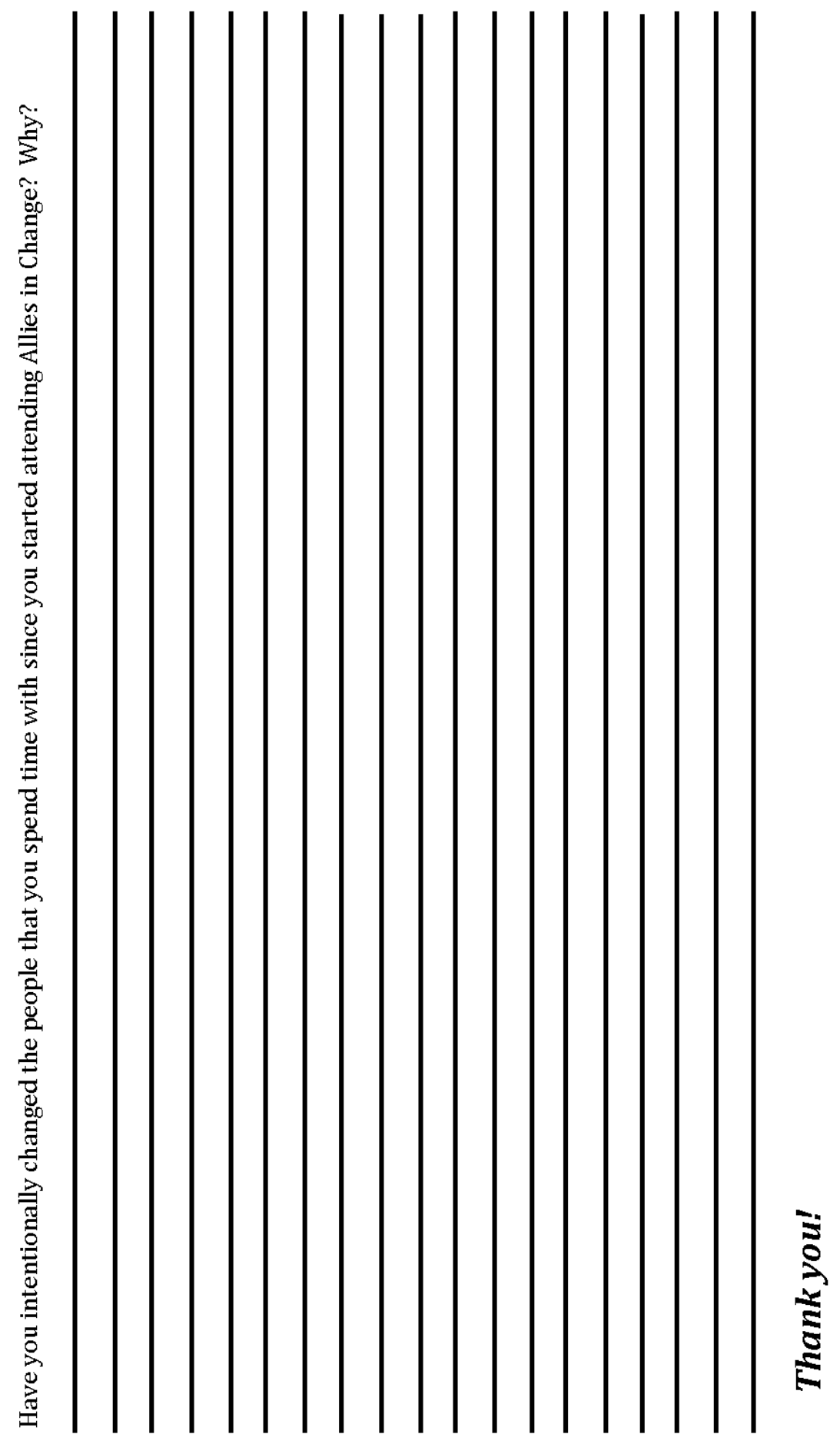




\title{
SOCIAL NETWORKS OF INTIMATE PARTNER VIOLENCE PERPETRATORS
}

\author{
Appendix P: Consent Form for Survey Administration
}

\section{P Portland $\underset{\text { UNIVERSITY }}{\text { State }}$}

\author{
Social Networks and Relationships Study
}

You are invited to participate in a research study conducted by Wendy Viola, M.S., from Portland State University. The researcher hopes to learn about the friends, family members, coworkers, or other community members who are important in your life, and their attitudes and behavior towards women. You were selected as a possible participant in this study because you are currently enrolled in a group at Allies in Change.

If you decide to participate today, you will be asked to complete a survey of the people who are important in your life, and some behaviors that you, and they, have done in the last three months. The survey should take about forty minutes to complete. It is possible that completing the survey will make you remember events that were upsetting, or realize new things about your friends and family members that may be uncomfortable. Your group facilitator will be available to talk about any discomfort that you may experience as a result, and your group may provide a space for talking about many of these issues. Participating in this study may benefit you in that you will be asked to reflect on you and your friends' attitudes and behavior, giving you the opportunity to think about how you influence each other's behavior. It is also possible that you may not receive any direct benefit from taking part in this study, but the study may contribute to understanding how men's communities contribute to the work that they (you) do in group, and possibly help Allies in Change make their groups more effective.

No one from Allies in Change will ever have your completed survey in their possession, and will never see any of your responses. Your surveys will be stored in a locked research lab on the Portland State University campus, and you will not be asked to provide any identifying information on the survey. Your identity will not be matched to any of the information that you provide on the survey. However, if you report any behavior that suggests that you are at an immediate risk of harming yourself or another person, this information will be reported to the police.

Your participation is voluntary. You do not have to take part in this study, and whether or not you choose to participate will not affect your standing or relationship with Allies in Change. You may also withdraw from this study at any time without affecting your status with Allies in Change. Just because you are here today does not mean that you must complete a survey. As long as you are present at Allies in Change today, you will be marked as present, and your attendance will count towards your minimum number of required sessions. 


\section{SOCIAL NETWORKS OF INTIMATE PARTNER VIOLENCE PERPETRATORS}

If you have concerns or problems with your participation in this research project or your rights as a research subject, please contact the Portland State University Human Subjects Research Review Committee, PO Box 751, Portland, OR 97207, (503) 725--4288 / 1--877--480--4400. If you have questions about the study itself, contact Eric Mankowski at mankowskie@pdx.edu or (503) 725 -3901, or Wendy Viola at violaw@pdx.edu or (503) 725--3955.

Your signature indicates that you have read and understand the above information and agree to take part in this study. Please understand that you may withdraw your consent at any time, without penalty, and that, by signing, you are not waiving any legal claims, rights, or remedies. The researcher will provide you with a copy of this form for your own records.

Name (Please print):

Signature:

Date: 


\title{
SOCIAL NETWORKS OF INTIMATE PARTNER VIOLENCE PERPETRATORS
}

\author{
Appendix Q: Consent Form for Release of Administrative Records
}

\section{P Portland $\underset{\text { UNIVERSITY }}{\text { State }}$}

\author{
Social Networks and Relationships Study
}

You are invited to participate in a research study conducted by Wendy Viola, M.S., from Portland State University. The researcher hopes to learn about the friends, family members, coworkers, or other community members who are important in your life, and their attitudes and behavior towards women. In order to do so, I would like access to the following information from Allies in Change: the number of sessions you've attended at Allies in Change, the source of your referral to Allies in Change (were you directed to the program by a judge, your P.O., Children's Services, your partner, or some other source?), and how we might be able to contact you in the future. You were selected as a possible participant in this study because you are currently enrolled in a group at Allies in Change and may complete a survey for the Social Networks and Relationships Study.

I will send Allies in Change a list of clients who have agreed to let this information be released to the research team, and ID numbers that will be used for the purpose of the study so that your name will not be linked to your survey responses. If you decide to allow Allies in Change to release this information, your name and the numeric code that is on your survey will appear on the list. Allies in Change will fill in the list with the information that you have agreed to be released, and delete your name from the list. The research team will receive a list back from Allies in Change that will contain only the information that you have agreed to be released, and your study ID number. The research team will no longer have a way of matching your name to this information, or to your survey responses. Even if you agree to let Allies in Change release this information to the research team, no one at Allies in Change will ever have your completed survey in their possession or be able to figure out which survey belonged to you.

If you would like the opportunity to participate in other studies in the future, you may allow Allies in Change to release your contact information to the research team, in perpetuity. This means that, if you consent to Allies in Change's release of your contact information, Allies in Change will provide the research team with the most recent contact information that they have for you, at any point in the future that the research team would like to reach you. You may allow Allies in Change to release your attendance records and referral source but not your contact information if you prefer.

By allowing Allies in Change to share your attendance record and referral source with the research team, you will help the research team figure out how participating in groups at Allies in Change is related to clients' interactions with their friends, family members, coworkers, and 


\section{SOCIAL NETWORKS OF INTIMATE PARTNER VIOLENCE PERPETRATORS}

other community members about attitudes and behavior towards women. This information may help Allies in Change make their groups more effective.

Your consent to the release of information to the research team is voluntary. You do not have to allow Allies in Change to release this information, and whether or not you choose to do so will not affect your standing or relationship with Allies in Change.

If you have concerns or problems with your participation in this research project or your rights as a research subject, please contact the Portland State University Human Subjects Research Review Committee, PO Box 751, Portland, OR 97207, (503) 725--4288 / 1--877--480--4400. If you have questions about the study itself, contact Eric Mankowski at mankowskie@pdx.edu or (503) 725 -3901, or Wendy Viola at violaw@pdx.edu or (503) 725--3955.

Your signature indicates that you have read and understand the above information and agree to release the information indicated below to the research team. Please understand that you may withdraw your consent at any time without penalty, and that, by signing, you are not waiving any legal claims, rights, or remedies. The researcher will provide you with a copy of this form for your own records.

I (Please print your name): allow Allies in Change to release the following information to the researchers of the Social Networks and Relationships Study at Portland State University:

Please check all of the information that you give permission to Allies in Change to share with the research team:

The number of groups I've attended at Allies in Change

The source of my referral to Allies in Change

My most recent contact information, in perpetuity

Signature:

Date: 


\title{
SOCIAL NETWORKS OF INTIMATE PARTNER VIOLENCE PERPETRATORS
}

\author{
Appendix R: Consent Form for Member Checking Focus Group
}

\section{P Portland $\underset{\text { UNIVERSITY }}{\text { State }}$}

\section{Social Networks and Relationships Study}

You are invited to participate in a group conversation facilitated by Wendy Viola, M.S., from Portland State University. The researcher hopes to learn your reactions to some findings about the friends, family members, coworkers, and other community members who are important to participants at Allies in Change, and how they interact about abuse. You were selected as a possible participant because you are currently enrolled in a group at Allies in Change.

If you decide to participate, you will take part in a small group conversation about the social networks of others who attend Allies in Change and how they communicate with them about abuse. Other group members will be the men with whom you usually attend groups at Allies in Change, and the group will be much like the groups that you usually attend. The researcher will co-facilitate the group, along with your usual group facilitator. At the start of the f group, the researcher will provide some ground rules for the conversation and introduce the topic. The researcher will pose six or seven main questions to the group, and you will be asked to share your experiences and opinions about them.

The conversation will be recorded with a digital recorder so that the researcher can concentrate on what is being said and guide the conversation. The recording will only be heard by the research team, and kept in a locked laboratory on the Portland State University campus.

If you choose to participate, your identity as a participant will not be revealed to anyone who is not present at the time of the focus group. Your identity will not be attached to any information that the focus group produces. However, the researcher cannot guarantee that other group members will keep information that you share during the focus group confidential. Additionally, if you report any behavior that suggests that you are at an immediate risk of harming yourself or another person, this information will be reported to the police. Additionally, your Allies in Change facilitator will be present during the focus group and will hear what you say during the group. Allies in Change's policies about responding to disclosures of illegal activity will apply as they usually do.

The discussion will be held during your regularly scheduled group meetings at Allies in Change on Wednesday, February $26^{\text {th }}, 2014$. The discussion is expected to last for about an hour and a half. It is possible that participating in the discussion will make you remember events that were upsetting, or realize new things about the people in your life that may be uncomfortable. Your Allies in Change group facilitator will be available to talk about any discomfort that you may experience as a result, and your group may provide a space for talking about many of these issues. Participating in this focus group may be beneficial to you in that you will have the opportunity to talk about and reflect on your interactions with other people in your community, 


\section{SOCIAL NETWORKS OF INTIMATE PARTNER VIOLENCE PERPETRATORS}

in a group of other men who also attend Allies in Change. It is also possible that you may not receive any direct benefit from taking part in this conversation, but in the information that you share will be used to understand the results of survey research conducted on the topic. The results of the research project may further our understanding of how men's communities contribute to the work that they (you) do in group, and possibly help Allies in Change make their groups more effective.

Your participation is voluntary. You do not have to take part in this conversation, and whether or not you choose to participate will not affect your standing or relationship with Allies in Change. You may also withdraw from this discussion at any time without affecting your status with Allies in Change. If you choose not to attend your Allies in Change group on the day that the focus group is conducted (February $26^{\text {th }}, 2014$ ), you will receive an excused absence for that day. However, if you are not present at that group meeting, you will not receive credit for attending that group meeting, and it will not count towards your minimum required number of sessions. You have the option of attending your Allies in Change on the evening of February $26^{\text {th }}, 2014$, and not participating in the conversation. As long as you are present at Allies in Change for the meeting on the evening of February $26^{\text {th }}, 2014$, you will be marked as present, and your attendance will count towards your minimum number of required sessions.

If you have concerns or problems with your participation in this focus group or your rights as a research participant, please contact the Portland State University Human Subjects Research Review Committee, PO Box 751, Portland, OR 97207, (503) 725-4288 / 1-877-480-4400. If you have questions about the study itself, contact Eric Mankowski at mankowskie@pdx.edu or (503) 725 -3901, or Wendy Viola at violaw@pdx.edu or (503) 725-3955.

Your signature indicates that you have read and understand the above information and agree to take part in this conversation. Please understand that you may withdraw your consent at any time without penalty, and that, by signing, you are not waiving any legal claims, rights, or remedies. The researcher will provide you with a copy of this form for your own records.

Name (Please print):

Signature:

Date: 


\title{
SOCIAL NETWORKS OF INTIMATE PARTNER VIOLENCE PERPETRATORS
}

\author{
Appendix S: Handout of Quantitative Findings for Member Checking Focus Group
}

\section{胥 Portland State}

Social Networks and Relationships Study: Preliminary Findings

\section{Who are participants' social contacts?}

The 102 men who took the survey identified an average of about 3.5 social contacts each.

- Participants' social contacts were about half men and half women.

- Social contacts included friends/roommates, members of participants' families of origin, current/former romantic partners, bosses/coworkers, children, and in-laws.

\section{How satisfied are participants with their relationships with their social contacts?}

- On average, participants were somewhere between "satisfied" and "very satisfied" with their relationships with their social contacts.

- Participants were about equally satisfied with their relationships with men and women.

\begin{tabular}{lcc}
\hline Ties to Social Contacts & $\begin{array}{c}\text { Average Number of } \\
\text { Friends/roommates }\end{array}$ & $\begin{array}{c}\text { Average } \\
\text { Satisfaction* }\end{array}$ \\
Bosses/Coworkers & 1.0 & 2.8 \\
Family of origin & 0.4 & 2.1 \\
Children & 0.8 & 2.5 \\
In-laws & 0.3 & 2.5 \\
Current/former partners & 0.1 & 1.8 \\
Other relational ties & 0.5 & 1.8 \\
\hline
\end{tabular}

${ }^{*}$ Measured on a scale of -4 to 4 , where higher numbers represent more satisfaction

What do participants and their social contacts communicate about abuse?

- On average, social contacts used each anti-abuse communication method more often than each pro-abuse form of communication listed on the survey.

- Participants' communications were separated into 4 categories. Participants used selfdisclosures and theoretical discussions of abuse most often.

\begin{tabular}{|c|c|c|c|c|c|c|}
\hline & \multicolumn{6}{|c|}{ Type of Communication } \\
\hline & \multicolumn{2}{|c|}{ Used by Social Contacts } & \multicolumn{4}{|c|}{ Used by Participants } \\
\hline & Pro-Abuse & Anti-Abuse & $\begin{array}{l}\text { Intervention } \\
\text { in Behavior }\end{array}$ & $\begin{array}{l}\text { Theoretical } \\
\text { Discussion }\end{array}$ & $\begin{array}{c}\text { Self- } \\
\text { Disclosure }\end{array}$ & $\begin{array}{c}\text { Sharing } \\
\text { Information }\end{array}$ \\
\hline Friend/Roommate & & & & + & + & \\
\hline Boss/Coworker & & & & & & \\
\hline Family of origin & & + & & + & + & \\
\hline Child & & & & + & + & \\
\hline In- law & & & & & + & \\
\hline Current/ former partner & & + & + & + & + & + \\
\hline Other & & + & & + & & \\
\hline
\end{tabular}




\section{SOCIAL NETWORKS OF INTIMATE PARTNER VIOLENCE PERPETRATORS}

\section{How often do participants and their social contacts communicate about abuse?}

- On average, participants communicated about abuse about 16 times with each social contact over the last 3 months.

- Participants communicated about abuse an average of 54 times with their current/former partners, 33 times with their children, and 29 times with their family of origin.

- The average social contact communicated about abuse $\mathbf{3 0}$ times in the last 3 months.

- Participants' current/former partners communicated about abuse more than any other social contacts.

Both participants' and their social contacts' communication about abuse was related to how long participants had been attending Allies in Change. Here are some other differences in communication that were related to time in the program:

\begin{tabular}{|c|c|}
\hline \multicolumn{2}{|c|}{ Participants who had been attending Allies in Change for more time... } \\
\hline Did these more: & Did these less: \\
\hline $\begin{array}{l}\text { - Shared information about abuse, and/or } \\
\text { resources for victims of abuse }\end{array}$ & - Asked this person not to talk about abuse or act abusively around you \\
\hline - Told this person that you go to Allies in Change & - Spoke up against sexist jokes or jokes about abuse \\
\hline $\begin{array}{l}\text { - Made amends with this person for your } \\
\text { abusive behavior } \\
\text { - Apologized to this person for demonstrating } \\
\text { abusive behavior in the past }\end{array}$ & - Recommended Allies in Change or a similar program \\
\hline Had social contacts who did this more: & Had social contacts who did these less: \\
\hline - Supported them in being accountable & $\begin{array}{l}\text { - Told you that your current/former partner deserved your abusive } \\
\text { behavior }\end{array}$ \\
\hline & - Refused to accept that you have been abusive \\
\hline & - Contacted your current/former partner to harass or monitor them \\
\hline & $\begin{array}{l}\text { - Made fun of you for letting your current/former partner call the shots } \\
\text { in your relationship }\end{array}$ \\
\hline & - Done or said anything else that has made you think about abuse \\
\hline
\end{tabular}

\section{Some additional findings}

The more pro-abuse behaviors participants' social contacts used, the less satisfied participants were with their relationships with them. Participants rated their satisfaction with their social contacts one point lower for about every five pro-abuse behaviors that their social contacts used.

The more that social contacts communicated about abuse with participants, the more participants communicated about abuse with them. Social contacts communicated pro-abuse messages about twice as often as participants communicated about abuse. Social contacts communicated anti-abuse messages less often than participants communicated about abuse. 


\section{SOCIAL NETWORKS OF INTIMATE PARTNER VIOLENCE PERPETRATORS}

Appendix T: Script for Member Checking Focus Group

Over the last few months, we've been doing some research here at Allies in Change about the ways that participants receive support for the work that they do here, and the ways that they communicate about Allies in Change with others. We developed a survey on the topic by talking to facilitators from programs similar to Allies in Change, and consulting with 2 groups here at Allies. The survey asked participants to think of up to 8 people who were important to them, and to identify their relationships to each of those people, rate how satisfied they were with their relationships with each of those people, and indicate how they and their network members communicated about abuse. We gave the survey to over a hundred participants here at Allies, and we've prepared some of the results to share with you today. We'd like to get your feedback on the findings. But first...

Consent forms: will not be linked to the focus group, your identity will be kept confidential, the audio recording will only be used so that I can focus on what you're saying without having to worry about taking notes.

Before we begin, let's go around and introduce ourselves. Please share your name, and tell us how long you've been coming to groups at Allies in Change.

How the conversation will go:

- A conversation between you. I'll step in to guide the conversation, as will Chris, but about dialogue between you.

- Wide participation would be great-l'd like to hear from everyone!

- l'd also like to ask that we speak one at a time.

- While it's likely that we have a diversity of opinions represented in this group, and we welcome disagreement, l'd like to ask that you disagree with each other respectfully - the goal is not to reach consensus

- Finally, just like in every other group you attend at Allies in Change, what people say in the group should stay in the group. You're welcome to debrief today's conversation with your partner, but remember not to discuss any information that would reveal the identities of other people who are here today.

- One more note before we get started: you'll notice that Chris is here, and he'll be participating in this conversation too. He'll also hear whatever you say and have the responsibility to react the way that he normally would. Allies in Change's policies about the limits of confidentiality apply here as well. This means that if there's anything that you would usually avoid saying in front of your facilitator, this meeting is no different. As researchers, we also have a responsibility to report to the police if you say anything about immediate plans to harm yourself or someone else. 


\section{SOCIAL NETWORKS OF INTIMATE PARTNER VIOLENCE PERPETRATORS}

Does this sound alright? Anything to add? If not, l'll go ahead and turn on the recorder...

I'm passing around a handout, which briefly summarizes the study and some of what I've learned. In case you're interested in exactly what we asked participants, we have some copies of the survey here. Let's go through the sheet together. If you have any questions as we're going through the sheet, please ask... [walk participants through the sheet]

1. Do you have any initial reactions to the results?

If this does not spark conversation: I have some more specific questions for you.

2. Participants nominated more friends/roommates than any other kind of network member. However, there was less communication about abuse with friends/roommates than with other kinds of network members. Participants also reported that they were the most satisfied with their relationships with their friends/roommates. I think that this might be because participants choose their friends: if their friends communicate pro-abuse messages, they can stop spending time with them. Does this seem right to you?

3. Similarly, the more pro-abuse behaviors that participants' network members used, the less satisfied participants were with their relationships with them: has this been true in your experience? If so, what has been the ultimate outcome? (i.e, have you communicated more anti-abuse messages to this person, or have you withdraw from them?)

4. Do you have any thoughts about behaviors that participants used less if they had been at Allies in Change for more time? The fact that their network members used less pro-abuse communication makes me think that there would be less of a need for participants to ask them not to talk about abuse, speak up against sexist jokes, or to recommend Allies in Change. Why do you think this might be? (i.e., are network members learning from participants so participants don't have to keep intervening in their behavior, or are participants changing the people who they spend time with?)

a. For every 2 pro-abuse behaviors that participants' network members used, participants used 1 anti-abuse behavior. For every 2 anti-abuse behaviors that participants' network members used, participants used 3 


\section{SOCIAL NETWORKS OF INTIMATE PARTNER VIOLENCE PERPETRATORS}

anti-abuse behaviors. Are network members saying things about abuse that participants are then responding to? Or are participants initiating conversations and their network members are responding to them? Which, if either of these, happen more in your relationships?

5. In the cases that you have communicated about abuse with your network members, how have they responded? Has this made you more or less likely to do so again?

6. Have you withdrawn from any of your network members as a result of coming to Allies in Change? If so, how has that impacted you?

If there's extra time:

1. Why might there be less communication about abuse from children of participants who'd been coming to Allies for longer? 


\section{SOCIAL NETWORKS OF INTIMATE PARTNER VIOLENCE PERPETRATORS}

Appendix U: Themes from Member Checking Focus Group

Limitations of current study:

- shouldn't combine current \& former partners

- additional item: talking about relationship in general, with network members

Don't get many messages about abuse from network members:

- participants try to avoid discussing abuse with partners (partners are more likely to bring it up)

- network members who know about abuse in relationship are more likely ask about abuse than send any messages about it

- Some participants maintain that they never spoke negatively about their partners, because they never felt that way, they thought it was inappropriate, or all of their network members were also friends with their partner

Changes in network members' behaviors:

- Network members' behaviors have changed over participants' time at Allies in Change

- How participants have intentionally generated changes in network members' behavior:

- Talked to family of origin about multiple abusive dynamics within family

- Others share disparaging comments about their partners, participants respond (1) with stories about productively addressing conflict in their own relationships, (2) by setting an example of discussing their own fault in conflicts with their partners, and (3) by using it as an opportunity to make selfdisclosures and information about abusive behavior and describing it as such

- How network members have changed behavior in response to changes in participants' attitudes

- Network members tend to empathize/agree with whatever network members tell them. When participants stop speaking about their partners so negatively, their network members don't support them in villainizing their partners as much. As partners start expressing more empathy for their partners, social network members express more support for partners, too.

How network member contribute to participants' behavior 


\section{SOCIAL NETWORKS OF INTIMATE PARTNER VIOLENCE PERPETRATORS}

- Participants tell stories to network members that are very skewed and portray their partners as crazy, and network members support these characterizations of partners.

- Participants can especially trust other members of 12-step programs to respond to their bad behavior

\section{Why participants' anti-abuse behaviors drop off}

- Initial (1) excitement, (2) spike in awareness, and (3) desire to show off new knowledge (especially to partners) upon beginning at Allies in Change

- Participants who have been at Allies in Change longer are better able to identify abuse-relevant behaviors in network members, and are also better able to avoid abuse-relevant conversation more than those who don't go to Allies:

- Participants learn not to talk about abuse with network members based on negative reactions/lack of responses to early self-disclosures/attempts to intervene. Eventually, try to avoid exposure to others' abusive behavior (as an alternative to confronting it); try to steer the conversation away from abuse instead of engaging with network members about it.

- There's a risk-reward balance: if participants address others' abusive behavior directly, there's a high risk of losing the relationship, and the chances that network members actually change their behavior is pretty low. Participants feel (1) badly that they can't change their network members' behaviors, (2) guilty that they so rarely try to do so, and (3) lonely. However, it does make participants closer to their partners, with whom they do feel comfortable discussing Allies in Change.

\section{Satisfaction: the road to selection}

- As participants attend Allies in Change, their consciousness is raised, and their understanding of abuse broadens until they begin to see it everywhere, including in their network members' relationships. While noticing these abusive dynamics has not led to a change in the status of these relationships, it has resulted in participants feeling less satisfied with their relationships with those network members.

- Some participants have actually said something to network members when they noticed abuse in their relationships, ("well that happens a lot, and here are resources that are available"). When these network members didn't do anything differently, participants maintained the relationship, but don't feel as positively as they did before they recognized the abusive or pro-abusive behavior. 


\section{SOCIAL NETWORKS OF INTIMATE PARTNER VIOLENCE PERPETRATORS}

Participants may distance themselves if they believe that the abusive behavior is getting worse. One participant did have some initial success in reducing his friends' inappropriate behavior, but when the behavior came back, he ended his relationships with these friends.

\section{Regarding Selection}

- Participants say that they have a hard time with the idea that men would eliminate relationships as a result of going to Allies, but described ways in which they have done so

- Some participants intentionally distanced himself from a group of friends who were inappropriate and negatively impacted his relationships with this family

- The threshold for selection is different for different participants: one participant could interpret anything his friends said to validate his behavior, unless they were actively calling him out on his behavior, so he had to discontinue relationships with friends who did not actively hold him accountable

- Participants will remove themselves from situations where strangers are being abusive as a form of self-care

The importance of Allies in Change as source of social support

- Coming to Allies has opened up participants' relationships with others who also have anger issues. It can be validating to talk to others who have struggled with anger problems and have a shared history of abuse.

- Some participants maintain relationships with each other outside of group. Even in unrelated interactions before and after group, it seems that participants are generally supportive of each other and their positive behavior, care for each other, and support each other's self-care. This helps participants...

- Feel supported and supportive, makes them want to encourage others to get the same benefit from the group that they have

- Establish friendships (with each other) in which they can speak openly and freely about the abuse in their relationships, and subsequently receive support around abuse-relevant issues, which they will not do with other network members

- Socialize with men who, participants can be confident, won't make any sexist or otherwise inappropriate comments, who know the program jargon, and who can invoke facilitators and ways of being that the program teaches. 